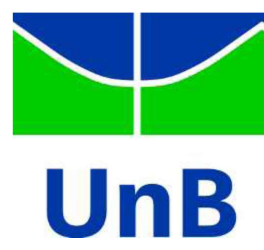

Universidade de Brasília

Programa de Pós-Graduação em Ecologia

Carlos Eduardo Pianca Marinelli

\title{
Aprimoramento da governança no âmbito de conselhos gestores para a efetividade de unidades de conservação na Amazônia: fatores-chave, mecanismos e impactos
}

\author{
Tese apresentada ao Programa \\ de Pós-Graduação em Ecologia \\ da Universidade de Brasília, \\ como requisito para a obtenção \\ do título de Doutor em Ecologia.
}

Orientador: Prof. Paulo Sérgio Bretas de Almeida Salles 
Dedicatória

A minha filha Maya e seu apaixonante sorriso! 


\section{AGRADECIMENTOS}

À Camila, minha fiel companheira. Pelo empenho, dedicação e principalmente paciência durante densos anos de desenvolvimento desta tese. Pelo apoio, troca de idéias, considerações e sugestões sempre valiosas e por ter me dado a oportunidade de compartilharmos da alegria de sermos os pais da Maya.

A minha mãe (Noeli) e aos meus pais agregados (Tico e Rosa Maria). Sem o apoio constante, cuidados e atenção de vocês três, essa tese nunca teria tornado-se viável.

Ao meu amigo, orientador e parceiro em muitas empreitadas ao longo desse doutorado, Prof. Paulo Salles. Pela oportunidade de convívio, aprendizados e apoio com sua singular experiência. Pela confiança, paciência e apoio.

A meus irmãos (Lisnia, Mona e Caio), que sempre me apoiaram e estimularam na busca pelos meus ideais.

Aos companheiros do Grupo NSC (Natureza, Sociedade e Conservação): Henrique Santiago, Camila Pianca, Daniel Munari, Ana Bocchini, Beatriz Ribeiro, Petra Pantoja, João Pantoja e Wládia Silva. Pelo convívio, rica troca de aprendizados, colaboração no constante aprimoramento e aplicações do SISUC e pelos três felizes anos de ideais, esforços e avanços compartilhados.

A banca de defesa, os professores Pedro Jacobi (USP), Cristiana Seixas (Unicamp), Isabel Schmidt e Fernando Scardua (UnB), pelos comentários e sugestões que contribuiram para agregar maior sentido às reflexões sobre os resultados obtidos e o aprimoramento desta tese.

A banca de qualificação, os professores Marta Irving (UFRJ), Henyo BarretoFilho (IEB), Mário Neto (UFG) e Fabiano Toni (UnB), pelos comentários e sugestões que constribuíram para o enriquecimento e desenvolvimento da tese. 
Aos professores Davi Pantoja (UFPI), Rita Mesquita (INPA), Nurit Bensusan (ISA), Henrique Pereira (UFAM) e Mariana Clauzet (Unisanta) pela leitura dos manuscritos e valiosas sugestões.

A todos os conselheiros e gestores (Ana Fávia Zingra, Ana Luiza Figueiredo, Mariana Leitão, Alcilene de Paula, Jaime Bonaerge, Pablo Pacheco e Prisicila Santos), das UCs do Mosaico de Áreas Protegidas do Baixo Rio Negro que se envolveram e contribuíram para que esse trabalho fosse possível.

A Adriana Ramos e Alicia Rolla, que sempre acreditaram no potencial do SISUC. Pela confiança, oportunidade de trabalharmos juntos e contribuições.

Ao Instituto Socioambiental, por ter possibilitado a oportunidade de desenvolver essa tese concomitante e integrada aos compromissos de trabalho.

Ao PPG em Ecologia da Universidade de Brasília.

A todos aqueles que de alguma forma contribuíram para tornar esse trabalho possível. 


\title{
Aprimoramento da governança no âmbito de conselhos gestores para a efetividade de unidades de conservação na Amazônia: fatores-chave, mecanismos e impactos
}

\begin{abstract}
RESUMO
Parte dos avanços conquistados com a publicação da lei do Sistema Nacional de Unidades de Conservação (SNUC), em 2000, ainda não foram adequadamente colocados em prática. No âmbito local, conselhos gestores, métodos de avaliação e planos de manejo ainda não firmaram-se como instrumentos de apoio à governança de unidades de conservação (UCs). Essa situação tem gerado efeitos negativos para a efetividade dessas áreas protegidas, que se refletem no desempenho de processos participativos, nos resultados das ações e no monitoramento da gestão. 0 objetivo do presente trabalho foi investigar os efeitos da implantação do método Sistema de Indicadores Socioambientais para UCs (SISUC) sobre o conselho gestor e as condições socioecológicas de um conjunto de seis UCs do Mosaico de Áreas Protegidas do Baixo Rio Negro, estado do Amazonas. Entre os anos de 2010 e 2014, o SISUC foi aplicado em três UCs federais (Parna do Jaú, Parna de Anavilhanas e Resex Unini) e três UCs estaduais (PE do Rio Negro - Setor Sul, PE do Rio Negro - Setor Norte e RDS do Rio Negro), incluídas UCs de proteção integral e uso sustentável. Para analisar os efeitos do SISUC, resultados da avaliação de indicadores foram comparados antes e após a implantação do método SISUC, para cada UC, entre as UCs e para o conjunto das UCs pesquisadas, e o alcance de metas estabelecidas para indicadores foi avaliado. Foi adotada a técnica de pesquisa-ação, com dois protocolos de avaliação qualitativa: um de transformação deliberada de sistemas socioecológicos e outro de princípios de governança de áreas protegidas. Testes de chi-quadrado e modelos lineares generalizados foram utilizados para análise estatística de variáveis preditivas das condições socioecológicas locais. Os resultados obtidos permitem constatar que a implantação do SISUC propiciou o estabelecimento de um sistema estruturado de tomada de decisão, que qualificou a governança local das UCs. Os fatores-chave geradores desse processo foram as atividades de monitoramento e avaliação de indicadores e de ações, e a prática da gestão adaptativa. Esses fatores desencadearam mecanismos de comunicação, aprendizagem social, adaptação e tomada de decisão. A implantação do SISUC também foi fator-chave para melhoria das condições socioecológicas locais. Os mecanismos geradores desse processo foram a priorização de indicadores e,
\end{abstract}


principalmente, o desempenho das ações estabelecidas e monitoradas com fins de favorecer o alcance das metas estabelecidas. 0 contexto de gestão das UCs também contribuiu para melhorar as condições do sistema socioecológico das UCs. Esses resultados sustentam que a implantação do método SISUC deu suporte às atividades dos conselhos gestores, incentivou o engajamento de conselheiros e estabeleceu um sistema estruturado de tomada de decisão que, ao integrar a governança local à gestão, melhorou a efetividade das UCs. Observou-se que o SISUC induziu e catalisou mecanismos de retroalimentação entre o sistema social e o sistema socioecológico. Defende-se que mudanças intencionais promovidas por meio de governança estruturada, gestão transicional e inovação constituem maneira viável para melhorar a efetividade de UCs e que o uso de ferramenta de suporte sob abordagem socioecológica, participativa, contextualizada, adaptativa e funcional, é alternativa complementar aos demais instrumentos de apoio aos conselhos gestores.

Palavras-chave: sistemas socioecológicos, SISUC, indicadores, monitoramento $e$ avaliação, gestão adaptativa, Amazônia 


\title{
Governance improvement within Management Councils for the effectiveness of Conservation Units in the Amazon: key factors, mechanisms and impacts
}

\begin{abstract}
Some of the improvements achieved with the publication of the National System of Conservation Units law (in Portuguese, SNUC), in 2000, are not properly put into practice yet. At the local level, Management Councils, evaluation methods and management plans are not consolidated as mechanisms to support the governance of Conservation Units (UCs) yet. This situation has negative effects on the UC's effectiveness, which are reflected in the participatory processes performance, actions' results and in the management monitoring. This study aims at investigating the implementation effects of the Protected Areas Social-Ecological Indicators System method (in Portuguese, SISUC) on the Management Council performance and social-ecological conditions of six protected areas in the Mosaic of Protected Areas of the Lower Rio Negro, state of Amazonas. Between 2010 and 2014, SISUC was implemented in three federal level UCs (Jaú National Park, Anavilhanas National Park and Unini Extractive Reserve) and three state level UCs (Rio Negro State Park - South Sector, Rio Negro State Park - North Sector and Rio Negro Sustainable Development Reserve), which include SNUC's categories 'strictly protected' and 'sustainable-use'. To analyze the SISUC effects, evaluation results of the indicators collected before and after the SISUC method implementation were compared in each UC, between UCs and in the set of surveyed UCs, along with the achievement of targets measured by these indicators. The action-research technique was adopted with two qualitative evaluation protocols: deliberate transformation of social-ecological systems and governance principles of protected areas. Chi-square test and Generalized Linear Models were used for statistical analysis of local social-ecological conditions predictive variables. The results support that implementation of SISUC has established a structured decision-making system, which qualified the UC's local governance. The key factors that generated this improvement were the monitoring and the evaluation of indicators and actions, and the adaptive management practice. These factors have fostered communication, social learning, adaptation and decision making mechanisms. The SISUC implementation was also a key factor for improving local social-ecological conditions. The driving forces of this process were the prioritization of indicators and especially the performance of monitored actions defined for promoting the achievement of targets. The UCs' management context also
\end{abstract}


contributed to improve the conditions of their social-ecological system. These results support that SISUC method implementation has helped in Management Council's activities, encouraged stakeholders' engagement and established a structured decision-making system that, by integrating local governance to the UC management, improved the UC's effectiveness. It was observed that feedback mechanisms involving social and social-ecological systems were induced and catalyzed by SISUC. It is argued that intentional changes promoted by means of structured governance, transitional management and innovation are a feasible way to improve UCs' effectiveness. Moreover, the use of support tools based on social-ecological, participatory, contextualized, adaptive and functional approaches is a complementary alternative for other support instruments used by Management Councils.

Keywords: social-ecological systems, SISUC, indicators, monitoring and evaluation, adaptive management, Amazon 


\section{SUMÁRIO}

SEÇÃo

Pág.

Capítulo 1. Contextualização 22

1.1 NO PAPEL: COMO AS COISAS DEVEM SER!___ 22

1.2 NA PRÁTICA: COMO SÃO AS COISAS ____ 25

1.3. EXISTEM SOLUÇõES ALTERNATIVAS PARA ESSES PROBLEMAS?_____ 35

Capítulo2. Área de Estudo $\quad 42$

2.1. A BACIA HIDROGRÁFICA DO RIO NEGRO E A REGIÃo Do BAIXO RIO NEGRO___ 42

2.2. O Mosaico de Áreas Protegidas do Baixo Rio Negro____ $\quad 44$

Capítulo3. Material e Métodos $\quad 50$

3.1. COLETA DE DADOS E INFORMAÇÃO EM CAMPO: APLICAÇÃO DO MÉTODO SISUC_ 50

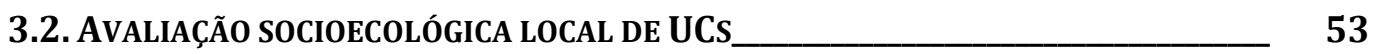

3.3. AVALIAÇÃo DE PROCESSOS No ÂMBITO do CONSELHO GESTOR DE UCS ____ 54

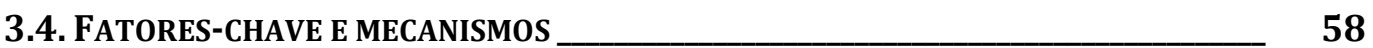

Capítulo 4. Resultados $\quad 64$

4.1 MudanÇAS NA EFETIVIDAdE dAS UCs____ 64

4.2. AdERÊNCIA do MÉtodo SISUC A PROCESSOS DE TRANSFORMAÇÃo DELIBERADA DE SISTEMAS SOCIOECOLÓGICOS

4.3. FATORES-CHAVE E MECANISMOS DAS MUDANÇAS NA EFETIVIDADE DAS UCS 79 


\section{SUMÁRIO (Continuação)}

$\begin{array}{lr}\text { Capítulo 5. Discussão } & 87\end{array}$

5.1. TRANSFORMAÇÃo DELIBERADA DE SISTEMAS SOCIOECOLÓGICOS DAS UCS_ 87

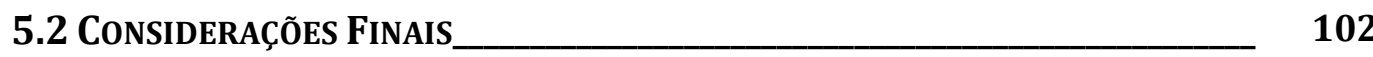

Capítulo 6. Conclusões $\quad 109$

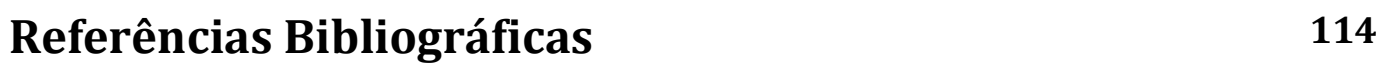

$\begin{array}{ll}\text { Apêndices } & 124\end{array}$

$\begin{array}{ll}\text { Anexos } & 154\end{array}$ 


\section{LISTA DE TABELAS}

Tabela 4.1. Distribuição das frequências absolutas e relativas do conjunto de indicadores avaliados, de acordo com a situação em que se encontravam nos anos 2010 e 2014 (i.e., sucesso, satisfatória, insatisfatória ou alarmante), para o total das seis UCs pesquisadas do MBRN, estado do Amazonas.

Tabela 4.2. Distribuição das frequências absolutas e relativas dos indicadores avaliados, de acordo com a sua evolução entre os anos de 2010 e 2014 (i.e. avançou, estagnou ou retrocedeu), para cada uma das seis UCs pesquisadas do MBRN, estado do Amazonas.

Tabela 4.3. Distribuição das frequências absolutas e relativas dos indicadores priorizados e não-priorizados, de acordo com sua evolução (i.e. avançou, estagnou ou retrocedeu) entre os anos de 2010 e 2014, para o total das seis UCs pesquisadas do MBRN, estado do Amazonas.

Tabela 4.4 Distribuições absolutas e relativas da variação no desempenho das metas estabelecidas para o ano de 2014 (i.e. alcançada e não-alcançada) para 24 indicadores priorizados para o total das seis UCs pesquisadas do MBRN, estado do Amazonas.

Tabela 4.5. Distribuição da freqüência absoluta de indicadores de acordo com a situação avaliada no ano de 2014 (i.e. alarmante, insatisfatória, satisfatória e sucesso) na comparação do grau de atualização do planos de manejo/gestão para o conjunto de UCs pesquisadas do MBRN, estado do Amazonas.

Tabela 4.6. Distribuição da freqüência absoluta de indicadores de acordo com a situação avaliada no ano de 2014 (i.e. alarmante, insatisfatória, satisfatória e sucesso) na comparação da idade do conselho gestor para o conjunto de UCs pesquisadas do MBRN, estado do Amazonas.

Tabela 4.7. Distribuição da freqüência absoluta de indicadores de acordo com a situação avaliada no ano de 2014 (i.e. alarmante, insatisfatória, satisfatória e sucesso) na comparação da idade das UCs para o conjunto de UCs pesquisadas do MBRN, estado do Amazonas. 


\section{LISTA DE FIGURAS}

Figura 1.1. Quadro lógico da efetividade de governança, no qual estão incluidos elementos do quadro lógico da efetividade de gestão proposto por Hockings et al. (2006). Fonte: Lockwood (2010).

Figura 1.2. A gestão adaptativa, frequentemente caracterizada pelo 'aprenderfazendo', é um processo formal e iterativo de gestão que reconhece incertezas e alcances de objetivos de gestão pelo desenvolvimento de um sistema de conhecimento mediado por processos de retroalimentação estruturados. Como ilustrado, o processo de gestão adaptativa integra o componente de decisão à oportunidades para aprendizagem. A tomada de decisão estruturada (círculos cinza), um termo frequentemente confundido com gestão adaptativa, é uma abordagem organizada e transparente de processos de decisão para identificação, avaliação e argumentação de alternativas para decisões complexas; entretanto, a tomada de decisão estruturada não necessita da iteração e conseqüente aprendizado (círculos branco) inerentes da gestão adaptativa (extraída de Allen et al., 2011).

Figura 2.1. Mapa geopolítico e do uso e ocupação da região do baixo-médio rio Negro, estado do Amazonas, com destaque para área ao sul do MBRN, que se encontra sobre maior pressão da expansão urbana e demográfica da cidade de Manaus. Acima: bacia do rio Negro (área hachurada) com quadrante delimitando a área ampliada. Fonte: Ricardo \& Antongiovanni (2008).

Figura 2.2. Mapa da região de inserção do MBRN com destaque para as UCs pesquisadas (limites demarcados em preto).

Figura 4.1. Distribuição do número absoluto total de indicadores avaliados nas diferentes situações nos anos de 2010 (154 indicadores) e 2014 (142 indicadores) para o total das seis UCs pesquisadas do MBRN, estado do Amazonas.

Figura 4.2. Distribuições das frequências relativas do conjunto de indicadores, de acordo com a situação em que se encontravam nos anos de 2010 (154 indicadores) e 2014 (142 indicadores), na comparação entre cada uma das seis UCs pesquisadas do MBRN, estado do Amazonas.

Figura 4.3. Distribuições das frequências relativas do conjunto de indicadores avaliados, de acordo com a situação em que se encontravam nos anos de 2010 (154 indicadores) e 2014 (142 indicadores), na comparação entre cada um dos diferentes temas (i.e. sociocultural, gestão, meio ambiente e economia) para o total das seis UCs pesquisadas do MBRN, estado do Amazonas.

Figura 4.4. Distribuições das frequências relativas do conjunto de 111 indicadores avaliados, de acordo com a sua variação entre os anos de 2010 e 2014, na comparação entre as seis UCs pesquisadas no MBRN, estado do Amazonas. 
Figura 4.5. Distribuição relativa da variação observada entre os anos de 2010 e 2014 na situação dos indicadores avaliados (i.e. avanço, estagnação e retrocesso), para o total das seis UCs pesquisadas do MBRN, estado do Amazonas.

Figura 4.6. Distribuição relativa da variação no desempenho das metas a serem alcançadas no ano de 2014 (i.e. atingida, não-atingida mas avançou e nãoatingida e estagnou) para 24 indicadores priorizados, no total das seis UCs pesquisadas do MBRN, estado do Amazonas.

Figura 4.7. Distribuições das freqüências relativas da variação no desempenho das metas a serem alcançadas no ano de 2014 (i.e. atingida, não-atingida, mas avançou e não-atingida e estagnou), de acordo com a dimensão do sistema socioecológico avaliado, para 24 indicadores priorizados, no total das seis UCs pesquisadas do MBRN, estado do Amazonas. 


\section{LISTA DE QUADROS}

Quadro 2.1. UCs que compõem o MBRN e área total ocupada por cada uma delas.

Quadro 2.2. Informações sobre as datas de criação das UCs, conselhos gestores e de aprovação de planos de manejo/gestão das UCs pesquisadas no MBRN entre os anos de 2010 e 2014.

Quadro 3.1. Etapas e passos da aplicação do método SISUC e cronograma de ações relacionadas, executadas no âmbito do presente trabalho de pesquisa, entre os anos de 2010 e 2014.

Quadro 3.2. Múltiplos subprocessos em cada fase da transformação deliberada de um sistema socioecológico (Moore et al., 2014).

Quadro 3.3. Parâmetros do protocolo de avaliação de princípios de boa governança de áreas protegidas (modificado de Lockwood, 2010).

Quadro 3.4. Fontes de variação (variáveis independentes) e tipos de dados utilizados no desenvolvimento dos GLMs de acordo com as variáveis teóricas testadas.

Quadro 3.5. Fontes de variação (variáveis dependentes) e tipos de dados utilizados no desenvolvimento dos GLMs para o teste da variável teórica 'situação do sistema socioecológico'.

Quadro 4.1. Situação dos 27 indicadores nos anos de 2010 e 2014 e desempenho de metas dos indicadores priorizados em 2010 (texto nas células coloridas) das seis UCs pesquisadas do MBRN, estado do Amazonas, utilizando o método SISUC.

Quadro 4.2. Análise de múltiplos subprocessos em cada fase da transformação deliberada de sistemas socioecológicos ( $c f$. Moore et al., 2014) a partir da implantação do SISUC junto à conselhos gestores de seis UCs do MBRN, no estado do Amazonas, entre os anos de 2010 e 2014.

Quadro 4.3. Análise de parâmetros de governança de áreas protegidas adotando o protocolo proposto por Lockwood (2010), a partir do conjunto de atividades passos do ciclo de aplicação do SISUC executadas durante reuniões dos conselhos gestores das seis UCs pesquisadas do MBRN, estado do Amazonas, entre os anos de 2010 e 2014.

Quadro 4.4. Resultados do modelo GLM 1 para o teste da influência de variáveis independentes referentes ao contexto de gestão e ao conselho gestor das UCs sobre a evolução na situação dos indicadores (2010-2014) para o conjunto de UCs pesquisadas do MBRN, estado do Amazonas.

Quadro 4.5. Resultados do modelo GLM 2 para o teste da influência da priorização de indicadores (referente ao método SISUC) sobre a evolução na situação dos indicadores (2010-2014) para o conjunto de UCs pesquisadas do MBRN, estado do Amazonas.

Quadro 4.6. Resultados do modelo GLM 3 para o teste da influência do desempenho das ações que foram estabelecidas e monitoradas (referentes ao método SISUC) sobre a evolução na situação dos indicadores (2010-2014) para o conjunto de UCs pesquisadas do MBRN, estado do Amazonas. 
Quadro 4.7. Resultados do modelo GLM 4 para o teste da influência de variáveis independentes referentes ao método SISUC e ao conselho gestor das UCs sobre a evolução na situação dos indicadores (2010-2014) para o conjunto de UCs pesquisadas do MBRN, estado do Amazonas.

Quadro 4.8. Resultados do modelo GLM 5 para o teste da influência da priorização de indicadores (referente ao método SISUC) sobre a situação dos indicadores em 2014 para o conjunto de UCs pesquisadas do MBRN, estado do Amazonas.

Quadro 4.9. Resultados do modelo GLM 6 para o teste da influência da priorização de indicadores (referente ao método SISUC) sobre a situação dos indicadores em 2014 para o conjunto de UCs pesquisadas do MBRN, estado do Amazonas.

Quadro 4.10. Resultados do modelo GLM 7 para o teste da influência de variáveis independentes referentes ao contexto de gestão e ao conselho gestor das UCs sobre o desempenho das ações que foram estabelecidas e monitoradas para o conjunto de UCs pesquisadas do MBRN, estado do Amazonas.

Quadro 4.11. Resultados do modelo GLM 8 para o teste da influência de variáveis independentes referentes ao contexto de gestão e ao conselho gestor das UCs sobre o desempenho das ações que foram estabelecidas e monitoradas para o conjunto de UCs pesquisadas do MBRN, estado do Amazonas. 


\section{Capítulo 1}

\section{Contextualização}

Um dilema está instalado no que se refere à governança e à gestão local de unidades de conservação brasileiras no âmbito de seus conselhos gestores. 0 marco regulatório sobre o conselho gestor de UCs é abrangente (SNUC, 2000; 2002), qualificado (Prado et al, 2015) e coerente com políticas e acordos internacionais inovadores (Irving \& Prates, 2015). Porém, a aplicação de parte dos instrumentos que materializam esses avanços ainda não preenche lacunas importantes observadas na abordagem adotada pelo poder público, o que limita a vinculação entre a governança local e a gestão e, por conseqüência, na efetividade de unidades de conservação. Este é um desafio que parece difícil de ser superado e que, com o passar do tempo, consolida problemas para os quais até o momento não existem propostas sistêmicas que sinalizem potencial eficácia, abrangência e durabilidade. Esse cenário leva às seguintes indagações que serão desenvolvidas no presente capítulo: Que fatores podem explicar a situação descrita, e quais são as possíveis conseqüências? A abordagem de sistemas socioecológicos pode ser uma alternativa para lidar com isso?

\subsection{NO PAPEL: COMO AS COISAS DEVEM SER!}

De acordo com a União Internacional para Conservação da Natureza (UICN), áreas protegidas são espaços geográficos claramente definidos, reconhecidos, dedicados e geridos por meios legais ou outros meios efetivos, para alcançar, no longo prazo, a conservação da natureza associada aos serviços ecossistêmicos e valores culturais (citada em Dudley et al., 2008).

No Brasil, áreas protegidas com fins de conservação da natureza associadas ao uso sustentável dos recursos naturais e à manutenção dos modos de vida das populações humanas locais, são reconhecidas na legislação como unidades de conservação (UCs). De acordo com o Sistema Nacional de Unidades de Conservação SNUC (Lei no 9.985, de 18 de julho de 2000, art. 2º, I), unidade de conservação é um "espaço territorial e seus recursos ambientais, incluindo as águas jurisdicionais, com características naturais relevantes, legalmente instituído pelo poder publico, com 
objetivos de conservação e limites definidos, sob um regime especial de administração, ao qual se aplicam garantias adequadas de proteção".

As condições determinantes do sucesso de UCs não diferem daquelas que, em geral, servem para qualquer tipo de área protegida: planejamento, organização e controle, e obtenção e tratamento de informações que subsidiem a tomada de decisões de gestão, ou seja, uma estrutura de governança (Dudley et al., 2010).

Governança é definida pela UICN como "a interação entre estruturas, processos e tradições, que determina como o poder e as responsabilidades são exercidos, como decisões são tomadas e quem toma as decisões" (citada em Graham et al., 2003; Borrini-Feyerabend et al., 2006). Portanto, a governança de áreas protegidas refere-se a poder, relações e compromissos, a quem tem influência, quem decide e a como os envolvidos são responsabilizados pelas decisões tomadas.

A governança de áreas protegidas acontece em diferentes níveis: mundial, transnacional, bilateral, nacional e subnacional/regional. No âmbito específico de uma área protegida, fala-se em governança de subunidades/zonas ou de uma unidade socioecológica (de interesse especial)(Borrini-Feyerabend et al., 2014).

Quatro tipos de governança de áreas protegidas são reconhecidas pela UICN (2002): 1. A governança promovida pelo próprio governo, por meio de seus ministérios e órgãos de gestão, caso da governança no nível nacional das UCs por meio do Ministério do Meio Ambiente (MMA) e do Instituto Chico Mendes de Conservação da Biodiversidade (ICMBio) na esfera federal e das organizações estaduais e municipais de meio ambiente; 2 . A governança compartilhada, por meio de um organismo plural ou que envolve múltiplas partes, caso dos conselhos gestores de UCs; 3. A governança privada, caso das Reservas Particulares do Patrimônio Natural, as RPPNs do Brasil; e 4. A governança por povos indígenas e comunidades, caso das terras indígenas e quilombolas do Brasil.

Independente do tipo de governança, sua função principal é criar e manter as condições necessárias para gestão efetiva (Abrams et al., 2003). Por sua vez, a gestão de uma área protegida consiste no que se faz para que ela alcance seus objetivos e nas ações e meios necessários para que isso aconteça (BorriniFeyerabend et al., 2014). A efetividade da gestão de áreas protegidas depende do constante aprimoramento dos elementos que fazem parte do chamado ciclo de gestão: contexto, planejamento, insumos, processos, resultados e desfechos 
(Hockings et al., 2006). Consequentemente, se a gestão de áreas protegidas envolve os planos, ações e resultados oriundos das práticas de governança (Lockwood, 2010), então, a efetividade de gestão tem por pré-requisito a efetividade de governança (UNEP, 2002; Lockwood, 2010). Logo, para ser efetiva, a gestão não pode ser feita na ausência da governança (Ostrom, 2009). Pelo contrário, gestão e governança devem operar de forma acoplada, como ilustra a Figura 1.1, de forma a aumentar a responsabilidade da sociedade e dos órgãos públicos sobre a expansão e a evolução das demandas das áreas protegidas (Nkhata \& Breen, 2010).

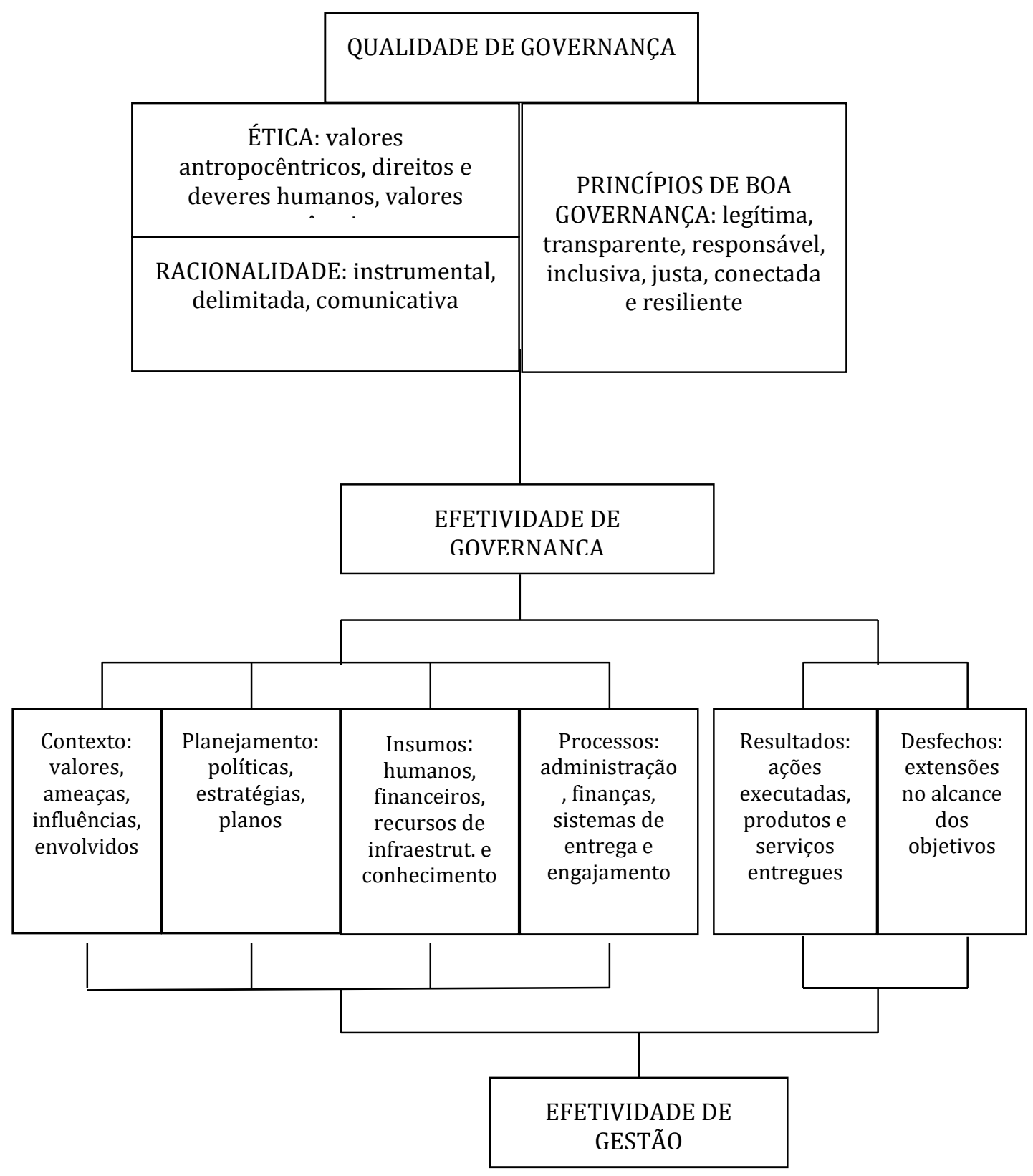

Figura 1.1. Quadro lógico da efetividade de governança, no qual estão incluidos elementos do quadro lógico da efetividade de gestão proposto por Hockings et al. (2006). Fonte: Lockwood (2010). 
No âmbito do conselho gestor de UCs, objeto central de investigação do presente trabalho de pesquisa, os processos de governança e gestão local são baseados na materialização dos elementos do ciclo de gestão. Essa materialização acontece por meio de instrumentos regulatórios que abrangem sistemas de áreas protegidas ou de iniciativas incidentes sobre algumas UCs, promovidas por órgãos públicos de gestão, com ou sem o envolvimento de organizações parceiras.

Entre esses instrumentos ou iniciativas, alguns são de interesse primário para a presente pesquisa, pois ainda apresentam limitações práticas para atender, de maneira adequada, as necessidades locais de governança de UCs: o conselho gestor e a avaliação da situação de UCs (ligados aos elementos 'contexto' e 'insumos' do ciclo de gestão) e plano de manejo (ligado ao elemento 'planejamento' do ciclo de gestão).

\subsection{NA PRÁTICA: COMO SÃO AS COISAS}

\subsubsection{Conselhos Gestores: falta efetividade e sobra desmotivação}

O conselho gestor de uma UC constitui-se como espaço público, fórum político e técnico de negociações e de articulação interinstitucional, no qual são feitas reflexões sobre o funcionamento da UC e tomadas decisões sobre assuntos pertinentes à sua conservação e controle social (Amazonas, 2008; Castro, 2009). Trata-se, de um espaço em que a governança orienta as relações entre os órgãos gestores de áreas protegidas e a sociedade e, como tal, é ambiente de articulação de interesses, exercício de direitos e obrigações sociais, e de mediação entre as partes envolvidas (Nkhata \& Breen, 2010).

Conselhos gestores são constituídos por membros (conselheiros) que têm poder de voz, orientação e opinião, e devem trazer para o conselho os interesses e conhecimentos locais e/ou do grupo ou instituição que representam, e levar de volta aos mesmos os assuntos tratados e as decisões tomadas (Castro, 2009). Em UCs de proteção integral, o conselho gestor é consultivo e os conselheiros influenciam a tomada de decisões; em UCs de uso sustentável, o conselho é deliberativo e os conselheiros influenciam, decidem e deliberam sobre a gestão (SNUC, 2000; Castro, 2009), desde que a lei seja respeitada e que as proposições sejam viáveis em sua execução (Amazonas, 2008). 
Seja o conselho consultivo ou deliberativo, o fato da governança ser compartilhada entre o governo, no caso os órgãos públicos de gestão, e outros atores, faz com que as decisões sejam colocadas em prática pelo sistema de cogestão (Carlsson \& Berkes, 2005). Existem muitas definições para o termo 'cogestão' (Armitage et al., 2007), o qual, muitas vezes, é apresentado como se fosse restrito ao contexto da gestão de recursos naturais, quando, na verdade, segundo Natcher et al. (2005), a cogestão trata de mecanismos práticos de gestão. Cogestão refere-se a uma amplitude de arranjos, de diferentes níveis de divisão de poder, adotados para que a tomada de decisão seja feita de maneira integrada entre o governo e os grupos de usuários de um conjunto de recursos ou área (Berkes, 2009). Por isso, e considerando que a governança é determinante para gestão, a inclusão social é um dos princípios para boa governança local de áreas protegidas (Lockwood, 2010).

O SNUC expressa a preocupação com "a participação efetiva das populações locais na criação, implantação e gestão das unidades de conservação das unidades de conservação" (Lei no 9.985, de 18 de julho de 2000, art. 5o, III), e prevê o compromisso da gestão participativa, com o estabelecimento de conselhos gestores em cada UC (Cozzolino et al., 2015). Essa perspectiva é reforçada no Plano Estratégico Nacional de Áreas Protegidas - PNAP (Decreto n 5.758, de 13 de abril de 2006), com especial atenção para questões relativas ao fomento à participação social para acompanhar, influir e exercer controle social nos processos de gestão (Cozzolino et al., 2015). No entanto, como detalhado a seguir, esse marco regulatório ainda encontra uma série de desafios importantes para que seja efetivo em sua aplicação.

Normas regulatórias para o fortalecimento da participação social nos conselhos gestores de UCs têm evoluído desde o reconhecimento desses espaços pelo Sistema Nacional de UCs (Prado et al., 2015), de modo que, atualmente, o funcionamento dos conselhos gestores pressupõe um verdadeiro compartilhamento de poder e de responsabilidades nas tomadas de decisão (Cozzolino et al., 2015). Entretanto, o conhecimento de como isso vem dando-se na prática ainda é incipiente.

Avaliações empíricas da efetividade de conselhos gestores são escassas, recentes, de abordagem diversificada e não-sistêmica, e consideram desde uma UC (e.g. Teixeira, 2009) até, no máximo, quatro UCs (e.g. Santos, 2008; Souza, 2013; Carrillo \& Luz, 2013; Dantas, 2015). A única avaliação sistemática, geograficamente mais ampla e disponível, foi executada pelo ICMBio (2011) para um conjunto de 310 
UCs, cerca de 1/3 das UCs do Brasil. No entanto, de maneira geral, essas avaliações apontam uma variedade de problemas comuns nas práticas desse espaço de governança: $32 \%$ dos processos de constituição dos conselhos nas UCs leva de três a quatro anos e, mesmo depois de instituídos, $6 \%$ deles podem estar inativos; 44\% não tem um planejamento anual após os primeiros cinco meses do ano; 68\% não tem contribuído efetivamente para gestão; e órgãos públicos são instituições relativamente pouco presentes nas reuniões de conselhos gestores (ICMBio, 2011).

Em relação às rotinas práticas, conselhos gestores de UCs de diferentes biomas também evidenciam limitações e fragilidades, entre as quais podem ser citadas: disputas de poder entre o Estado e o setor privado; desigualdade no acesso ao conhecimento técnico que embasa decisões; participação controlada; lacunas para desafiar assimetrias de poder; fragilidades na independência, representação e na capacidade de atuação de conselheiros e gestores; baixa motivação e pouca efetividade das decisões (Castro, 2009; ICMBio, 2011; Marinelli, 2014; Maneschy et al., 2015; Prado et al., 2015).

Especificamente em UCs da Amazônia, foco do presente trabalho de pesquisa, ao analisar cinco conselhos gestores de diferentes regiões apoiados pelo Programa Arpa (Áreas Protegidas da Amazônia), Carrillo \& Luz (2013) concluem que as estratégias de comunicação nesse espaço de governança são débeis; que os procedimentos de trabalho, na maioria das vezes, não tiram proveito da geração de um fluxo contínuo de informações; que a maior parte dos conselheiros não se sente empoderada para desenvolver sua função da maneira ampla como deveriam; e que os mesmos atuam orientados por reações às demandas e pressões externas, sem plano de ação e com precário monitoramento de atividades, quando ocorre algum monitoramento.

Esse conjunto de condições no funcionamento de conselhos gestores leva a uma baixa motivação para a participação de conselheiros. Nesse sentido, no caso de UCs da Amazônia, Castro (2009) ressalta a impotência para decisões e ações transformadoras e a baixa produtividade nas reuniões e dos próprios conselhos, mas destaca também fatores ligados à origem dos conselhos gestores e até das próprias UCs, entre os quais estão incluídos interesses conflitantes e baixa percepção acerca das vantagens da conservação e da importância da UC; baixa percepção acerca dos benefícios da representação em questões que envolvem a gestão; e visão negativa sobre a história da criação da UC ou do conselho e do órgão gestor. 
Sem uma estrutura para a tomada de decisão propriamente dita, a governança ainda é pouco valorizada em suas particularidades no âmbito dos conselhos gestores, caracterizando-se mais como um momento de gestão em virtude de circunstâncias que o tornam necessário, do que um processo estratégico e acoplado à gestão. De fato, a governança torna-se um mecanismo distinto da gestão.

\subsubsection{Planos de Manejo: incompletos e incoerentes}

Aos fatores de resistência ao desenvolvimento de princípios da governança local de UCs (v. Cozzolino et al., 2015), somam-se limitações e fragilidades de instrumentos de apoio à governança e gestão, como os planos de manejo (v. Kinouchi, 2014).

O plano de manejo é um documento técnico, mediante o qual se estabelece um zoneamento com objetivo de manejar os recursos naturais, e que traz normas específicas para proporcionar os meios e as condições para que todos os objetivos da UC possam ser alcançados. É, portanto, o principal instrumento para a gestão de todas as categorias de UCs (Lei no 9.985, de 18 de julho de 2000, art. $2^{\circ}$, XVII).

Ao analisar encartes dos planos de manejo e pareceres emitidos por técnicos envolvidos na coordenação dos processos de gestão em um conjunto de 29 UCs da Amazônia, Vasconcelos \& Cases (2009) concluem que os planos de manejo não têm sido efetivos em seu papel, apresentando problemas que envolvem desde as informações utilizadas para subsidiar seu conteúdo até o monitoramento de sua execução.

As equipes de gestores das UCs são insuficientes para conciliar o conjunto de atividades de rotina com a coordenação do processo de elaboração de planos de manejo, de modo que, a maioria deles são elaborados via contratação de pessoa jurídica, o que torna o processo moroso e aumenta o custo final do produto (Vasconcelos \& Cases, 2009).

Problemas também são observados nas diferentes partes dos roteiros utilizados para elaboração dos planos de manejo. Segundo Vasconcelos \& Cases (2009), esses roteiros propõem diagnósticos volumosos e sem foco no conhecimento necessário (e.g. Ibama, 2002); as orientações para execução dos estudos são vagas (e.g. SDS, 2006) e nem sempre obedecem a uma sequência lógica (e.g. SEDAM, 2005); os objetivos de conservação e as necessidades de manejo são desconsiderados (e.g. 
Ibama, 2007); o planejamento estratégico raramente propõe a identificação da missão, a visão de futuro e o objetivo estratégico da UC (e.g. Ibama 2002; SEDAM, 2005; Ibama, 2007); e os conteúdos sobre o zoneamento nem sempre oferecem as orientações com os detalhes necessários (e.g. SEDAM, 2005; SDS, 2006).

De modo geral, semelhanças entre roteiros para elaboração de planos de manejo indicam que o do Ibama (2002), muito detalhado e o primeiro a ser publicado, vem sendo amplamente utilizado como referência, inclusive sendo citado nos roteiros estaduais (e.g. SEDAM, 2002; SDS, 2006), o que resulta em processos de elaboração semelhantes (Vasconcelos \& Cases, 2009). Consequentemente, essas experiências compartilham dos mesmos problemas: inexistem registros sistematizados do processo de planejamento do plano de manejo; lacunas nos conhecimentos sobre as UCs e entraves de gestão não são identificados antes da elaboração do plano; os termos de referência adotados para as contratações de empresas para elaborar planos são inespecíficos quanto às características locais e aspectos socioecológicos regionais; as metodologias adotadas não permitem o acompanhamento da elaboração do plano pelos gestores e a apropriação desse processo pela sociedade; a participação social limita-se aos diagnósticos participativos; e os planos de manejo não são monitorados para fins de avaliação (Vasconcelos \& Cases, 2009).

Além dos aspectos operativos, merece destaque também o modelo conceitual adotado para a elaboração de planos de manejo, baseado em um cenário único e de condições ideais para execução de programas e ações que os compõem. É como se os planos de manejo adotassem a premissa que as UCs são sistemas estáticos (Marinelli, 2014), ao invés de reconhecer que são sistemas dinâmicos regidos por interações entre as dimensões ecológica, sociocultural, econômica e de gestão (Marinelli et al., 2011a).

O cenário de gestão das UCs envolve múltiplos usuários, que atuam em áreas complexas, e que sofrem transformações institucionais frequentes, sejam elas informais ou formais (Souza \& Beduschi Filho, 2010). Servem de exemplo os processos de afetação por projetos de mineração e de construção de barragens (e.g. Ferreira et al., 2014) e de desafetação, redução e recategorização de UCs (e.g. Bernard et al., 2014) na Amazônia brasileira. Mas esse não é um contexto específico das UCs. A dinâmica das áreas protegidas é influenciada por suas vulnerabilidades a 
mudanças políticas, ecológicas e a flutuações econômicas (Cumming et al., 2015), pois constituem, de fato, sistemas socioecológicos (Palomo et al., 2014).

Sistemas socioecológicos consistem de elementos sociais, econômicos e ecológicos (Cumming \& Collier, 2005), constantemente mutáveis e interdependentes (Poteete et al., 2013). As interações entre esses elementos são dinâmicas, regidas por mecanismos de retroalimentação que atuam em múltiplas escalas, condições que permitem a esses sistemas se auto-organizarem (Holland, 1995). Tratam-se, portanto, de sistemas complexos (Holling, 1978), que apresentam condições de imprevisibilidade e incerteza (Simonsen et al., 2014).

Devido à sua dinâmica e à contínua mudança (Berkes e Folke, 2003), sistemas socioecológicos coevoluem por meio de interações entre atores, instituições e recursos, de acordo com contextos específicos (Holling e Gunderson 2002). Essa complexidade torna difícil a possibilidade de prever como ações específicas interferem nas condições do sistema socioecológico (Poteete et al., 2013). Consequentemente, variações imprevisíveis diminuem a probabilidade de algumas formas de gestão (Halsted \& O'Shea, 1989 apud Poteete et al., 2013) e podem inviabilizar a adoção de modelos conceituais (estáticos), como tem sido o caso dos planos de manejo.

Conforme exposto, incertezas ecológicas e sociais são inerentes à governança de sistemas socioecológicos, por isso, arranjos sociais flexíveis são necessários para o desenvolvimento de instituições, regras e incentivos que influenciem os resultados da gestão em um mundo complexo e incerto (Plummer et al., 2009). Dessa forma, estruturas burocráticas limitadas e persistência de premissas convencionais referentes à estabilidade social e ecológica criam desafios para lidar com incertezas e responder a mudanças, limitações típicas de problemas na governança (Plummer et al., 2009).

\subsubsection{Avaliação de Unidades de Conservação: descontextualizadas}

A inclusão e o controle social de UCs ampliam a participação da sociedade nos processos de tomada de decisão local e têm nos conselhos gestores e planos de manejo dois mecanismos potenciais para isso (Irving et al., 2006). No entanto, ainda que regulamentados pelo SNUC (2000) e reconhecidos em sua importância (e.g. Castro, 2009), conselhos gestores estão desmotivados e planos de manejo estão 
sendo pouco funcionais, sitação que compromete os processos de governança e gestão local participativos (Marinelli, 2014). Essa situação faz aumentar a relevância de um terceiro instrumento: os métodos de avaliação de UCs.

Métodos de avaliação de áreas protegidas são direcionados a, no mínimo, um entre os quatro princípios básicos seguintes: melhorar a gestão, aumentar a responsabilização, comunicar ao público e auxiliar na priorização de recursos (Leverington \& Hockings, 2004). Ao gerar uma caracterização da situação local (Hockings, 2003), avaliações de áreas protegidas fornecem subsídios a debates e decisões (Stem et al., 2005). Porém, tão importante quanto a avaliação das condições das áreas protegidas, o desenvolvimento desse processo de forma participativa é uma oportunidade para que os diferentes atores envolvidos na gestão aprendam uns com os outros e encontrem uma forma de gestão local (Leverington et al., 2010) que atenda às suas necessidades. Por isso, programas de avaliação de áreas protegidas à longo prazo devem, idealmente, oferecer oportunidades para a participação de diversos atores nesses processos (Heck et al., 2011) e promover a aprendizagem social (Keen et al., 2005).

A aprendizagem social caracteriza um processo cíclico de identificação de problema, visão/desejo de futuro, monitoramento, tomada de medidas, reflexão e redefinição do problema (Cundill \& Fabricius, 2009). Ações e idéias, relações entre conhecimentos, comportamentos e valores constituem-se em plataforma importante de aprendizagem social (Keen et al., 2005) para que métodos participativos de avaliação de áreas protegidas sejam efetivos.

Para que métodos de avaliação de áreas protegidas cumpram sua função adequadamente, além da participação da sociedade na avaliação da situação local (Leverington et al., 2010) também devem propiciar o seu envolvimento nos processos de tomada de decisão (Lockwood, 2010) a partir dos resultados obtidos na avaliação e oferecer suporte à gestão adaptativa (Stem et al., 2005).

A gestão adaptativa é uma forma natural, intuitiva e potencialmente eficaz para a tomada de decisões diante de incertezas que se apresentam nos desafios de gestão ambiental (Williams \& Brown, 2014). Essa forma de gestão envolve o uso da própria atividade de gestão para perseguir os seus objetivos e, simultaneamente, promover a aprendizagem a partir das consequências desse processo. Com a gestão adaptativa, o acúmulo de conhecimentos (aprendizados), que levam a ajustes de gestão (adaptações) e subsidiam análises para novas decisões (intervenções) 
(Williams \& Brown, 2014), retroalimenta novos aprendizados (Walters, 1986), conforme ilustrado na Figura 1.2.

A gestão adaptativa no nível local é um dos suportes em que a avaliação de áreas protegidas com foco na efetividade da gestão pode contribuir (Coad et al., 2013). Nesse sentido, métodos de avaliação de áreas protegidas vêm subsidiando decisões importantes de gestão desde o terceiro Congresso Mundial de Parques promovido pela UICN, em 1982, na Indonésia (Hockings, 2003; Caves et al., 2013; Coad et al., 2014).

No Brasil, desde os primeiros métodos de avaliação de UCs desenvolvidos, o objetivo principal tem sido avaliar a efetividade de gestão (e.g. Padovan, 2003; Faria, 2004), uma tendência que se reforçou com o passar do tempo (e.g. WWF-Brasil \& ICMBio, 2012). Seguindo uma outra tendência, neste caso, mundial, os métodos de avaliação da efetividade de gestão de UCs tratam de adaptações a partir de propostas internacionais originárias da necessidade de agências financiadoras de recursos avaliarem seus investimentos em áreas protegidas (Belokurov et al., 2009 apud Leverington, 2010).

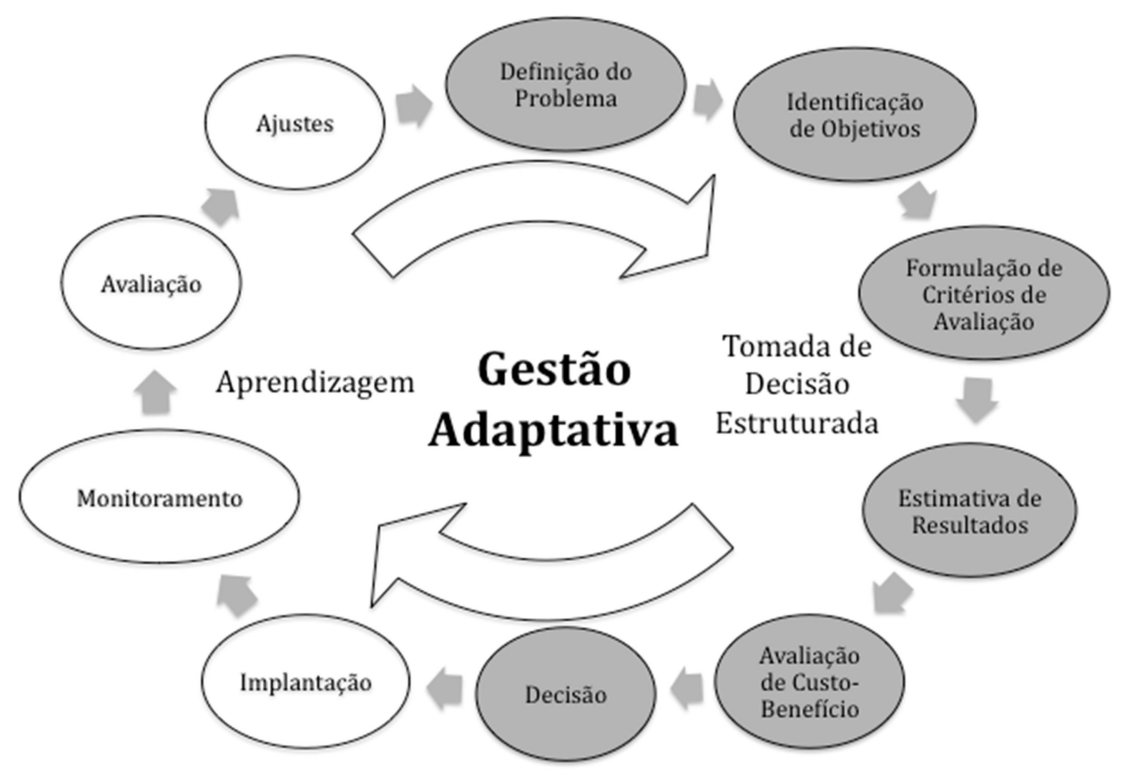

Figura 1.2. A gestão adaptativa, frequentemente caracterizada pelo 'aprender-fazendo', é um processo formal e iterativo de gestão que reconhece incertezas e alcances de objetivos de gestão pelo desenvolvimento de um sistema de conhecimento mediado por processos de retroalimentação estruturados. Como ilustrado, o processo de gestão adaptativa integra o componente de decisão à oportunidades para aprendizagem. A tomada de decisão estruturada (círculos cinza), um termo frequentemente confundido com gestão adaptativa, é uma abordagem organizada e transparente de processos de decisão para identificação, avaliação e argumentação de alternativas para decisões complexas; entretanto, a tomada de decisão estruturada não necessita da iteração e conseqüente aprendizado (círculos branco) inerentes da gestão adaptativa (extraída de Allen et al., 2011). 
Existem mais de 50 métodos de avaliação de efetividade de áreas protegidas (Leverington et al., 2010), os quais exigem informações precisas (Cook \& Hockings, 2011), consideram critérios diferentes (Stoll-Kleemann, 2010) e variam de acordo com o público usuário ao qual se destinam (Heck et al., 2011).

Nas UCs da Amazônia brasileira, três métodos podem ser citados, se considerarmos aqueles irrestritos à UC de aplicação e passíveis de replicação a partir do suporte oferecido pelas publicações de referência dos mesmos: o Tracking Tool, os Indicadores da Efetividade de Implementação e o Rapid Assessment Priorization of Protected Area Management.

O Tracking Tool (do inglês Management Effectiveness Tracking Tool) , também chamado TT, desenvolvido por Stolton et al. (2003), foi adaptado para aplicação em UCs brasileiras e recebeu o nome de Ferramenta para Avaliação de Unidades de Conservação - FAUC (MMA, 2009). Desde então, a FAUC é anualmente aplicada por gestores públicos de UCs contempladas pelo Programa Arpa, que atualmente totalizam $114 \mathrm{UCs}^{1}$.

Também inspirado no TT, o governo do Amazonas elaborou um método para avaliação anual de Indicadores da Efetividade de Implementação (IEI) das UCs estaduais (Marinelli et al., 2006), aplicado por grupos de trabalho constituídos por representantes de organizações governamentais e não-governamentais atuantes na gestão local de UCs.

O governo federal adaptou o Rapid Assessment Priorization of Protected Area Management - RAPPAM (Ervin, 2003a), sigla pela qual o método também é conhecido no Brasil (WWF-Brasil \& ICMBio, 2012). O RAPPAM brasileiro (adaptado) é aplicado por gestores públicos de UCs a cada cinco anos, e é o único método de avaliação da efetividade que já foi utilizado em todas as UCs federais do Brasil, tornando-se, por isso, o mais difundido na Amazônia brasileira.

Métodos aplicados somente por gestores de áreas protegidas podem apresentar viéses de informação em seus resultados (Coad et al., 2013) - casos da FAUC e do RAPPAM brasileiro - , e assim comprometer a avaliação da efetividade (Ervin, 2003b; Cook \& Hockings, 2011) e a credibilidade desses métodos (Heck et al., 2011).

${ }^{1}$ Acessivel em: programaarpa.gov.br/lista-de-ucs-2/ (acessado em 29/03/2016) 
O Programa de Trabalho de Áreas Protegidas da Convenção da Diversidade Biológica (CBD) defende que "métodos para monitoramento, avaliação e divulgação da efetividade de gestão de áreas protegidas e seus sistemas regionais e nacionais devem ser adotados e implementados", e seus resultados devem ser utilizados para melhorar a gestão (CDB, 2004). Porém, métodos de avaliação de efetividade de gestão têm por finalidade a definição de prioridades e comparações, dando ênfase ao papel do órgão gestor no controle do sistema de áreas protegidas (Chape et al., 2008), casos da FAUC, IEI e do RAPPAM brasileiro.

Os métodos FAUC, IEI e RAPPAM brasileiro não possibilitam debates que promovam a construção de propostas de gestão participativa, contextualizadas às necessidades e à realidade local a partir de um espectro mais amplo de temas avaliados para além da gestão, já que se tratam de adaptações do TT e RAPPAM, internacionalmente reconhecidos por seu foco no atendimento às demandas de órgãos gestores (e.g. Stoll-Kleemann, 2010).

Por isso, ainda que a maioria das ferramentas de efetividade de gestão tenham sido projetadas para ajudar gestores no processo de gestão adaptativa no nível local e de sistema (Coad et al., 2013), os métodos utilizados em UCs da Amazônia brasileira não contribuem para isso, pois são restritos à caracterização da situação de UCs, o que, segundo Leverington et al. (2010), limita seu aproveitamento na gestão. Isso restringe a integração entre planejamento, gestão e monitoramento, proposto por Hockings (1999), que poderia ocorrer por meio de um processo consecutivo de exame sistemático de intervenções para adaptação e promoção de aprendizados para melhorar avanços (Stem et al., 2005; Williams \& Brown, 2014).

A combinação do engajamento de atores interessados na gestão com a gestão adaptativa viabiliza acordos sobre questões controversas, promove soluções inovadoras e uma gestão mais eficaz (Caves et al., 2013). Sendo um componente essencial da estratégia de gestão de áreas protegidas, essa integração precisa ser priorizada (Nolte et al, 2010) e as ferramentas de avaliação de efetividade podem contribuir sobremaneira para isso. 


\subsection{EXISTEM SOLUÇÕES ALTERNATIVAS PARA ESSES PROBLEMAS?}

Conselhos gestores de UCs têm se apresentado como interessante instrumento para intermediação das relações entre a sociedade civil e o Estado em um ambiente institucionalizado e formal (Souza, 2012). Por outro lado, quinze anos após a instituição do SNUC, parte dos avanços conquistados 'no papel', ainda não são adequadamente praticados. Fragilidades na estrutura para tomada de decisão e nos mecanismos de participação social nesse processo e planos de manejo limitados em sua utilidade, restringem a atuação de conselheiros, comprometem a efetividade de conselhos gestores como espaços de governança local e, consequentemente, a gestão de UCs.

Pesquisas realizadas não só na Amazônia (e.g. Carrillo \& Luz, 2013; Castro, 2013; Maneschy et al., 2015), mas também na Mata Atlântica (e.g. Souza, 2012; Costa \& Silva, 2013), evidenciam que as condições descritas no presente capítulo são um problema crônico das UCs do Brasil, o que é refletido na última avaliação da efetividade dessas áreas protegidas. Segundo o WWF-Brasil \& ICMBio (2012), processos participativos de planejamento, resultados de planejamento e o monitoramento de resultados, estão entre os indicadores de menor desempenho, todos em situação de baixa efetividade de gestão.

Limitações nas condições para atuação de atores sociais em processos de tomada de decisão são impeditivos para participação eficaz em espaços de governança de sistemas socioecológicos (Simonsen et al., 2014) e a atual situação dos conselhos gestores de UCs do Brasil não será resolvida apenas com a regulamentação do seu marco legal (Macedo, 2007; Cozzolino et al., 2015; Prado et al., 2015).

O Brasil não constitui-se de uma exceção aos problemas de governança e gestão de muitos sistemas de áreas protegidas ao redor do mundo (e.g. Leverington et al., 2010; Laurance et al., 2012). No entanto, os problemas expostos no presente capítulo apontam para desafios a serem superados para aprimorar a democratização das decisões e a consolidação de uma cultura política participativa, que possam contribuir para efetividade de UCs. Nesse sentido, o presente trabalho de pesquisa se propõe a analisar esses aspectos a partir de uma abordagem socioecológica. 


\subsubsection{Abordagem de sistemas socioecológicos para governança e gestão UCs: um caminho possível?}

Nas últimas décadas, o entendimento da sociedade sobre os objetivos das áreas protegidas vem, gradativamente, passando de um foco estrito na conservação biológica para a consideração de que esta é uma das partes importantes que compõem os ecossistemas e os serviços por eles providos para o bem-estar humano (Palomo et al., 2014). Por isso, os atuais sistemas de governança socioecológica evidenciam a necessidade de se repensar os modelos de gestão pública com base em modelos teóricos e metodológicos e novas racionalidades alimentadas por visões sistêmicas, críticas e complexas (Philippi et al., 2011). Diante disso, a abordagem socioecológica, mais estratégica, integrada e resiliente, na qual mudanças ecológicas e sociais são incorporadas à gestão em regime de caráter adaptativo (Palomo et al., 2014) parece também ser coerente para as UCs, diante de seus problemas atuais de governança local no âmbito de seus conselhos gestores.

A abordagem de sistemas socioecológicos na realização de pesquisas é comumente adotada com ênfase na gestão de recursos naturais (Plummer et al., 2012), inclusive quando se trata de de áreas protegidas, seja na Amazônia internacional (e.g. Iwamura et al., 2016), na Europa (e.g. Risvoll et al., 2014) ou no Brasil (e.g. Berkes \& Seixas, 2005). Na gestão local de áreas protegidas em caráter mais amplo, a abordagem de sistemas socioecológicos é recente e, até o momento, restrita a alguns casos simbólicos, como na Cayos Cochinos Marine Protected Area, em Honduras (e.g. Bown et al., 2013); no Kruguer National Park, na África do Sul (e.g. Simonsen et al., 2014) e no Parque Nacional de Galápagos, no Equador (e.g. Palomo et al., 2014). Essa tendência também se faz presente nas UCs do Brasil, de forma que pesquisas sob abordagem de sistemas socioecológicos relacionadas a gestão de áreas protegidas são restritas a casos pontuais, como Abdala (2002), que analisa a gestão do Parque Nacional de Brasília e suas relações com a estrutura social da cidade, e Marinelli et al. (2011a), que propõem um modelo conceitual da dinâmica socioecológica de UCs e suas relações com a gestão local dessas áreas protegidas.

Mudanças em sistemas socioecológicos como as UCs ocorrem em virtude de sua dinâmica, conforme detalhado no subitem 1.2.2 do presente capítulo. Porém, também podem acontecer a partir de transformações deliberadas (intencionais), voltadas ao bem estar humano e ampliação dos serviços ecossistêmicos (Moore et al., 2014). Essas transformações intencionais podem ser desencadeadas por meio de 
mudanças em elementos-chave de partes das dimensões social ou ecológica, influenciando mecanismos de retroalimentação do sistema socioecológico (Moore et al., 2014), o que é abordado no presente trabalho de pesquisa.

Respostas apropriadas a mudanças ou em busca das mesmas (i.e. intencionais) são fortemente determinadas por caracterizações de estado e de processos (Bellamy et al. 2001). Perceber esses fenômenos é possível, por exemplo, por meio de métodos de avaliação de áreas protegidas em que a adoção da abordagem adaptativa para promover a aprendizagem é implementada ( $v$. subitem 1.2.3 do presente capítulo). Isso porque o processo de adaptação de decisões baseiase na identificação das condições iniciais do sistema, seguido de decisões e da obtenção de respostas para a adaptação das ações (Smith e Lenhart 1996; Füssel 2007). Em todas essas etapas, o monitoramento e a avaliação são fundamentais (Cundill \& Fabricius, 2009), pois contribuem para reflexão em contextos empíricos específicos (Armitage et al., 2009), que permitem influenciar mecanismos de retroalimentação socioecológicos.

Nesse sentido, faz-se necessário que iniciativas de monitoramento integrem variáveis de diferentes escalas espaciais e temporais, sejam preditivas, apontem para limiares de resiliência, monitorem resultados de desempenho e de processos, estimulem a reflexão, a colaboração em todas as etapas do processo, o aprendizado e o direcionamento para tomada de decisão, o encorajamento para a experimentação, a ação e a busca por ideais e por melhores práticas e metas (Cundill \& Fabricius, 2009).

Parâmetros consistentes e a seleção de indicadores são necessários para que essas condições sejam possíveis (Armitage et al., 2009), assim como o uso de processos participativos para o desenvolvimento e execução do monitoramento dos mesmos (Prabhu et al. 2001; Garaway e Arthur 2004). Esses indicadores devem levar em conta variáveis lentas e rápidas (Gunderson \& Holling, 2002), que correspondam à escala do sistema socioecológico em questão (Boyd \& Charles 2006) e as dimensões social e biofísica (Ostrom, 2007 apud Armitage et al., 2009), que abordem o estado do ecossistema, os resultados socioeconômicos e de subsistência, processos e condições institucionais (Plummer \& Armitage, 2007). 


\subsubsection{Sistema de Indicadores Socioambientais para UCs (SISUC) e esta tese}

O Sistema de Indicadores Socioambientais para UCs - SISUC (Marinelli, 2011), é uma ferramenta pública de monitoramento e avaliação, construída para oferecer suporte ao trabalho do conselho gestor, contribuir para o fortalecimento da gestão participativa e ampliar o controle social sobre essas áreas protegidas (Marinelli, 2011). Porém, para que seja viável alcançar esses objetivos, apesar da sigla SISUC destacar o seu conjunto de indicadores, sua aplicação vai além da avaliação socioecológica local de UCs. Os resultados dos indicadores remetem ao estabelecimento de ações prioritárias e de metas a serem alcançadas, sendo ambas monitoradas e avaliadas por meio da geração e análise de dados e informações, debates, proposições e encaminhamentos produzidos pelos membros do conselho gestor da UC².

A definição dos objetivos do SISUC são produto de reflexões de um coletivo formado por mais de 600 pessoas e 80 organizações (governamentais e nãogovernamentais) atuantes em UCs, promovidas como parte integrante (doravante projeto SISUC - liderado pelo autor da presente pesquisa) de um projeto mais amplo3, desenvolvido pelo Instituto Socioambiental (ISA) com suporte financeiro da Fundação Betty \& Gordon Moore.

A primeira fase do projeto SISUC teve início em 2008 e, a partir de 2009, esse projeto passou a ser desenvolvido tendo como uma de suas bases as pesquisas realizadas no âmbito do curso de doutorado que deu origem a presente tese.

Finalizada a primeira fase do projeto em 2011 com a publicação da ferramenta SISUC pelo ISA (Marinelli, 2011), teve início a segunda fase do projeto, executada de 2012 a 2014. Nesse período, da mesma forma que já havia sido durante a primeira fase, manteve-se o arranjo de desenvolvimento concomitante e complementar ao do presente trabalho de pesquisa.

Dessa forma, o SISUC é uma ferramenta que valoriza visões e entendimentos por parte dos diferentes setores da sociedade brasileira atuantes em UCs, quanto às necessidades dessas áreas protegidas por um sistema de monitoramento e avaliação estratégico, socioecológico, contextualizado e participativo, respaldada no rigor

\footnotetext{
2 Informações gerais da metodologia de aplicação do SISUC são apresentadas no Capítulo 3 (Material e Métodos) e o passo a passo detalhado dos procedimentos, bem como o conjunto de indicadores e suas opções de resposta, são apresentados nos apêndices 1 e 2.

3 Projeto Amazônia Socioambiental: consolidação de áreas protegidas na Amazônia brasileira.
} 
científico e no conhecimento internacional disponível relacionado ao tema. Contudo, e ainda que, teoricamente, o SISUC apresente-se como um método que valoriza características da abordagem de sistemas socioecológicos, não se sabe se, ou em que medida, o uso dessa ferramenta pode contribuir para lidar com os atuais problemas de governança local no âmbito do conselho gestor de UCs que são apresentados no subitem 1.2 do presente capítulo.

A literatura internacional enfatiza os desafios para implementação de medidas de efetividade que funcionem de fato (e.g. Williams \& Brown, 2014), adotando mecanismos participativos de conservação (e.g. Garcia \& Lescuyer, 2007; Conrad \& Hilchey, 2011). As raras evidências empíricas de sucesso nos resultados e impactos dessas iniciativas (Plummer \& Armitage, 2007) reforçam esse cenário, principalmente, no caso de áreas protegidas (e.g. Stoll-Kleemann, 2010; Bown et al., 2013) e considerando associações entre aspectos de sua governança e efetividade (e.g. Lockwood, 2010; Nkhata \& Breen, 2010).

Macura et al. (2013) destacam que a importância de processos locais sobre a efetividade de áreas protegidas é frequentemente ignorada na literatura, como por exemplo, no que refere-se às características do processo de governança e à sua interferência na efetividade. Nesse sentido, diante de desafios impostos pelas condições sociais, novas direções de pesquisa e de atividades práticas são necessárias para dar suporte a intervenções efetivas, nas quais os temas monitoramento, indicadores e análise de outcomes (i.e. desfechos) são fundamentais (Armitage et al., 2009).

Em se tratando de desfechos, mais especificamente, suas relações com alguns aspectos-chave, como por exemplo, a avaliação sistemática de metas alcançadas e a gestão participativa e adaptativa são importantes para o entendimento dos diferentes fatores que contribuem para o sucesso ou para as falhas observadas nos processos locais (Plummer et al., 2012). Nesse sentido, a análise de impactos de incentivos e resultados devem se concentrar na combinação de variáveis ao invés de presumir que uma variável é determinante (Pottete et al., 2013). Por isso, entender como múltiplas variáveis endógenas (processos sociais associados) e exógenas (que contribuem para transformação de sistemas socioecológicos) combinam-se para precipitar mudanças torna-se uma tarefa importante (Plummer, 2009). 
Diante do exposto neste capítulo, as questões que se colocam são: Se a implantação do SISUC, realmente, permite que as inovações propostas por esse método sejam colocadas em prática,

(1) Que avanços a implantação do SISUC propiciaria no âmbito da governança local de UCs?

(2) A implantação do SISUC no âmbito do conselho gestor de UCs pode ter implicações sobre as condições socioecológicas locais?

(3) Caso positivo, quais os fatores-chave a esse resultado e os principais mecanismos deste processo?

Para responder essas perguntas de pesquisa, a presente tese tem por objetivo geral investigar os efeitos da implantação do método SISUC (Sistema de Indicadores Socioambientais para Unidades de Conservação) sobre a governança local e as condições socioecológicas de unidades de conservação do Mosaico de Áreas Protegidas do Baixo Rio Negro, no estado do Amazonas.

Os objetivos específicos do presente trabalho de pesquisa foram os seguintes:

- implantar um ciclo completo do método SISUC durante reuniões de conselhos gestores de UCs e comparar as condições socioecológicas locais, antes e depois da aplicação do SISUC;

- testar a aderência entre atividades e resultados propiciados pelo método SISUC, processos de transformação deliberada de sistemas socioecológicos e a qualidade da governança local das UCs em que o método SISUC foi aplicado;

- analisar quais os fatores-chave e mecanismos envolvidos nos processos locais desencadeados a partir da aplicação do método SISUC; e

- avaliar a influência da aplicação do método SISUC sobre a efetividade das UCs pesquisadas. 


\section{Capítulo 2}

\section{Área de Estudo}

Para que os objetivos propostos pelo presente trabalho de pesquisa fossem alcançados, as atividades de campo ( $v$. detalhes no Capitulo 3 - Material e Métodos) foram realizadas em um conjunto de seis UCs do Mosaico de Áreas Protegidas do Baixo Rio Negro (MBRN), estado do Amazonas.

\subsection{A BACIA HIDROgRÁfICA do RIO NEgRo E A REgIÃo do baIXo RIo NEGRO}

A bacia do rio Negro é a maior bacia hidrográfica de águas pretas do mundo, na qual, ao longo dos $1.700 \mathrm{~km}$ do rio Negro, águas do Brasil, Colômbia, Venezuela e Guiana, drenam um mosaico de territórios protegidos por unidades de conservação e terras indígenas, que cobre $79 \%$ da área dessa bacia (Ricardo \& Antongiovanni, 2008).

Os trechos mais superiores da bacia do rio Negro, divididos principalmente entre Brasil e Colômbia, podem ser caracterizados como uma área cultural e ecologicamente complexa, basicamente ocupada por terras indígenas. 0 trecho médio pode ser caracterizado como uma região em início de ordenamento territorial, envolvendo a identificação de terras indígenas e a criação ou redefinição de unidades de conservação. 0 baixo rio Negro (Figura 2.1) abriga mais de $75 \%$ da população de 2.5 milhão de habitantes que ocupam toda a bacia, fazendo desta uma região de tensões e complexidades. Destaca-se Manaus, que, apesar de ser importante nos fluxos migratórios e para o desenvolvimento econômico da Amazônia Central, adotou políticas públicas pouco adequadas para ordenar esse processo (Ricardo \& Antongiovanni, 2008). 


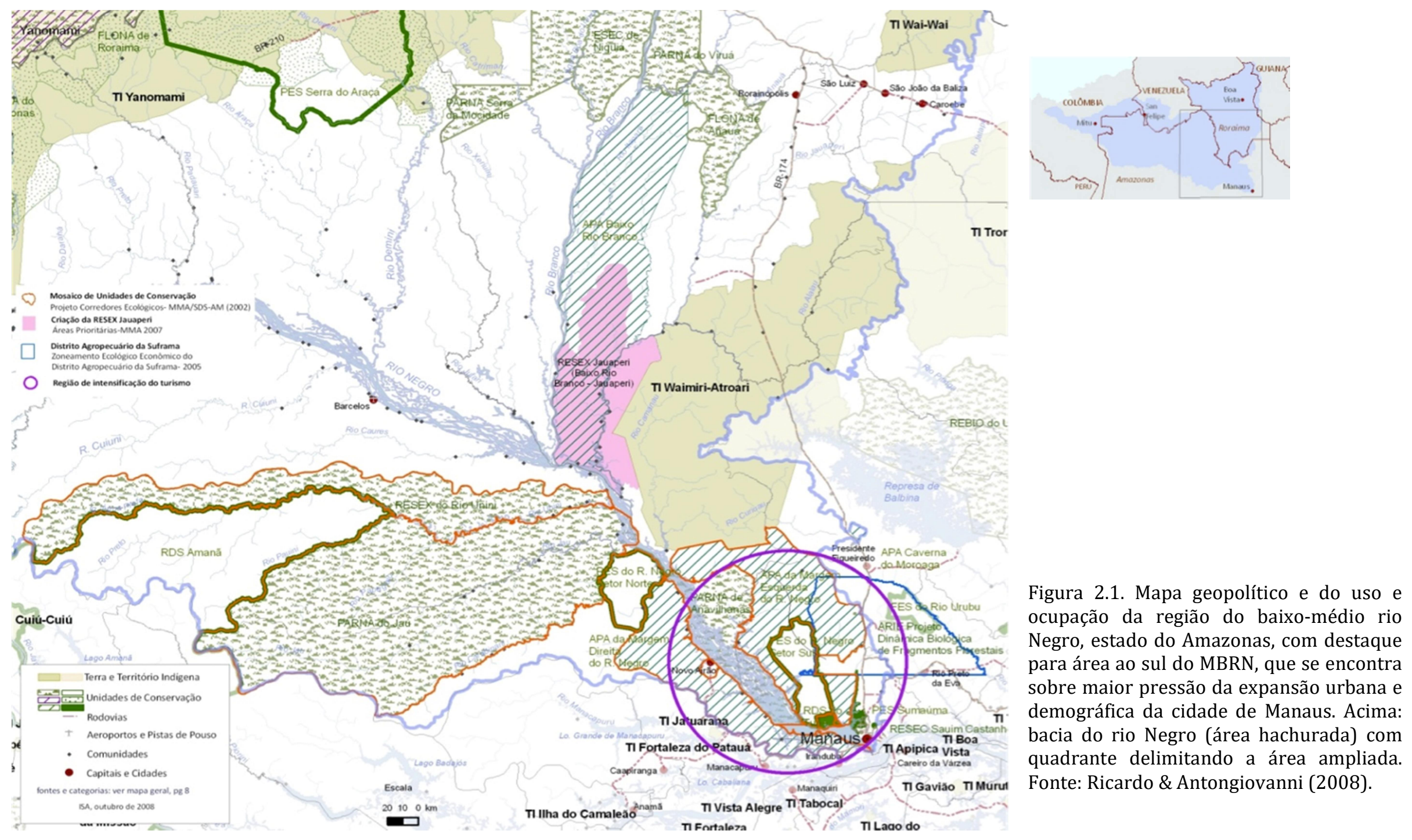


Na região do baixo rio Negro, segundo a classificação de Koppen, o clima é do tipo AM, de floresta tropical úmida, com estação seca e média anual de $28{ }^{\circ} \mathrm{C}$. Nessa área, o relevo é formado por platôs dissecados nas áreas de terra firme e planícies fluviais nas áreas sazonalmente inundáveis (D’Antona et al., 2007). A vegetação é representada por uma província fitogeográfica bem individualizada, de grande biomassa e heterogeneidade, na qual se destacam os ecossistemas de florestas inundadas (Igapós), florestas de Terra Firme, de Campina e de Campinarana. A diversidade da fauna regional reúne cerca de 500 espécies de peixes, 100 de anfíbios e répteis, 500 de aves, e dezenas de mamíferos dos variados grupos taxonômicos, mas pode-se dizer que ela ainda é pouco conhecida (IPÊ, 2010).

Em território brasileiro, onde 50,6\% da bacia do rio Negro é ocupada por áreas protegidas, as taxas de desmatamento são no máximo de 1,3\% de sua área de drenagem (Trancoso et al., 2010). Dessa maneira, os recursos naturais estão bem conservados, em virtude da presença de populações nativas que tradicionalmente ocupam essa bacia, o que também faz do rio Negro uma das regiões da Amazônia com altíssima diversidade socioambiental (Ricardo \& Antongiovanni, 2008).

Historicamente ocupada por povos indígenas e tradicionais, com fisionomias florestais únicas e de grande interesse para o manejo sustentável e a pesquisa científica, a bacia o rio Negro constitui arena estratégica para implementação de ações inovadoras, oferecendo enorme potencial para modelos locais de repartição de benefícios da biodiversidade, desenvolvimento sustentável e conservação. Em grande parte fora dos vetores de ocupação econômica e de grandes projetos, a bacia do rio Negro oferece oportunidade ímpar para que seja construido um processo compartilhado de desenvolvimento regional sustentável (Ricardo \& Antongiovanni, 2008).

\subsection{O Mosaico de Áreas Protegidas do Baixo Rio Negro (MBRN)}

O MBRN, instituído pela Portaria ${ }^{\circ} 483$ do Ministério do Meio Ambiente, de 14 de dezembro de 2010, ocupa uma área de cerca de 7,3 milhões de hectares, na qual estão inseridas onze UCs, distribuídas por nove municípios, constituídas por: três UCs federais, sete UCs estaduais e uma UC municipal, sete delas pertencentes ao grupo de uso sustentável - três delas Áreas de Proteção Ambiental (APAs) - e quatro ao grupo de proteção integral, conforme Quadro 2.1. 
Quadro 2.1. UCs que compõem o MBRN e respectivas áreas totais ocupadas.

\begin{tabular}{|c|l|c|}
\hline & Unidade de Conservação & Área (ha) $^{*}$ \\
\hline 1 & Resex do Amanã & 2.350 .000 \\
\hline 2 & Parna do Jaú & 2.272 .000 \\
\hline 3 & Resex do Unini & 883.000 \\
\hline 4 & APA do Rio Negro AA & 643.000 \\
\hline 5 & APA do Rio Negro PS & 566.000 \\
\hline 6 & Parna de Anavilhanas & 350.000 \\
\hline 7 & PE do Rio Negro (Setor Sul) & 158.000 \\
\hline 8 & PE do Rio Negro (Setor Norte) & 146.000 \\
\hline 9 & RDS do Rio Negro & 103.000 \\
\hline 10 & APA do Tarumã & 57.000 \\
\hline 11 & RDS do Tupé & 12.000 \\
\hline
\end{tabular}

Onde: Itens destacados em verde referem-se as UCs pesquisadas no presente trabalho ( $v$. detalhes mais abaixo); * fonte: IPÊ (2010).

Até o ano de 2015 e, portanto, durante todo período de atividades em campo do presente trabalho de pesquisa, as UCs estaduais do MBRN foram geridas pelo Centro Estadual de Unidades de Conservação do Amazonas (CEUC-AM), órgão da Secretaria de Estado do Meio Ambiente e Desenvolvimento Sustentável do Amazonas. A partir do Decreto no 36.219, de 09 de setembro de 2015, essa função passou a ser executada pelo Departamento de Mudanças Climáticas e Gestão de UCs (DEMUC) da então criada Secretaria de Estado do Meio Ambiente do Amazonas (Sema-AM). As três UCs federais são geridas pelo Instituto Chico Mendes de Conservação da Biodiversidade (ICMBio), ligado ao Ministério do Meio Ambiente, e uma UC é gerida pela Secretaria Municipal do Meio Ambiente de Manaus.

A gestão articulada de um conjunto complexo de áreas protegidas, espalhadas por extensas regiões, é um dos grandes desafios institucionais para a Amazônia (Borges et al., 2007). A criação do MBRN vem ao encontro dessa proposta, delimitando o contorno territorial de lugares e referências da sociobiodiversidade, ao mesmo tempo em que contribui para solucionar a situação de isolamento e dificuldades de gestão de cada uma das áreas, por meio de gestão participativa, e de espaços de gestão compartilhada e de resolução de conflitos (IPÊ, 2010).

Apesar de só recentemente ter sido reconhecido como Mosaico, o processo de ordenamento e destinação do conjunto de territórios que constituem essa área teve início em 1980. Esse processo, que se estendeu por mais de 32 anos, foi caracterizado 
por uma série de problemas resultantes da imposição de regras por parte do Estado, que criaram um passivo de conflitos sociais latentes até os dias de hoje (IPÊ, 2010).

Embora o ordenamento territorial dessa região esteja em grande parte definido, persistem conflitos territoriais em função da ausência de regularização fundiária e do uso inadequado da terra. O Parna do Jaú e PE do Rio Negro (Setor Norte) são exemplos de categoria de manejo restritiva ao uso, mas que englobam comunidades ribeirinhas, com suas respectivas áreas de exploração de recursos naturais e de atividades agrícolas. Os conflitos também são gerados por sobreposição de ações de governo com finalidades contraditórias, como é o caso dos assentamentos do INCRA estabelecidos na área do PE do Rio Negro (Setor Sul) ${ }^{4}$ (Ricardo \& Antongiovanni, 2008).

${ }^{4}$ Além dos fatores já apresentados, vale ressaltar atividades que geram conflitos com os objetivos definidos para essas UCs: RDS do Tupé, turismo desordenado; APA Tarumã, exploração de recursos minerais e madeireiros; APA do Rio Negro AA, turismo desordenado, extração de madeira, destruição de sítios arqueológicos, ocupações e loteamentos irregulares; APA do Rio Negro PS, ocupação desordenada; PE do Rio Negro (Setor Norte), extrativismo vegetal e mineral, pesca comercial, caça e turismo desordenado e área de treinamento de tiro da Marinha do Brasil; Resex do Unini, pesca comercial, esportiva e ornamental; Parna do Jaú, exploração de peixes ornamentais, madeira, quelônios e ovos dos mesmos para comercialização; e Parna de Anavilhanas, navegação fluvial, exploração vegetal (madeireira e não-madeireira), caça e pesca comercial e, extração de areia e atividades agropecuárias no seu entorno (IPÊ, 2010).

Esse mosaico apresenta algumas características importantes do ponto de vista do uso e ocupação humana do território legalmente protegido e do contexto socioecológico regional, tornando-a interessante para ser pesquisada e adequada aos objetivos dessa tese, justificando a sua escolha como área de estudo: i. Um conjunto de UCs representativo da realidade Amazônica em relação à distribuição de suas categorias de gestão por grupos de manejo e esferas públicas de gestão; ii. Uma taxa de cobertura vegetal e nível de conservação ambiental entre os menores de toda Amazônia internacional, apesar da margem do Mosaico estar a menos de $100 \mathrm{~km}$ da capital Manaus, onde vivem mais de 1,5 milhão de pessoas; iii. Um histórico de

${ }^{4}$ Características presentes no ano de 2010, quando tiveram início as atividades de campo do presente trabalho de pesquisa. 
mobilização socioambiental, primeiro na luta por direitos sociais devido aos conflitos originários da criação de UCs de proteção integral em um território tradicionalmente ocupado por populações humanas; depois, para criação de UCs de uso sustentável para aliar a conservação da natureza à manutenção dessas tradicionalidades e, finalmente, para o fortalecimento do processo de implementação dessas UCs; e iii. UCs de proteção integral com populações humanas estabelecidas dentro de seus limites e fazendo uso de recursos naturais a partir de arranjos de gestão em regime especial, construídos para que essa condição não signifique entraves para a gestão e o menor rompimento possível dos modos de vida tradicionais dessas populações.

Porém, das onze UCs que constituem esse mosaico de áreas protegidas, apenas seis delas foram escolhidas para o desenvolvimento desta tese (Figura 2.2).

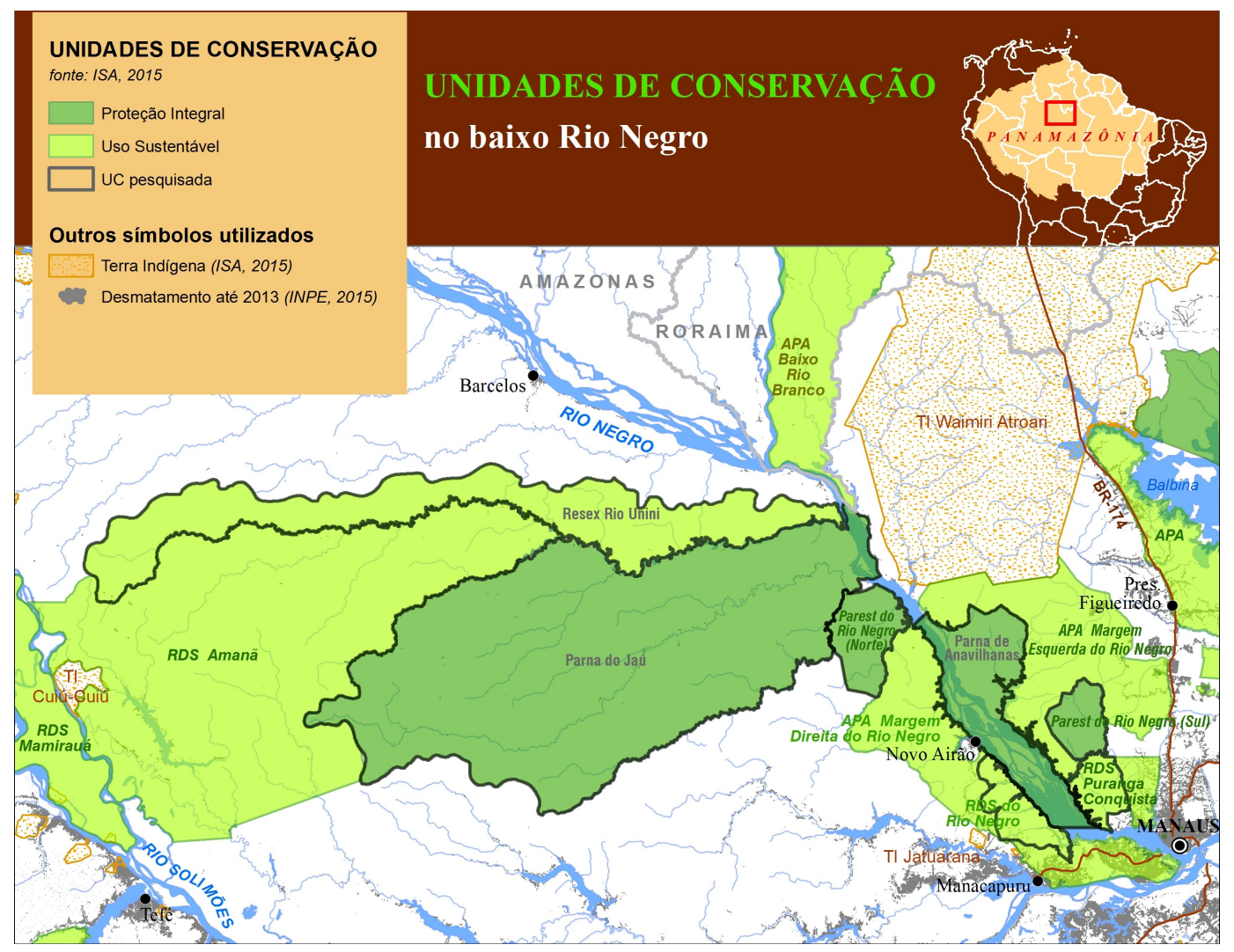

Figura 2.2. Mapa da região de inserção do MBRN com destaque para as UCs pesquisadas (limites demarcados em preto).

Três das UCs pesquisadas são federais, das quais duas são de proteção integral (Parna do Jaú e Parna de Anavilhanas) e uma de uso sustentável (Resex Unini). Duas são UCs estaduais, sendo uma de uso sustentável (RDS do Rio Negro) e uma de proteção integral (PE do Rio Negro). No caso desta última, por ser dividida em duas glebas (setor norte e setor sul) geograficamente distantes, possuírem 
estruturas de gestão completamente independentes, serem geridas como duas UCs, inclusive com o MBRN tendo reconhecido oficialmente essa divisão, assim foram consideradas no presente trabalho, totalizando portanto seis UCs pesquisadas.

As UCs pesquisadas no presente trabalho foram definidas a partir da consideração dos seguintes fatores: i. Permitem um desenho amostral homogêneo quanto a distribuição do número de UCs por grupo de manejo e esfera públicas de gestão; ii. Com mais de $50 \%$ das UCs do mosaico amostradas e não havendo variabilidade quanto ao objeto de estudo (conselhos gestores), constituem amostra suficiente para validação dos resultados considerando-se a representatividade do mosaico; iii. Das cinco UCs excluídas da amostragem, quatro são estaduais, das quais três são APAs e, portanto, assim como a maior parte das APAs brasileiras, ainda não estavam em fase de implementação, não possuíam conselho gestor e nem mesmo processo de mobilização de lideranças ou de organizações em andamento em 2010 (ano de definição das UCs a serem amostradas), assim como a RDS do Amanã; e iv. 0 mesmo argumento serviu para descartar a RDS do Tupé, que, além disso, é uma UC municipal, o que comprometeria a homogeneidade da amostragem.

Apesar de quase 30 anos separarem as datas de criação das UCs pesquisadas, o intervalo de criação de seus conselhos gestores foi de no máximo quatro anos, concluídos em 2010 (Quadro 2.2), quando iniciaram-se as atividades de campo do presente trabalho.

Quadro 2.2. Informações sobre as datas de criação das UCs, conselhos gestores e de aprovação de planos de manejo/gestão das UCs pesquisadas no MBRN entre os anos de 2010 e 2014.

\begin{tabular}{|l|c|c|c|}
\hline \multirow{2}{*}{ Unidade de Conservação } & \multicolumn{3}{|c|}{ Ano } \\
\cline { 2 - 4 } & Criação & Conselho Gestor & Plano de Manejo/ Gestão* \\
\hline Parna do Jaú & 1980 & 2008 & 2002 \\
\hline Parna de Anavilhanas** & 1981 & 2006 & 2002 (em revisão/adequação) \\
\hline PE do Rio Negro (Setor Sul)*** & 1995 & 2010 & 2010 \\
\hline PE do Rio Negro (Setor Norte) & 1995 & 2008 & 2009 \\
\hline Resex do Unini & 2006 & 2009 & $2014^{* * * *}$ \\
\hline RDS do Rio Negro & 2008 & 2010 & Em elaboração \\
\hline
\end{tabular}

Onde: * plano de manejo nas UCs federais ( $c f$. SNUC, 2000) e planos de gestão nas UCs estaduais (cf. SEUC, 2007) ; ** Parna de Anavilhanas: criado como Estação Ecológica em 1981 teve plano de manejo aprovado (2002) e conselho gestor criado (2006). A UC foi recategorizada em 2008 e passou a ser Parque Nacional e até o momento não tem um plano de manejo atualizado; *** PE do Rio Negro (Setor Sul): criado como Parque Estadual em 1995 teve seu plano de manejo disponibilizado para consulta pública em 2010, mas o plano não chegou a ser aprovado. A UC foi recategorizada em 2014 e passou a ser Reserva de Desenvolvimento Sustentável, o que não incorreu em nenhum tipo de problema para continuidade das atividades do presente projeto de pesquisa; ${ }^{* * * *}$ apesar de aprovado em 2014, o plano de manejo da Resex do Unini estava pronto desde 2010. 
Os conselhos gestores dessas UCs possuem, em média, 18 cadeiras e são constituídos por atores dos diversos setores da sociedade, sendo em sua maior parte lideranças representantes de comunidades localizadas dentro dessas áreas protegidas. Enquadram-se nesse perfil os conselhos gestores do Parna do Jaú e Resex Unini, que desde 2012 realizam suas reuniões de maneira integrada, devido a alguns ribeirinhos serem conselheiros de ambas as UCs por viverem no Parque, mas manterem atividades extrativistas e histórico de relações familiares dentro da Resex. Também enquadram-se nesse perfil os conselhos gestores dos PEs do Rio Negro (Setor Sul e Setor Norte).

A maioria dos membros do conselho gestor da RDS do Rio Negro também são lideranças sociais locais. Porém, por ser esta uma UC de uso sustentável e estar próxima de Manaus, possui diversidade maior de atores representados, que inclui empresas e um número maior de organizações que têm sua sede na capital.

O conselho gestor do Parna de Anavilhanas também enquadra-se no perfil descrito acima, mas diferencia-se pela ampla representação geográfica de seus conselheiros. Apesar de ser a única UC pesquisada sem moradores em seu interior, está inserida na área central do MBRN e por isso tem um conselho com representantes das várias UCs que cercam o Parna. Seu conselho não chega a ter a representatividade ou composição de perspectiva política como é o caso do conselho do MBRN, mas fica entre este conselho, de caráter mais regional, e os conselhos das demais UCs, geograficamente mais restritos. 


\section{Capítulo 3}

\section{Material e Métodos}

Para investigar os efeitos locais da implantação do método SISUC em processos no âmbito dos conselhos gestores e nas condições socioecológicas de seis UCs do MBRN, no estado do Amazonas, foi adotada a abordagem multimétodos utilizada na ciência socioecológica ( $c f$. Cox, 2015). Os detalhes dos procedimentos utilizados seguem descritos ao longo deste capítulo.

Em linhas gerais, os métodos adotados nesta tese podem ser divididos em três frentes principais: pesquisa da literatura internacional e nacional de referência sobre os temas primários e secundários investigados, incluindo artigos científicos, livros, relatórios e outros tipos de documentos; trabalho de campo para coleta de dados e informação; e análise dos dados e informações obtidas.

O trabalho de campo, realizado junto aos conselhos gestores das seis UCs pesquisadas (v. detalhes em Área de Estudo, Capítulo 2), ocorreu durante reuniões semestrais ou quadrimestrais desses colegiados. Essas reuniões ocorreram entre os anos de 2010 e 2014 e totalizaram cerca de 96 dias de trabalho em campo (2 reuniões x 2 dias cada x 6 UCs x 4 anos $=48$ reuniões e 96 dias) $)^{5}$, quando foram executadas ações do SISUC e acompanhados os debates das demais pautas de cada reunião.

\subsection{COLETA DE DADOS E INFORMAÇÃO EM CAMPO: APLICAÇÃO DO MÉTODO SISUC}

Para a coleta de dados e informação em campo, foi adotado o método SISUC (Sistema de Indicadores Socioambientais para Unidades de Conservação - Marinelli, 2011). O SISUC foi desenvolvido para oferecer suporte ao trabalho do conselho

\footnotetext{
${ }^{5}$ A realização e a freqüência anual de reuniões de conselhos gestores de UCs na Amazônia brasileira, em geral, são irregulares, incluindo-se as das UCs aqui pesquisadas. Dificuldades na conciliação de agendas, na disponibilidade de recursos financeiros, logísticas (em virtude de secas extremas) e até a integração de conselhos gestores em uma mesma reunião, casos do Parna do Jaú com a Resex Unini (a partir de 2012), fazem do número de reuniões apresentado uma aproximação. Ainda assim, esse número pode ser considerado uma boa referência mínima do número de reuniões oficiais, pois foram gerados a partir de critérios conservadores.
} 
gestor de UCs, contribuir para o fortalecimento da gestão participativa e ampliar o controle social sobre essas áreas protegidas.

Estruturado em uma ferramenta que, entre outros, oferece suporte à gestão dos dados e informações obtidas, o SISUC consta de um conjunto de 27 indicadores (econômicos, socioculturais, ambientais e de gestão), que servem para avaliação da situação socioecológica local de UCs. Indicadores identificados em situação indesejada são priorizados e servem de referência para o estabelecimento de um plano estratégico de ações. A viabilidade dessas ações é avaliada e, uma vez validadas, sua execução passa a ser monitorada durante um período de no mínimo dois e no máximo três anos. Os resultados obtidos no monitoramento do desempenho de ações são utilizados para promover ajustes e correções orientadas ao alcance de metas para o mesmo período, definidas a partir das opções de resposta às mesmas 27 perguntas indicadoras. Ao final desse ciclo, é realizado um balanço dos resultados alcançados e o conjunto completo de indicadores é reavaliado, com o objetivo de atualizar o plano de ações e as metas a serem alcançadas, dando início a um novo ciclo iterativo. Maiores detalhes sobre o método SISUC são apresentados nos apêndices 1 e 2 e nos anexos II e III.

O SISUC foi aplicado em dois momentos em cada uma das UCs pesquisadas: no intervalo de 2010 a 2014, período em que foi executado um ciclo completo desse método ( $v$. descrição no Quadro 3.1); e no mesmo ano de 2014, quando teve início o segundo ciclo (que segue até 2017), do qual apenas a reavaliação dos indicadores tem seus resultados considerados no presente trabalho de pesquisa.

A aplicação desse método acontece por meio de oficinas participativas durante reuniões do conselho gestor de UCs ( $v$. Apêndice 1), nas quais a geração e a análise de dados e informações, debates, proposições e encaminhamentos são todos feitos pelos próprios conselheiros, coordenados por um facilitador (no caso, o autor desta tese ou consultores) com apoio de até três pessoas (no caso, gestores públicos das UCs e/ou consultores).

Para não comprometer o tempo das demais pautas das reuniões dos conselhos gestores, as atividades do SISUC não podiam durar mais do que um período, do total de quatro que normalmente constituem cada reunião. Como o presente trabalho de pesquisa foi a primeira oportunidade para implantar o método SISUC, os passos de sua aplicação foram executados um por vez a cada reunião dos conselhos gestores. Dessa forma, para o cumprimento do primeiro ciclo completo de 
aplicação do SISUC no conjunto de UCs pesquisadas e devido a alguns cancelamentos de reuniões, foram necessários um total de três anos e meio.

De modo geral, em cada uma das UCs pesquisadas, a coleta de dados e informações seguiu a sequência de etapas e passos de aplicação do método SISUC, conforme organizado no Quadro 3.1 e o detalhamento dos mesmos são apresentados no Apêndice 1.

Quadro 3.1. Etapas e passos da aplicação do método SISUC e cronograma de ações relacionadas, executadas no âmbito do presente trabalho de pesquisa, entre os anos de 2010 e 2014.

\begin{tabular}{|c|c|c|}
\hline $\begin{array}{l}\text { Etapa do método } \\
\text { SISUC }\end{array}$ & Ano & Passos do método SISUC/ações desenvolvidas \\
\hline $\begin{array}{l}\text { Etapa 1: } \\
\text { Apresentação do } \\
\text { método SISUC }\end{array}$ & \multirow[t]{4}{*}{2010} & 1. Apresentação do SISUC \\
\hline \multirow[t]{6}{*}{$\begin{array}{l}\text { Etapa 2: Oficina de } \\
\text { aplicação do SISUC }\end{array}$} & & $\begin{array}{l}\text { Início do Ciclo } 1 \text { de aplicação do SISUC } \\
\text { 2. Aplicação dos indicadores de avaliação socioecológica }\end{array}$ \\
\hline & & 3. Interpretação e validação de resultados dos indicadores \\
\hline & & $\begin{array}{l}\text { 4. Priorização de indicadores em situação indesejável e } \\
\text { proposição de ações socioambientais para melhoria da } \\
\text { condição desses indicadores }\end{array}$ \\
\hline & \multirow[t]{2}{*}{2011} & $\begin{array}{l}\text { 5. Análise de viabilidade das ações socioambientais propostas e } \\
\text { definição do conjunto de ações a serem executadas para } \\
\text { melhoria da condição dos indicadores em situação indesejável }\end{array}$ \\
\hline & & $\begin{array}{l}\text { 6. Estabelecimento de metas a serem alcançadas pelos } \\
\text { indicadores em situação indesejável }\end{array}$ \\
\hline & \multirow[t]{2}{*}{2012} & $\begin{array}{l}\text { 7. Organização de grupos de conselheiros e treinamento dos } \\
\text { mesmos para o monitoramento e avaliação do desempenho } \\
\text { das ações estabelecidas }\end{array}$ \\
\hline \multirow{3}{*}{$\begin{array}{l}\text { Etapa 3: } \\
\text { Monitoramento de } \\
\text { ações }\end{array}$} & & 8. Início das atividades de monitoramento e avaliação \\
\hline & \multirow{2}{*}{$\begin{array}{l}2012- \\
2013\end{array}$} & 8. Continuação das atividades de monitoramento e avaliação \\
\hline & & $\begin{array}{l}\text { 9. Balanço do desempenho de ações e metas } \\
\text { Término do ciclo } 1 \text { de aplicação do SISUC }\end{array}$ \\
\hline $\begin{array}{l}\text { Etapa 2: Oficina de } \\
\text { (re)aplicação do } \\
\text { SISUC }\end{array}$ & 2014 & $\begin{array}{l}\text { Início do ciclo } 2 \text { de aplicação do SISUC } \\
\text { 10. Atualização da avaliação socioecológica }\end{array}$ \\
\hline
\end{tabular}

Aplicações posteriores do SISUC, que seguem os mesmos procedimentos aqui descritos, duram um total de dois dias para serem completamente executadas. 


\subsection{AVALIAÇão SOCIOECOLÓGICA LOCAL DE UCS}

Para a avaliação socioecológica local, foram utilizados os resultados obtidos a partir da implantação do SISUC em cada UC pesquisada, com ênfase em três aspectos: 1. situação dos indicadores socioecológicos nos anos de 2010 e 2014 e 2. evolução da situação desses indicadores durante o mesmo intervalo (ambos a partir dos resultados obtidos nas ações 2 e 10 do Quadro 3.1, respectivamente); e 3. desempenho de indicadores no alcance de metas estabelecidas em 2010 para que fossem alcançadas até 2014 (ação 9 do Quadro 3.1). Esses resultados são apresentados no Quadro 4.1, Capítulo 4, Resultados.

Importante frisar que os resultados da avaliação dos indicadores não foi utilizado para fins de análise interpretativa das condições locais do sistema socioecológico das UCs pesquisadas. Seja na evolução dos indicadores entre 2010 e 2014, ou na descrição da situação observada em 2014, no presente trabalho, esses resultados são abordados na perspectiva de investigar o efeito do método SISUC na situação do sistema socioecológico dessas UCs e, principalmente, na identificação dos fatores-chave e mecanismos envolvidos nesse processo.

Para análise exploratória dos dados e informações obtidas, os resultados das avaliações dos indicadores realizadas nos anos de 2010 e 2014 foram comparados em perspectiva espaço-temporal por meio de quadros, tabelas, gráficos e testes de chi-quadrado, estes últimos, usando-se a linguagem R (R Core Team, 2015). Foram tomados como fonte de variação os seguintes aspectos: situação de cada indicador por UC; situação geral dos indicadores do conjunto das UCs pesquisadas; situação geral dos indicadores do conjunto das UCs pesquisadas por dimensão (econômica, sociocultural, ambiental e de gestão); e situação geral dos indicadores avaliados em 2010 e em 2014. Em todos esses casos, as seguintes categorias de avaliação da situação de cada indicador atendem àquelas adotadas pelo método SISUC: alarmante, insatisfatório, satisfatório ou sucesso, conforme detalhado no Apêndice 2. Como a interpretação temática dos indicadores não é foco da presente pesquisa, dados da situação geral dos indicadores por dimensão não receberam tratamento estatístico, sendo utilizados apenas como complemento descritivo.

A abordagem de análise espaço-temporal foi utilizada também para explorar a evolução da situação do conjunto de indicadores avaliados em 2010 e 2014, neste caso, tendo por fonte de variação: cada UC, o conjunto das UCs pesquisadas; e o 
conjunto das UCs pesquisadas, comparando-se indicadores priorizados e nãopriorizados em 2010. Em todos esses casos, as categorias de avaliação da evolução da situação de cada indicador foram as seguintes: retrocedeu/piorou, estagnou ou avançou/melhorou.

Abordagem de análise espaço-temporal similar foi utilizada para explorar o desempenho de indicadores priorizados no alcance de metas estabelecidas em 2010, para que fossem alcançadas até 2014, tendo-se por fonte de variação: cada UC; o conjunto de UCs pesquisadas; e o conjunto pesquisadas de UCs por dimensão (econômica, sociocultural, ambiental e de gestão). Em todos esses casos, as categorias de avaliação quanto ao alcance de metas para cada indicador foram as seguintes: não-atingida (estagnou), não-atingida (avançou) ou atingida.

Além de avaliações socioecológicas locais das UCs, para investigar os efeitos da implantação do método SISUC, também foram realizadas avaliações de processos no âmbito dos conselhos gestores das UCs pesquisadas, conforme descrito no próximo item.

\subsection{AVALIAÇ̃̃o DE PROCESSOS NO ÂMBITO DO CONSELHO GESTOR DE UCS}

No caso de processos no âmbito dos conselhos gestores das UCs, para coleta de dados e informações em campo, foi adotada a abordagem de pesquisa-ação (Deshler \& Ewert, 1995) associada à aplicação do SISUC. O questionamento sistêmico da pesquisa-ação teve por referência dois protocolos de avaliação que foram testados quanto à aderência do SISUC: 1. o protocolo de transformação deliberada de sistemas socioecológicos, proposto por Moore et al. (2014 - adaptado de Olsson, 2004) e 2. o protocolo de princípios de boa governança de áreas protegidas, proposto por Lockwood (2010). Ambos os protocolos e os testes de aderência são detalhados abaixo (subitens 3.3.1 e 3.3.2).

A coleta de dados e informação referente aos questionamentos da pesquisaação propostos por esses dois protocolos (Moore et al., 2014; Lockwood, 2010) foi feita ao longo das atividades de aplicação do SISUC durante as reuniões dos conselhos gestores, por meio de uma técnica de abordagem qualitativa, a observação participante (Seixas, 2005). 
Como explicado na introdução do presente capítulo, a sequência de passos do SISUC desenvolvidas a cada ciclo de reuniões foram os mesmos para todos os conselhos gestores pesquisados, de forma que, obtidos os dados e as informações de um determinado passo, nas demais reuniões para execução do mesmo passo em outras UCs, tais dados e informações eram usados como referência, depois de checados em sua coerência e, se necessário, complementados e/ou ajustados.

\subsubsection{Avaliação da transformação deliberada de sistemas socioecológicos}

O protocolo de transformação deliberada de sistemas socioecológicos (Moore et al., 2014) adota uma abordagem de caráter transformacional baseada em aspectos de governança, gestão transicional e inovação social, que considera múltiplos subprocessos das seguintes quatro fases: pré-transformação, preparação para mudança, transição e institucionalização da mudança, as quais seguem detalhadas no Quadro 3.2.

Quadro 3.2. Múltiplos subprocessos em cada fase da transformação deliberada de um sistema socioecológico (Moore et al., 2014).

\begin{tabular}{|c|c|}
\hline Fase & Subprocessos \\
\hline \multirow{2}{*}{$\begin{array}{l}\text { Pré } \\
\text { Transformação }\end{array}$} & Perturbações sociais ou ecológicas criam janelas de oportunidade \\
\hline & $\begin{array}{l}\text { Oportunidade de mudança do contexto atual torna-se transparente para } \\
\text { os atores }\end{array}$ \\
\hline \multirow[t]{3}{*}{$\begin{array}{l}\text { Preparação para } \\
\text { Mudança }\end{array}$} & $\begin{array}{l}\text { 'Despertar para o fazer': análise das estruturas que são mais } \\
\text { problemáticas na trajetória atual do sistema socioecológico }\end{array}$ \\
\hline & 'Prever': geração de inovação e novas visões para o futuro \\
\hline & $\begin{array}{l}\text { 'Ganhar impulso': auto-organização a partir de novas idéias, criação e } \\
\text { mobilização de redes de apoio e experimentação em "nichos" protegidos }\end{array}$ \\
\hline \multirow[t]{3}{*}{ Transição } & $\begin{array}{l}\text { 'Selecionar': escolha da inovação ou processo de mudança em que se } \\
\text { quer investir capital social, intelectual e financeiro }\end{array}$ \\
\hline & $\begin{array}{l}\text { 'Aprender': avaliação dos resultados de experiências anteriores e } \\
\text { desenvolvimento de entendimentos compartilhados e novas formas de } \\
\text { conhecimento }\end{array}$ \\
\hline & $\begin{array}{l}\text { 'Adotar': absorção e replicação da mudança inovadora que foi bem } \\
\text { sucedida em fase experimental - ponto de inflexão }\end{array}$ \\
\hline $\begin{array}{l}\text { Institucionalização } \\
\text { da nova trajetória }\end{array}$ & $\begin{array}{l}\text { 'Estabelecer rotinas': gestão de estabilidade dinâmica para incorporar } \\
\text { nova trajetória ao sistema socioecológico e estabelecer ou reforçar } \\
\text { novos mecanismos de retroalimentação }\end{array}$ \\
\hline
\end{tabular}




\begin{tabular}{|l|l|}
\hline $\begin{array}{l}\text { Institucionalização } \\
\text { da nova trajetória }\end{array}$ & $\begin{array}{l}\text { 'Fortalecer relações entre-escalas': expansão da mudança envolvendo } \\
\text { um tipo diferente de inovação do que foi criado originalmente, } \\
\text { adequando-se a diferentes contextos }\end{array}$ \\
\cline { 2 - 2 } & $\begin{array}{l}\text { 'Estabilizar': sistema transformado atinge novos interessados e precisa } \\
\text { lidar com as próximas e prováveis perturbações inesperadas, como } \\
\text { atores influentes que podem oferecer resistência. }\end{array}$ \\
\hline
\end{tabular}

\subsubsection{Avaliação de princípios de governança de áreas protegidas}

O protocolo de avaliação de princípios de boa governança de áreas protegidas (Lockwood, 2010) é composto por 30 parâmetros referentes a sete princípios: legitimidade, transparência, responsabilização, inclusão, justiça, conectividade e resiliência. Esse protocolo pode ser utilizado para uma área protegida, para um conjunto ou para um sistema de áreas protegidas.

Como o presente trabalho de pesquisa analisa as práticas de governança local de um conjunto de seis UCs, 11 dos 30 parâmetros do protocolo original, os quais são voltados para sistemas de áreas protegidas (e.g. marco regulatório de governança), foram excluídos da avaliação. Os demais 19 parâmetros são apresentados no Quadro 3.3., conforme sua distribuição entre os princípios de boa governança de áreas protegidas.

Quadro 3.3. Parâmetros do protocolo de avaliação de princípios de boa governança de áreas protegidas (modificado de Lockwood, 2010).

\begin{tabular}{|c|c|}
\hline Princípio & Parâmetro \\
\hline Legitimidade & 1. Conselho gestor atua de acordo com o seu mandato e o propósito da UC \\
\hline \multirow[t]{4}{*}{ Transparência } & $\begin{array}{l}\text { 2. Governança e tomada de decisão são abertas para participação dos } \\
\text { conselheiros }\end{array}$ \\
\hline & 3. As razões por trás das decisões são evidentes \\
\hline & 4. Sucessos e falhas são evidentes \\
\hline & $\begin{array}{l}\text { 5. Informações são apresentadas de forma adequada às necessidades dos } \\
\text { conselheiros }\end{array}$ \\
\hline \multirow[t]{3}{*}{ Responsabilidade } & $\begin{array}{l}\text { 6. Conselho gestor e conselheiros têm claramente definidos seus papéis e } \\
\text { responsabilidades }\end{array}$ \\
\hline & 7. Conselho gestor tem prestado contas aos atores nele representados \\
\hline & $\begin{array}{l}\text { 8. Conselho gestor está sujeito à prestação de contas para instâncias } \\
\text { superiores }\end{array}$ \\
\hline
\end{tabular}




\begin{tabular}{|c|c|}
\hline Responsabilidade & $\begin{array}{l}\text { 9. O nível no qual o poder é exercido corresponde ao dos direitos, } \\
\text { necessidades, temas e valores associados }\end{array}$ \\
\hline \multirow[t]{2}{*}{ Inclusão } & $\begin{array}{lcccc}\text { 10. Todos os conselheiros têm } & \text { oportunidades } & \text { apropriadas } & \text { no } \\
\text { encaminhamento de processos e ações } & & & & \end{array}$ \\
\hline & $\begin{array}{l}\text { 11. O conselho busca, ativamente, engajar as lideranças interessadas que } \\
\text { estejam em desvantagem ou marginalizadas }\end{array}$ \\
\hline \multirow[t]{2}{*}{ Justiça } & 12. Decisões são tomadas de maneira consistente e sem enviesamento \\
\hline & $\begin{array}{l}\text { 13. Direitos humanos e das populações tradicionais/ povos indígenas são } \\
\text { respeitados }\end{array}$ \\
\hline \multirow[t]{2}{*}{ Conectividade } & $\begin{array}{l}\text { 14. O conselho gestor é efetivamente conectado com colegiados de } \\
\text { diferentes níveis de governança }\end{array}$ \\
\hline & $\begin{array}{l}\text { 15. O conselho gestor é efetivamente conectado com colegiados que operam } \\
\text { no mesmo nível de governança }\end{array}$ \\
\hline \multirow[t]{4}{*}{ Resiliência } & $\begin{array}{l}\text { 16. O conselho gestor tem uma cultura de, intencionalmente, aprender a } \\
\text { partir das experiências e absorver novos conhecimentos }\end{array}$ \\
\hline & $\begin{array}{l}\text { 17. O conselho gestor tem flexibilidade para rearranjar processos internos e } \\
\text { procedimentos, em resposta a mudança de condições internas e externas }\end{array}$ \\
\hline & $\begin{array}{l}\text { 18. O conselho gestor utiliza processos de planejamento e gestão } \\
\text { adaptativos }\end{array}$ \\
\hline & $\begin{array}{l}\text { 19. O conselho tem procedimentos para identificar, caracterizar e gerir } \\
\text { riscos }\end{array}$ \\
\hline
\end{tabular}

Apesar de o ciclo completo de aplicação do SISUC ser composto por nove passos (v. Quadro 3.1), para avaliação da aderência deste método a princípios de boa governança foram realizados agrupamentos e exclusões de alguns passos, de forma que ao final são considerados um total de cinco tipos de atividades. Por serem complementares entre si, os passos 2, 3 e 4 foram agrupados em um único tipo de atividade (avaliação de indicadores=AVAL.). Os passos 5 (análise de viabilidade e definição de ações=AÇÃO), 6 (estabelecimento de meta para indicadores=META), 8 (monitoramento e avaliação de ações e indicadores=M\&A) e 9 (balanço do desempenho das ações e metas=BAL.) foram considerados tipos de atividade independentes. 0 passo 7 (treinamento de conselheiros para o monitoramento de ações) foi excluído por não ser relacionado à governança propriamente dita.

Em caráter complementar à pesquisa-ação, relatórios e publicações referentes ao SISUC (disponíveis em www.blogdosisuc.socioambiental.org) 6 também

\footnotetext{
${ }^{6}$ Para download de arquivos do blog do SISUC é necessário o cadastro do usuário, disponível na página principal do blog, na coluna à direita, no ícone 'cadastre-se'.
} 
foram utilizados para compor os resultados qualitativos da análise de aderência entre o SISUC e os protocolos propostos por Moore et al. (2014) e Lockwood (2010). Os produtos dessas análises foram organizados em quadros-síntese, que integram os resultados do conjunto de UCs pesquisadas (Quadros 4.2 e 4.3, Capítulo 4, Resultados).

Além de avaliar efeitos da implantação do método SISUC sobre a situação socioecológica das UCs pesquisadas e no âmbito de seus conselhos gestores, foram investigados também quais os fatores-chave e mecanismos envolvidos nesses processos, conforme descrito no subitem abaixo.

\subsection{FATORES-CHAVE E MECANISMOS}

Para investigar os fatores-chave e mecanismos relacionados a situação socioecológica das UCs e processos no âmbito de seus conselhos gestores a partir da implantação do SISUC, foram gerados modelos lineares generalizados (GLMs, do inglês General Linear Models) e realizados testes de chi-quadrado, ambos utilizandose a linguagem R (R Core Team, 2015), cujos procedimentos são detalhados abaixo.

\subsubsection{Modelos Lineares Generalizados (GLMs)}

Em situações nas quais a suposição de normalidade de conjuntos de dados não é plausível, ao invés de transformar a variável resposta ou adotar métodos nãoparamétricos, indica-se o uso de GLMs, assumindo-se que a variável dependente é gerada a partir de variáveis com diversos tipos de distribuição, como a binomial (presença/ausência) e a ordinal (ranqueamento) (Provete et al., 2010). Estes são os casos dos dados utilizados na presente pesquisa.

Diante da complexidade dos sistemas socioecológicos pesquisados é importante que análises de mecanismos e fatores-chave concentrem-se nas combinações entre variáveis e não em variáveis isoladas, na efemeridade e temporalidade das variáveis, e no momento da gestão (Poteete et al., 2013).

Dessa forma, foram testados dezenas de GLMs para analisar correlações entre nove variáveis independentes (um total de 39 situações possíveis) referentes a três variáveis teóricas (método SISUC - três fontes de variação; contexto de gestão das 
UCs - três fontes de variação; e conselho gestor - três fontes de variação), como mostra o Quadro 3.4, sobre três variáveis dependentes: evolução na situação dos indicadores (2010-2014), situação dos indicadores em 2014 e desempenho das ações que foram estabelecidas e monitoradas, totalizando juntas 12 situações possíveis (Quadro 3.5).

Quadro 3.4. Fontes de variação (variáveis independentes) e tipos de dados utilizados no desenvolvimento dos GLMs de acordo com as variáveis teóricas testadas.

\begin{tabular}{|c|c|c|}
\hline $\begin{array}{l}\text { Variável } \\
\text { téorica }\end{array}$ & Fonte de variação & Tipo de dado \\
\hline \multirow{3}{*}{ Método SISUC } & Priorização do indicador & Binário: não-priorizado $=0 ;$ priorizado $=1$ \\
\hline & Tema da ação estabelecida & Categórico: 21 temas (de 1 a 21) \\
\hline & Desempenho da ação estabelecida & $\begin{array}{l}\text { Ordinal: retrocedeu=-1; estagnou=0; } \\
\text { avançou=1 }\end{array}$ \\
\hline \multirow{3}{*}{$\begin{array}{l}\text { Conselho } \\
\text { gestor da UC }\end{array}$} & Idade do conselho gestor & $\begin{array}{l}\text { Binário: primeiro mandato }=0 \text {; segundo } \\
\text { mandato em diante }=1\end{array}$ \\
\hline & $\begin{array}{l}\text { Gerência do conselho gestor sobre } \\
\text { as ações estabelecidas }\end{array}$ & $\begin{array}{l}\text { Binário: ingerente sobre a ação=0; gerente } \\
\text { sobre a ação=1 }\end{array}$ \\
\hline & $\begin{array}{l}\text { Atuação do conselho gestor nas } \\
\text { ações estabelecidas }\end{array}$ & $\begin{array}{l}\text { Binário: não atua na ação=0; atua na } \\
\qquad \text { ação=1 }\end{array}$ \\
\hline \multirow{3}{*}{$\begin{array}{l}\text { Contexto de } \\
\text { gestão das UCs }\end{array}$} & $\begin{array}{l}\text { Atuação da equipe local de gestão } \\
\text { nas ações estabelecidas }\end{array}$ & $\begin{array}{l}\text { Binário: não atua na ação=0; atua na } \\
\qquad \text { ação=1 }\end{array}$ \\
\hline & $\begin{array}{l}\text { Idade do plano de } \\
\text { manejo/gestão* }\end{array}$ & $\begin{array}{l}\text { Binário: não tem ou tem mais de } 4 \text { anos }=0 \text {; } \\
\text { menos de } 4 \text { anos }=1\end{array}$ \\
\hline & Idade da UC & Ordinal: $<5 ; 6-15 ;>16$ (anos) \\
\hline
\end{tabular}

* Onde: plano de gestão para as UCs federais ( $c f$. SNUC, 2000) e plano de manejo para as UCs estaduais do Amazonas (cf. SEUC, 2007).

Quadro 3.5. Fontes de variação (variáveis dependentes) e tipos de dados utilizados no desenvolvimento dos GLMs para o teste da variável teórica 'situação do sistema socioecológico'.

\begin{tabular}{|l|c|c|}
\hline $\begin{array}{l}\text { Variável } \\
\text { téorica }\end{array}$ & Fonte de variação & Tipo de dado \\
\hline \multirow{3}{*}{$\begin{array}{l}\text { Situação do } \\
\text { Sistema }\end{array}$} & $\begin{array}{c}\text { Evolução na situação } \\
\text { dos indicadores } \\
\text { Socioecológico }\end{array}$ & $\begin{array}{c}\text { Ordinal: situação piorou muito=-2; situação piorou=- } \\
1 ; \text { situação estável=0; situação melhorou=1; ou } \\
\text { situação melhorou muito=2 }\end{array}$ \\
\cline { 2 - 3 } & $\begin{array}{c}\text { Desempenho das } \\
\text { ações que foram } \\
\text { estabelecidas e } \\
\text { monitoradas }\end{array}$ & $\begin{array}{c}\text { Ordinal: retrocedeu de uma avaliação para outra =-1; } \\
\text { estagnou de uma avaliação para outra =0; ou avançou } \\
\text { de uma avaliação para outra =1 }\end{array}$ \\
\cline { 2 - 3 } & $\begin{array}{c}\text { Situação dos } \\
\text { indicadores em 2014 }\end{array}$ & $\begin{array}{c}\text { Ordinal: situação alarmante=0; situação } \\
\text { insatisfatória=1; situação satisfatório=2; ou situação } \\
\text { sucesso=3 }\end{array}$ \\
\hline
\end{tabular}




\subsubsection{Fonte dos dados para os modelos GLM}

Quanto às fontes de variação dos modelos que testaram os efeitos do método SISUC na situação socioecológica das UCs, dados referentes à priorização do indicador foram gerados na ação 4 de aplicação do SISUC (Quadro 3.1) e seguem dispostos no Quadro 4.1 (Capítulo 4, Resultados). Dados referentes ao desempenho das ações estabelecidas foram gerados na ação 8 de aplicação do SISUC (Quadro 3.1) e detalhes dessas ações estão disponíveis no Apêndice 3.

As ações socioecológicas estabelecidas para melhoria da situação dos indicadores priorizados pelo método SISUC são descritivas ('o que fazer', 'como' e 'onde'). Às vezes, mais de uma ação é desenvolvida simultaneamente ou por meio da integração entre elas. Para evitar que isso implicasse um enviesamento de ações nas análises GLM ou mesmo a divisão de ações relacionadas entre subgrupos muito específicos, o conjunto de ações estabelecidas foi dividido em grupos de 'temas de ação', como por exemplo: 'realização de um diagnóstico de pressões e ameaças' e 'execução do programa de conhecimento' foram agrupados no tema 'pesquisa e conhecimento'. Para composição desses grupos, a referência adotada foi a organização dos programas que compõem os planos de manejo de UCs (SDS, 2006). No caso de temas mais específicos, foi considerado também se os mesmos foram tratados juntos ou em separado durante as reuniões dos conselhos gestores das UCs pesquisadas. Dados referentes ao tema das ações socioecológicas podem ser conferidos no Apêndice 4.

Quanto às fontes de variação dos modelos que testaram os efeitos do conselho gestor e do contexto de gestão na situação socioecológica das UCs pesquisadas, informações referentes à idade das UCs, dos planos de gestão/manejo e dos conselhos gestores foram geradas a partir de cálculos feitos sobre os dados apresentados no Quadro 2.2 (Capítulo 2, Área de Estudo), considerando-se o intervalo até o ano de 2010, quando o presente trabalho de pesquisa foi iniciado.

Dados sobre a gerência e atuação do conselho gestor e da equipe local de gestão na ação estabelecida tiveram origem em registros feitos pela técnica de observação participante, durante os debates e encaminhamentos ocorridos nas reuniões dos conselhos gestores de cada UC pesquisada. 
A gerência do conselho gestor sobre a ação estabelecida refere-se à ação depender ou não do conselho gestor para que seja executada. Por exemplo, uma ação a ser executada pela câmara de vereadores de um município depende da própria câmara para ser executada e não do conselho gestor da UC que estabeleceu a ação.

A atuação do conselho gestor e da equipe local de gestão na ação estabelecida refere-se à dependência de cada um desses grupos para a execução da ação. Usando o exemplo anterior, caso a câmara de vereadores faça parte do conselho gestor, a ação depende do conselho para que seja executada. 0 mesmo serve para o caso de uma ação que envolva mais de um membro do conselho gestor. A atuação da equipe local de gestão refere-se à dependência da mesma para que uma ação seja executada, seja ela apenas pelos analistas do órgão gestor ou em parceria com outras organizações, como, por exemplo, uma ação de fiscalização. Uma ação que dependa de outros setores ou da sede do órgão gestor não foi considerada dependente da equipe local de gestão.

Os GLMs gerados consideraram o efeito de variáveis independentes de duas formas: 1. apenas uma variável independente por modelo; ou 2. em interações de primeira, segunda ou terceira ordem, ou seja, considerando o efeito de duas, três ou quatro variáveis, respectivamente ${ }^{7}$.

Em virtude de terem sido testados dezenas de modelos GLM, no Capítulo 4 (Resultados), foram organizados em quadros-síntese somente aqueles em que o intervalo de confiança foi de pelo menos $95 \%(\mathrm{P}=0,05)$ para ao menos uma das variáveis independentes testadas em cada modelo (R Core Team, 2015).

A qualidade dos GLMs é fornecida pelo Critério de Informação de Akaike (AIC, do inglês Akaike Information Criteria). 0 valor desse critério gerencia uma relação de custo-benefício entre o ajuste do modelo e sua complexidade e, portanto, proporciona um meio para seleção do modelo que melhor explica a variável resposta (Akaike, 1974). Quanto menor o valor do AIC, melhor o GLM (Provete et al., 2010). Porém, o AIC deve ser considerado com cautela e nunca como única fonte para seleção do modelo, pois seu valor é relativo e deve ser comparado com o AIC obtido para outros modelo. Além disso, devem ser considerados também o número de variáveis resposta (entre as que foram testadas) e os valores de P para cada uma

\footnotetext{
7 Testes sobre o efeito isolado de cada variável considerada nas análises em interação fazem parte do
} default dos GLMs gerados na linguagem R (R Core Team, 2015). 
delas, incluindo o P do Intercepto (conjunto de variáveis 'não identificadas' que também podem estar explicando o modelo), se for o caso.

\subsubsection{Testes de chi-quadrado}

Testes de chi-quadrado utilizando a linguagem R (R Core Team, 2015) foram realizados considerando-se os resultados da avaliação socioecológica realizada em 2014, baseada na situação dos indicadores do SISUC (ação 10 do Quadro 3.1), com o objetivo de ocultar o possível efeito do método SISUC sobre a situação socioecológica das UCs pesquisadas. Adotando-se o contexto de gestão e o conselho gestor das UCs como variável teórica, as fontes de variação foram as seguintes: grupo de manejo (i.e. proteção integral e uso sustentável), esfera pública de gestão da UC (i.e. federal e estadual) e idades das UCs, dos seus conselhos gestores e de seus planos de manejo/gestão (conforme Quadro 3.5). Os dados referentes a essas variáveis foram gerados a partir de cálculos baseados nas informações apresentados no Quadro 2.2 (Capítulo 2, Área de Estudo), considerando-se o intervalo até o ano de 2010, quando o presente trabalho de pesquisa foi iniciado. 


\section{Capítulo 4}

\section{Resultados}

Este capítulo traz os resultados de análises do efeito da implantação do método SISUC em UCs do MBRN, no estado do Amazonas. Primeiro é apresentada uma comparação da situação socioecológica das UCs pesquisadas entre os de 2010 e 2014, ou seja, antes e depois da implantação do SISUC. Em seguida são apresentados resultados de testes de aderência entre a implantação do método SISUC e processos de transformação deliberada de sistemas socioecológicos e de governança local no âmbito dos conselhos gestores dessas UCs. Por último, são apresentadas análises sobre os fatores-chave e mecanismos que influenciam a situação socioecológica das UCs pesquisadas, processos e desfechos no âmbito de seus conselhos gestores.

\subsection{MUdANÇAS NA EFETIVIDADE DAS UCS}

Um total de 27 indicadores foram avaliados para o conjunto das seis UCs do MBRN no ano de 2010. Entre eles, 16 indicadores (59\% do total) que encontravam-se em situação indesejada foram priorizados pelos conselhos gestores de pelo menos uma das UCs, totalizando 24 priorizações. Depois de estabelecer ações viáveis para a melhoria da condição de cada um dos indicadores priorizados, o conselho gestor de cada UC atribuiu uma meta a ser atingida pelos mesmos até o ano de 2014, quando a situação de todo o conjunto de indicadores seria reavaliado ( $v$. ações 2, 4, 5, 6 e 10 no Quadro 3.1, Capítulo 3, Material e Métodos). Os resultados das avaliações de todos os indicadores, em 2010 e em 2014, são mostrados no Quadro 4.1. 
Quadro 4.1. Situação dos 27 indicadores nos anos de 2010 e 2014 e desempenho de metas dos indicadores priorizados em 2010 (texto nas células coloridas) das seis UCs pesquisadas do MBRN, estado do Amazonas, utilizando o método SISUC.

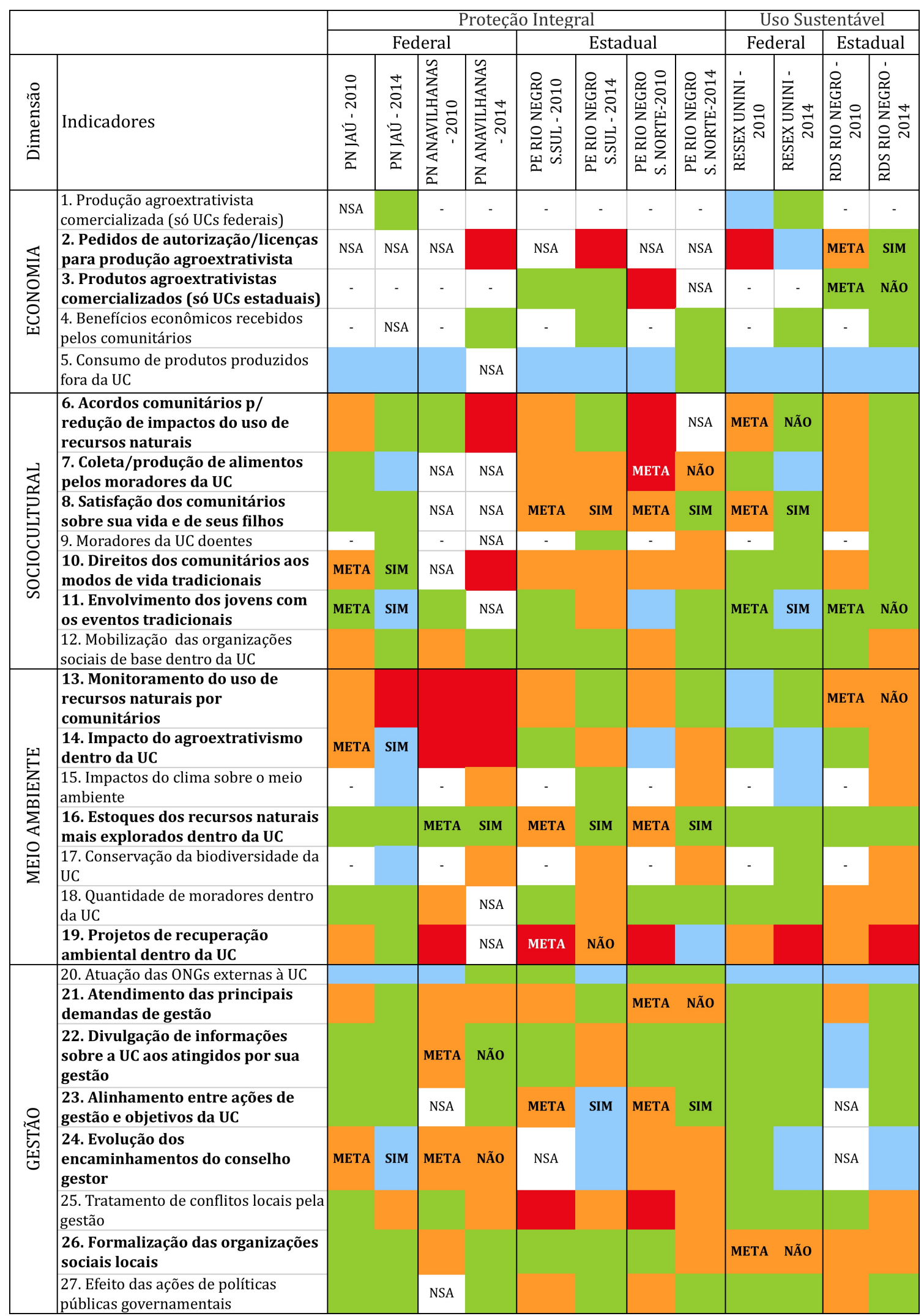

Onde: indicador em negrito = priorizado em 2011 com meta estabelecida para 2014; células coloridas (convenção) = azul (indicador em situação de sucesso), verde (indicador em situação satisfatória), laranja (indicador em situação insatisfatória) e vermelho (indicador em situação alarmante); NSA = não se aplica às características da UC na época; - (traço) = não se aplica ao contexto de gestão, usos e ocupação da UC na época; META = indicador teve meta estabelecida em 2010; e SIM ou NÃO = referente ao alcance (sim) ou não da meta em 2014. 


\subsubsection{Situação dos Indicadores em 2010 e 2014}

No ano de 2010, no total das seis UCs estudadas do MBRN, 154 indicadores foram avaliados. Na época, a maioria dos indicadores estava em situação insatisfatória (39\%), frequência aproximadamente igual à dos indicadores em situação satisfatória (38\%). Eram similares também as freqüências entre os indicadores em situação alarmante (11\%) e de sucesso (9\%) (Figura 4.1).
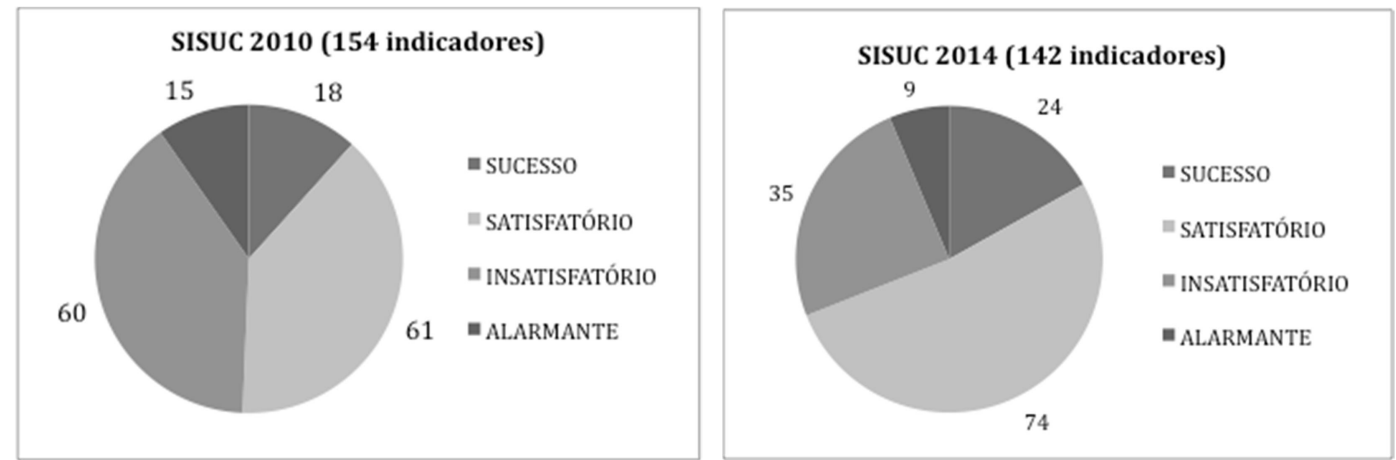

Figura 4.1. Distribuição do número absoluto total de indicadores avaliados nas diferentes situações nos anos de 2010 (154 indicadores) e 2014 (142 indicadores) para o total das seis UCs pesquisadas do MBRN, estado do Amazonas.

Apesar de terem sido avaliados 154 indicadores em 2010, esse número caiu para 142 indicadores em 2014, pois mudanças no contexto das UCs podem alterar a lista de indicadores a serem avaliados ou fazer com que algum indicador não seja aplicável (NSA) na época ( $v$. exemplos reais no Quadro 4.1, e a explicação de cada caso no Apêndice 2). Na segunda avaliação, foram registradas mudanças no padrão de distribuição dos indicadores entre as classes de situação em comparação com o ano de 2010. A frequência de indicadores em situação indesejada apresentou redução média de 41,5\%, totalizando 30\%, distribuído entre $24 \%$ de indicadores em situação insatisfatória e apenas 6\% em situação alarmante. Ao mesmo tempo, indicadores em situação desejada apresentaram um aumento médio de 29,5\% em sua frequência, totalizando $68 \%$, distribuído entre 52\% em situação satisfatória e 16\% em situação de sucesso.

Esse padrão de melhoria na situação geral dos indicadores de 2010 para 2014 também foi encontrado para o conjunto de indicadores aplicados em cada UC (Figura $4.2)$. 


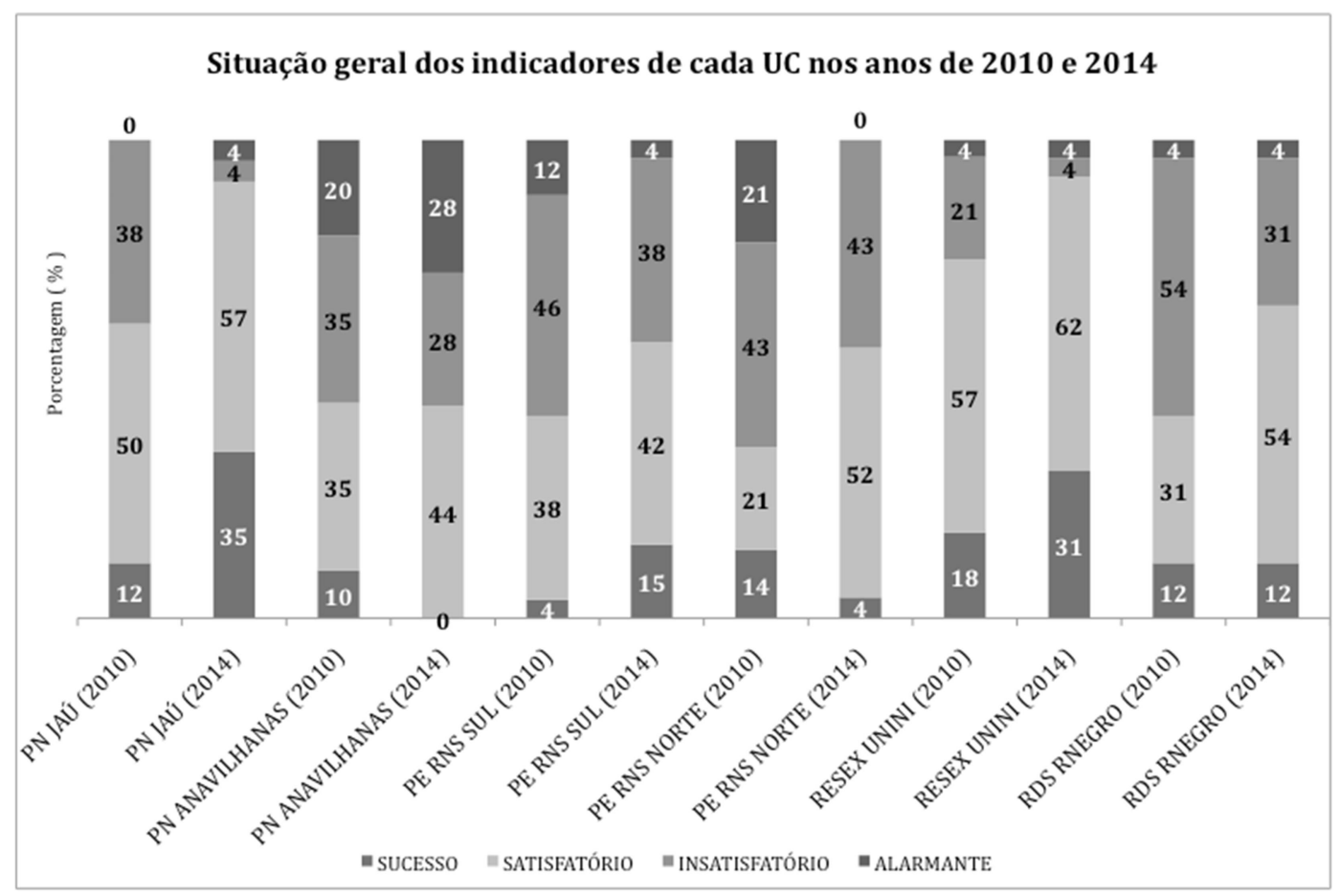

Figura 4.2. Distribuições das frequências relativas do conjunto de indicadores, de acordo com a situação em que se encontravam nos anos de 2010 (154 indicadores) e 2014 (142 indicadores), na comparação entre cada uma das seis UCs pesquisadas do MBRN, estado do Amazonas.

PN do Jaú, PE do Rio Negro (Setor Sul), Resex Unini e RDS do Rio Negro melhoraram de situação segundo a avaliação dos indicadores do SISUC. O PE do Rio Negro (Setor Norte) também melhorou sua situação, pois apesar da redução de seus indicadores em situação do sucesso, os indicadores das demais classes apresentaram uma melhoria geral: seis indicadores em situação alarmante no ano de 2010 evoluíram para situações mais favoráveis em 2014. O PN de Anavilhanas foi exceção aos demais casos, com redução de dois indicadores em situação de sucesso e aumento de um indicador em situação alarmante.

A melhoria na situação do conjunto total de indicadores aplicados e aqueles aplicados e, de maneira geral, daqueles aplicados em cada UC também foi verificado quando consideradas as quatro dimensões do sistema socioecológico (i.e. economia, sociocultural, ambiental e de gestão), que agrupam os subconjuntos de indicadores que foram avaliados (Figura 4.3). 


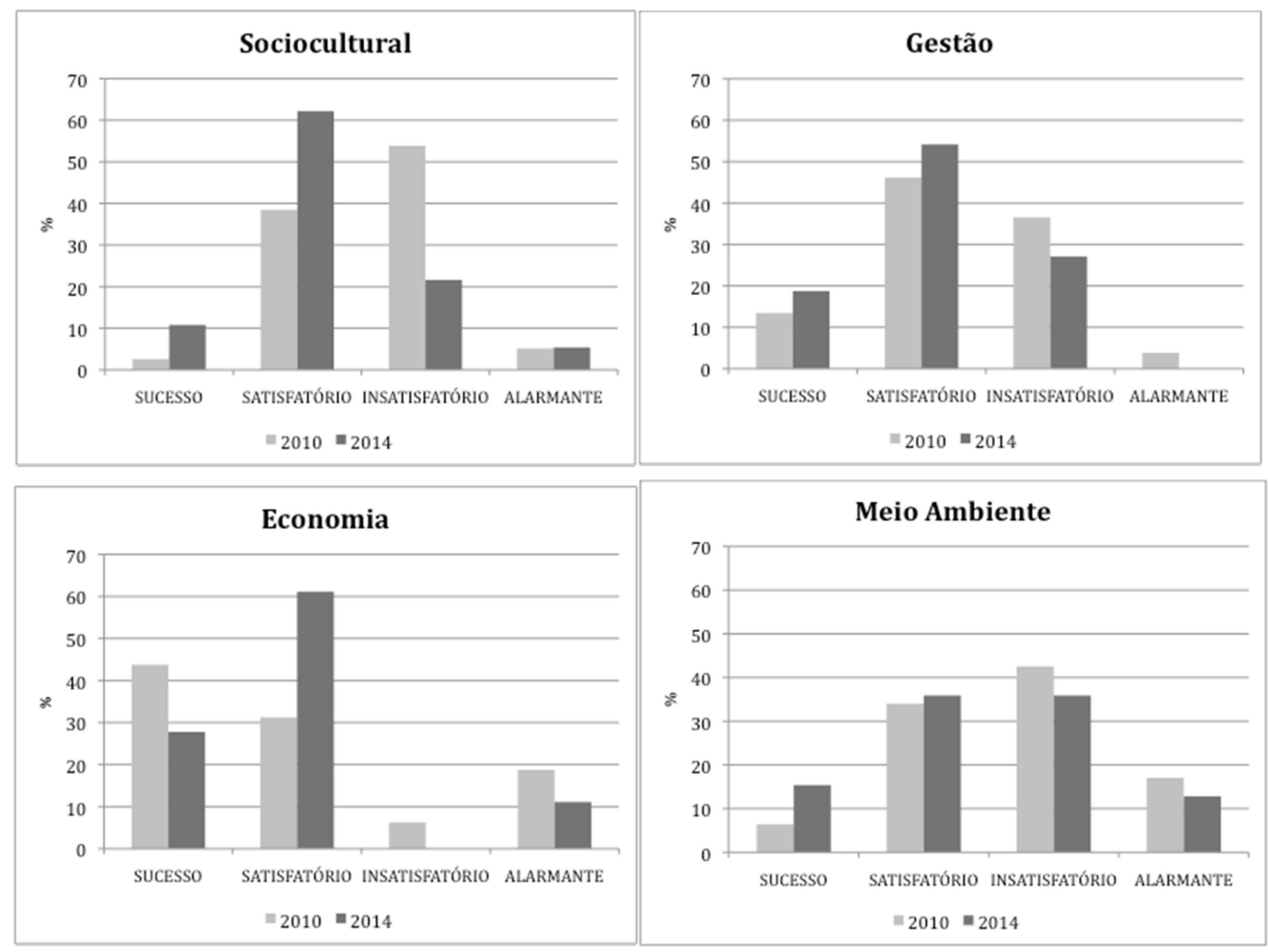

Figura 4.3. Distribuições das frequências relativas do conjunto de indicadores avaliados, de acordo com a situação em que se encontravam nos anos de 2010 (154 indicadores) e 2014 (142 indicadores), na comparação entre cada um dos diferentes temas (i.e. sociocultural, gestão, meio ambiente e economia) para o total das seis UCs pesquisadas do MBRN, estado do Amazonas.

Entre os quatro temas analisados, as dimensões 'sociocultural' e 'gestão' apresentaram as evoluções mais positivas na situação geral de seus indicadores e um padrão similar de aumento daqueles de classes desejadas (sucesso e satisfatória) em detrimento de uma redução daqueles de classes indesejáveis (insatisfatória e alarmante). 0 tema 'meio ambiente' também evoluiu positivamente, com redução de apenas um indicador na situação satisfatória do ano de 2010 para 2014, enquanto o tema 'economia', teve redução de apenas um indicador na situação de sucesso.

Conforme já foi explicado, o conjunto de indicadores aplicados em 2010 e em 2014 não foi o mesmo para cada UC e, consequentemente, para o conjunto de UCs. Do total de 142 indicadores avaliados em 2014, 111 haviam sido avaliados em 2010. Uma comparação na frequência das diferentes situações em que se encontravam esses indicadores mostrou que houve diferença significativa do ano de 2010 para o ano $2014\left(\chi^{2}=3,863 ;\right.$ g.l. $\left.=3 ; p=0,05\right)$ (Tabela 4.1). 
Tabela 4.1. Distribuição das frequências absolutas e relativas do conjunto de indicadores avaliados, de acordo com a situação em que se encontravam nos anos 2010 e 2014 (i.e., sucesso, satisfatória, insatisfatória ou alarmante), para o total das seis UCs pesquisadas do MBRN, estado do Amazonas.

\begin{tabular}{lccccc}
\hline \multirow{2}{*}{ Ano } & \multicolumn{4}{c}{ Situação } & \\
\cline { 2 - 5 } & Sucesso & Satisfatória & Insatisfatória & Alarmante & Total Marginal \\
\hline 2010 & $14(13 \%)$ & $44(40 \%)$ & $45(40 \%)$ & $8(7 \%)$ & $111(100 \%)$ \\
2014 & $19(17 \%)$ & $59(53 \%)$ & $27(24 \%)$ & $6(5 \%)$ & $111(100 \%)$ \\
\hline Total Marginal & $33(15 \%)$ & $103(46 \%)$ & $72(32 \%)$ & $14(6 \%)$ & $222(100 \%)$ \\
\hline
\end{tabular}

\subsubsection{Evolução de indicadores e desempenho de metas}

Uma análise voltada a 111 indicadores no total das seis UCs, comparáveis em sua evolução entre as avaliações de 2010 e 2014, demonstrou que o retrocesso na situação de indicadores foi o evento de menor frequência em todas as UCs pesquisadas, variando entre $10 \%$ no PN do Jaú e $27 \%$ no PN de Anavilhanas. As demais categorias apresentaram comportamentos diferentes entre as UCs pesquisadas: PE do Rio Negro (Setor Sul) e PE do Rio Negro (Setor Norte) apresentaram maior freqüência de melhoria em seus indicadores, PN de Anavilhanas e Resex Unini apresentaram maior frequência de estagnação e PN do Jaú e RDS do Rio Negro apresentaram freqüências similares entre indicadores que melhoraram e aqueles que estagnaram sua situação (Figura 4.4).

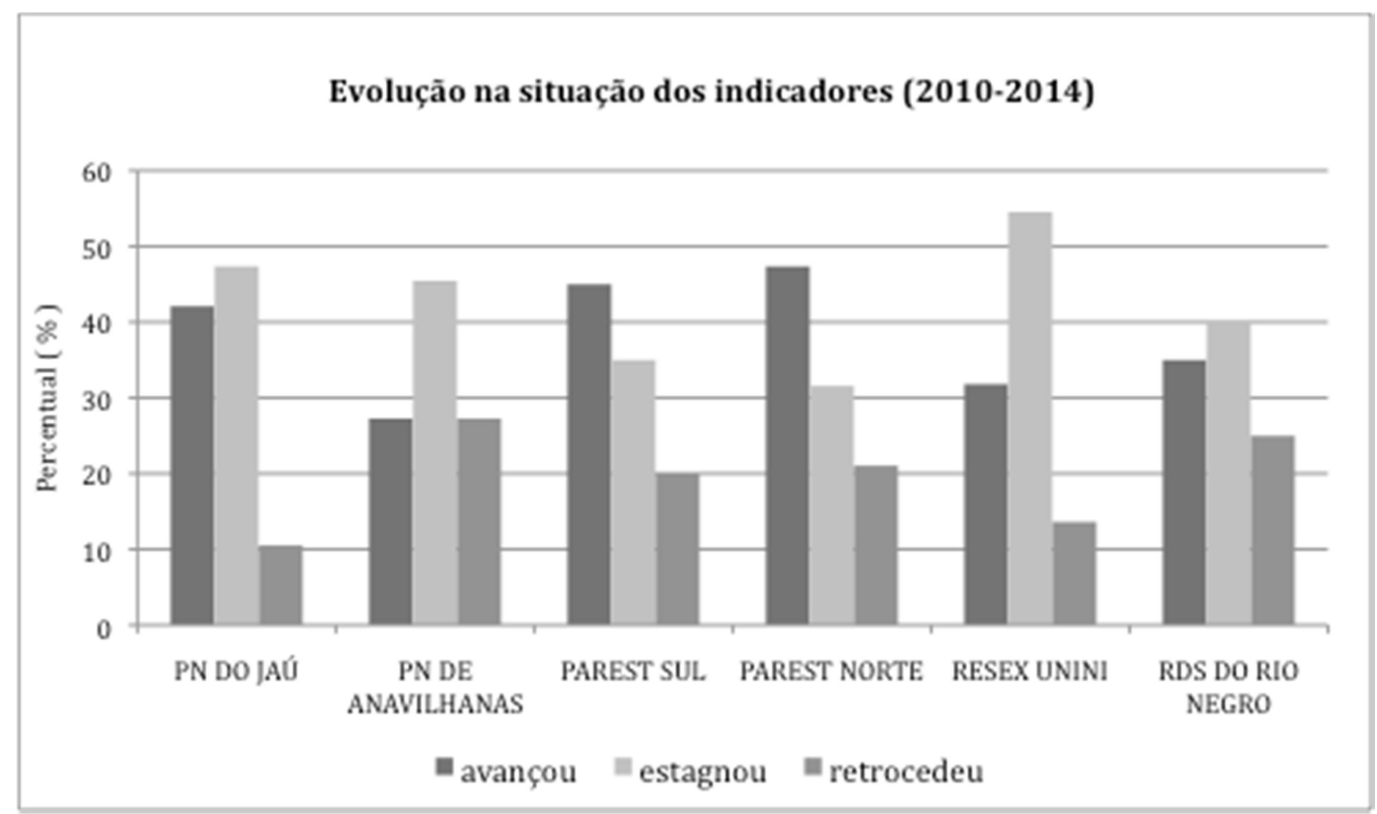

Figura 4.4. Distribuições das frequências relativas do conjunto de 111 indicadores avaliados, de acordo com a sua variação entre os anos de 2010 e 2014, na comparação entre as seis UCs pesquisadas no MBRN, estado do Amazonas. 
Ainda que a figura acima ilustre uma variação na situação dos indicadores de cada UC do ano de 2010 para o ano de 2014, na comparação entre UCs a variação é menor, de maneira que não foi verificada diferença estatisticamente significativa entre as mesmas $\left(\chi^{2}=4,312 ;\right.$ g.l. $\left.=10 ; p=0,93\right)$ (Tabela 4.2).

Tabela 4.2. Distribuição das frequências absolutas e relativas dos indicadores avaliados, de acordo com a sua evolução entre os anos de 2010 e 2014 (i.e. avançou, estagnou ou retrocedeu), para cada uma das seis UCs pesquisadas do MBRN, estado do Amazonas.

\begin{tabular}{lcccc}
\hline \multirow{2}{*}{ UC } & \multicolumn{3}{c}{ Evolução de Indicadores } & \\
\cline { 2 - 4 } & Avançou & Estagnou & Retrocedeu & Total Marginal \\
\hline PN do Jaú & $8(42 \%)$ & $9(47 \%)$ & $2(11 \%)$ & $19(100 \%)$ \\
PN de Anavilhanas & $3(27 \%)$ & $5(45 \%)$ & $3(27 \%)$ & $11(100 \%)$ \\
PE do Rio Negro (Setor Sul) & $9(45 \%)$ & $7(35 \%)$ & $4(20 \%)$ & $20(100 \%)$ \\
PE do Rio Negro (Setor Norte) & $9(47 \%)$ & $6(32 \%)$ & $4(21 \%)$ & $19(100 \%)$ \\
Resex Unini & $7(32 \%)$ & $12(55 \%)$ & $3(14 \%)$ & $22(100 \%)$ \\
RDS do Rio Negro & $7(35 \%)$ & $8(40 \%)$ & $5(25 \%)$ & $20(100 \%)$ \\
\hline Total Marginal & $43(39 \%)$ & $47(41 \%)$ & $21(20 \%)$ & $111(100 \%)$ \\
\hline
\end{tabular}

No total das seis UCs, dos 24 indicadores que foram priorizados no ano de 2010 e tiveram metas estabelecidas para serem alcançadas até o ano de 2014, nenhum deles apresentou retrocesso em sua situação, conforme ilustra o Quadro 4.1. A maioria deles (16) melhoraram sua situação e uma parte bem menor (08) mantiveram-se na mesma situação (Figura 4.5). No caso dos 87 indicadores nãopriorizados no ano de 2010, 39 deles mantiveram-se na mesma situação, 27 deles avançaram e 31 pioraram de situação de 2010 para 2014.

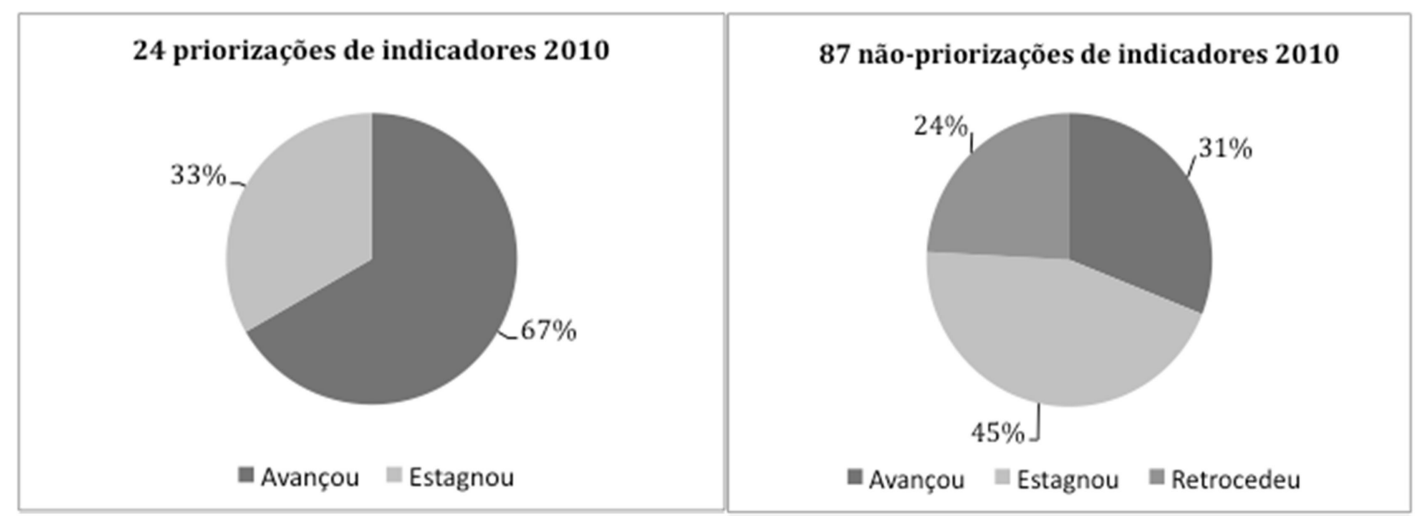

Figura 4.5. Distribuição relativa da variação observada entre os anos de 2010 e 2014 na situação dos indicadores avaliados (i.e. avanço, estagnação e retrocesso), para o total das seis UCs pesquisadas do MBRN, estado do Amazonas. 
Houve diferença significativa entre as frequências observadas e esperadas quanto aos efeitos da priorização e não-priorização de indicadores $\left(\chi^{2}=12,926\right.$; g.l. = $2 ; \mathrm{p}<0,05)$. A frequência de avanço foi maior para indicadores priorizados, enquanto a frequência de estagnação e retrocesso foi maior para os indicadores nãopriorizados (Tabela 4.3).

Tabela 4.3. Distribuição das frequências absolutas e relativas dos indicadores priorizados e não-priorizados, de acordo com sua evolução (i.e. avançou, estagnou ou retrocedeu) entre os anos de 2010 e 2014, para o total das seis UCs pesquisadas do MBRN, estado do Amazonas.

\begin{tabular}{lcccc}
\hline & \multicolumn{3}{c}{ Efeito } & \\
\cline { 2 - 5 } Indicador & Avançou & Estagnou & Retrocedeu & Total Marginal \\
\hline Priorizado & $16(67 \%)$ & $8(33 \%)$ & $0(0 \%)$ & $24(100 \%)$ \\
Não-priorizado & $27(31 \%)$ & $39(45 \%)$ & $21(24 \%)$ & $87(100 \%)$ \\
\hline Total Marginal & $43(38 \%)$ & $47(43 \%)$ & $21(19 \%)$ & $111(100 \%)$ \\
\hline
\end{tabular}

As metas estabelecidas para os indicadores foram alcançadas para 14 dos 24 que foram priorizados (Figura 4.6). Outros 10 indicadores não alcançaram suas metas estabelecidas, dos quais 4 melhoraram sua situação e 6 permaneceram na mesma situação que no ano de 2010.

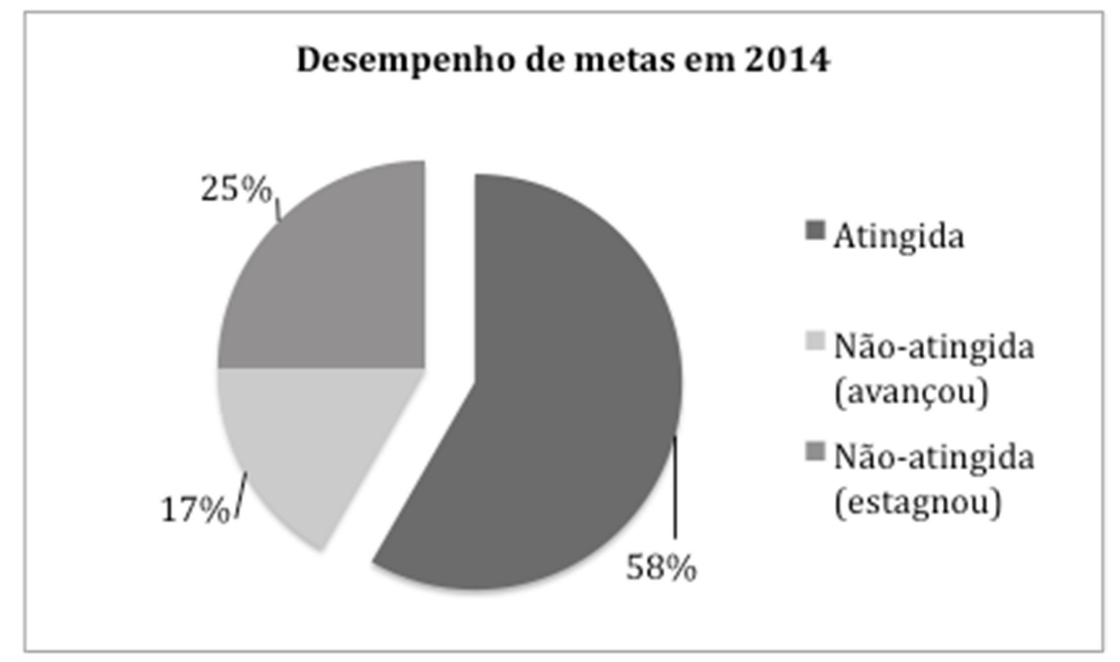

Figura 4.6. Distribuição relativa da variação no desempenho das metas a serem alcançadas no ano de 2014 (i.e. atingida, não-atingida mas avançou e não-atingida e estagnou) para 24 indicadores priorizados, no total das seis UCs pesquisadas do MBRN, estado do Amazonas.

Na comparação estatística entre as seis UCs, a freqüência de metas alcançadas e não-alcançadas não foi diferente entre elas $\left(\chi^{2}=6,034\right.$; g.l. $\left.=5 ; p=0,30\right)$ ou seja não houve variação significativa entre as UCs com relação ao alcance das metas estabelecidas para cada uma delas (Tabela 4.4). 
Tabela 4.4 Distribuições absolutas e relativas da variação no desempenho das metas estabelecidas para o ano de 2014 (i.e. alcançada e não-alcançada) para 24 indicadores priorizados para o total das seis UCs pesquisadas do MBRN, estado do Amazonas.

\begin{tabular}{lccc}
\hline \multirow{2}{*}{ UC } & \multicolumn{2}{c}{ Metas } & \\
\cline { 2 - 3 } & Alcançada & Não-alcançada & Total marginal \\
\hline PN do Jaú & $4(100 \%)$ & $0(0 \%)$ & $4(100 \%)$ \\
PN de Anavilhanas & $1(33 \%)$ & $2(67 \%)$ & $3(100 \%)$ \\
PE do Rio Negro (S. Sul) & $3(75 \%)$ & $1(25 \%)$ & $4(100 \%)$ \\
PE do Rio Negro (S. Norte) & $3(60 \%)$ & $2(40 \%)$ & $5(100 \%)$ \\
Resex Unini & $2(50 \%)$ & $2(50 \%)$ & $4(100 \%)$ \\
RDS do Rio Negro & $1(25 \%)$ & $3(75 \%)$ & $4(100 \%)$ \\
\hline Total marginal & $14(58 \%)$ & $10(42 \%)$ & $24(100 \%)$ \\
\hline
\end{tabular}

Com relação ao desempenho de metas nos quatro temas avaliados, as dimensões sociocultural e meio ambiente estiveram melhor (67\% de alcance) (Figura 4.7). As dimensões gestão e economia tiveram desempenho inferior e apresentaram a mesma freqüência de metas alcançadas e não-alcançadas, com uma pequena vantagem para dimensão gestão, que apresentou $14 \%$ de indicadores em situação de avanço em direção a meta, ainda que essas não tenham sido alcançadas.

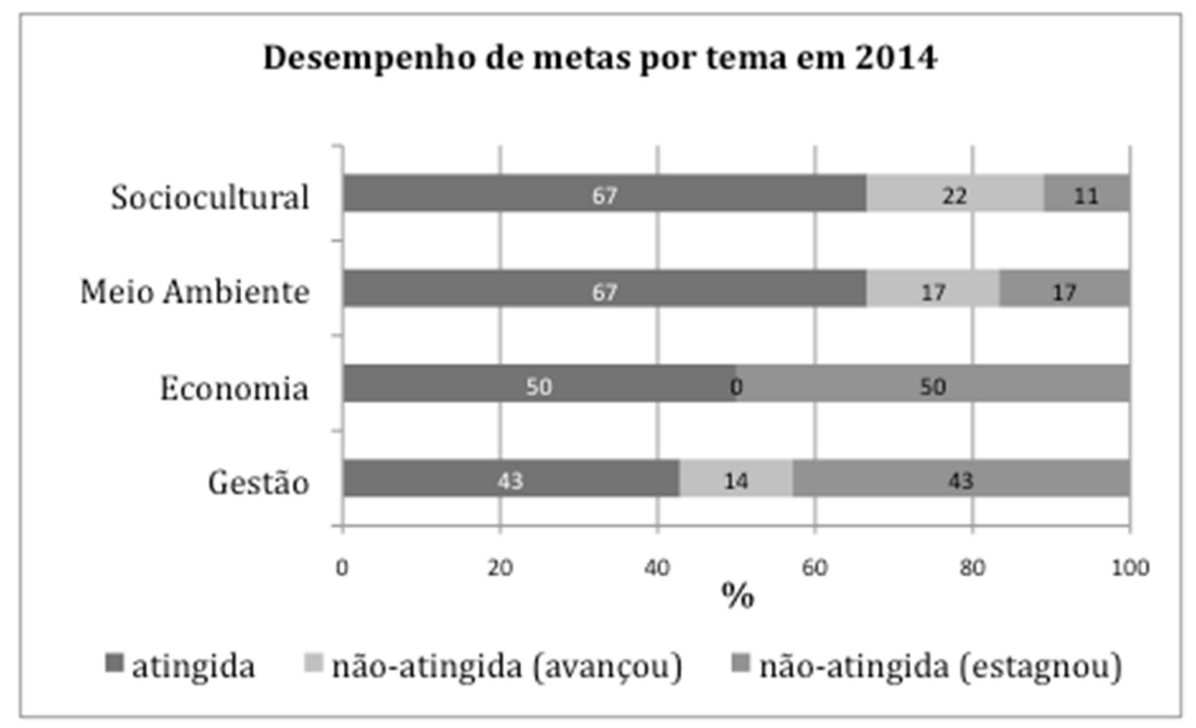

Figura 4.7. Distribuições das freqüências relativas da variação no desempenho das metas a serem alcançadas no ano de 2014 (i.e. atingida, não-atingida, mas avançou e não-atingida e estagnou), de acordo com a dimensão do sistema socioecológico avaliado, para 24 indicadores priorizados, no total das seis UCs pesquisadas do MBRN, estado do Amazonas. 


\subsection{ADERÊNCIA DO MÉTODO SISUC A PROCESSOS DE TRANSFORMAÇÃO DELIBERADA DE SISTEMAS SOCIOECOLÓGICOS}

Informações referentes as práticas promovidas pelo SISUC no âmbito dos conselhos gestores foram utilizadas para análise de fases e subprocessos de transformação deliberada do sistema socioecológico das UCs pesquisadas, os quais seguem sintetizados no Quadro 4.2.

Quadro 4.2. Análise de múltiplos subprocessos em cada fase da transformação deliberada de sistemas socioecológicos ( $c f$. Moore et al., 2014) a partir da implantação do SISUC junto à conselhos gestores de seis UCs do MBRN, no estado do Amazonas, entre os anos de 2010 e 2014.

\begin{tabular}{|c|c|c|}
\hline Fase & Subprocesso & $\begin{array}{l}\text { Subprocesso promovido pelo uso do } \\
\text { SISUC }\end{array}$ \\
\hline \multirow[t]{2}{*}{ Pré-Transformação } & $\begin{array}{l}\text { Perturbações sociais ou } \\
\text { ecológicas criam janelas de } \\
\text { oportunidade }\end{array}$ & $\begin{array}{l}\text { Organizações que fazem parte dos } \\
\text { conselhos gestores das UCs buscam } \\
\text { alternativas para o aprimoramento de } \\
\text { processos de governança local* }\end{array}$ \\
\hline & $\begin{array}{l}\text { Oportunidade de mudança } \\
\text { do contexto atual torna-se } \\
\text { transparente para os atores }\end{array}$ & $\begin{array}{l}\text { O método SISUC é apresentado aos } \\
\text { conselhos gestores de cada UC, os } \\
\text { quais encaminham na aplicação de um } \\
\text { ciclo completo da ferramenta }\end{array}$ \\
\hline \multirow[t]{3}{*}{$\begin{array}{l}\text { Preparação para } \\
\text { Mudança }\end{array}$} & $\begin{array}{l}\text { Análise das estruturas que } \\
\text { atualmente são mais } \\
\text { problemáticas no sistema } \\
\text { socioecológico }\end{array}$ & $\begin{array}{c}\text { Realização de avaliação socioecológica } \\
\text { participativa e priorização de } \\
\text { indicadores em situação indesejada } \\
\text { em cada UC }\end{array}$ \\
\hline & $\begin{array}{c}\text { Geração de inovação e novas } \\
\text { visões para o futuro }\end{array}$ & $\begin{array}{l}\text { Estabelecimento de um plano } \\
\text { estratégico de ações e de metas para } \\
\text { melhoria da situação de indicadores } \\
\text { priorizados }\end{array}$ \\
\hline & $\begin{array}{l}\text { Auto-organização a partir de } \\
\text { novas idéias, criação e } \\
\text { mobilização de redes de } \\
\text { apoio e experimentação em } \\
\text { "nichos" protegidos }\end{array}$ & $\begin{array}{c}\text { Implementação de uma rede } \\
\text { multiatores para que nas reuniões do } \\
\text { conselho gestor de cada UC fosse } \\
\text { monitorado e avaliado o desempenho } \\
\text { das ações estabelecidas }\end{array}$ \\
\hline \multirow[t]{2}{*}{ Transição } & $\begin{array}{l}\text { Escolha da inovação ou } \\
\text { processo de mudança em } \\
\text { que se quer investir capital } \\
\text { social, intelectual e } \\
\text { financeiro }\end{array}$ & $\begin{array}{c}\text { Mecanismos de monitoramento e } \\
\text { avaliação levam os conselheiros a } \\
\text { processos iterativos de reflexão e ao } \\
\text { seu comprometimento na execução de } \\
\text { ações que foram estabelecidas }\end{array}$ \\
\hline & $\begin{array}{l}\text { Avaliação dos resultados de } \\
\text { experiências anteriores e } \\
\text { desenvolvimento de } \\
\text { entendimentos } \\
\text { compartilhados e novas } \\
\text { formas de conhecimento }\end{array}$ & $\begin{array}{c}\text { Adaptação, aprendizagem e tomada de } \\
\text { decisão a partir dos resultados do } \\
\text { desempenho de ações e metas } \\
\text { estabelecidas para indicadores } \\
\text { prioritários e da influência do } \\
\text { desempenho das ações sobre o } \\
\text { desempenho das metas }\end{array}$ \\
\hline
\end{tabular}




\begin{tabular}{|c|c|c|}
\hline Transição & $\begin{array}{l}\text { Absorção e replicação da } \\
\text { mudança inovadora que foi } \\
\text { bem sucedida em fase } \\
\text { experimental - ponto de } \\
\text { inflexão }\end{array}$ & $\begin{array}{l}\text { Atualização da avaliação } \\
\text { socioecológica e de ações e metas para } \\
\text { melhoria da situação de indicadores } \\
\text { prioritários em situação indesejada }\end{array}$ \\
\hline \multirow[t]{3}{*}{$\begin{array}{l}\text { Institucionalização } \\
\text { da nova trajetória }\end{array}$} & $\begin{array}{c}\text { Gestão de estabilidade } \\
\text { dinâmica para incorporar } \\
\text { nova trajetória ao sistema } \\
\text { socioecológico e estabelecer } \\
\text { ou reforçar novos feedbacks }\end{array}$ & $\begin{array}{c}\text { Consolidação de um sistema } \\
\text { estruturado em dois círculos } \\
\text { concêntricos de monitoramento e } \\
\text { avaliação (indicadores e ações) e } \\
\text { estabelecimento de rotinas e } \\
\text { procedimentos para qualificação de } \\
\text { processos de governança acoplada à } \\
\text { gestão local }\end{array}$ \\
\hline & $\begin{array}{c}\text { Expansão da mudança } \\
\text { envolvendo um tipo } \\
\text { diferente de inovação do que } \\
\text { foi criado originalmente, } \\
\text { adequando-se a diferentes } \\
\text { contextos }\end{array}$ & $\begin{array}{l}\text { Resultados integrados dos dois níveis } \\
\text { de monitoramento e avaliação das UCs } \\
\text { disponibilizados ao conselho gestor } \\
\text { do MBRN usados como subsídio a } \\
\text { diferentes desdobramentos }\end{array}$ \\
\hline & $\begin{array}{l}\text { Sistema transformado atinge } \\
\text { novos interessados e precisa } \\
\text { lidar com as próximas e } \\
\text { prováveis perturbações } \\
\text { inesperadas, como atores } \\
\text { poderosos que podem } \\
\text { oferecer resistência. }\end{array}$ & $\begin{array}{l}\text { Conselhos gestores (em novos } \\
\text { mandatos) onde o método SISUC } \\
\text { vinha sendo utilizado e outras } \\
\text { organizações atuantes no MBRN } \\
\text { manifestam interesse na continuidade } \\
\text { ou adoção do método SISUC }\end{array}$ \\
\hline
\end{tabular}

* Embora buscas por alternativas para o aprimoramento de processos no âmbito de conselhos gestores tenham resultado na implantação do SISUC, perturbações sociais ou ecológicas não foram usadas ( $c f$. Moore et al., 2014) para justificar a aplicação desse método das UCs pesquisadas.

\subsection{ADERÊNCIA ENTRE O MÉTODO SISUC E PRINCÍPIOS DE BOA GOVERNANÇA DE ÁREAS PROTEGIDAS}

No geral, o método SISUC apresenta-se aderente a todos os princípios de boa governança de áreas protegidas propostos por Lockwood (2010) e apresentados no Quadro 4.3. 
Quadro 4.3. Análise de parâmetros de governança de áreas protegidas adotando o protocolo proposto por Lockwood (2010), a partir do conjunto de atividades passos do ciclo de aplicação do SISUC executadas durante reuniões dos conselhos gestores das seis UCs pesquisadas do MBRN, estado do Amazonas, entre os anos de 2010 e 2014.

\begin{tabular}{|c|c|c|}
\hline Princípio & Parâmetro & Atividades do método SISUC \\
\hline Legitimidade & $\begin{array}{l}\text { 1. Conselho gestor atua de acordo com } \\
\text { o seu mandato e o propósito da UC }\end{array}$ & $\begin{array}{l}\text { Não interfere no mandato do conselho gestor. O propósito da UC e também o seu contexto atual } \\
\text { (territorial, de gestão, socioecológico, de conflitos etc) são valorizados ao longo dos diferentes passos } \\
\text { da aplicação do SISUC (i.e. AVAL., AÇÃO, META e M\&A). }\end{array}$ \\
\hline \multirow[t]{4}{*}{ Transparência } & $\begin{array}{l}\text { 2. Governança e tomada de decisão são } \\
\text { abertas para participação dos } \\
\text { conselheiros }\end{array}$ & $\begin{array}{l}\text { Aspectos de governança e do processo de tomada de decisão têm por condição a participação de } \\
\text { conselheiros por meio de atividades individuais, em grupos e coletivas (AVAL., AÇÃO, META, M\&A e } \\
\text { BAL.). }\end{array}$ \\
\hline & $\begin{array}{l}\text { 3. As razões por trás das decisões são } \\
\text { evidentes }\end{array}$ & $\begin{array}{l}\text { Decisões são propostas ao longo de diferentes passos da aplicação do SISUC, tendo base em } \\
\text { informações atuais produzidas pelo próprio conselho gestor da UC. Por meio de debates coletivos, } \\
\text { em cada passo, as decisões são validadas coletivamente e subsidiam atividades consecutivas, entre } \\
\text { elas as que demandam a tomada de decisão (i.e. AÇÃO, META e M\&A). }\end{array}$ \\
\hline & 4. Sucessos e falhas são evidentes & $\begin{array}{l}\text { Registro, controle de resultados e comparações (temporais e espaciais) ao longo de diferentes passos } \\
\text { da aplicação do SISUC (i.e. AVAL., AÇÃO, M\&A e BAL.) promovem a percepção e constatação de } \\
\text { sucessos e falhas. }\end{array}$ \\
\hline & $\begin{array}{l}\text { 5. Informações são apresentadas de } \\
\text { forma adequada as necessidades dos } \\
\text { conselheiros }\end{array}$ & $\begin{array}{l}\text { Figuras, tabelas, fichas, impressos, tarjetas, projeções e painéis, símbolos e cores (representativas de } \\
\text { respostas, situações e opiniões), fazem parte do material de trabalho e são uma constante em todos } \\
\text { os passos da aplicação do SISUC (AVAL., AÇÃO, META, M\&A e BAL.). }\end{array}$ \\
\hline Responsabilidade & $\begin{array}{l}\text { 6. Conselho gestor e conselheiros têm } \\
\text { claramente definidos seus papéis e } \\
\text { responsabilidades }\end{array}$ & $\begin{array}{l}\text { Papéis e responsabilidades são pré-determinados e não variam entre os conselheiros em todos os } \\
\text { passos da aplicação do SISUC (AVAL., AÇÃO, META, M\&A e BAL.). }\end{array}$ \\
\hline
\end{tabular}

Onde: AVAL. (Avaliação) = avaliação/re (avaliação) socioecológica local de UCs; AÇÃO = análise de viabilidade e definição de ações para melhoria de indicadores priorizados em situação indesejada; META = estabelecimento de metas para indicadores em situação indesejada; ; M\&A (Monitoramento e Avaliação) = monitoramento e avaliação das ações e de indicadores; e BAL. = balanço do desempenho das metas e ações estabelecidas para o seu alcance. 


\begin{tabular}{|c|c|c|}
\hline Princípio & Parâmetro & Atividades do método SISUC \\
\hline \multirow[t]{2}{*}{ Responsabilidade } & $\begin{array}{l}\text { 7. Conselho gestor tem prestado contas } \\
\text { aos atores nele representados }\end{array}$ & $\begin{array}{l}\text { Relatórios (digitais) completos de atividades, painéis (impressos) de resultados dos indicadores e do } \\
\text { desempenho de ações, e boletins (impressos, personalizados para cada conselheiro da UC) trazendo } \\
\text { resultados de diferentes passos da aplicação do SISUC (i.e. AVAL., AÇÃO, META e M\&A) são } \\
\text { disponibilizados aos conselheiros. }\end{array}$ \\
\hline & $\begin{array}{l}\text { 8. Conselho gestor está sujeito a } \\
\text { prestação de contas para instâncias } \\
\text { superiores }\end{array}$ & $\begin{array}{l}\text { Relatórios (digitais) completos para cada UC, com resultados de diferentes etapas da SISUC (i.e. } \\
\text { AVAL., ACĈ̃O, META e M\&A) são entregues a presidência do conselho e disponibilizados para todos } \\
\text { os conselheiros da UC. }\end{array}$ \\
\hline Inclusão & $\begin{array}{l}\text { 10. Todos conselheiros tem } \\
\text { oportunidades apropriadas no } \\
\text { encaminhamento de processos e ações }\end{array}$ & $\begin{array}{l}\text { Encaminhamentos de processos e ações se dão por meio de mecanismos específicos de suporte a a } \\
\text { atividades com vistas a geração de informação, promoção de debates e apresentação de proposições } \\
\text { que são validadas coletivamente em diferentes passos da aplicação do SISUC (i.e. AÇÃO, META e } \\
\text { M\&A). }\end{array}$ \\
\hline Justiça & $\begin{array}{l}\text { 12. Decisões são tomadas de maneira } \\
\text { consistente e sem enviesamento }\end{array}$ & $\begin{array}{l}\text { Decisões são propostas em cada passo da aplicação do SISUC com base em informações atualizadas } \\
\text { produzidas (individualmente ou em grupos), as quais são debatidas e validadas (coletivamente) pelo } \\
\text { conselho gestor da UC, sendo utilizadas também como referência as etapas consecutivas (i.e. AVAL, } \\
\text { AÇÃO, META e M\&A). }\end{array}$ \\
\hline
\end{tabular}

Onde: AVAL. (Avaliação) = avaliação/re(avaliação) socioecológica local de UCS; $A C C A \tilde{O}$ = análise de viabilidade e definição de ações para melhoria de indicadores priorizados em situação indesejada; META = estabelecimento de metas para indicadores em situação indesejada; ; M\&A (Monitoramento e Avaliação) = monitoramento e avaliação das ações e de indicadores; e BAL. = balanço do desempenho das metas e ações estabelecidas para o seu alcance. 


\begin{tabular}{|c|c|c|}
\hline Princípio & Parâmetro & Atividades do método SISUC \\
\hline Justiça & $\begin{array}{l}\text { 13. Direitos humanos e das populações } \\
\text { tradicionais/ povos indígenas são } \\
\text { respeitados }\end{array}$ & $\begin{array}{l}\text { Reflexões de direitos sociais são valorizadas e oportunidades são criadas por meio de debates } \\
\text { sistematizados referentes as dimensões econômica, sociocultural, ambiental e das práticas de gestão } \\
\text { local em diferentes passos da aplicação do SISUC (i.e. AVAL., META e M\&A). }\end{array}$ \\
\hline \multirow[t]{2}{*}{ Conectividade } & $\begin{array}{l}\text { 14. O conselho gestor é efetivamente } \\
\text { conectado com colegiados de } \\
\text { diferentes níveis de governança }\end{array}$ & $\begin{array}{l}\text { Análises integradas de aspectos comuns no contexto regional a partir de resultados de cada UC } \\
\text { gerados em diferentes passos da aplicação do SISUC (i.e. AÇÃO, META e M\&A) são apresentadas e } \\
\text { entregues ao conselho gestor do MBRN ao final de cada ciclo de monitoramento e avaliação de } \\
\text { indicadores (a cada três anos). }\end{array}$ \\
\hline & $\begin{array}{l}\text { 15. } 0 \text { conselho gestor é efetivamente } \\
\text { conectado com colegiados operando no } \\
\text { mesmo nível de governança }\end{array}$ & $\begin{array}{l}\text { Relatórios (digitais) de resultados de cada UC são disponibilizados e análises comparativas de } \\
\text { aspectos comuns entre UCs a partir de resultados de diferentes passos da aplicação do SISUC (i.e. } \\
\text { AÇÃO, META e M\&A) são apresentadas e entregues ao conselho gestor do MBRN ao final do ciclo de } \\
\text { monitoramento e avaliação de indicadores (a cada três anos). Em caráter complementar, no caso da } \\
\text { presente pesquisa, gestores públicos e técnicos de ONGs que apóiam a gestão das UCs pesquisadas } \\
\text { realizaram análises integradas dos resultados. }\end{array}$ \\
\hline \multirow[t]{2}{*}{ Resiliência } & $\begin{array}{l}\text { 16. O conselho gestor tem uma cultura } \\
\text { de intencionalmente aprender a partir } \\
\text { das experiências absorvendo novos } \\
\text { conhecimentos }\end{array}$ & $\begin{array}{l}\text { Etapas de planejamento e rotinas de monitoramento e avaliação nos diferentes passo da aplicação do } \\
\text { SISUC (AVAL., AÇÃO, META, M\&A e BAL.) demandam constante análise e reflexão de riscos, } \\
\text { viabilidade e balanço de resultados, gerando diferentes aprendizados em diferentes níveis e escalas, }\end{array}$ \\
\hline & $\begin{array}{l}\text { 17. } 0 \text { conselho gestor tem flexibilidade } \\
\text { para rearranjar processos internos e } \\
\text { procedimentos em resposta a mudança } \\
\text { de condições internas e externas }\end{array}$ & $\begin{array}{l}\text { Rotinas de monitoramento e avaliação do desempenho de ações (a cada reunião do conselho) e da } \\
\text { situação de indicadores socioambientais (a cada três anos), demandam constante análise dos } \\
\text { resultados com vistas a adaptações a partir das lições aprendidas em diferentes passos da aplicação } \\
\text { do SISUC (i.e. AVAL., META e M\&A). }\end{array}$ \\
\hline
\end{tabular}

Onde: AVAL. (Avaliação) = avaliação/re(avaliação) socioecológica local de UCs; AÇÃo = análise de viabilidade e definição de ações para melhoria de indicadores priorizados em situação indesejada; META = estabelecimento de metas para indicadores em situação indesejada; ; M\&A (Monitoramento e Avaliação) = monitoramento e avaliação das ações e de indicadores; e BAL. = balanço do desempenho das metas e ações estabelecidas para o seu alcance. 


\begin{tabular}{|l|l|l|}
\hline Princípio & Parâmetro & \multicolumn{1}{c|}{ Atividades do método SISUC } \\
\hline Resiliência & $\begin{array}{l}\text { 18. O conselho gestor utiliza processos } \\
\text { de planejamento e gestão adaptativos }\end{array}$ & $\begin{array}{l}\text { Processos de planejamento, e rotinas de monitoramento e avaliação do desempenho de ações (a cada } \\
\text { reunião do conselho gestor) e de metas e da situação de indicadores (a cada três anos), sob bases } \\
\text { adaptativas, são os principais mecanismos de funcionamento de diferentes passos da aplicação do } \\
\text { SISUC (i.e. AVAL., META e M\&A) }\end{array}$ \\
\cline { 2 - 3 } & $\begin{array}{l}\text { 19.0 conselho tem procedimentos para } \\
\text { identificar, caracterizar e gerir riscos }\end{array}$ & $\begin{array}{l}\text { A etapa de análise de viabilidade de ações propostas é específica para isso, mas riscos são } \\
\text { identificados, caracterizados e geridos por meio do controle de resultados em diferentes passo da } \\
\text { aplicação do SISUC (i.e. AVAL., AÇÃO, META e M\&A). }\end{array}$ \\
\hline
\end{tabular}

Onde: AVAL. $($ Avaliação) = avaliação/re(avaliação) socioecológica local de UCs; AÇ̃̃o = análise de viabilidade e definição de ações para melhoria de indicadores priorizados em situação indesejada; $M E T A=$ estabelecimento de metas para indicadores em situação indesejada; M\&A (Monitoramento e Avaliação) = monitoramento e avaliação das ações e de indicadores; e BAL. = balanço do desempenho das metas e ações estabelecidas para o seu alcance. 
As maiores aderências do SISUC foram verificadas junto aos princípios de responsabilidade, transparência e legitimidade, 90\%, 85\% e 80\%, respectivamente, seguido dos princípios de resiliência (75\%), inclusão e justiça (ambos com 70\%) e conectividade $(60 \%)$.

Quatro tipos de atividade do método SISUC identificados entre os cinco considerados na presente análise, apresentam aderência a no mínimo 79\% dos 19 parâmetros de boa governança de áreas protegidas avaliados. Entre eles, verificam-se dois grupos distintos. 0 primeiro grupo é constituído por dois tipos de atividades: o monitoramento e avaliação do desempenho de ações e de indicadores, e o estabelecimento de metas para indicadores, aderentes a 100\% e 95\% dos 19 parâmetros avaliados, respectivamente. 0 segundo grupo é constituído por outros dois tipos de atividade: a análise de viabilidade e definição de ações, que não atendem totalmente aos princípios de justiça e resiliência, e, por isso, foi aderente a 84\% dos 19 parâmetros avaliados; e a avaliação de indicadores, que não atende totalmente o princípio de inclusão e não atende nenhum parâmetro do princípio de conectividade, e, por isso, foi aderente a 79\% dos 19 parâmetros avaliados. As atividades de balanço do desempenho de metas e ações apresentou 32\% de aderência aos parâmetros de boa governança de áreas protegidas e não apresentou nenhuma aderência aos princípios de legitimidade, inclusão e justiça.

\subsection{FATORES-CHAVE E MECANISMOS DAS MUDANÇAS NA EFETIVIDADE DAS UCS}

\subsubsection{Modelos GLM}

Foram usados oito modelos GLMs para analisar o efeito de nove variáveis independentes referentes a três variáveis teóricas: método SISUC, contexto de gestão e conselho gestor de UCs.

Os modelos GLM 1, 2, 3 e 4 foram usados para testar quais variáveis independentes poderiam explicar a evolução na situação dos indicadores (2010-2014). Os valores de AIC variaram pouco para três desses quatro modelos (i.e. entre 512 no modelo GLM 1 até 566 no modelo GLM 3) e apenas um deles apresentou um AIC de 823 (modelo GLM 2). Conforme explicado no subitem 3.4.2. do Capítulo 3 (Material e Métodos), ainda que o valor 823 seja consideravelmente maior do que os valores de AIC obtidos para os demais modelos, isso não significa (automaticamente) que o modelo GLM 2 é menos explicativo que os modelos 1, 3 e 4 quanto as variáveis que influenciram a evolução na 
situação dos indicadores (2010-2014). Um dos argumentos para isso é que o modelo GLM 2 não sugere a influência de intercepto, ou seja, estatisticamente, o comportamento da variável dependente evolução na situação dos indicadores (2010-2014) não é influenciado de maneira significativa por outras variáveis independentes que não aquelas consideradas no modelo testado.

O modelo GLM 1, usado para testar a influência de aspectos das variáveis teóricas 'contexto de gestão' e 'conselho gestor das UCs', indica a influência das quatro variáveis independentes que foram analisadas (i.e. atuação da equipe local de gestão nas ações estabelecidas, idade do plano de manejo/gestão, idade do conselho gestor e idade da UC) sobre a variável dependente evolução na situação dos indicadores (2010 - 2014) (Quadro 4.4). Esse resultado é constatado pelos valores de $P$ (probabilidade) $\leq 0,05$, conforme critério de decisão estabelecido para as análises dos modelos GLM (subitem 3.4.2. do Capítulo 3, Material e Métodos).

Quadro 4.4. Resultados do modelo GLM 1 para o teste da influência de variáveis independentes referentes ao contexto de gestão e ao conselho gestor das UCs sobre a evolução na situação dos indicadores (2010-2014) para o conjunto de UCs pesquisadas do MBRN, estado do Amazonas.

\begin{tabular}{|c|c|c|c|c|}
\hline \multicolumn{2}{|c|}{ Dados utilizados } & \multicolumn{3}{|c|}{ Resultados para AIC $=512,8$} \\
\hline $\begin{array}{c}\text { Variável } \\
\text { independente }\end{array}$ & $\begin{array}{c}\text { Variável } \\
\text { dependente }\end{array}$ & Variável explicativa & $\mathrm{t}$ & $P$ \\
\hline \multirow{5}{*}{$\begin{array}{l}\text { Atuação da equipe local } \\
\text { de gestão nas ações } \\
\text { estabelecidas + Idade } \\
\text { do plano de } \\
\text { manejo/gestão } \\
\text { atualizado + Idade do } \\
\text { conselho gestor da UC + } \\
\text { Idade da UC }\end{array}$} & \multirow{5}{*}{$\begin{array}{c}\text { Evolução na } \\
\text { situação dos } \\
\text { indicadores } \\
(2010-2014)\end{array}$} & $\begin{array}{c}\text { Atuação da equipe local de gestão } \\
\text { nas ações estabelecidas }\end{array}$ & 2,34 & 0,020 \\
\hline & & Idade plano de manejo/gestão & 4,09 & $<0,001$ \\
\hline & & Idade do conselho gestor & $-2,66$ & 0,008 \\
\hline & & Idade da UC (6 até 15 anos) & 2,59 & 0,010 \\
\hline & & Idade da UC (mais de 15 anos) & 6,97 & $<0,001$ \\
\hline
\end{tabular}

Os modelos GLM 2 e 3, usados para testar a influência de variáveis independentes referentes ao método SISUC, indicam a influência da priorização de indicadores e do desempenho de ações socioambientais que foram estabelecidas e monitoradas sobre a variável dependente evolução na situação dos indicadores (2010-2014), conforme os valores de $\mathrm{P} \leq 0,05$ obtidos (Quadro 4.5 e 4.6). 
Quadro 4.5. Resultados do modelo GLM 2 para o teste da influência da priorização de indicadores (referente ao método SISUC) sobre a evolução na situaç̧ão dos indicadores (2010-2014) para o conjunto de UCs pesquisadas do MBRN, estado do Amazonas.

\begin{tabular}{|c|c|c|c|c|}
\hline \multicolumn{2}{|c|}{ Dados utilizados } & \multicolumn{3}{c|}{ Resultados para AIC=823,8 } \\
\hline $\begin{array}{c}\text { Variável } \\
\text { independente }\end{array}$ & Variável dependente & Variável explicativa & $\mathrm{t}$ & $\mathrm{P}$ \\
\hline $\begin{array}{c}\text { Priorização de } \\
\text { indicadores }\end{array}$ & $\begin{array}{c}\text { Evolução na situação dos } \\
\text { indicadores (2010-2014) }\end{array}$ & $\begin{array}{c}\text { Priorização de } \\
\text { indicadores }\end{array}$ & 8,23 & $<0,001$ \\
\hline
\end{tabular}

Quadro 4.6. Resultados do modelo GLM 3 para o teste da influência do desempenho das ações que foram estabelecidas e monitoradas (referentes ao método SISUC) sobre a evolução na situação dos indicadores (2010-2014) para o conjunto de UCs pesquisadas do MBRN, estado do Amazonas.

\begin{tabular}{|c|c|c|c|c|}
\hline \multicolumn{2}{|c|}{ Dados utilizados } & \multicolumn{3}{|c|}{ Resultados para AIC=566,6 } \\
\hline $\begin{array}{c}\text { Variável } \\
\text { independente }\end{array}$ & $\begin{array}{c}\text { Variável } \\
\text { dependente }\end{array}$ & Variável explicativa & $\mathrm{t}$ & $P$ \\
\hline \multirow{2}{*}{$\begin{array}{l}\text { Desempenho das } \\
\text { ações que foram } \\
\text { estabelecidas e } \\
\text { monitoradas }\end{array}$} & \multirow{2}{*}{$\begin{array}{c}\text { Evolução na } \\
\text { situação dos } \\
\text { indicadores } \\
(2010-2014)\end{array}$} & Intercepto* & 10,23 & $<0,001$ \\
\hline & & $\begin{array}{l}\text { Desempenho das ações que foram } \\
\text { estabelecidas e monitoradas }\end{array}$ & $-2,15$ & 0,032 \\
\hline
\end{tabular}

* Intercepto não é uma variável, mas um fator explicativo que representa o efeito de um conjunto de variáveis não identificadas pelo modelo (v. explicação no subitem 3.4.2, Capítulo 3, Material e Métodos).

O modelo GLM 4, usado para testar a influência de aspectos das variáveis teóricas método SISUC e conselho gestor, indica a influência da variável explicativa desempenho de ações que foram estabelecidas e monitoradas sobre a variável dependente evolução na situação dos indicadores (2010 - 2014), conforme os valores de $\mathrm{P} \leq 0,05$ que foram obtidos (Quadro 4.7). Nenhuma das duas variáveis independentes referentes ao conselho gestor (i.e. gerência do conselho gestor sobre as ações estabelecidas e atuação do conselho gestor sobre as ações estabelecidas) explicam a variável dependente evolução na situação dos indicadores (2010-2014). 
Quadro 4.7. Resultados do modelo GLM 4 para o teste da influência de variáveis independentes referentes ao método SISUC e ao conselho gestor das UCs sobre a evolução na situação dos indicadores (2010-2014) para o conjunto de UCs pesquisadas do MBRN, estado do Amazonas.

\begin{tabular}{|c|c|c|c|c|}
\hline \multicolumn{2}{|c|}{ Dados utilizados } & \multicolumn{2}{c|}{ Resultados para AIC=546,69 } \\
\hline Variável independente & $\begin{array}{c}\text { Variável } \\
\text { dependente }\end{array}$ & $\begin{array}{c}\text { Variável } \\
\text { explicativa }\end{array}$ & $\mathrm{t}$ & $\mathrm{P}$ \\
\hline $\begin{array}{c}\text { Desempenho das ações que } \\
\text { foram estabelecidas e } \\
\text { monitoradas + Gerência do } \\
\text { conselho gestor sobre as ações } \\
\text { estabelecidas + Atuação do } \\
\text { conselho gestor nas ações } \\
\text { estabelecidas }\end{array}$ & $\begin{array}{c}\text { Evolução na } \\
\text { situação dos } \\
\text { indicadores (2010- } \\
2014)\end{array}$ & $\begin{array}{c}\text { Desempenho das } \\
\text { ações que foram } \\
\text { estabelecidas e } \\
\text { monitoradas }\end{array}$ & $-2,49$ & 0,013 \\
\cline { 3 - 5 } & & 0,32 & 013 \\
\end{tabular}

* Intercepto não é uma variável, mas um fator explicativo que representa o efeito de um conjunto de variáveis não identificadas pelo modelo (v. explicação no subitem 3.4.2, Capítulo 3, Material e Métodos).

Os modelos GLM 5 e 6 foram usados para testar se variáveis independentes referentes ao método SISUC poderiam explicar a situação dos indicadores em 2014. Considerando a lógica adotada para interpretação dos valores de AIC obtidos nos modelos GLM 1, 2, 3 e 4, mesmo diante do valor de AIC consideravelmente maior, o modelo 6 é mais explicativo do que o modelo GLM 5, já que este último indica apenas o intercepto (i.e. outras variáveis que não a considerada no modelo testado) como fator explicativo (Quadro 4.8). 0 modelo GLM 6, indica a influência da variável explicativa priorização de indicadores sobre a variável dependente situação dos indicadores em 2014, conforme os valores de $\mathrm{P} \leq 0,05$ obtidos (Quadro 4.9).

Quadro 4.8. Resultados do modelo GLM 5 para o teste da influência da priorização de indicadores (referente ao método SISUC) sobre a situação dos indicadores em 2014 para o conjunto de UCs pesquisadas do MBRN, estado do Amazonas.

\begin{tabular}{|c|c|c|c|c|}
\hline \multicolumn{2}{|c|}{ Dados utilizados } & \multicolumn{2}{c|}{ Resultados para AIC=625,3 } \\
\hline Variável independente & Variável dependente & Variável explicativa & $\mathrm{t}$ & $\mathrm{P}$ \\
\hline $\begin{array}{c}\text { Desempenho das ações que } \\
\text { foram estabelecidas e } \\
\text { monitoradas }\end{array}$ & $\begin{array}{c}\text { Situação dos } \\
\text { indicadores em 2014 }\end{array}$ & Intercepto & 18,20 & $<0,001$ \\
\hline
\end{tabular}

* Intercepto não é uma variável, mas um fator explicativo que representa o efeito de um conjunto de variáveis não identificadas pelo modelo (v. explicação no subitem 3.4.2, Capítulo 3, Material e Métodos). 
Quadro 4.9. Resultados do modelo GLM 6 para o teste da influência da priorização de indicadores (referente ao método SISUC) sobre a situação dos indicadores em 2014 para o conjunto de UCs pesquisadas do MBRN, estado do Amazonas.

\begin{tabular}{|c|c|c|c|c|}
\hline \multicolumn{2}{|c|}{ Dados utilizados } & \multicolumn{3}{c|}{ Resultados para AIC=875,8 } \\
\hline Variável independente & Variável dependente & $\begin{array}{c}\text { Variável } \\
\text { explicativa }\end{array}$ & $\mathrm{t}$ & $\mathrm{P}$ \\
\hline Priorização de & Situação dos indicadores em \\
Indicadores & 2014 & Intercepto & 23,65 & $<0,001$ \\
\cline { 3 - 5 } & $\begin{array}{c}\text { Priorização de } \\
\text { Indicadores }\end{array}$ & 2,19 & 0,029 \\
\hline
\end{tabular}

* Intercepto não é uma variável, mas um fator explicativo que representa o efeito de um conjunto de variáveis não identificadas pelo modelo (v. explicação no subitem 3.4.2, Capítulo 3, Material e Métodos).

Os modelos GLM 7 e 8 foram usados para testar quais variáveis independentes poderiam explicar o desempenho das ações que foram estabelecidas e monitoradas. Diferente dos modelos testados para analisar o efeito de variáveis independentes sobre a evolução na situação dos indicadores (2010-2014) e sobre a situação dos indicadores em 2014, os modelos 7 e 8 não apresentaram valores de AIC consideravelmente diferentes entre si. Além disso, ambos indicam o intercepto como fator explicativo do desempenho das ações que foram estabelecidas e monitoradas e valores de $\mathrm{P}$ no limite do critério considerado estatisticamente significativo, conforme subitem 3.4.2. (Capítulo 3, Material e Métodos). Ainda assim, considerando a lógica prática vale a análise comparativa desses resultados.

Neste sentido, o modelo 7 (Quadro 4.10) é mais explicativo do que o modelo 8 (Quadro 4.11), já que este último identificou apenas duas categorias como variáveis explicativas, de um total de 21 categorias que foram testadas (v. lista no Apêndice 4).

0 modelo 7, usado para testar a influência de aspectos das variáveis teóricas 'contexto de gestão' e 'conselho gestor das UCs', indica a influência da variável explicativa idade do conselho gestor sobre a variável dependente desempenho das ações que foram estabelecidas e monitoradas. 0 modelo 8, usado para testar a influência de aspectos das variáveis teóricas 'método SISUC' e 'conselho gestor' indica a influência da variável explicativa idade do conselho gestor sobre a variável dependente desempenho das ações que foram estabelecidas e monitoradas. 
Quadro 4.10. Resultados do modelo GLM 7 para o teste da influência de variáveis independentes referentes ao contexto de gestão e ao conselho gestor das UCs sobre o desempenho das ações que foram estabelecidas e monitoradas para o conjunto de UCs pesquisadas do MBRN, estado do Amazonas.

\begin{tabular}{|c|c|c|c|c|}
\hline \multicolumn{2}{|c|}{ Dados utilizados } & \multicolumn{2}{c|}{ Resultados para AIC=573,4 } \\
\hline Variável independente & $\begin{array}{c}\text { Variável } \\
\text { dependente }\end{array}$ & $\begin{array}{c}\text { Variável } \\
\text { explicativa }\end{array}$ & $\mathrm{t}$ & $\mathrm{P}$ \\
\hline $\begin{array}{c}\text { Atuação da equipe local de } \\
\text { gestão nas ações estabelecidas + } \\
\text { Idade do plano de manejo/gestão } \\
\text { + Idade do conselho gestor }\end{array}$ & $\begin{array}{c}\text { Desempenho das } \\
\text { ações que foram } \\
\text { estabelecidas e } \\
\text { monitoradas }\end{array}$ & $\begin{array}{c}\text { Idade do conselho } \\
\text { gestor }\end{array}$ & $-1,93$ & 0,059 \\
\cline { 3 - 5 } & untercepto & 20,71 & $<0,001$ \\
\hline
\end{tabular}

* Intercepto não é uma variável, mas um fator explicativo que representa o efeito de um conjunto de variáveis não identificadas pelo modelo (v. explicação no subitem 3.4.2, Capítulo 3, Material e Métodos).

Quadro 4.11. Resultados do modelo GLM 8 para o teste da influência de variáveis independentes referentes ao contexto de gestão e ao conselho gestor das UCs sobre o desempenho das ações que foram estabelecidas e monitoradas para o conjunto de UCs pesquisadas do MBRN, estado do Amazonas.

\begin{tabular}{|c|c|c|c|c|}
\hline \multicolumn{2}{|c|}{ Dados utilizados } & \multicolumn{3}{|c|}{ Resultados para AIC=566,1 } \\
\hline Variável independente & $\begin{array}{c}\text { Variável } \\
\text { dependente }\end{array}$ & Variável explicativa & $\mathrm{t}$ & $P$ \\
\hline \multirow{3}{*}{$\begin{array}{l}\text { Tema da ação estabelecida } \\
\text { + Atuação do conselho } \\
\text { gestor na ação } \\
\text { estabelecida + Gerência do } \\
\text { conselho gestor sobre a } \\
\text { ação estabelecida }\end{array}$} & \multirow{3}{*}{$\begin{array}{l}\text { Desempenho } \\
\text { das ações que } \\
\text { foram } \\
\text { estabelecidas e } \\
\text { monitoradas }\end{array}$} & Intercepto & 2,64 & 0,009 \\
\hline & & $\begin{array}{l}\text { Ação (tema): Acesso a } \\
\text { serviços públicos }\end{array}$ & 1,90 & 0,058 \\
\hline & & $\begin{array}{c}\text { Ação (tema): Pesquisa e } \\
\text { Conhecimento }\end{array}$ & $-1,89$ & 0,059 \\
\hline
\end{tabular}

* Intercepto não é uma variável, mas um fator explicativo que representa o efeito de um conjunto de variáveis não identificadas pelo modelo (v. explicação no subitem 3.4.2, Capítulo 3, Material e Métodos).

Em rápido sumário, os valores de AIC gerados pelos modelos GLM testados não apresentaram variação que permitisse utilizá-los como referência única para identificar os modelos que melhor explicavam as variáveis preditoras das variáveis resposta.

A maioria dos modelos GLM testados apresentaram o intercepto como um fator explicativo e nenhum dos modelos demonstraram efeito da combinação aditiva de diferentes variáveis independentes entre si, sejam elas referentes a uma ou duas variáveis teóricas, sobre nenhuma das três variáveis dependentes consideradas (i.e. evolução dos indicadores [2010-2014], situação dos indicadores em 2014 e desempenho das ações que foram estabelecidas e monitoradas).

O método SISUC é a principal variável teórica preditiva dos modelos analisados: as variáveis independentes priorização de indicadores e, principalmente, desempenho das ações estabelecidas e monitoradas são preditoras da evolução na situação dos indicadores 
(2010-2014); a variável independente priorização de indicadores também é preditora da situação dos indicadores em 2014.

O contexto de gestão das UCs é variável teórica preditiva da evolução na situação dos indicadores (2010-2014) a variável e independente idade do conselho gestor é preditiva da situação dos indicadores em 2014. Mas esse resultado não permite afirmar que o conselho gestor seja uma variável teórica preditiva de nenhuma das variáveis dependentes analisadas.

Apesar do desempenho das ações que foram estabelecidas e monitoradas apresentar-se como a variável preditiva mais importante entre as nove variáveis independentes analisadas, quando considerada como variável resposta, ela não foi explicativa de nenhuma das três variáveis teóricas analisadas (i.e. método SISUC, contexto de gestão das UCs e conselho gestor das UCs)

\subsubsection{Testes chi-quadrado}

Pelos testes chi-quadrado, o efeito da exclusão da variável teórica 'método SISUC' sobre a variável dependente situação dos indicadores em 2014, foram testados a partir de um total de 1764 indicadores avaliados pelos conselheiros. As três variáveis independentes testadas (i.e. idade da UC, idade do plano de manejo/gestão e idade do conselho gestor) são preditivas da situação dos indicadores em 2014. As condições mais favoráveis aos indicadores foram as seguintes: UCs com planos de manejo/gestão com até quatro anos $\left(\chi^{2}=26.1765, \mathrm{df}=3, \mathrm{p}<0.01\right.$, Tabela 4.5); conselho gestor com até dois anos $\left(\chi^{2}=32.4555, \mathrm{df}=3, \mathrm{p}<0.01\right.$, Tabela 4.6); e UCs com até 4 anos de idade desde a sua criação $\left(\chi^{2}=70.48, \mathrm{df}=6, \mathrm{p}<0.05\right.$, Tabela 4.7).

Tabela 4.5. Distribuição da freqüência absoluta de indicadores de acordo com a situação avaliada no ano de 2014 (i.e. alarmante, insatisfatória, satisfatória e sucesso) na comparação do grau de atualização do planos de manejo/gestão para o conjunto de UCs pesquisadas do MBRN, estado do Amazonas.

\begin{tabular}{lccccc}
\hline & \multicolumn{5}{c}{ Situação do indicador } \\
\cline { 2 - 6 } Plano de & Alarmante & Insatisfatória & Satisfatória & Sucesso & $\begin{array}{c}\text { Total } \\
\text { manejo/gestão }\end{array}$ \\
\hline Até 4 anos & 64 & 185 & 418 & 235 & 902 \\
Mais de 4 anos & 109 & 195 & 399 & 159 & 862 \\
\hline Total Marginal & 173 & 380 & 817 & 394 & 1764 \\
\hline
\end{tabular}

Onde: Plano de manejo para as UFs federais ( $c f$. SNUC, 2000) e Plano de gestão para as UCs estaduais do Amazonas ( $c f$. SEUC, 2007). 
Tabela 4.6. Distribuição da freqüência absoluta de indicadores de acordo com a situação avaliada no ano de 2014 (i.e. alarmante, insatisfatória, satisfatória e sucesso) na comparação da idade do conselho gestor para o conjunto de UCs pesquisadas do MBRN, estado do Amazonas.

\begin{tabular}{lccccc}
\hline & \multicolumn{5}{c}{ Situação do indicador } \\
\cline { 2 - 6 } Idade do conselho gestor & Alarmante & Insatisfatória & Satisfatória & Sucesso & $\begin{array}{c}\text { Total } \\
\text { Marginal }\end{array}$ \\
\hline $\begin{array}{l}\text { Até dois anos (primeiro } \\
\text { mandato) }\end{array}$ & 96 & 147 & 273 & 132 & 648 \\
$\begin{array}{l}\text { Mais de dois anos (segundo } \\
\text { mandato em diante) }\end{array}$ & 77 & 233 & 544 & 262 & 1116 \\
\hline Total Marginal & 173 & 380 & 817 & 394 & 1764 \\
\hline
\end{tabular}

Tabela 4.7. Distribuição da freqüência absoluta de indicadores de acordo com a situação avaliada no ano de 2014 (i.e. alarmante, insatisfatória, satisfatória e sucesso) na comparação da idade das UCs para o conjunto de UCs pesquisadas do MBRN, estado do Amazonas.

\begin{tabular}{lccccc}
\hline & \multicolumn{4}{c}{ Situação do indicador } & \\
\cline { 2 - 5 } $\begin{array}{l}\text { Idade da UC (tempo } \\
\text { desde a sua criação) }\end{array}$ & Alarmante & Insatisfatória & Satisfatória & Sucesso & $\begin{array}{c}\text { Total } \\
\text { Marginal }\end{array}$ \\
\hline Até 4 anos & 48 & 142 & 400 & 206 & 796 \\
$5-15$ anos & 49 & 151 & 225 & 88 & 513 \\
Mais de 15 anos & 76 & 87 & 192 & 100 & 455 \\
\hline Total Marginal & 173 & 380 & 817 & 394 & 1764 \\
\hline
\end{tabular}




\section{Capítulo 5}

\section{Discussão}

Este capítulo traz a discussão dos resultados das análises do efeito influência da implantação do método SISUC em UCs do MBRN, no estado do Amazonas. A aderência do método SISUC ao processo de transformação deliberada de sistemas socioecológicos é utilizada como substrato para discussão dos resultados obtidos. Primeiro, é apresentada a discussão sobre a aderência do método SISUC a parâmetros de boa governança no âmbito do conselho gestor das UCs pesquisadas, com ênfase nos fatores-chave e mecanismos que emergem da aplicação desse método. Em seguida, é apresentada a discussão sobre as mudanças ocorridas no sistema socioecológico dessas UCs a partir da implantação do método SISUC no âmbito de conselhos gestores. A influência do contexto de gestão e dos próprios conselhos gestores das UCs também são discutidas. Finalmente, considerações finais trazem aspectos gerais sobre o método SISUC, que não são objetos de investigação do presente trabalho de pesquisa, e informações de base para as conclusões finais desta tese.

\subsection{TRANSFORMAÇÃO DELIBERADA DE SISTEMAS SOCIOECOLÓGICOS DAS UCS}

Análises multimétodos ( $c f$. Cox, 2015) utilizadas na presente pesquisa demonstram que, entre o ano de 2010 e o ano de 2014, as UCs do Mosaico de Áreas Protegidas do Baixo Rio Negro nas quais o método SISUC foi implantado passaram por mudanças evidenciadas em diferentes âmbitos e escalas de análise: processos de governança local no âmbito dos conselhos gestores de UCs foram aprimorados, processos de transformação deliberada de sistemas socioecológicos foram observados, e melhoria na condição socioecológica de cada UC e do conjunto de UCs, verificada por meio de indicadores e das diferentes dimensões avaliadas dos sistemas socioecológicos.

As mudanças verificadas corroboram as considerações de Moore et al. (2014) à respeito da influência de aspectos de governança, gestão transicional e inovação social sobre outcomes (i.e. desfechos) sociais e ecológicos que ocorrem durante a transformação 
de sistemas socioecológicos. Sistemas socioecológicos complexos são controlados por mecanismos de retroalimentação, de forma que transformações em seu espaço de deliberação, no caso os conselhos gestores, afetam as dimensões ecológica, social e econômica (e.g. Plummer \& Armitage, 2007), como no caso das UCs pesquisadas.

Moore et al. (2014) identificam quatro fases principais ao longo do processo de transformação deliberada de sistemas socioecológicos: Pré-transformação, Preparação para a mudança, Transição, e Institucionalização da nova trajetória. Essas etapas são descritas abaixo, de acordo com o que foi verificado ao longo da implantação do método SISUC nas UCs pesquisadas.

\subsubsection{Pré-transformação e Preparação para mudança}

Embora o SISUC (Marinelli, 2011) ainda não tivesse sido publicado, no ano de 2010 já havia proposta metodológica sistematizada, resultante do somatório de pesquisas iniciais conduzidas no âmbito do presente trabalho e de produtos e encaminhamentos resultantes dos dois primeiros anos do projeto SISUC, executado pelo ISA e liderado pelo autor desta tese, conforme item 1.3.2 (Capítulo 1, Contextualização).

Nessa época, organizações (governamentais e não-governamentais) que atuavam como membros dos conselhos gestores das UCs pesquisadas buscavam o suporte de algum método ou ferramenta que minimizasse alguns problemas crônicos nacionais que atingem a gestão local, e que fosse voltada para necessidades funcionais dos conselhos gestores, entre os principais, a saber: propiciar a avaliação de UCs sob abordagem socioecológica e participativa, em alternativa aos métodos e ferramentas então em uso, e complementar os planos de manejo, à medida em que promovesse desdobramentos de resultados em um plano de ação dinâmicamente atualizado e gerenciável pelo conselho gestor. Esse cenário de demanda pela mudança do contexto corrente à época tornou-se transparente para os conselhos gestores e, com isso, deu início a fase de prétransformação do sistema socioecológico.

Parcerias formais do ISA (no âmbito do projeto SISUC) junto ao ICMBio e o CEUCAM, foram celebradas com o intuito de aplicar o método SISUC em seis conselhos gestores das UCs (entre as federais e as estaduais) que se tornaram objeto de estudo do presente trabalho de pesquisa. A fase de pré-transformação concretizou-se a partir da apresentação e interesse dos conselhos gestores dessas UCs na execução de um ciclo completo do método SISUC. Este fato selou o compromisso desses conselhos gestores com 
a realização de oficinas para aplicação desse método, com vistas à avaliação de condições socioecológicas locais e à geração de inovação e de novas visões para o futuro, a partir do estabelecimento de ações para melhoria de indicadores em situação indesejada e de metas a serem alcançadas por indicadores prioritários.

Mesmo que necessário para melhor caracterização da situação de áreas protegidas e de sua efetividade (Leverington et al., 2010), o monitoramento e avaliação sistemáticos e sob abordagem socioecológica, contextualizada e participativa, por si só, constitui-se de uma inovação no Brasil e, mesmo internacionalmente, constitui-se de algo pouco comum, com um caso em alguns países da Europa (Pediaditi et al., 2011) e outro na Austrália (Izurieta et al., 2011).

A partir de então, iniciou-se a fase de preparação para a mudança, quando passaria a ser realizado o monitoramento e a avaliação das ações que foram estabelecidas a partir da implantação do método SISUC, impulsionadas por uma rede de apoio e experimentação formada por conselheiros monitores. Essas ações passaram a constituir uma atividade de 3 horas, que constava da pauta fixa de cada reunião dos conselhos gestores até a reavaliação dos indicadores realizada em 2014.

\subsubsection{Transição: a implantação do método SISUC}

A escolha do método SISUC como alternativa inovadora para o investimento na busca por mudanças deu origem à fase de transição para a transformação deliberada do sistema socioecológico, conforme as fases identificadas por Moore et al. (2014).

A implantação do método SISUC em 2010 e o processo de avaliação até o ano de 2014 (na presente pesquisa), possibilita a identificação de dois tipos de impactos locais, os quais estão correlacionados entre si: (1) impacto social, no âmbito do conselho gestor das UCs, a partir do estabelecimento de um sistema estruturado de tomada de decisão, que atende a parâmetros de boa governança de áreas protegidas; e (2) impacto socioecológico, no âmbito das UCs, a partir do aprimoramento de processos de governança local que melhoraram a situação dos indicadores avaliados e, por conseqüência, aumentaram a efetividade das UCs, conforme detalhado abaixo, nos subitens 5.1.2.1. e 5.1.2.2. 
5.1.2.1. Impacto social no âmbito dos conselhos gestores de UCs: o método SISUC e o aprimoramento da governança local

Poucas pesquisas abordam a avaliação da governança de UCs no Brasil (e.g. Cozzolino, 2005; Cozzolino \& Irving, 2006; Loureiro e Cunha, 2008; Alcântara \& Furlan, 2011; Nobre \& Schiavetti, 2013) e todas elas adotaram o método proposto por Graham et al. (2003) ou derivações (e.g. Abrams et al, 2003) surgidas a partir do protocolo do Programa de Desenvolvimento das Nações Unidas (UNDP, 1997).

Esta tese, materializa a aplicação inédita no Brasil, do protocolo de avaliação da governança de áreas protegidas proposto por Lockwood (2010), no qual a coerência estrutural e a ampliação da abrangência dos parâmetros avaliados são aprimorados em relação aos protocolos citados acima já usados no país.

No geral, o método SISUC apresenta-se aderente a todos os princípios de boa governança de áreas protegidas, propostos por Lockwood (2010) e apresentados no Quadro 4.3, Capítulo 4, Resultados. A partir da análise das atividades do SISUC identificam-se dois níveis de aderência diferentes aos princípios de boa governança: responsabilidade, transparência e legitimidade (muito boa aderência) e resiliência, inclusão e justiça (boa aderência).

Quatro tipos de atividade do método SISUC identificados entre os cinco analisados, apresentam aderência a maior parte dos parâmetros de boa governança avaliados: monitoramento e a avaliação do desempenho de ações e de indicadores, estabelecimento de metas para indicadores, análise de viabilidade e definição de ações e a avaliação de indicadores. A aderência parcial de alguns tipos de atividade do método SISUC aos princípios de boa governança de UCs deve-se à própria natureza dos elementos analisados. Não espera-se, por exemplo, que a análise de viabilidade e definição de ações seja aderente à parâmetros do princípio de resiliência, que abordam processos de adaptação baseados em resultados. A mesma lógica vale para atividade de balanço do desempenho de metas e ações.

- Fatores e mecanismos para o aprimoramento da governança

Os quatro tipos de atividades do SISUC que mais contribuem para aderência desse método a princípios de boa governança (listados no subitem anterior) remetem à avaliação do desempenho de decisões tomadas e a prestação de contas de resultados 
obtidos, dois processos já reconhecidos como importantes para as UCs (e.g. Loureiro e Cunha, 2008). Esses processos compõem parte importante do ciclo de diagnóstico, planejamento, tomada de decisão, avaliação de resultados das decisões e geração de mecanismos de retroalimentação, elementos que, de acordo com a literatura, estruturam a base para tomada de decisões (e.g. Allen et al., 2011; Williams \& Brown, 2014).

Tratam-se de processos incidentes no começo, meio e fim do ciclo de aplicação do SISUC, que, na verdade, constata-se que é composto por dois círculos concêntricos e integrados: o círculo externo, constituído pelo monitoramento e avaliação/reavaliação de indicadores, estabelecimento/revisão de metas para melhoria da situação de indicadores em situação indesejada e pelo estabelecimento de ações que contribuam para o alcance dessas metas, ou seja, atividades de incidência bi ou trienal; e o círculo interno, da atividade de monitoramento e avaliação de ações, que ocorrem a cada reunião do conselho gestor e que, por sua vez, retroalimenta o círculo externo, integrando esses dois círculos entre si.

Dessa forma, o sistema de monitoramento e avaliação promovido pelo SISUC permite a mensuração de variáveis rápidas (do círculo interno) e variáveis mais lentas (do círculo externo), caracterizando duas escalas diferentes de monitoramento e avaliação no mesmo sistema de informação, um processo reconhecido na literatura internacional devido ao desafio prático que representa sua aplicação na gestão ambiental (e.g. Cundill \& Fabricius, 2009; Williams \& Brown, 2014).

O monitoramento e a avaliação em dois círculos promovidos pelo SISUC subsidiam a adaptação de decisões em diferentes instâncias e fortalecem o ciclo de gestão adaptativa, caracterizado pelo 'aprender-fazendo' a partir de processos iterativos e formais que, segundo a literatura internacional (e.g. Allen et al., 2011; Williams \& Brown, 2014), estabelecem uma estrutura para tomada de decisão.

- Aprendizagem: mecanismo-chave da gestão adaptativa no método SISUC

A incorporação de processos adaptativos em momentos distintos, antes e depois que decisões são tomadas como no SISUC, também é citada por Smith \& Lenhart (1996) e Füssel (2007 apud Munareto et al., 2014) como componente da gestão adaptativa. Mas, para que a capacidade adaptativa seja praticada, são necessárias flexibilidade e plataformas, não só para encaminhamentos que remetam a mecanismos de retroalimentação, como também para a aprendizagem (Plummer et al., 2013), a qual deve 
ser estimulada por meio de interações sociais que fomentem conhecimentos diferentes (Armitage et al., 2009; Simonsen et al., 2014).

Sendo o SISUC um método participativo, no qual se destacam atividades individuais, em grupos e coletivas, diferentes possibilidades de aquisição de conhecimentos são reunidas ao longo de sua aplicação. Esses conhecimentos são transmitidos nos saberes trazidos pelos conselheiros, no uso e na combinação dos mesmos durante a prática de atividades de integração e na complementação de saberes propiciada pelas atividades desse método.

Estratégias de aprendizagem como essas adotadas no SISUC por meio das etapas e passos de sua aplicação, intencionais, experienciais e experimentais, associadas ao monitoramento do 'aprender-fazendo' na gestão adaptativa, são caminhos promissores para a tomada de decisão sobre sistemas socioecológicos (e.g. Armitage et al., 2009; Simonsen et al. 2014). No caso do SISUC, ainda que a aprendizagem seja estimulada em todo o seu ciclo de aplicação, ela é estrategicamente promovida durante os processos de gestão adaptativa e potencializada por sua abordagem socioecológica, contextualizada e participativa.

O monitoramento das ações que foram estabelecidas para atingir resultados específicos, e que ocorre a cada reunião do conselho gestor, ocasião em que é feita a avaliação da situação de cada ação e a interpretação das causas do histórico de desempenho das mesmas. Isso favoreceu a análise de desempenho de ações e a reflexão a partir de elementos que, de acordo com Cundill \& Fabricius (2009), compõem a ação, como por exemplo, quem é o responsável por sua execução, como isso está sendo feito e qual o alvo dessa ação. A identificação das justificativas para problemas encontrados contribuiu para que emergissem argumentos em favor de medidas corretivas a partir dos resultados obtidos e do aprendizado que essas experiências ofereceram, como é relatado em casos de processos similares por Armitage et al. (2008) e Munaretto et al. (2014). Esse fenômeno ao longo do processo de monitoramento das ações apresenta características de duas teorias da aprendizagem individual: a aprendizagem experiencial, baseada na geração de conhecimento por meio de experiências e das práticas (Keen \& Mahanty, 2006), e a aprendizagem transformativa, que habilita a percepção dos indivíduos e altera sua consciência sobre os fatos verificados (Mezirow, 2000).

As atividades de aplicação do método SISUC proporcionaram o compartilhamento desse aprendizado individual entre conselheiros, reforçado por meio da participação (e.g. Diduck, 2004 apud Berkes, 2009) e de processos colaborativos (e.g. Plummer \& 
FitzGibbon, 2007). Dessa forma, o processo contínuo de reflexão voltada para ações e idéias, e da busca de relações entre conhecimentos, comportamentos e valores, acabaram oferecendo também uma plataforma para aprendizagem social (Keen et al., 2005 apud Cundill \& Fabricius, 2009), o qual é destacado na literatura relacionada ao monitoramento de sistemas socioecológicos por vários autores (e.g. Armitage et al., 2008; Cundill \& Fabricius, 2009).

O processo de aprendizagem social promovido pelas atividades do SISUC são caracterizadas pelos três ciclos de aprendizagem social descritos por King \& Jiggins (sensu 2002 apud Armitage et al., 2008): o ciclo único, por meio da correção de rotinas (i.e. pelo estabelecimento de ações para melhorar a situação de indicadores indesejados); o ciclo duplo, quando além do ciclo único, visões e valores são desafiados (i.e. durante avaliações de desempenho das ações e balanço das metas estabelecidas para melhorar a situação de indicadores); e o ciclo triplo, por meio de normas e protocolos incidentes nos ciclos único e duplo (i.e. pela própria estrutura de suporte à tomada de decisão e ao regime adaptativo implementado).

Considerando-se o modelo de aprendizagem integrada à gestão de áreas protegidas apresentado por Nkhata \& Breen (2010), verifica-se que as práticas do método SISUC estimulam aprendizagem de governança, por meio da execução e do cumprimento da governança, convicções/valores sociais e interesse público; aprendizagem de gestão, por meio da missão, visão e objetivos da UC, estratégias de gestão e monitoramento, e avaliação de gestão; e aprendizagem integrada de governança e gestão, por meio de características multinível, tensões entre interesses que competem e fluxo de informação.

Empoderados, conselheiros são mais autônomos e conscientes de seu espaço de poder, exercitam a reflexão e o questionamento ativo, e reproduzem seus entendimentos nas rotinas do conselho gestor. 0 intercâmbio e a integração de conhecimentos entre conselheiros contribuem para o entendimento de processos, melhoria das proposições apresentadas e, consequentente, dos resultados e impactos.

Em resumo, adaptação e aprendizagem, constituem-se em dois mecanismos-chave emergentes das atividades e passos do SISUC associados a aprendizagem intencional, flexibilidade em resposta à mudanças, processos adaptativos e gerenciamento de riscos, parâmetros do princípio de resiliência para boa governança de áreas protegidas ( $c f$. Lockwood, 2010). 
Além de adaptação e aprendizagem, partes essenciais do ciclo de gestão adaptativa, a tomada de decisão também é um mecanismo importante nas atividades e passos da aplicação do SISUC para que esse método atenda aos parâmetros da boa governança de áreas protegidas. No caso da tomada de decisão, além do princípio da resiliência, outros quatro princípios de boa governança de áreas protegidas ( $c f$. Lockwood, 2010) têm seus parâmetros atendidos por meio da aplicação do SISUC: (a) transparência, por meio da participação e argumentação de decisões e do controle de resultados; (b) responsabilidade, por meio da clara divisão equitativa do papel dos conselheiros e da prestação de contas de resultados em diferentes instâncias; (c) inclusão, por meio de oportunidade apropriadas e do engajamento ativo de todos os envolvidos; e (d) justiça, por meio da consistência de decisões e respeito à direitos dos atingidos pelas mesmas.

O conjunto de princípios de boa governança e seus parâmetros atendidos pelo SISUC têm origem no desenvolvimento da capacidade de envolvimento coletivo dos conselheiros e em sua influência no exercício da autoridade e de decisões. Por meio de debates abertos e discursos de opinião, propostas são apresentadas, discordâncias são argumentadas, prioridades são definidas e entendimentos comuns podem ser alcançados. Por sua vez, para que isso seja possível, as atividades do SISUC demandam intercâmbios, construção de diálogos e compartilhamento de compreensões ao longo dos diferentes passos do ciclo de aplicação desse método. Por isso, para que adaptação, aprendizagem e tomada de decisão funcionem de forma adequada em um espaço participativo de governança acoplada à gestão, a comunicação também constitui-se em mecanismo-chave. A comunicação é tão importante ao longo da aplicação do SISUC que, além de contribuir para os cinco princípios que emergem da tomada de decisão (i.e. resiliência, transparência, responsabilidade, inclusão e justiça), por ter propiciado vínculos entre conselhos gestores das UCs pesquisadas e com o conselho gestor do MBRN (v. Quadro 4.2, Capítulo 4, Resultados), a comunicação também contribui para o princípio de conectividade.

De acordo com Poteete et al. (2013) a comunicação favorece a confiança e o desejo de cooperação, e assim muda as expectativas dos envolvidos e amplia a capacidade de resolver dilemas, tornando-se importante para os resultados obtidos em espaços coletivos de governança. Investir em estratégias de comunicação, como os grupos de conselheiros monitores do desempenho de ações (ações 7 e 8 da aplicação SISUC, Quadro 
3.1, Capítulo 3, Material e Métodos) constituem redes de cooperação que tendem a configurar mobilizações efetivas para exercício do controle social de áreas protegidas (Cozzolino et al., 2015).

A adoção de procedimentos técnicos para facilitar a participação dos conselheiros, fator determinante para a tomada de decisão e condicionante para o funcionamento de conselhos gestores, já havia sido observada por Souza (2012) para UCs de proteção integral e de uso sustentável da costa brasileira. Cardoso \& Cândido (2015) também ressaltam que procedimentos técnicos permitem que os atores se relacionem no espaço de trabalho, possam rever informações e conhecimentos, e refletir sobre a realidade da Reserva Nacional Sistema de Islas, Islotes y Puntas Guaneras, no Peru. Constatações como essas são corroboradas pelo presente trabalho de pesquisa, e constituem alguns dos argumentos que levam Orbell et al. (2004 apud Poteete et al., 2013) a afirmar que, em espaços de tomada de decisão coletiva sobre a gestão ambiental, os atributos da situação na qual os indivíduos interagem são mais importantes para a precisão de resultados do que a própria racionalidade por eles praticada.

5.1.2.2 Impacto socioecológico no âmbito das UCs: as influências do SISUC na melhoria das condições socioecológicas locais

A absorção e a replicação da mudança bem sucedida em fase experimental, promoveram a oportunidade de reavaliação dos indicadores em 2014, caracterizando o último subprocesso da fase de transição para transformação do sistema socioecológico (cf. Moore et al., 2014).

Não foi encontrado na literatura nenhum método ou ferramenta que já tenha sido aplicado em UCs do Brasil que permita a avaliação sistemática de indicadores adotando uma abordagem socioecológica, contextualizada e participativa como o SISUC. Mesmo para as UCs em que o SISUC já foi aplicado, tanto na Amazônia (Pianca et al., 2013) como na Mata Atlântica (Spindel, 2014; Silva, 2016), como até o momento não foi realizada a primeira reavaliação dos indicadores (ação 10 do Quadro 3.1, Capítulo 3, Material e Métodos), a presente pesquisa inaugura a análise da evolução espaço-temporal de indicadores sob essa abordagem em UCs.

A comparação entre as avaliações socioambientais de 2010 e 2014 demonstra uma mudança acentuada no padrão de distribuição da situação do conjunto dos indicadores aplicados nas UCs pesquisadas. Os resultados revelam que indicadores em 
situação satisfatória e de sucesso passaram de uma freqüência relativa de 52\% em 2010 para 68\% em 2014 (v. Quadro 4.1 e Figura 4.1, Capítulo 4, Resultados). Essa mudança para uma situação mais favorável também foi reforçada nas análises dos indicadores por dimensão (i.e. econômica, sociocultural, ambiental e de gestão) e para cada uma das UCs.

O gerenciamento sobre os objetivos, as metas e as opções de gestão que melhor podem contribuir para o alcance de situações desejadas são componentes-chave de qualquer forma de gestão (Allen et al., 2011). No caso das UCs pesquisadas, a priorização de indicadores (em 2010), proporcionada pelo método SISUC, foi uma variável explicativa da evolução na situação dos indicadores (2010-2014) (modelo 2: $\mathrm{t}=8,23 ; \mathrm{P}<0,001$, Quadro 4.5, Capítulo 4, Resultados) e da situação dos indicadores em 2014 (modelo 5: $\mathrm{t}=2,19$; $\mathrm{P}=0,029$, Quadro 4.8, Capítulo 4, Resultados).

Indicadores priorizados não só apresentaram evolução com melhor desempenho, comparado a indicadores não-priorizados, como também nenhum deles piorou de situação do ano de 2010 para 2014. Esse fato foi corroborado pelos resultados mostrados no modelo 3 ( $\mathrm{t}=-2,15 ; \mathrm{P}=0,032$, Quadro 4.6, Capítulo 4, Resultados), no qual o desempenho das ações que foram estabelecidas e monitoradas explica a evolução na situação dos indicadores (2010-2014).

A priorização de indicadores e o desempenho de ações que foram estabelecidas e monitoradas influenciaram as mudanças no sistema socioecológico das UCs pesquisadas em diferentes escalas e, consequentemente, contribuíram para que as metas estabelecidas em 2010 para melhoria da situação desses indicadores fossem alcançadas. Mesmo no caso da minoria dos indicadores priorizados que não alcançaram suas metas em 2014, nenhum deles apresentou situação de retrocesso, mantendo-se na mesma situação ou já avançando em direção à meta estabelecida. Esses resultados corroboram a consideração de Ostrom (2009) de que metas de gestão influenciam e são influenciadas pela governança local e afetam variáveis de sistemas socioecológicos. Dessa forma, indicadores que não foram priorizados apresentaram uma tendência de evolução inversa aos que foram priorizados: $45 \%$ dos não-priorizados permaneceram estagnados e $24 \%$ apresentaram retrocesso em sua situação de 2010 para 2014 (Figura 4.5, Capítulo 4, Resultados). Como esses indicadores totalizaram 73\% do total de indicadores avaliados em 2010 e a tendência de evolução desse grupo foi diferente daquela dos $24 \%$ dos indicadores que foram priorizados, o modelo $6(\mathrm{t}=2,19 ; \mathrm{P}=0,029$, Quadro 4.9, Capítulo 4, Resultados) não demonstra que a variável desempenho das ações que foram estabelecidas 
e monitoradas explica as mudanças observadas na variável situação dos indicadores em 2014.

Esse conjunto de resultados conduz ao entendimento de que a priorização de indicadores é uma das atividades do SISUC que explica as mudanças ocorridas no sistema socioecológico das UCs pesquisadas, mas não a única: a principal causa de mudanças foi o desempenho das ações estabelecidas e monitoradas com vistas à melhoria da situação dos indicadores priorizados. 0 monitoramento e a avaliação oferecem plataforma e informações necessárias para a aprendizagem, sustentam a tomada de decisão e retroalimentam tanto a avaliação como a própria aprendizagem a partir das decisões tomadas, habilitando o sistema para mudanças socioecológicas (e.g. Folke et al., 2003).

- A influência do contexto de gestão e a neutralidade do conselho gestor na melhoria das condições socioecológicas

A partir da aprendizagem individual e alertas para o processo de divisão de poder, o mecanismo de retroalimentação iterativo entre os conselheiros (i.e. conselho gestor) e o sistema socioecológico promove mudanças em ambos. Durante a realização da presente pesquisa, observou-se que, influenciados pela aprendizagem social, conselheiros passaram a influenciar as reflexões do conselho, o que reforçou o potencial para mudar a condução da gestão ambiental (cf. Berkes et al., 2009). Nesse sentido, conselheiros das UCs pesquisadas passaram não só a aprimorar as propostas de ação a partir de seus aprendizados, como também a se responsabilizar pela execução de determinadas ações (v. Quadro 4.2, Capítulo 4, Resultados), corroborando o que é citado por Munaretto et al. (2014).

Apesar do comprometimento de conselheiros na execução de ações que estejam sob gerência do conselho gestor ser um fator importante para o fortalecimento da cogestão de UCs, isso não é comum e sim raro. Possivelmente, esse é um dos fatores que contribuem para que a variável atuação do conselho gestor nas ações estabelecidas não tenha explicado as mudanças na variável desempenho das ações monitoradas (modelo 8, Quadro 4.11, Capítulo 4, Resultados). Este fato, somado à constatação da influência da priorização de indicadores e do desempenho das ações monitoradas sobre a evolução na situação dos indicadores (2010-2014), reforça a influência da implantação do método SISUC nas mudanças do sistema socioecológico ilustradas no subitem 5.1.2.2. 
O momento da gestão é um fator que gera influências sobre variáveis de sistemas socioecológicos (Poteete et al., 2013), o que foi corroborado pelos resultados obtidos nos modelos em que o 'contexto de gestão' das UCs foi testado como variável teórica explicativa das mudanças no sistema socioecológico pesquisado (modelo 1, Quadro 4.4, Capítulo 4, Resultados).

A variável atuação da equipe local de gestão nas ações estabelecidas mostrou-se importante para o sistema socioecológico, uma correlação citada por Williams \& Brown (2014) e que, no caso das UCs pesquisadas, influenciou a variável resposta evolução na situação dos indicadores (2010-2014) (modelo 1: $\mathrm{t}=2,34 ; \mathrm{P}=0,02$, Quadro 4.4, Capítulo 4, Resultados). Esse fenômeno era esperado, pois 66\% das ações estabelecidas dependem do órgão gestor e por isso estão sob a responsabilidade de gestores públicos.

A idade do conselho gestor influenciou a variável desempenho das ações monitoradas (modelo 7: $\mathrm{t}=-1,93 ; \mathrm{P}=0,059$, Quadro 4.10, Capítulo 4, Resultados), mas também, e principalmente, a variável evolução na situação dos indicadores (2010-2014) (modelo 1: $\mathrm{t}=-2,66 ; \mathrm{P}=0,008$, Quadro 4.4, Capítulo 4, Resultados). Com exceção das práticas do método SISUC durante parte das reuniões dos conselhos gestores das UCs pesquisadas, a operacionalização das atividades seguiu o modo convencional e usualmente adotado, ou seja, sem uma estrutura sistemática de tomada de decisão, um dos problemas crônicos dos conselhos gestores de UCs, conforme descrito no subitem 1.2.1, Capítulo 1, Contextualização.

Portanto, a única diferença entre os conselhos gestores das UCs pesquisadas é que aqueles instituídos a partir de 2010 tiveram o suporte do método SISUC em todas as suas reuniões até o ano de 2014, quando encerraram-se as atividades de campo da presente pesquisa. A tentativa de seguir princípios de boa governança de áreas protegidas, como a inclusão social, transparência e responsabilidade (v. Quadro 4.5, Capítulo 4, Resultados), promovidos por meio do suporte técnico oferecido pelo SISUC, fizeram parte da rotina dos conselhos gestores instituídos a partir de 2010, o que estimulou a atuação de seus conselheiros, um efeito lembrado por Lockwood (2010) para o caso de áreas protegidas.

Outra variável testada foi a idade do plano de manejo/gestão das UCs pesquisadas (i.e. tempo transcorrido desde a sua aprovação). No início da implantação do SISUC (2010), o plano de manejo da Resex Unini havia sido recentemente finalizado (ainda que aprovado somente em 2014) e, no caso do PE do Rio Negro (Setor Sul) e do PE do Rio Negro (Setor Norte), os planos de gestão tinham menos de cinco anos. 
Infelizmente, a dinâmica de gestão de UCs tem um caráter remediador (Carrillo \& Luz, 2013) diante da pouca funcionalidade de planos de manejo (Vasconcelos \& Cases, 2009; Kinouchi, 2014; Marinelli, 2014). Porém, a participação de conselheiros nos diagnósticos e planejamento para elaboração de planos de manejo contribui para que os envolvidos adquiram conhecimentos sobre temas, estratégias e ações importantes localmente. Esse fato viabiliza a recuperação de processos relevantes para gestão local, que outrora fizeram parte dos debates para elaboração dos planos de manejo/gestão ou que foram reconhecidos por esse instrumento, mas não foram colocados em prática, e possibilita a atualização de demandas contextualizadas ao momento em que se encontravam as UCs.

Diante das atuais fragilidades dos planos de manejo (detalhadas no subitem 1.2.2, Capítulo1, Contextualização), a complementaridade e o caráter atualizador promovidos pelo SISUC já haviam sido demonstrados por Pianca et al. (2013) para as Florestas Estaduais (Flotas) de Faro, do Paru e do Trombetas, na Calha Norte do Rio Amazonas, estado do Pará. Ao utilizar os programas dos planos de manejo dessas Flotas para subsidiar o estabelecimento de ações na aplicação do método SISUC, Pianca et al. (2013) descrevem dois efeitos: 1 . ações referentes às dimensões meio ambiente e gestão - as mais comuns em planos de manejo/gestão de UCs - ganharam atualização e detalhamento; e 2. enquanto isso, ações referentes as dimensões econômica e sociocultural - menos comuns na maioria dos planos de manejo/gestão de UC - foram valorizadas e receberam encaminhamentos concretos de ações.

Por isso, além das variáveis atuação da equipe local de gestão nas ações estabelecidas, e idade dos conselhos gestores, a variável idade dos planos de manejo/gestão também ajudou a explicar a evolução na situação dos indicadores (2010-2014), segundo o modelo 1 ( $\mathrm{t}=4,09 ; \mathrm{P}<0,001$, Quadro 4.4, Capítulo 4, Resultados).

Análises a partir do contexto de gestão das UCs pesquisadas apresentaram evidências de que a variável idade da UC também explica mudanças em evolução na situação dos indicadores (2010-2014), favorecendo aquelas criadas há mais tempo: UCs de 5-15 anos (PE do Rio Negro - Setor Norte e PE do Rio Negro - Setor Sul: $t=6,97 ; P<0,001$ ) e UCs $>15$ anos (Parna do Jaú e Parna de Anavilhanas: $t=2,59 ; P=0,01$ ), conforme $o$ modelo 1 (Quadro 4.4, Capítulo 4, Resultados). Uma das explicações para esse resultado pode estar no fato de que, na avaliação de 2010 (v. Quadro 4.1, Capítulo 4, Resultados), de maneira geral, os indicadores das UCs do grupo de proteção integral, criadas há mais tempo (cf. Quadro 2.2, Capítulo2, Área de Estudo) estavam em condições menos 
favoráveis do que as UCs do grupo de uso sustentável, criadas no máximo cinco anos antes dessa avaliação (i.e. Resex Unini e RDS do Rio Negro).

Por outro lado, as avaliações dos indicadores dessas duas UCs de uso sustentável em 2010, época da instituição de seus conselhos gestores, podem ter gerado um ambiente de otimismo e expectativa que influenciou as opiniões dos conselheiros. Como a criação de UCs de uso sustentável reconhece garantias para manutenção de modos de vida tradicionais e ampliam oportunidades de desenvolvimento local (e.g. Peres, 2011), opiniões sobre a situação de alguns indicadores podem ter sido superestimadas na avaliação realizada em 2010. Com isso, ao serem reavaliados em 2014, de maneira geral, a situação dos indicadores das UCs de uso sustentável evoluíram relativamente menos do que os indicadores das UCs de proteção integral.

Assim como os modelos GLMs, os resultados obtidos com testes chi-quadrado reforçam o efeito da variável teórica 'contexto de gestão' sobre a variável situação dos indicadores em 2014 e a associação entre 'contexto de gestão' e a variável teórica 'método SISUC'. UCs criadas há menos tempo, com conselhos gestores instituídos na época da implantação do SISUC e com planos manejo/gestão mais recentes, apresentaram indicadores em situação mais favorável que os das UCs nas quais essas variáveis apresentam-se em condições diferentes.

Este fato, juntamente com a constatação de ausência de influência, tanto das variáveis gerência do conselho gestor sobre as ações estabelecidas como da atuação do conselhos gestores nas ações estabelecidas sobre a variável situação dos indicadores em 2014, reforçam que a variável teórica explicativa da melhoria das condições socioecológicas não são os 'conselhos gestores', mas sim o 'método SISUC' e sua associação com o 'contexto de gestão' das UCs pesquisadas.

\subsubsection{Institucionalização da nova trajetória}

A última fase de transformação deliberada do sistema socioecológico é a fase de institucionalização da nova trajetória, marcada pelo estabelecimento de rotinas que valorizam a estabilidade dinâmica e o ganho de escala ( $c f$. Moore et al., 2014). 
Relações interescalares foram constatadas por meio da integração de resultados de cada UC e alguns aspectos comuns para o conjunto de UCs pesquisadas. Esses pontos foram apresentados e disponibilizados para o conselho gestor do MBRN (Anexo I) e subsidiou reflexões e decisões sobre o plano de ação para o território de sua abrangência.

Essa ligação entre grupos e conhecimentos na escala vertical, do local para o regional, dos conselhos gestores de cada UC para o conselho gestor do MBRN, é citada por Armitage et al. (2008) para outra ocasião e materializa a conectividade, um dos princípios da boa governança de áreas protegidas ao qual o SISUC mostrou-se aderente.

O subprocesso de estabelecimento de rotinas da fase de institucionalização da nova trajetória foi alcançado a partir da consolidação dos procedimentos técnicos de suporte à governança local das UCs pesquisadas e da manutenção dos dois ciclos concêntricos de monitoramento (i.e. desempenho de ações e indicadores). 0 monitoramento colaborativo, executado por meio de dois ciclos aninhados, promoveu processos de aprendizagem e adaptação em diferentes escalas estruturais e temporais e potencializou-se na escala geográfica, característicos da governança adaptativa (Plummer et al., 2013; Simonsen et al., 2014).

Formas colaborativas de governança são dinâmicas, processos de resolução de problemas para os quais a aprendizagem sobre mudanças no sistema socioecológico é essencial (Carlsson \& Berkes, 2005) e fornecem a base para ação integrada requerida para responder aos mecanismos de retroalimentação socioecológicos. A reavaliação dos indicadores em 2014 evidenciou mecanismos de retroalimentação entre as mudanças ocorridas no sistema socioecológico das UCs e aquelas promovidas no âmbito de seus conselhos gestores durante a fase de transição (item 5.1.2).

Reinaugurando um novo ciclo do SISUC em 2014, o conjunto de ações estabelecidas serviu de base para o plano de ação do conselho gestor das UCs Parna do Jaú, Parna de Anavilhanas e RDS do Rio Negro, e deu início à retomada do monitoramento do desempenho das ações atualizadas, a ser realizado até 2016-2017.

Esforços empregados nos mecanismos de controle social aliados à aprendizagem multiescalar, como a possibilitada pelo SISUC ao fomentar o conselho gestor do MBRN, são destacados na literatura (e.g. Armitage et al., 2008; Pahl-Wostl, 2009; Simonsen et al. 2014), pois incorporam visão analítica e tornam a governança do território mais robusta (Armitage et al., 2008). Essa abordagem contribui para que o conselho gestor possa lidar com perturbações inesperadas e as incertezas dos sistemas socioecológicos complexos 
(Poteete et al., 2013) nas diferentes escalas (Cumming et al., 2015): em cada UC, no conjunto de UCs pesquisadas e no MBRN.

\subsection{CONSIDERAÇõES FinAIS}

Conselhos gestores, planos de manejo e métodos de avaliação de UCs são pilares estruturantes para o acompanhamento, o debate e a tomada de decisão local sobre a gestão de uma UC. 0 fato de esses instrumentos não estarem cumprindo seus propósitos de maneira adequada, gera limitações para os mecanismos funcionais de gestão, o que compromete processos que poderiam ser socialmente mais legítimos, atender melhor o contexto local e ter maior aderência à dinâmica dessas áreas protegidas na Amazônia. Assim como esse cenário não é particular às UCs da Amazônia, as evidências aqui apresentadas não devem ser usadas para defender, de maneira equivocada, que esses instrumentos devam ser substituídos ou excluídos do processo de gestão de UC.

Entretanto, quinze anos após o SNUC (2000) ter sido instituído, é evidente que aprimoramentos de alguns processos no âmbito local de UCs são necessários. Os conselhos gestores demandam mecanismos eficientes de participação e comprometimento. Planos de manejo são importantes, mas as diretrizes de gestão precisam ser contextualizadas e passíveis de adaptações a diferentes situações que influenciam a dinâmica das UCs. Os métodos e as ferramentas que subsidiam os debates de gestão devem ir além da avaliação da situação local, e fornecer suporte para a obtenção de respostas e indicações de ações viáveis para a resolução de problemas, as quais devem ser monitoradas e avaliadas.

Tornam-se necessários procedimentos que melhorem o sistema de geração, acesso e disponibilização de informação e conhecimento, de modo a reduzir a desigualdade de condições entre os diversos atores dos conselhos, e promover uma via de duas mãos entre os grupos e/ou instituições e esses atores que os/as representam. Para que sejam mais estratégicas e menos paliativas, decisões locais de gestão devem ser baseadas na constante reflexão coletiva sobre as intervenções estabelecidas. Assim, valoriza-se o aprendizado e o desenvolvimento de habilidades e competências que tornam a comunidade envolvida mais orgânica e qualificada. Por fim, mas não menos importante, todos esses aspectos não devem ser considerados necessidades momentâneas, das quais deve-se esperar resultados imediatos. Pelo contrário, tais fatores precisam ser incorporados e mantidos por meio de investimentos contínuos, que permitam consolidar um modo de governança que fortaleça a efetividade de UCs. 
0 presente trabalho de pesquisa permite a constatação de que existem alternativas viáveis para contribuir com esses processos, e que não significam rompimento com aqueles em prática. De fato, trata-se de dar mais atenção para as adequações necessárias, aproveitar lições aprendidas a partir dos avanços conquistados, e enfrentar os novos desafios que continuarão a surgir, diante do curto histórico do SNUC e da amplitude que representa sua implantação.

\subsubsection{O SISUC para além desta tese}

Mesmo antes da finalização da presente tese, o SISUC vem sendo utilizado por gestores e pesquisadores em novos contextos. 0 próprio método SISUC é fruto de um processo contínuo de consultas e debates iniciados em 2009 e que já envolveu cerca de 100 organizações, entre instituições governamentais, da sociedade civil, acadêmicas e dos movimentos sociais dos nove estados da Amazônia Legal e do Distrito Federal. Essa sinergia de esforços tem contribuído para reflexões coletivas importantes para o fortalecimento do Sistema Nacional de Unidades de Conservação. Entre estas pode-se citar: i. finalidades e contribuições (locais e regionais) das diferentes abordagens de monitoramento e avaliação de UCs; ii. conceitos práticos e mecanismos de gestão participativa e controle social de UCs das diferentes categorias de manejo; iii. procedimentos sistemáticos e estratégicos de trabalho nos conselhos gestores; e iv. aprendizados sobre sistemas integrados de governança e gestão.

Em cinco anos, o SISUC foi implantado em um total de 12 UCs, dos estados do Amazonas (incluindo as estudadas no presente trabalho), Pará, Sergipe e Rio de Janeiro, incluindo os grupos de proteção integral e de uso sustentável. Cerca de 80 pessoas, entre gestores públicos (estaduais e federais) e técnicos de organizações não-governamentais, atuantes em 57 UCs de seis estados da Amazônia e no DF, receberam treinamento para o uso da ferramenta para aplicação do SISUC Marinelli et al. (2015).

O método SISUC foi apresentado em cerca de 20 eventos técnicos e científicos, regionais, nacionais e internacionais, dos quais resultaram publicações completas (e.g. Marinelli, 2014) capítulos de livros (e.g. Marinelli, 2014) e artigos (Brusnello \& Marinelli, 2014; Marinelli et al., 2015).

Academicamente, o método SISUC despertou a atenção de instituições de ensino e pesquisa de diferentes regiões do país e foi utilizado como objeto de estudos conduzidos na Amazônia e na Mata Atlântica. O trabalho de mestrado de Mesquita (2014), 
desenvolvido no Instituto Nacional de Pesquisas da Amazônia (INPA), utiliza os resultados alcançados pela aplicação do método SISUC nas Flotas de Faro, do Trombetas e do Paru, na Calha Norte do rio Amazonas (PA), como casos de contribuição do SISUC para o controle social no âmbito dos conselhos gestores dessas UCs. Também na Amazônia, ao pesquisar aplicações do SISUC, em seu mestrado no Jardim Botânico do Rio de Janeiro, Brusnello (2015), conclui que esse método tem características que permitem o uso no monitoramento de planos de uso e acordos de gestão, para os quais até o momento não existe proposta amplamente reconhecida e aceita.

Na Mata Atlântica, Spindel (2014) usou o SISUC como método de pesquisa em seu trabalho de conclusão de curso de graduação na Universidade de São Paulo. Ao aplicar o SISUC na Reserva Ecológica da Juatinga (RJ), uma UC em processo de recategorização, os resultados da avaliação dos indicadores da situação socioecológica local foram usados para embasar a proposição de uma Reserva de Desenvolvimento Sustentável. Também na Mata Atântica, Silva (2016), em seu trabalho de mestrado pela Universidade Federal de Sergipe, fez uma aplicação convencional do SISUC no Refúgio de Vida Silvestre Mata do Junco e reconheceu a contribuição do método para a capacitação do conselho gestor e a qualificação da gestão local.

Em linhas gerais, esses estudos sugerem que o SISUC oferece mais clareza em aspectos fundamentais, capazes de influenciar a própria forma de promover a gestão de UCs no âmbito do arcabouço legal estabelecido para o país. Indicam também que sua utilização poderá ser ampliada e, com adaptações que certamente serão necessárias, levar a metodologia a novas aplicações.

O potencial de replicação e ganho de escala do SISUC tem provocado discussões de sua aplicação em outros conselhos gestores de UCs. Nesse sentido, o SISUC tem servido de referência para debates sobre políticas públicas federais ${ }^{8}$ e para construção de outros sistemas de monitoramento e indicadores socioecológicos', e vem gerando indagações

\footnotetext{
8 Oficina Debates e Revisão da Estratégia Nacional de Educação Ambiental e Comunicação em Unidades de Conservação (ENCEA), promovida pelo Ministério do Meio Ambiente e Instituto Chico Mendes de Conservação da Biodiversidade (2014); Encontro da Comunidade de Aprendizado em Gestão Participativa de Unidades de Conservação, promovido pelo Instituto Chico Mendes de Conservação da Biodiversidade (2014); Oficina de Revisão das Instruções Normativas 02/2007 (Conselhos Deliberativos) e 11/2010 (Conselhos Consultivos), promovida pelo Instituto Chico Mendes de Conservação da Biodiversidade (2013); e Reunião do Grupo de Trabalho sobre Monitoramento e Avaliação de UCs do CONAMA (CTGTUC), promovida pelo Ministério do Meio Ambiente (2013).

9 Sistema Integrado de Gestão de Informação e Conhecimento do Fundo Vale: indicadores de desempenho (institucionais e do portfolio de projetos) e de impacto (sobre territórios e populações beneficiárias) (2015); Sistema de Garantia e Rastreabilidade da Produção Agroextrativista de Áreas Protegidas - Origens Brasil ${ }^{\circledR}$ (Imaflora): indicadores para monitoramento e avaliação de impactos (2015).
} 
sobre possibilidades de adaptação da ferramenta com vistas à sua utilização em Terras Indígenas (Marinelli et al., 2015).

Apesar de vir contribuindo de maneira mais ampla do que se vislumbrou originalmente, deve ser reforçado que o SISUC não propõe a ser um modo alternativo de gestão, e não foi concebido com a pretensão de substituir qualquer dos instrumentos utilizados atualmente no apoio à gestão de UC. A inserção do SISUC na governança tem caráter complementar à gestão de UCs. Sendo uma ferramenta de suporte, não resolve todas as limitações e desafios que fazem parte da atuação de conselhos gestores e da gestão local. No mais, se, de fato, busca-se a efetividade das UC do Brasil e sendo elas um bem público, nada pode substituir o comprometimento do Estado no sentido de incentivar as experiências conduzidas pela própria sociedade, e promover a apropriação de bons resultados como contribuição ao aprimoramento da gestão de áreas protegidas.

Como qualquer método sistemático, o SISUC possui limitações e, à medida em que vem sendo utilizado, surgem novas perguntas e necessidades de análise e de adaptações. Mesmo porque, apesar do aprendizado contribuir para a redução de incertezas, questões importantes (como reconhecê-las, representá-las, e como lidar com elas nas escalas temporais), continuam sendo um desafio. Como resolver essas limitações e ampliar as capacidades preditivas sobre os efeitos das intervenções propostas, por exemplo, ainda são questões em aberto.

Como o presente trabalho de pesquisa constitui-se na primeira análise acadêmica do funcionamento do SISUC voltada a fatores-chave e mecanismos, novos procedimentos metodológicos precisam ser explorados. Para citar alguns importantes: a viabilidade e os efeitos da priorização de mais de seis indicadores; os efeitos da freqüência dos conselheiros nas atividades do SISUC e de mudanças na composição dos grupos de conselheiros monitores sobre os resultados obtidos; o impacto do material de comunicação utilizado durante as atividades e da divulgação de relatórios na atuação dos conselheiros, entre outros.

Da mesma forma, os achados do presente trabalho de pesquisa trazem à tona novos olhares e demandas de análise sobre o efeito do SISUC nas condições socioecológicas, como por exemplo: a reincidência na priorização de indicadores entre ciclos diferentes de aplicação do SISUC; o efeito das justificativas do desempenho de ações sobre a situação dos indicadores; os impactos do uso de subsídios que emergem das próprias UCs durante a aplicação do SISUC, sobre a governança e as condições socioecológicas de mosaicos de áreas protegidas. 
Finalizando, no campo teórico, os resultados apresentados nesta tese evidenciam que o método SISUC apresenta um conjunto de características inerentes a princípios de cogestão adaptativa, que merecem ser investigados em profundidade. A cogestão adaptativa é um processo pelo qual arranjos institucionais e conhecimento ecológico são testados e revistos em um contínuo processo dinâmico e auto-organizado de 'aprenderfazendo' (Folke et al., 2002). Nesse sentido, seria interessante prosseguir na análise dos mecanismos de retroalimentação entre os sistemas social e socioecológico identificados no presente trabalho (subitem 5.1.2).

\subsubsection{A caminho das conclusões}

Em se tratando dos aspectos investigados nesta tese, apesar de menos tangíveis que resultados e desdobramentos quantificáveis, o incremento da participação, da transparência, do aprendizado (institucional, social e técnico), do intercâmbio de informações e o empoderamento dos conselhos gestores, são essenciais aos elementos do ciclo de gestão, que levam à efetividade de áreas protegidas ( $c f$. Hockings et al., 2006). Retomando os elementos que fazem parte do ciclo de gestão (item 1.1, Capítulo 1, Contextualização) descrito por Hockings et al. (2006), o contexto propiciado pelo SISUC contribui para o desenvolvimento de capital humano e de conhecimentos (Insumos), permite debates e decisões mais qualificadas dentro dos conselhos gestores (Processos), remete a diretrizes mais assertivas para mudar a realidade das ameaças (Planejamento) e influencia a atuação dos interessados na gestão (Contexto), potencializando avanços (Resultados, Produtos e Desfechos) de diferentes ordens e escalas.

Profissionais que atuam na gestão de UCs precisam aprender sobre mudanças e desafios de gestão que continuarão se apresentando, e por isso as respostas que essas áreas protegidas darão a isso e as formas de lidar com sua gestão fortalecem a aprendizagem social e promovem abordagens adaptativas (Williams \& Brown, 2014).

Para isso, organizações envolvidas na gestão das UCs precisam fazer uma transição do tradicional sistema de "comando e controle" para uma gestão mais inclusiva, colaborativa, tolerante a riscos e flexível (Stankey et al., 2005). Para Williams \& Brown (2014) existe uma tensão natural em se lançar na abordagem adaptativa, já que isso remete a incertezas e à quebra de paradigmas institucionais. Porém, barreiras institucionais e pouco esforço dos envolvidos são frutos de desconhecimento de processos de governança e gestão alternativos àqueles convencionalmente adotados, o que precisa ser superado para que sejam repensados riscos e estabelecidas condições que 
encorajem e conduzam em direção à aprendizagem oferecida pelas abordagens adaptativas.

Decisões sobre a gestão das UCs seguirão sendo tomadas todos os dias e sob condições complexas e urgentes. Buscar aprimorá-la deve ser o fator motivador para fazer da gestão de áreas protegidas um processo consciente de intervenção orientada a objetivos predeterminados para mudar a realidade e alcançar as condições almejadas. Ao privilegiar o papel dos conselhos gestores, o método SISUC tem dado contribuições relevantes para esse processo. 


\section{Capítulo 6}

\section{Conclusões}

Quinze anos após a instituição do SNUC, parte dos avanços conquistados no marco regulatório de UCs ainda não são praticados, localmente, de forma adequada. Limitações nos procedimentos para tomada de decisão no âmbito dos conselhos gestores e para a atuação de conselheiros, planos de manejo incompletos e não adaptáveis à dinâmica de sistemas socioecológicos, métodos de avaliação de UCs restritos quanto aos temas abordados, participação do público usuário e aplicação de resultados obtidos, ainda não permitem que esses instrumentos sejam efetivos no apoio à governança local.

O comprometimento da governança local de UCs, incluindo mecanismos para o seu acoplamento à gestão, constitui-se em problema crônico e tem gerado efeitos negativos sobre a efetividade dessas áreas protegidas, o que é refletido no baixo desempenho de processos participativos de planejamento, nos resultados das ações planejadas e no monitoramento de resultados de gestão.

Apesar deste cenário não constituir-se em exceção entre países em desenvolvimento, ele aponta para desafios importantes a serem superados pelas UCs do Brasil para que a governança local contribua para efetividade dessas áreas protegidas. A presente pesquisa investiga esses aspectos a partir da análise de instrumentos de apoio à governança local e sob abordagem de sistemas socioecológicos.

O Sistema de Indicadores Socioambientais para UCs (SISUC) foi desenvolvido como ferramenta pública de monitoramento e avaliação de UCs, destinada a oferecer suporte para o trabalho do conselho gestor, contribuir para o fortalecimento da gestão participativa e ampliar o controle social dessas áreas protegidas. Ainda que, teoricamente, o método SISUC atenda características da abordagem socioecológica, não se sabe se, ou em que medida, o uso dessa ferramenta - estruturada em atividades de monitoramento e avaliação - pode contribuir para tratar dos problemas de governança local de UCs. 
Diante do exposto, o trabalho de pesquisa apresentado nesta tese foi desenvolvido no intuito de responder três perguntas de pesquisa:

(1) Que avanços a implantação do SISUC propicia no âmbito do conselho gestor de UCs?

(2) A implantação do SISUC no âmbito do conselho gestor de UCs tem implicações sobre as condições socioecológicas locais?

(3) Em caso de resposta positiva às perguntas anteriores, que fatores-chave levam a esses resultados e quais os principais mecanismos que emergem desse processo de mudança?

Análises multimétodos demonstram que, entre os anos de 2010 e 2014, as UCs do Mosaico de Áreas Protegidas do Baixo Rio Negro, nas quais o método SISUC foi implantado, passaram por mudanças verificadas em diferentes âmbitos e escalas. Em linhas gerais, os resultados dão suporte à conclusão que o método SISUC promoveu a transformação deliberada do sistema socioecológico das UCs pesquisadas. Esse processo teve como fator-chave o aprimoramento da governança local, que desencadeou mecanismos de retroalimentação entre o sistema social (no âmbito dos conselhos gestores) e o sistema socioecológico (no âmbito das UCs) e culminou na melhoria da efetividade das UCs.

A implantação do método SISUC propiciou o estabelecimento de um sistema estruturado de tomada de decisão que agregou os princípios de responsabilidade, transparência, resiliência, inclusão e justiça às atividades do conselho gestor das UCs e qualificaram a governança local. Três foram os fatores-chave que levaram ao aprimoramento da governança local: atividades de monitoramento e avaliação de indicadores e de ações, que permitem a mensuração de variáveis rápidas e lentas que retroalimentam-se; e a prática da gestão adaptativa, subsidiada pelos resultados do monitoramento e avaliação, que propiciam a adaptação de decisões em duas instâncias diferentes.

O sistema de monitoramento, avaliação e gestão adaptativa promovidos pelo método SISUC desencadearam mecanismos de comunicação, aprendizagem social, adaptação e tomada de decisão apoiados e desenvolvidos por procedimentos sistemáticos, rotinas de trabalho e uso de material de suporte às atividades durante as reuniões do conselho gestor das UCs. Essas condições estimularam a participação e o envolvimento dos conselheiros nos debates, promoveram fluidez na comunicação e o 
compartilhamento de decisões, os quais foram determinantes para o aprimoramento da governança local.

Além do aprimoramento da governança local, a implantação do método SISUC propiciou a melhoria das condições socioecológicas locais, evidenciada pela melhoria da situação dos indicadores (de cada UC, do conjunto UCs e dos indicadores das diferentes dimensões avaliadas) e no alcance das metas estabelecidas para os indicadores priorizados. Portanto, com base nas análises estatísticas e nos resultados obtidos com os modelos lienares generalizados (seção 4.3), são fortes os indicativos de que, ao promover o aprimoramento da governança local no âmbito dos conselhos gestores de UCs (desencadeando mecanismos e processos subsequentes), o método SISUC foi o principal fator-chave para melhoria das condições do sistema socioecológico, seguido do contexto de gestão das UCs, que também esteve correlacionado ao método SISUC.

Dois foram os mecanismos para que o método SISUC contribuísse para melhoria das condições socioecológicas locais das UCs: a priorização de indicadores e, principalmente, o desempenho das ações que foram estabelecidas e monitoradas com fins de favorecer o alcance das metas dos indicadores que foram priorizados. Os mecanismos referentes ao contexto de gestão das UCs que contribuíram para melhoria das condições socioecológicas locais estiveram ligados a temporalidade, sendo eles: plano de manejo/gestão com conteúdo atualizado, tempo transcorrido desde a criação da UC e atuação da equipe de gestão nas ações estabelecidas.

Os resultados gerados a partir da implantação do método SISUC corroboram aqueles descritos na literatura internacional especializada, no que diz respeito a fatoreschave e mecanismos envolvidos em processos de governança e seus vínculos com a gestão de sistemas socioecológicos, e são também inovadores em relação ao sistema de governança de UCs do Brasil. 0 sistema de governança usualmente adotado no âmbito do conselho gestor de UCs não oferece condições adequadas para o exercício do planejamento, controle e geração de informações para decisão. Essa situação dificulta a adoção de práticas adequadas para atender o marco regulatório da governança e seu acoplamento à gestão local, compromete elementos do ciclo de gestão de UCs e, consequentemente, o sucesso no alcance dos objetivos para os quais essas áreas protegidas são criadas.

Em contraponto a esses problemas, os resultados obtidos no presente trabalho de pesquisa conduzem à conclusão de que a implantação do método SISUC promove o estabelecimento de procedimentos sistemáticos de suporte às atividades dos conselhos 
gestores, incentiva o engajamento de conselheiros, estabelece um sistema estruturado de tomada de decisão, e favorece o acoplamento da governança local à gestão, o que leva à melhoria da efetividade e, assim, à consecução dos objetivos das UCs. Com isso, alguns dos problemas originários das fragilidades e limitações dos instrumentos de apoio à governança local de UCs são reduzidos e condições importantes são oferecidas para fortalecer a gestão efetiva dessas áreas protegidas.

Ressalte-se que, caso não sejam reduzidas as fragilidades e limitações dos instrumentos de apoio à governança local de UCs, a melhoria da efetividade dessas áreas protegidas pode ficar à mercê de mecanismos de retroalimentação de sistemas socioecológicos complexos. Com efeito, observa-se que os resultados e desfechos da implantação de infraestrutura para gestão propiciam uma tendência de melhora inicial na gestão das UCs. Entretanto, depois de a UC alcançar um patamar de gestão específico, a ausência de mecanismos que promovem a busca intencional por mudanças pode levar fatores diretos e indiretos, relacionados a diferentes dimensões e níveis hierárquicos, a retroagir e influenciar mecanismos de gestão e, assim, limitar os avanços previamente observados. Dessa forma, o sistema de gestão pode se tornar incapaz para atender às necessidades da realidade local de cada área protegida e afastar as UCs dos objetivos para os quais foram criadas.

Na teoria, a presente tese defende que o SISUC funciona como método que induz e catalisa mecanismos de retroalimentação balanceada entre o sistema social e o sistema socioecológico, os quais se combinam e podem gerar mudanças favoráveis em ambos. A complementaridade e a integração dos processos de monitoramento e avaliação (de indicadores e de ações) com a gestão adaptativa são características do processo de governança local promovido pelo método SISUC no âmbito do conselho gestor. Dessa interação emergem mecanismos (variáveis endógenas) que contribuem para melhoria dos indicadores (variáveis exógenas) nas diferentes dimensões do sistema socioecológico.

Finalizando, o presente trabalho de pesquisa demonstra, na prática, que a indução e a catalisação intencional de mudanças por meio da estruturação da governança local, promovidas com apoio de ferramentas de suporte aos conselhos gestores de UCs, inspiradas em abordagem socioecológica, participativa, contextualizada, adaptativa e funcional, podem constituir-se em alternativa complementar aos demais instrumentos de apoio à governança local, e assim contribuir para a efetividade de Unidades de Conservação da Amazônia. 


\section{Referências Bibliográficas}

Abdala, G. C. (2002). Uma abordagem socioecológica do parque nacional de Brasília estudo de caso. Brasília: UNESCO, Cadernos UNESCO BRASIL. Série Meio Ambiente; 4.

Abrams, P.; Borrini-Feyerabend, G.; Gardner, J.; Heylings, P. (2003). Evaluating governance: a handbook to accompany a participation process for a protected area. Parks Canada and Tilcepa - Theme on Indigenous and Local Communities, Equity and Protected Areas of IUCN. CEESP/WCPA. 117p.

Alcântara, M. M., \& Angelo Furlan, S. (2011). Gestão compartilhada e comunitária em áreas protegidas: reflexões no vale do ribeira. São Paulo, Brasil: 1-20.

Allen, C. R.; Fontaine, J.J.; Pope, K. L.; Garmestani, A. S. (2011). Adaptive management for a turbulent future. Journal of Environmental Management, 92: 1339-1345.

Armitage D.; Marschke, M.; Plummer, R. (2008). Adaptive co-management and the paradox of learning. Global Environmental Change, 18: 86-98.

Armitage, D. R., Plummer, R., Berkes, F., Arthur, R. I., Charles, A. T., Davidson-Hunt, I. J., ... Wollenberg, E. K. (2009). Adaptive co-management for social-ecological complexity. Frontiers in Ecology and the Environment, 7(Ma 2005): 95-102.

Armitage, D., Fast, H., Newkirk, K., Ayles, B., \& Charles, A. (2007). Adaptive comanagement: a policy dialogue. In OMRN Conference. ACM Working Group; Ocean Management Research Network.

Bellamy JA, Walker DH, McDonald GT, and Syme GJ. (2001). A sys- tems approach to the evaluation of natural resource management initiatives. J Environ Manage 63: 40723.

Berkes, F. (2009). Evolution of co-management: Role of knowledge generation, bridging organizations and social learning. Journal of Environmental Management, 90(5): 1692-1702.

Berkes, F., J. Colding, and C. Folke, editors. (2003). Navigating social-ecological systems: building resilience for complexity and change. Cambridge University Press, Cambridge, UK.

Berkes, F.; Seixas, C.S. (2005). Building Resilience in Lagoon Social-Ecological Systems: A Local Level Perspective. Ecosystems, 8: 967-974.

Borges, S.; Iwanaga, S.; Moreira, M.P.; Durigan, C.C. (2007). Uma análise geopolítica do atual sistema de unidades de conservação na Amazônia brasileira. Revista Política Ambiental, 4. 
Borrini-Feyerabend, G.; Dudley, N.; Jaeger, T.; Lassen, B.; Broome, N. P.; Phillips, A.; Sandwith, T. (2014). Gobernanza de áreas protegidas: de la comprensión a la acción. No. 20 de la Serie Directrices para buenas prácticas en áreas protegidas. Gland, Suiza: UICN.

Bown, N. K.; Gray T. S.; Stead, S. M. (2013). Co-management and adaptive co-management: Two modes of governance in a Honduran marine protected area. Marine Policy, 39: 128-134.

Brusnello, L.D. (2015). Acordo de Gestão de Reserva Extrativista: análise histórica e subsídios ao monitoramento. Dissertação de Mestrado. ENBT, Instituto de Pesquisas Jardim Botânico do Rio de Janeiro. 125p.

Carrillo, A.C.; Luz, L. (2013). Reflexões sobre conselhos gestores de unidades de conservação federais apoiadas pelo WWF-Brasil. Relatório: Produto 3. WWF-Brasil. 65p.

Carlsson, L.; Berkes, F. (2005). Co-management: concepts and methodological implications. Journal of Environmental Management, 75: 65-76

Castro, I. (2009). Aprendizados com conselhos gestores das unidades de conservação no Programa Arpa. Programa Áreas Protegidas da Amazônia e Cooperação Técnica Alemã - GTZ. Série Cadernos Arpa. Número 2. Brasília: MMA. 56p.

Caves, J. K., Bodner, G. S., Simms, K., Fisher, L. a., \& Robertson, T. (2013). Integrating collaboration, adaptive management, and scenario-planning: Experiences at Las Cienegas National conservation area. Ecology and Society, 18(3).

Chape, S., Spalding, M., Jenkins, M.D. (2008). The World's Protected Areas: Status, Val- ues and Prospects in the 21st Century. Prepared by the UNEP World Conservation Monitoring Centre. University of California Press, Berkeley, USA.

Coad, L., Leverington, F., Burgess, N. D., Cuadros, I. C., Geldmann, J., Marthews, T. R., ... Hockings, M. (2013). Progress towards the CBD protected area management effectiveness targets. Parks, 19(1): 13-23.

Conrad, C. C.; Hilchey, K.G. (2011). A review of citizen science and community-based environmental monitoring: issues and opportunities. Environ Monit Assess, 176: 273-291.

Cozzolino, L. F. (2005). Unidades de Conservação e os processos de Governança Local: o caso da APA do Sana (Macaé, RJ). Rio de Janeiro, dissertação de Mestrado, Programa EICOS, IP, UFRJ.

Cozzolino, L. F., Irving, M. D. A., \& Soares, D. G. (2015). Gestão de áreas protegidas : análise dos marcos legais à luz dos princípios de governança democrática, 138-156.

Cumming, G. S., and J. Collier. (2005). Change and identity in complex systems. Ecology and Society 10:29. 
Cumming, G. S.; Allen, C. R.; Ban, N. C.; Biggs, D.; Biggs H. C.; Cumming, D. H. M.; Vos, A. D.; Epstein, G.; Etienne, M.; Maciejewski, K.; Mathevet, R.; Moore, C.; Nenadovic, M.; Schoon, M. (2015). Understanding protected area resilience: a multi-scale, socialecological approach. Ecological Applications, 25(2): 299-319.

Cundill, G.; Fabricius, C. (2009). Monitoring in adaptive co-management: Toward a learning based approach. Journal of Environmental Management, 90: 3205-3211.

D’Antona, R.J.G.; Reis, N.J.; Maia, M.A.M.; Rosa, S.F.; Nava, D.B. (2007). Projeto “Materiais de construção na área de Manacapuru - Iranduba - Manaus - Careiro (Domínio Baixo Solimões). Manaus: CPRM - Serviço Geológicos do Brasil.

Dudley, N. (2008) (Org.). Directrices para la aplicación de las categorías de gestión de áreas protegidas. Gland, Suiza: UICN. x + 96pp.

Dudley, N., Stolton, S., Belokurov, A., Krueger, L., Lopoukhine, N., MacKinnon, K., Sandwith, T. and Sekhran, N. (2010) Natural Solutions: Protected areas helping people cope with climate change. IUCNWCPA, TNC, UNDP, WCS, The World Bank and WWF, Gland, Switzerland, Washington DC and New York, USA.

Ervin, J. (2003a) Rapid assessment of protected area management effectiveness in four countries. BioScience 53/9, pp. 833-841.

Ervin, J. (2003b) WWF: Rapid Assessment and Prioritization of Protected Area Management (RAPPAM) Methodology. WWF, Gland, Switzerland.

Folke, C., Carpenter, S., Elmqvist, T., et al., (2002). Resilience for sustainable development: building adaptive capacity in a world of transformations. In: Rainbow Series 3. International Council for Scientific Unions (ICSU), Paris.

Folke, C., Colding, J., Berkes, F. (2003). Synthesis: building resilience and adaptive capacity in social-ecological systems. In: Berkes, F., Colding, J., Folke, C. (Eds.), Navigating Social-Ecological Systems: Building Resilience for Complexity and Change. Cambridge University Press, Cambridge, 352-387.

Füssel, H-M. (2007). Vulnerability: a generally applicable conceptual framework for climate change research. Global Environmental Change, 17:155-167.

Garaway CJ and Arthur R. (2004). Adaptive learning: a practical frame-work for the implementation of adaptive co-management - lessons from selected experiences in south and southeast Asia. London, UK: MRAG Ltd.

Garcia, C. A.; Lescuyer, G. (2008). Monitoring, indicators and community based forest management in the tropics: pretexts or red herrings? Biodiversity and Conservation, 17(6): 1303-1317.

Governo do Estado do Amazonas. (2008). Conselhos gestores das unidades de conservação: a participação social que fortalece a conservação da natureza e o desenvolvimento 
sustentável no Amazonas. Secretaria de Estado de Meio Ambiente e Desenvolvimento Sustentável do Amazonas. Manaus: SDS \SEAGA. 27p.

Graham, J., Amos, B., Plumptre, T. (2003). Governance Principles for Protected Areas in the 21st Century. Institute on Governance, Ottawa.

Holling, C.S.; Gunderson L.H. (2002). Panarchy: understanding transformations in human and natural systems. Washington, DC: Island Press.

Heck, N., Dearden, P., McDonald, A., \& Carver, S. (2011). Stakeholder opinions on the assessment of MPA effectiveness and their interests to participate at Pacific Rim National Park Reserve, Canada. Environmental Management, 47: 603-616.

Hockings, M. (2003). Systems for assessing the effectiveness of management in protected areas. BioScience 53:823-832.

Hockings, M., Stolton, S., Leverington, F., Dudley, N., \& Courrau, J. (2006). Evaluating Effectiveness: A Framework for Assessing Management Effectiveness of Protected Areas. Second edition.

Holland, J. (1995). Hidden Order: How Adaptation Builds Complexity. Addison-Wesley, Reading, MA.

Holling, C.S. (Ed.). (1978). Adaptive Environmental Assessment and Management. Wiley, London.

Ibama (Instituto Brasileiro de Meio Ambiente e dos Recursos Naturais Renováveis) (2002). Roteiro metodológico de planejamento, parques nacionais, reservas biológicas e estações ecológicas. Brasília: Ibama.

Ibama (Instituto Brasileiro de Meio Ambiente e dos Recursos Naturais Renováveis); WWF-Brasil (2007). Efetividade de Gestão das Unidades de Conservação Federais do Brasil. Implementação do Método Rappam - Avaliação Rápida e Priorização da Gestão de Unidades de Conservação. Brasília, p.96.

ICMBio (Instituto Chico Mendes de Conservação da Biodiversidade) (2011). Diagnóstico dos conselhos de unidades de conservação federais. Resultado Final. Outubro de 2011.

ICMBio \& WWF Brasil. (2011). Avaliação comparada das aplicações do método Rappam nas unidades de conservação federais, nos ciclos 2005-06 e 2010.

IPÊ (Instituto de Pesquisas Ecológicas) (2010). Diagnóstico para o Plano de Desenvolvimento Territorial do Mosaico de Áreas Protegidas do Baixo Rio Negro Amazonas. Manaus. Versão para revisão do conselho, p.103.

Irving, M.A.; Cozzolino, F.; Fragelli, C.; Sancho, A. (2006). Construção de governança democrática: interpretando a gestão dos parques nacionais no Brasil. In: Áreas Protegidas e Inclusão Social: Construindo novos significados. Marta de Azevedo 
Irving (organizadora). Rio de Janeiro: Fundação Bio-Rio: Núcleo de Produção Editorial. Aquarius.

Izurieta, A.; Sithole, B.; Stacey N.; Hunter-Xenie, H.; Campbell, B.; Donohoe, P.; Brown, J.; Wilson, L. (2011). Developing Indicators of Monitoring and Evaluating Joint Management Effectiveness in Protected Areas in the Northern Territory, Australia. Ecology and Society, 16(3): 9.

Keen, M., Bruck, T., Dyball, R., 2005. Social learning: a new approach to environ- mental management. In: Keen, M., Brown, V., Dyball, R. (Eds.), Social Learning in Environmental Management: Towards a Sustainable Future. Earthscan, London, 321.

Keen, M., Mahanty, S. (2006). Learning in sustainable natural resource management: challenges and opportunities in the Pacific. Society and Natural Resources, 19: 497513.

Kinouchi, M. R. (2014). Plano de manejo: fundamentos para mudança. In: Bensusan, N.; Prates, A. P. (Orgs.). A diversidade cabe na unidade?: áreas protegidas no Brasil. Brasília, IEB.

Leverington, F., Costa, K. L., Pavese, H., Lisle, A., \& Hockings, M. (2010). A global analysis of protected area management effectiveness. Environmental Management, 46: 685698.

Lockwood, M. (2010). Good governance for terrestrial protected areas: A framework, principles and performance outcomes. Journal of Environmental Management, 91: 754-766.

Loureiro, C. F. B., \& Cunha, C. C. (2008). Educação ambiental e gestão participativa de unidades de conservação: elementos para se pensar a sustentabilidade democrática. Ambiente \& Sociedade, 11(2), 237-253.

MACEDO, H. S. (2007). Processos participativos na gestão de Unidades de Conservação. In; Seminário nacional: movimentos sociais, participação e democracia, Florianópolis: UFSC, p.289-304.

Macura, B., Secco, L., \& Pullin, A. S. (2013). Does the effectiveness of forest protected areas differ conditionally on their type of governance? Environmental Evidence, 2(1), 14.

Marinelli C.E.; Salles P.S.B.; Ascher P.; Barreto-Filho, H.T. (2011a). Ciência, Tecnologia e Inovação para Construção de Conhecimento Coletivo sobre Unidades de Conservação da Amazônia Brasileira. In: Marinelli, C.E. (Org.). 10-16pp. De Olho nas Unidades de Conservação: Sistema de Indicadores Socioambientais para Unidades de Conservação da Amazônia Brasileira. São Paulo: Instituto Socioambiental. 
Marinelli, C.E. (2011). De Olho nas Unidades de Conservação: Sistema de Indicadores Socioambientais para Unidades de Conservação da Amazônia Brasileira. São Paulo: Instituto Socioambiental.

Marinelli, C.E. (2014). Cogestão Adaptativa de Unidades de Conservação. In: Bensusan, N. \& A.P. Prates (Orgs.). A Diversidade cabe na Unidade?: áreas protegidas no Brasil. Brasília: IEB Mil Folhas. 333-63p.

Marinelli, C.E.; Carvalho, R.; Pinheiro, P.S.; Bianchini, M.C. (2006). Indicadores de Efetividade da Implementação de Unidades de Conservação Estaduais do Amazonas. Série Técnica Meio Ambiente e Desenvolvimento Sustentável. N8. 63p.

Marinelli, C.E.; Ribeiro, M.B.N.; Bocchini, A.G.; Carlos, H.S.A.; Pianca, C.C. (2015). Seminário Amazônico do Sistema de Indicadores Socioambientais para Unidades de Conservação (SISUC). Relatório. Brasília-DF: Instituto Socioambiental e Grupo Natureza, Sociedade e Conservação. 49p.

Mesquita, J.C (2014). Estratégias de controle social de unidades de conservação: desafios para uma gestão democrática e participativa. Dissertação de Mestrado. MPGAP, Instituto Nacional de Pesquisas da Amazônia (INPA). 152p.

Mezirow, J. (2000). Learning to think like an adult: core concepts of transformative theory. In: Mezirow, J., et al. (Eds.), Learning as Transformation. Jossey-Bass, San Francisco, pp. 3-34.

MMA (Ministério do Meio Ambiente) (2009). Programa Áreas Protegidas da Amazônia (ARPA). Relatório de Atividades: setembro de 2007 a dezembro de 2008. Brasília: $M M A / S B F / D A P / A R P A .74 \mathrm{p}$.

MMA (Ministério do Meio Ambiente). (2006). Plano Estratégico Nacional de Áreas Protegidas (PNAP). Brasília: decreto no 5.758, de 13 de abril de 2006.

Moore, M.; Tjornbo, O.; Enfors, E.; Knapp, C.; Hodbod, J.; Baggio, J. A.; Norstrom, A.; Olsson, P.; Biggs, D. (2014). Studying the complexity of change: toward an analytical framework for understanding deliberate social-ecological transformations. Ecology and Society, 19(4): 54.

Munaretto, S., Siciliano, G., \& Turvani, M. E. (2014). Integrating adaptive governance and participatory multicriteria methods: A framework for climate adaptation governance. Ecology and Society, 19(2). doi:10.5751/ES-06381-190274

Nkhata, B. A.; Breen C. (2010) A framework for Exploring Integrated Learning Systems for the Governance and Management of Public Protected Areas. Environmental Management, 45: 403-413. 
Nobre, D.; Schiavetti, A. (2013). Pesca, Governança E Conselho Deliberativo De Reserva Extrativista: Caso Da Resex De Cassurubá, Caravelas, Bahia, Brasil. Boletim do Instituto de Pesca, 39(4): 445-455.

Nolte, C., Leverington, F., Kettner, A., Marr, M., Nielsen, G., Bomhard, B., Stolton, S., StollKleemann, S., Hockings, M. (2010). Protected area management effective- ness assessments in Europe. In: A Review of Application, Methods and Results. University of Greifswald, Germany.

Olsson, P., Folke, C., \& Berkes, F. (2004). Adaptive comanagement for building resilience in social-ecological systems. Environmental Management, 34(1), 75-90.

Ostrom, E. (2009). A General Framework for Analyzing Sustainability of Social-Ecological Systems. Science. 325 (5939): $419-422$.

Ostrom, E. 2007. A diagnostic approach for going beyond panaceas. Proceedings of the National Academy of Sciences USA 104:15181-15187.

Prado, D.S.; Gomes, A.L.; Chamy, P.; Esteves, A.C.; Seixas, C,S. (2015). Conselhos gestores de áreas protegidas no Brasl: reflexões sobre a participação social, desafios e possibilidades. In: N. Hanazaki et al. (Orgs.). Anais do VII SAPIS e II ELAPIS. Universidade Federal de Santa Catarina. Florianópolis, SC. 23-24pp.

Pahl-Wostl, C. (2009). A conceptual framework for analysing adaptive capacity and multilevel learning processes in resource governance regimes. Global Environmental Change, 19: 354-365.

Palomo, I., Montes, C., Martín-López, B., González, J. a., García-Llorente, M., Alcorlo, P., \& Mora, M. R. G. (2014). Incorporating the social-ecological approach in protected areas in the anthropocene. BioScience, 64(X), 181-191.

Pediaditi, K.; Buono, F.; Pompigna, F.; Bogliotti, C.; Nurlu, E.; Ladisa, G.; Petropoulos, G. P. (2011). A decision support system-based procedure for evaluation and monitoring of protected areas sustainability for the Mediterranean region. J. Earth Syst. Sci. 120 (5): 949-961.

Peres, C.A. (2011). Conservation in sustainable-use tropical forest reserves. Conservation Biology : The Journal of the Society for Conservation Biology, 25(6), 1124-9.

Philippi Jr., A.; Sampaio, C.A.C; Fernandes, V. (2012). Gestão de Natureza Pública e Sustentabilidade. Universidade de Sâo Paulo. Editora Manole.

Plummer, R. (2009). The adaptive co-management process: an initial synthesis of representative models and influential variables. Ecology and Society 14(2): 24.

Plummer, R., Armitage, D. R., \& de Loë, R. C. (2013). Adaptive comanagement and its relationship to environmental Governance. Ecology and Society, 18(1). 
Plummer, R., Crona, B., Armitage, D. R., Olsson, P., Tengö, M., \& Yudina, O. (2012). Adaptive comanagement: A systematic review and analysis. Ecology and Society, 17(3).

Plummer, R., FitzGibbon, J.E. (2007). Connecting adaptive co-manage- ment, social learning and social capital through theory and practice. In: Armitage, D., Berkes, F., Doubleday, N. (Eds.), Adaptive Co- Management: Collaboration, Learning and MultiLevel Governance. University of British Columbia Press, Vancouver.

Plummer, R.; Armitage, D. (2007). A resilience-based freamework for evaluating adaptive co-management: Linking ecology, economics and society in a complex world. Ecological Economics, 61: 62-74.

Poteete, A. R.; Ostrom, E.; Janssen, M. A. (2013). Trabalho em parceria: ação coletiva, bens comuns e múltiplos métodos. São Paulo: Editora Senac São Paulo.

Prabhu R, Ruitenbeek HJ, Boyle TJB, and Colfer CJP. (2001). Between voodoo science and adaptive management: the role and research needs for indicators of sustainable forest management. In: Raison J, Brown A, and Flinn D (Eds). Criteria and indicators for sustain- able forest management. Wallingford, UK: CAB International. IUFRO Research Series 7.

Prado, D. S.; Seixas, C. S.; Berkes, F. (2015). Looking back and looking forward: Exploring livelihood change and resilience building in a Brazilian coastal community. Ocean \& Coastal Management, 113: 29-37.

R Core Team (2015). R: A language and environment for statistical computing. R Foundation for Statistical Computing, Vienna, Austria. URL: http://www.Rproject.org/.

Ricardo, B.; Antongiovanni, M. (2008). Visões do Rio Babel: construindo uma rede socioambiental na maior bacia (cuenca) de águas pretas do mundo. São Paulo: Instituto Socioambiental, pp.103.

Risvoll, C., Fedreheim, G. E., Sandberg, A., \& BurnSilver, S. (2014). Does Pastoralists' participation in the management of national parks in northern Norway contribute to adaptive governance? Ecology and Society, 19(2).

SEDAM (Secretaria de Estado do Desenvolvimento Ambiental de Rondônia) (2005). Metodologia para elaboração de plano de manejo para reservas extrativistas do Estado de Rondônia. Porto Velho: Sedam.

Seixas, C. S. (2005). Abordagens e técnicas de pesquisa participativa em gestão de recursos naturais. In: Vieira, P. F.; Berkes, F.; Seixas, C. S. Gestão integrada e participativa de recursos naturais: conceitos métodos e experiências. Florianópolis: Secco/APED. 
Silva, C.M. (2016). Sistema de Indicadores Socioambientais para Unidades de Conservação (SISUC) como ferramenta para gestão adaptativa no Refúgio de Vida Silvestre Mata do Junco, Capela, Sergipe. Dissertação de Mestrado: Capítulo1. Programa de PósGraduação em Desenvolvimento e Meio Ambiente, Universidade Federal de Sergipe. 86p.

Simonsen, S. H. E. A. (2014). Applying resilience thinking. Seven principles for building resilience. In social-ecological systems, 1-20.

SNUC (Sistema Nacional de Unidades de Conservação da Natureza) (2000). Lei $n^{\circ}$ 9.985, de 18 de julho de 2000; decreto $n^{\circ} 4.340$, de 22 de agosto de 2002. 5.ed. aum. Brasília: MMA/SBF, 2004. p.56.

Souza, F. A. Z. (2012). Desafios e perspectivas da participação social nos conselhos gestores de duas unidades de conservação na baixada santista do Estado de São Paulo, 118.

Spindel, M. (2014). A recategorização da Reserva Ecológica da Juatinga (RJ): uma análise socioambiental. Trabalho de Conclusão de Curso. EACH, Universidade de São Paulo. $72 \mathrm{p}$.

Stacey, N., Izurieta, A., \& Garnett, S. T. (2013). Collaborative measurement of performance of jointly managed protected areas in northern Australia. Ecology and Society, 18(1). doi:10.5751/ES-05273-180119

Stankey, G.H.; Clark, R.N. (2006). Adaptive management: facing up to the challenges. In: Haynes, R.W.; Bormann, B.T.; Lee, D.C.; Martin, J.R. (eds). Northwest Forest plan-the first ten years (1994-2003): synthesis of monitoring and research results. General technical report PNW-GTR-651. U.S. Department of Agriculture, Forest Service, Portland, OR.

Stem, C., Margoluis, R., Salafsky, N., \& Brown, M. (2005). Monitoring and evaluation in conservation: a review of trends and appraoches. Conservation Biology, 19(2): 295309.

Stoll-Kleemann S. (2010). Evaluation of management affectiveness in protected areas: Methodologies and results. Basic and Applied Ecology, 11: 377-382.

Stolton, S., Hockings, M., Dudley, N., MacKinnon, K. and Whitten, T. (2003). Reporting Progress in Protected Areas: A Site-Level Management Effectiveness Tracking Tool. World Bank/WWF Alliance for Forest Conservation and Sustainable Use.

Teixeira, K. A. (2009). Gestão participativa em unidades de conservação: o conselho consultivo da APA do João Leite, Goiás. Dissertação de mestrado do Programa de Pesquisa e Pós-Graduação em Geografia do Instituto de Estudos Sócio-Ambientais IESA, Universidade Federal de Goiás - UFG. 
Trancoso, R.; Carneiro-Filho, A.; Tomasella, J.; Schietti, J.; Forsberg, B.R.; Miller, R.P. (2010). Deforestation and conservation in major watersheds of the Brazilian Amazon. Environmental Conservation, 36 (4): 277-288.

United Nations Development Programme (UNDP). (1997). Good governance for sustainable human development [online]. Source.

United Nations Environment Programme (UNEP). (2002). Global Environmental Outlook 3: Past, Present and Future Perspectives. Earthscan, London.

Vasconcelos, J.; Cases, M.O. (2009). Recomendações para o planejamento de unidades de conservação no bioma Amazônia. Programa Áreas Protegidas da Amazônia - Arpa e Cooperação Técnica Alemã - GTZ. Série Cadernos Arpa. Numero 1. Brasília: MMA. 84p.

Walters, C.J. (1986). Adaptive Management of Renewable Resources. McGraw Hill, New York.

Williams, B. k.; Brown, E. D. (2014). Adaptive Management: From More Talk to Real Action. Environmental Management, 53: 465-479.

WWF-Brasil, ICMBio (2012) Efetividade da Gestão das Unidades de Conservação Federais do Brasil Resultados de 2010. WWF, Brasília, p 72 
Apêndices 


\section{APÊNDICE 1. METODOLOGIA E PROCEDIMENTOS DE APLICAÇ̃̃o do SiSTEMA DE INDICADORES SOCIOAMBIENTAIS PARA UNIDADES DE CONSERVAÇÃo (SISUC)}

\section{Sistema de Indicadores Socioambientais para UCs}

O uso da ferramenta SISUC acontece junto ao conselho gestor de UCs por meio de três tipos de oficinas participativas: 1. oficina de avaliação socioecológica e planejamento estratégico; 2. oficina de monitoramento do desempenho de ações e 3. Oficina de balanço do desempenho de ações e metas. Nos três tipos de oficina, a geração e análise de dados e informações, debates, proposições e encaminhamentos são todos produzidos pelos membros do conselho gestor de UCs com o apoio de um facilitador das atividades ${ }^{10}$.

\section{Oficina de avaliação socioecológica e planejamento estratégico}

A oficina de avaliação socioecológica e planejamento estratégico é executada por meio de seis passos, conforme segue na Figura A.1 (próxima página), e tem duração prevista de dois dias de trabalho no total. No primeiro período de atividades, após a apresentação geral da ferramenta e das atividades programadas (Passo 1), 27 indicadores (econômicos, socioculturais, ambientais e de gestão), representados em escala ordinal por quatro situações ( $v$. lista completa nos quadros A.1, A.2, A3 e A.4), são avaliados individualmente conforme a percepção e opinião de cada conselheiro presente (Passo 2).

No período seguinte, os resultados totais da avaliação socioecológica são apresentados em plenária para o conselho gestor, visando a validação da situação de cada indicador avaliado (Passo 3). Caso constatado conflito de opinião (em no mínimo 20\% das respostas válidas) quanto a situação de algum indicador ou haja discordância da plenária quanto ao resultado final composto pelo conjunto de opiniões reunidas, o resultado do indicador é colocado para debate coletivo. A partir das argumentações dos diferentes pontos de vista apresentados e de acordo com o entendimento compartilhado pelo conselho gestor, a situação do indicador é então ajustada e validada em plenária.

\footnotetext{
10 As etapas e passos de aplicação do método SISUC descritas no presente Anexo têm como referência a última versão da apostila utilizada nos treinamentos para aplicação do método SISUC (Marinelli et al., 2014), aprimorada a partir da publicação da ferramenta de aplicação do método SISUC (Marinelli, 2011).
} 
Figura A.1. Mapa do caminho com as etapas (número dentro dos polígonos) e passo a passo das atividades a serem executadas durante a aplicação do método SISUC junto ao conselho gestor de UCs.

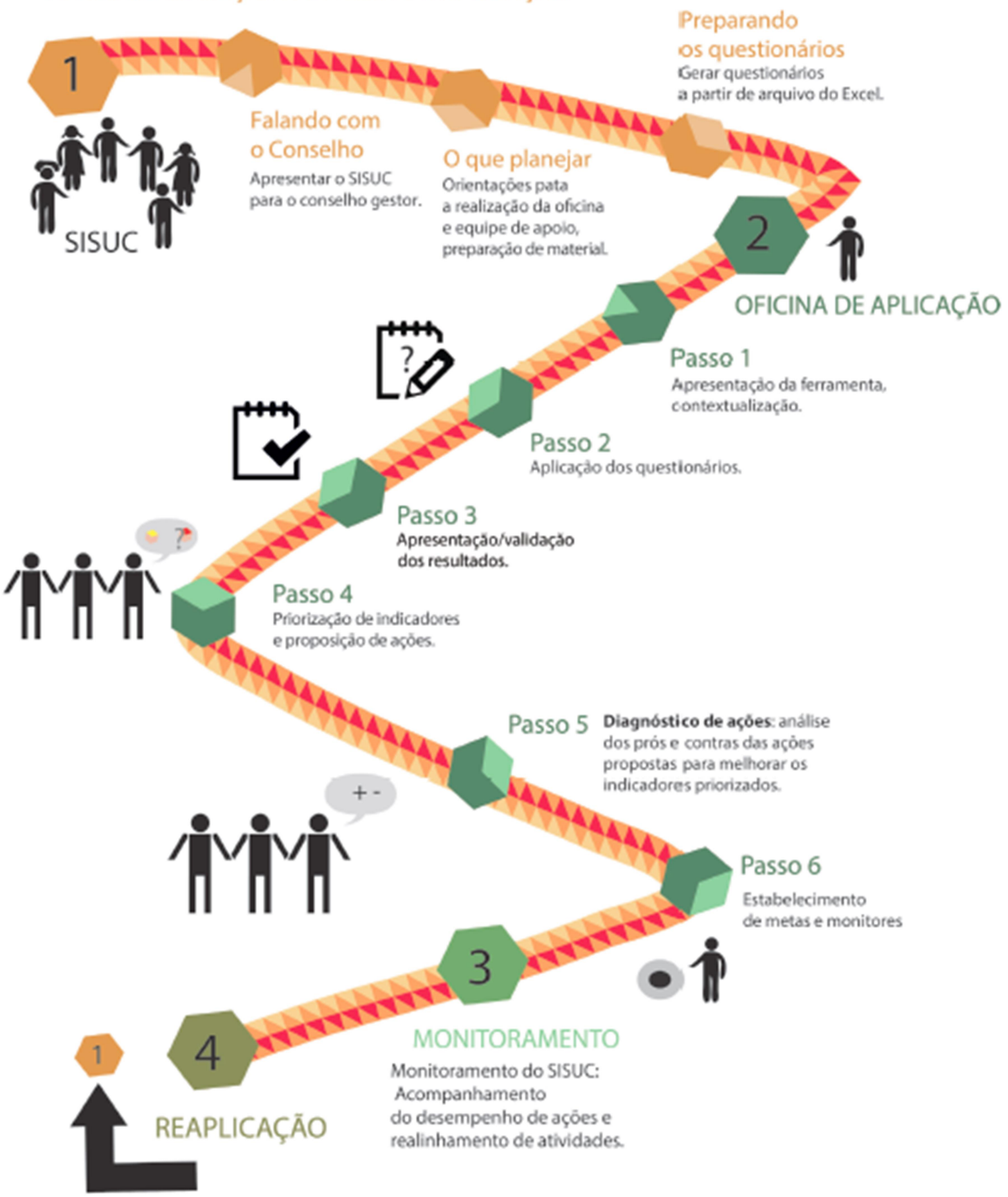

A seguir, um conjunto de indicadores, entre aqueles em pior situação é priorizado (sugere-se no máximo seis indicadores) para interpretação de suas causas, proposição de ações e identificação de oportunidades em andamento que possam favorecer a melhoria 
da condição dos mesmos em um período de dois a três anos (Passo 4). A duração desse período depende do número de reuniões do conselho gestor que são realizadas e do desempenho geral das ações planejadas: a tendência é que conselhos gestores que reúnem-se (em média) menos de duas vezes por ano ou que tem um baixo desempenho geral de ações devam levar mais tempo ( 3 anos).

No segundo dia de realização da oficina de avaliação socioecológica e planejamento estratégico, prós e contras de cada ação são analisados e servem para avaliar riscos na execução dessas ações, quando aquelas não factíveis em sua execução no período de dois a três anos são excluídas (Passo 5). Finalmente, considerando um conjunto de ações viáveis, as próprias opções de resposta para situação de cada indicador priorizado servem como referência para definição de metas a serem atingidas para mudar a realidade local (Passo 6).

Além de um relatório com os resultados principais, painéis com uma síntese das informações mais importantes são elaborados e distribuídos: em versão impressa para divulgação nas comunidades, associações, escolas, igrejas e outros grupos locais interessados na gestão da UC, e digital (para todos os interessados).

\section{Oficinas de monitoramento do desempenho de ações}

A partir da execução de todos os seis passos da oficina de avaliação socioecológica e planejamento estratégico, têm início as oficinas de monitoramento de ações. Essa atividade é executada durante a reunião do conselho gestor da UC por um período de dois a três anos, até a próxima avaliação dos indicadores e, portanto, passa a ser uma atividade ordinária da pauta de reuniões. Essas oficinas têm duração de duas a três horas, dependendo do número de ações que compõem o planejamento estratégico de cada UC: o número médio é de quatro ou cinco ações por indicador, com quatro ou cinco indicadores priorizados no total.

Nessas oficinas, grupos de trabalho constituídos por conselheiros monitores são responsáveis por avaliar e justificar o andamento de cada ação de um indicador a partir do que se sucedeu desde a avaliação realizada na última reunião do conselho gestor. Em alguns casos, o mesmo grupo de conselheiros pode ser responsável pelo monitoramento de ações de até dois indicadores, como por exemplo quando: o número de conselheiros é menor (entre doze e quinze, por exemplo), o número de indicadores priorizados é elevado (seis, por exemplo), dois indicadores sejam da mesma dimensão (meio ambiente, 
por exemplo) e não forem muitas as ações totalizadas pelos dois indicadores agregados (até cinco ou seis, por exemplo). Os resultados e justificativas considerados por cada grupo são então apresentados em plenária para avaliação e validação ou ajustes, se necessários.

As ações avaliadas por cada grupo de conselheiros monitores não muda de uma reunião para outra, mantendo-se as mesmas até o final do ciclo de monitoramento do desempenho de ações. Em caráter adaptativo, ações e, principalmente, as estratégias consideradas para sua execução podem ser revistas e modificadas de acordo com proposta apresentada pelo grupo de monitores responsável pela ação ou mesmo pela plenária.

Para ajudar neste trabalho, entre as reuniões de conselho, relatórios síntese são elaborados para o órgão gestor e disponibilizados aos conselheiros em versão digital, e boletins informativos personalizados, em versão impressa, são entregues a cada conselheiro.

\section{Oficina de balanço do desempenho de ações e metas}

Finalizada a fase de monitoramento do desempenho de ações, na próxima reunião do conselho gestor, é realizada uma oficina com duração de duas a três horas para avaliar o desempenho das ações executadas e das metas estabelecidas para melhoria dos indicadores priorizados. $\mathrm{Na}$ oportunidade, são revisitados e debatidos os resultados $(v$. Apêndice 2) e justificativas das ações que foram monitoradas e compartilhados entendimentos sobre as relações ou efeitos das ações sobre as metas estabelecidas.

Finalizado o ciclo completo de aplicação do SISUC, conforme ilustrado na Figura A.2, encaminhada pelo conselho gestor a continuidade na sua utilização, a próxima etapa é o início de um novo ciclo com a reavaliação de todos os 27 indicadores e a atualização do planejamento estratégico, conforme detalhado no item 1 acima. 


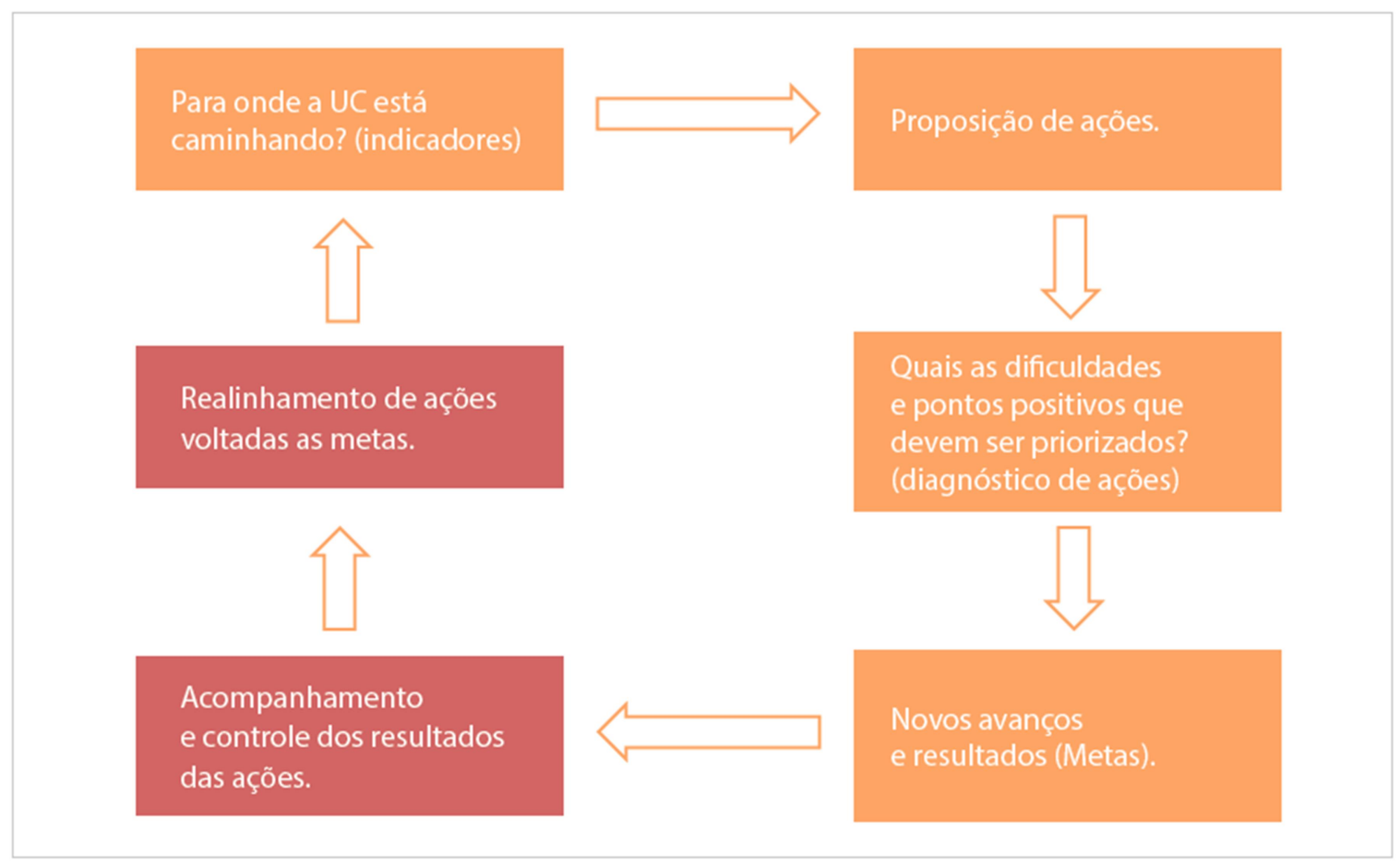

Figura A.2. Diagrama de fluxo de resultados e subsídios gerados ao longo das etapas e passos de aplicação do método SISUC, com destaque (células vermelhas) para a atividade de monitoramento e avaliação do desempenho de ações, desenvolvida sob bases adaptativas. Fonte: Marinelli et al. (2014) adaptado de Marinelli (2011). 


\section{APÊNDICE 2. Protocolo DE INDICADORES do MÉTOdo SISUC}

Quadro A.1. Organização hierárquica dos indicadores, perguntas indicadoras e opções de resposta para avaliação da situação de aspectos sobre a produção agroextrativista e consumo local, referentes a dimensão econômica, que compõem o protocolo de indicadores do método SISUC ( $c f$. Marinelli, 2014 aprimorado a partir de Marinelli, 2011).

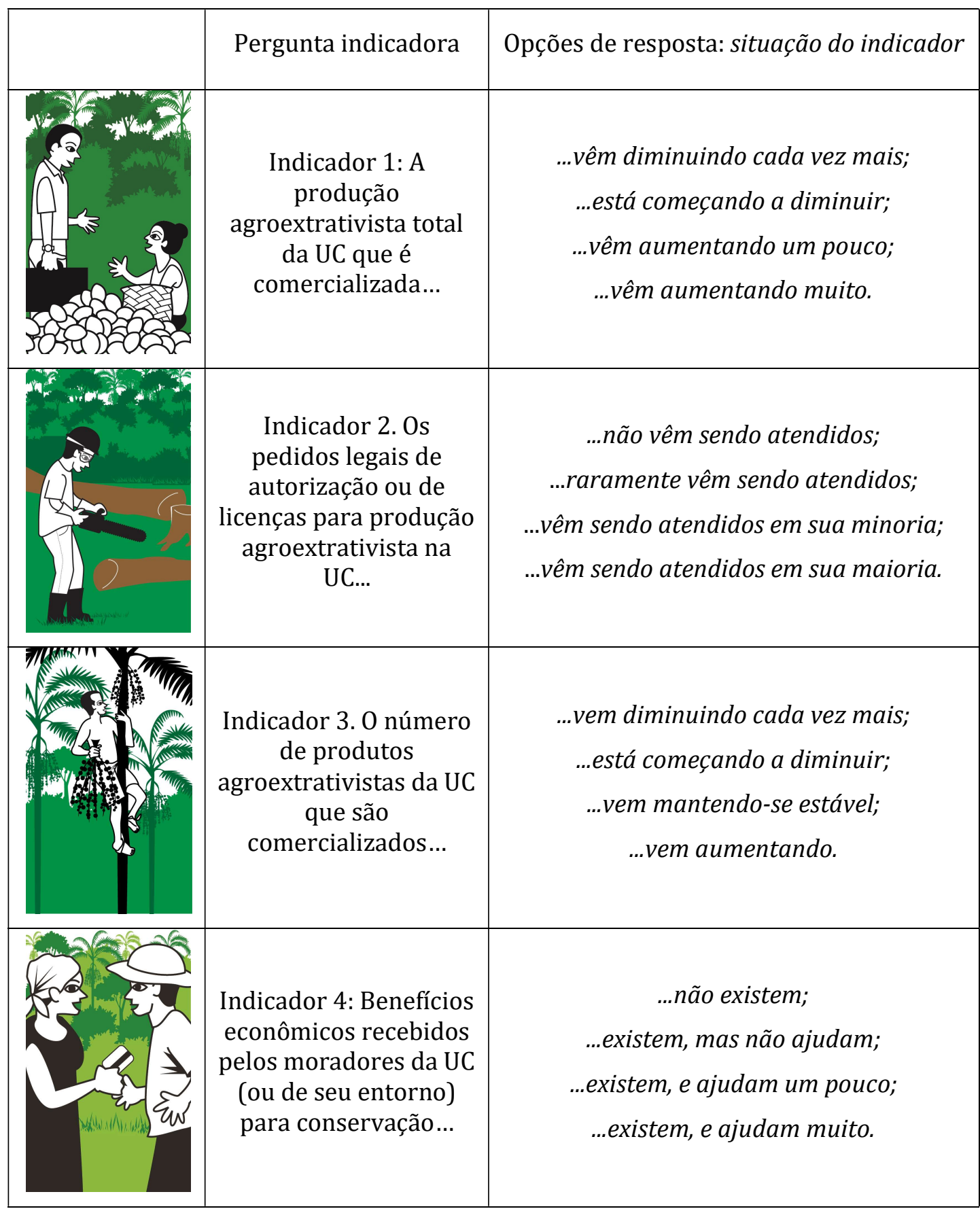


...continuação Quadro A.1.

\begin{tabular}{|c|c|c|}
\hline & Pergunta indicadora & Opções de resposta: situação do indicador \\
\hline $\begin{array}{c}\text { Indicador 5: A } \\
\text { capacidade de } \\
\text { consumo de produtos/ } \\
\text { mercadorias externas } \\
\text { à UC por seus } \\
\text { moradores... }\end{array}$ & $\begin{array}{c}\text {...vem diminuindo muito; } \\
\text {...está começando a diminuir; }\end{array}$ \\
\hline
\end{tabular}

Quadro A.2. Organização hierárquica dos indicadores, perguntas indicadoras e opções de resposta para avaliação da situação de aspectos sobre o bem estar humano e vida em sociedade, referentes a dimensão sociocultural, que compõem o protocolo de indicadores do método SISUC (cf. Marinelli, 2014 aprimorado a partir de Marinelli, 2011).

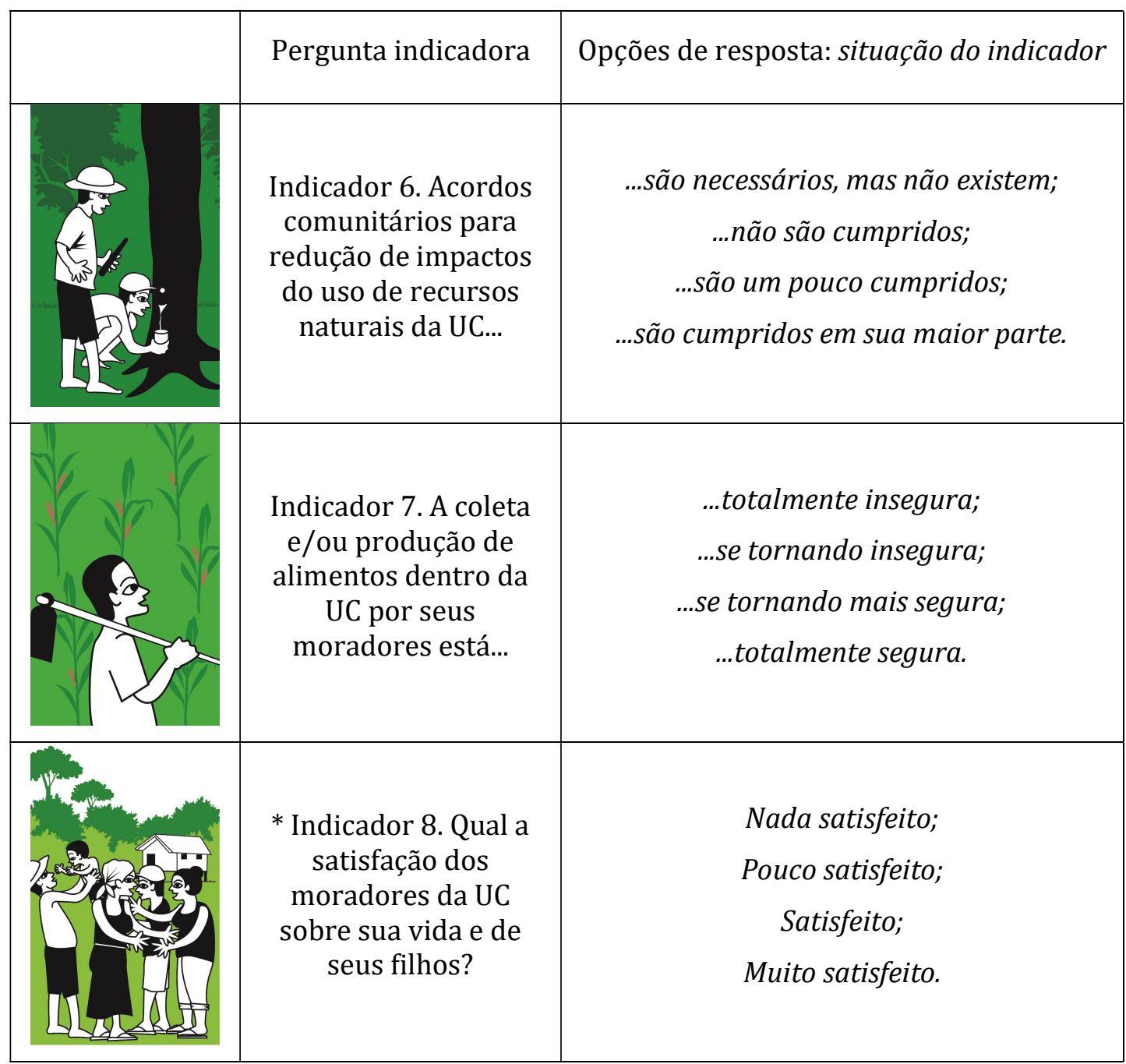

* Apenas conselheiros moradores da UC respondem. 
...continuação Quadro A.2.

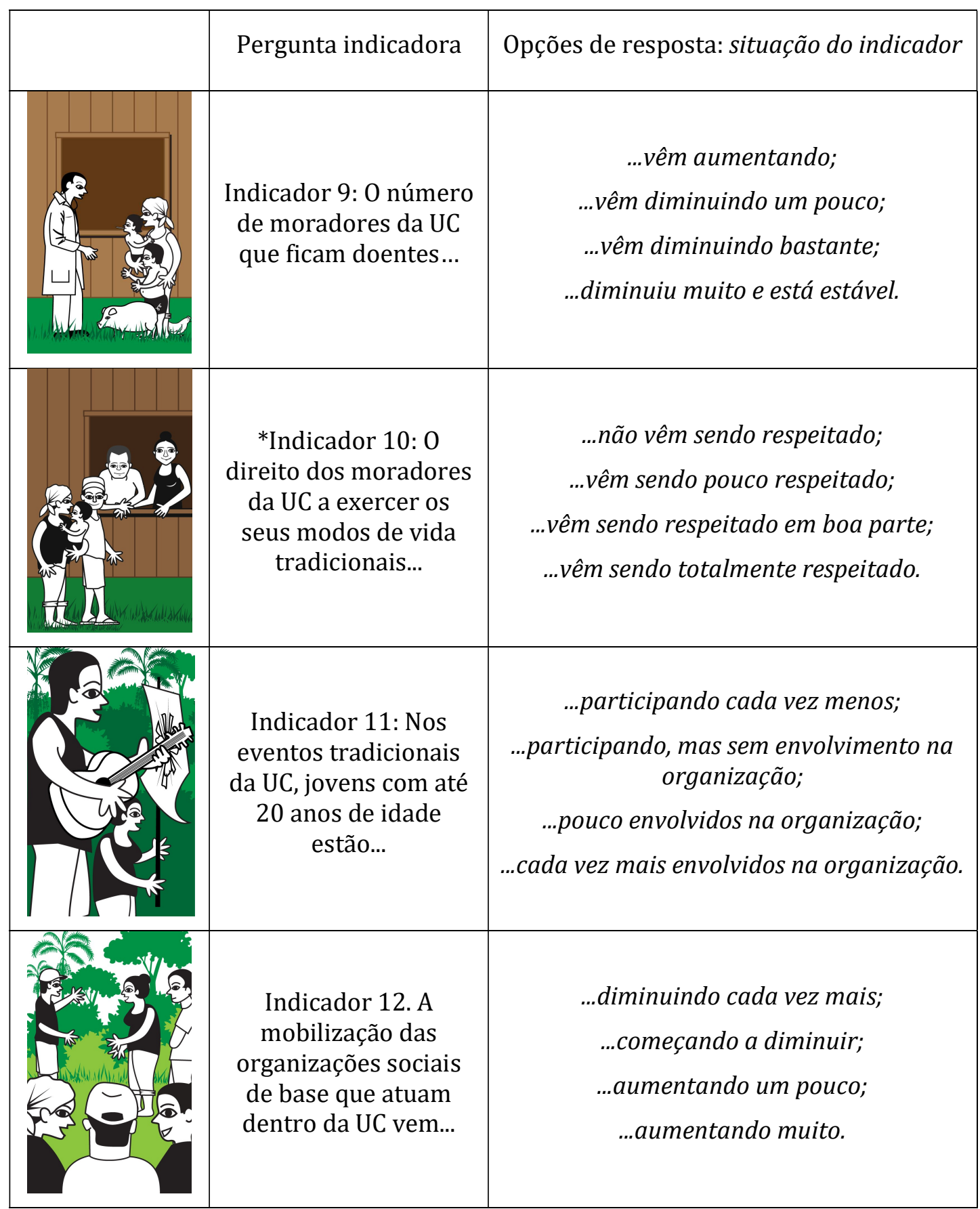

* Apenas conselheiros moradores da UC respondem. 
Quadro A.3. Organização hierárquica dos indicadores, perguntas indicadoras e opções de resposta para avaliação da situação de aspectos sobre a conservação da natureza e serviços ambientais, referentes a dimensão ambiental, que compõem o protocolo de indicadores do método SISUC ( $c f$. Marinelli, 2014 aprimorado a partir de Marinelli, 2011).

\begin{tabular}{|c|c|c|}
\hline & Pergunta indicadora & Opções de resposta: situação do indicador \\
\hline II & $\begin{array}{l}\text { Indicador } 13.0 \\
\text { monitoramento do } \\
\text { uso de recursos } \\
\text { naturais por } \\
\text { comunitários } \\
\text { moradores da UC ou } \\
\text { de seu entorno... }\end{array}$ & $\begin{array}{c}\text {...é necessário, mas não existe; } \\
\text {...existe, mas os resultados ainda não são } \\
\text { conhecidos; } \\
\text {...existe, e alguns resultados já são } \\
\text { conhecidos; } \\
\text { tem resultados utilizados nos debates de } \\
\text { gestão. }\end{array}$ \\
\hline & $\begin{array}{c}\text { Indicador } 14.0 \\
\text { agroextrativismo } \\
\text { praticado dentro da } \\
\text { UC por seus } \\
\text { moradores e usuários } \\
\text { é... }\end{array}$ & $\begin{array}{l}\text {...em sua maioria de alto impacto; } \\
\text {...em alguns casos de alto impacto; } \\
\text {...raramente de alto impacto; } \\
\text {...de impacto reduzido. }\end{array}$ \\
\hline & $\begin{array}{l}\text { Indicador 15: As } \\
\text { relações entre o clima } \\
\text { e o meio ambiente na } \\
\text { UC... }\end{array}$ & $\begin{array}{l}\text {...têm gerado muitos impactos negativos; } \\
\text {...têm gerado alguns impactos negativos; } \\
\text {...raramente gera impactos negativos; } \\
\text {...não têm gerado impactos negativos. }\end{array}$ \\
\hline & $\begin{array}{l}\text { Indicador } 16: \text { Os } \\
\text { estoques dos recursos } \\
\text { naturais mais } \\
\text { explorados dentro da } \\
\text { UC estão... }\end{array}$ & $\begin{array}{c}\text {...todos sendo reduzidos; } \\
\text {...em sua maioria sendo reduzidos; } \\
\text {...em alguns casos sendo reduzidos; } \\
\text {...não estão sendo reduzidos. }\end{array}$ \\
\hline & & \\
\hline
\end{tabular}




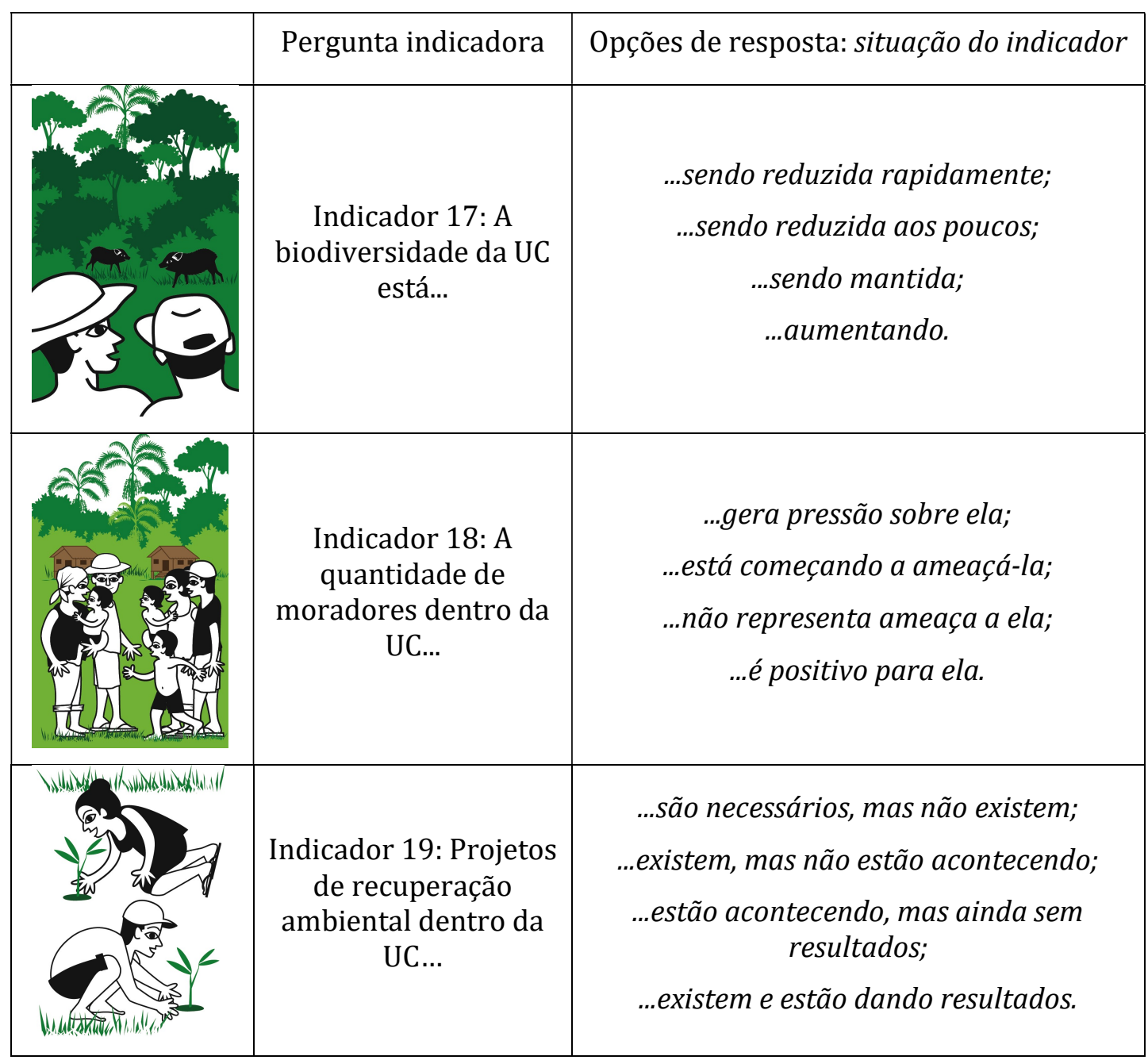

Quadro A.4. Organização hierárquica dos indicadores, perguntas indicadoras e opções de resposta para avaliação da situação de aspectos sobre gestão participativa, ações de gestão e políticas públicas, referentes a dimensão de gestão, que compõem o protocolo de indicadores do método SISUC ( $c f$. Marinelli, 2014 aprimorado a partir de Marinelli, 2011).

\begin{tabular}{|l|c|c|}
\hline & Pergunta indicadora & Opções de resposta: situação do indicador \\
& $\begin{array}{c}\text { Indicador 20: A } \\
\text { atuação de } \\
\text { organizações da } \\
\text { sociedade civil } \\
\text { externas à UC... }\end{array}$ & $\begin{array}{c}\text {....vem prejudicando a gestão da UC; } \\
\text {...ño prejudica, mas também não } \\
\text { contribui para gestão da UC; } \\
\text {...contribui muito para gestão da UC. }\end{array}$ \\
\hline
\end{tabular}

...continuação Quadro A.4. 


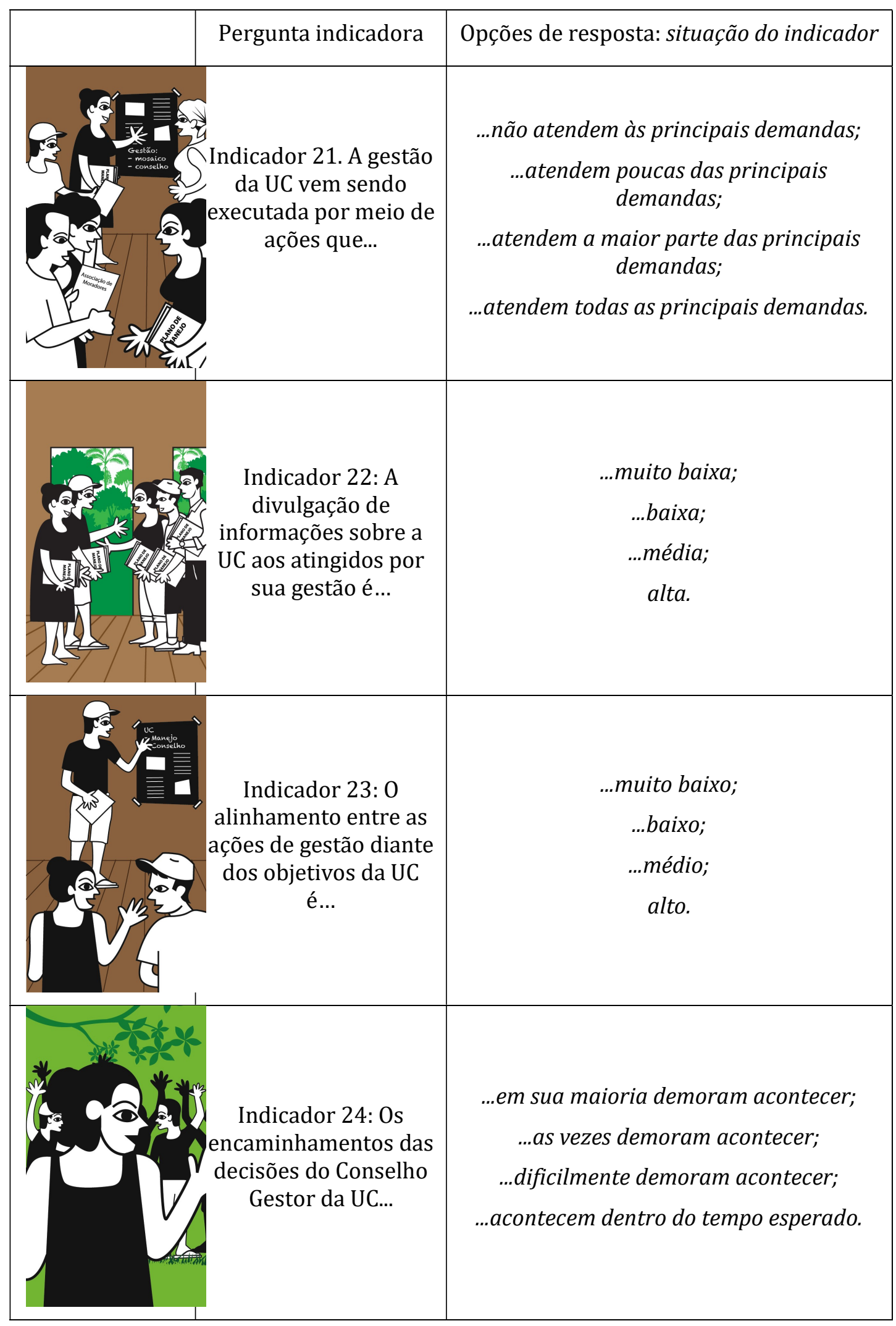

...continuação Quadro A.4. 


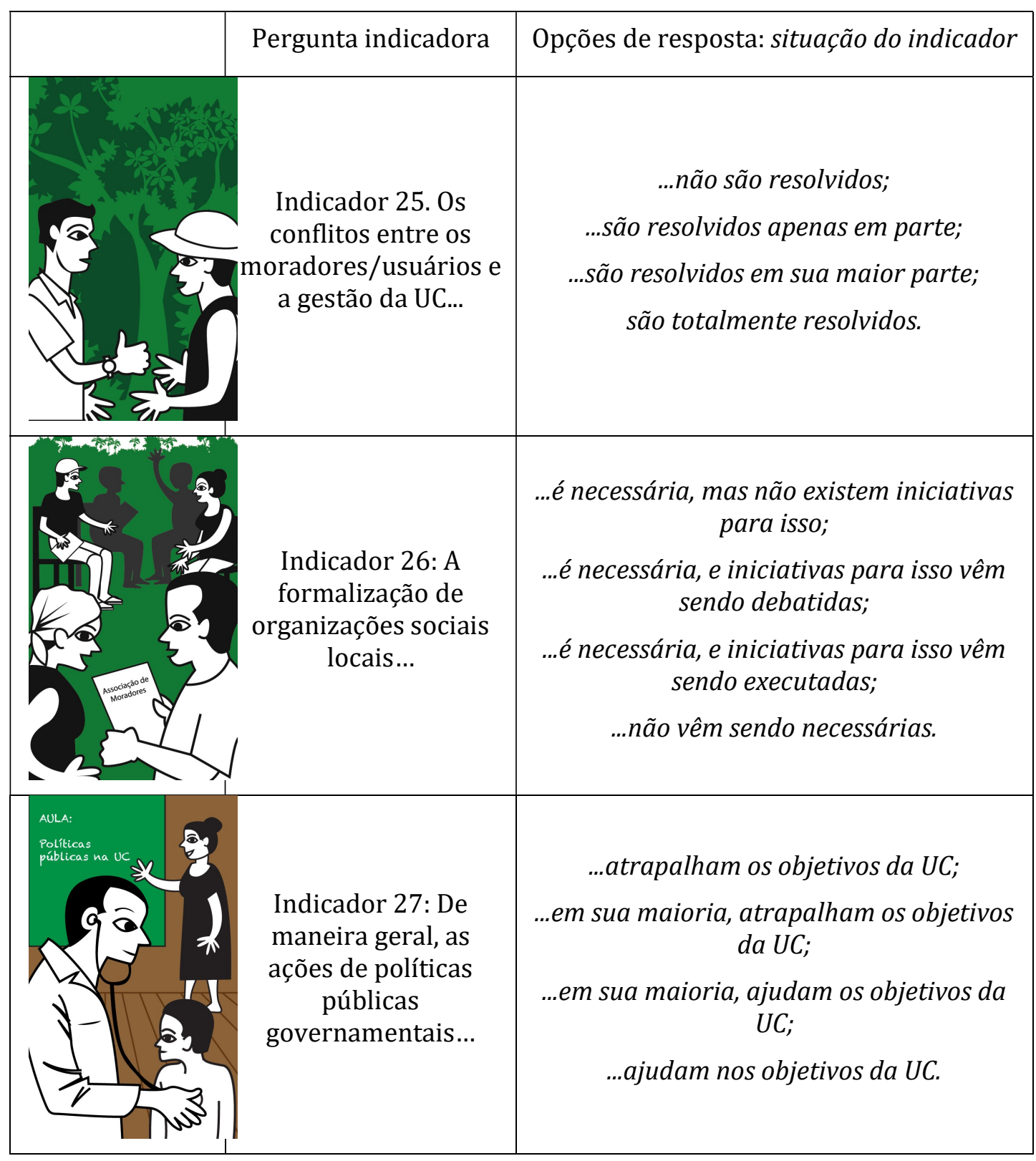

${ }^{11}$ Como pode-se notar, os indicadores do SISUC não abordam todos os aspectos envolvidos na complexa dinâmica de UCs, de maneira que nem tudo que é importante para gestão dessas áreas protegidas será encontrado nos resultados de aplicações desse método.

Muitos dos alvos identificados ao longo dos fóruns participativos ( $v$. detalhes no Anexo II), e parte daqueles contemplados pelos indicadores propostos para compor o

\footnotetext{
11 Todo o texto complementar aos quadros do presente Apêndice foi extraído (e adaptado) a partir do item 5, do encarte 2 (Do conceito à intervenção) da publicação de referência da ferramenta de aplicação do método SISUC (Marinelli, 2011).
} 
SISUC, foram excluídos durante o processo de validação da metodologia por mostraremse inadequados aos critérios de qualificação adotados, como demanda, vínculo, relevância, adequabilidade e viabilidade, entre outros. Para citar alguns exemplos: (i) dados de desmatamento são gerados por várias instituições, como o Instituto Nacional de Pesquisas Espaciais (INPE); (ii) o planejamento da gestão de UCs já é verificado por outros sistemas de informação, como o RAPPAM brasileiro (ICMbio \& WWf-Brasil, 2011); (iii) a sobreposição entre UCs e Terras Indígenas, não é uma informação a ser necessariamente obtida junto ao Conselho Gestor; e (iv) a regularização fundiária é uma política pública necessária para o Brasil, ou seja, um tema que extrapola os polígonos de UCs.

Apesar do protocolo completo de avaliação ser composto por 27 indicadores, a aplicação de cada um deles depende do contexto da UC: grupo de manejo (proteção integral ou uso sustentável); atividades agroextrativistas (existe, pontual/restrito, ou não existe); conselho gestor (constituído, em formação, ou inexistente); e população residente (presente, pequenas e isoladas, ou ausente).

Protocolos para avaliação de UCs de categorias de manejo mais restritivas e que atendem o marco regulatório referente a esses aspectos de contexto, tendem a ter número menor de indicadores aplicados, caso de UCs de proteção integral, sem moradores, sem atividades extrativistas e conselho gestor ainda inexistente. 0 conjunto completo de indicadores constitui o protocolo de UCs de uso sustentável, com população humana residente e atividades extrativistas em seus limites, e conselho gestor instituído.

Portanto, diante de mudanças em algum desses aspectos, o número de indicadores aplicado pode mudar de uma avaliação para outra (2-3 anos depois) na mesma UC. Além disso, mesmo que o protocolo de indicadores seja o mesmo, dependendo do momento da UC, diante de determinadas características do momento da UC, alguns deles podem mostrar-se não serem aplicáveis (NSA). Um exemplo disso é o indicador 4, sobre Benefícios econômicos recebidos pelos moradores da UC (ou de seu entorno) para conservação..., que pode não fazer parte da realidade da UC. 
APÊNDICE 3. RESULTADOS Do MONITORAMENTO do DESEMPENHO DE AÇõES ESTABELECIDAS A PARTIR do PLANEJAMENTO ESTRATÉGICO RESULTANTE DA APLICAÇÃo do MÉTOdo SISUC NO CONJUNTO DE UCS PESQUISADAS DO MBRN

Quadro A.6. Resultados do monitoramento do desempenho de ações estabelecidas para os indicadores priorizados no ano de 2010 pelo conselho gestor do PE do Rio Negro (Setor Sul) a partir do planejamento estratégico resultante da aplicação do método SISUC.

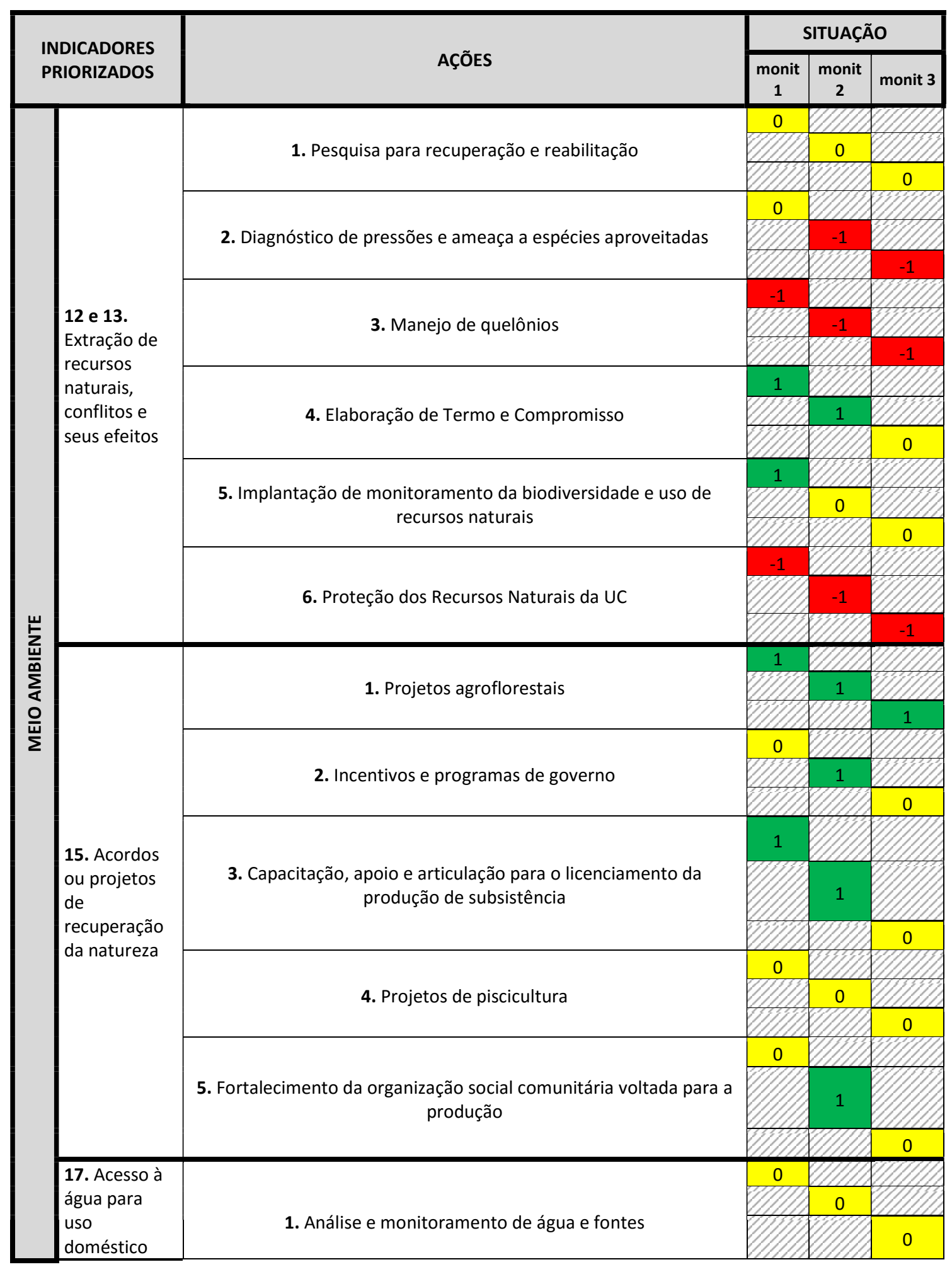




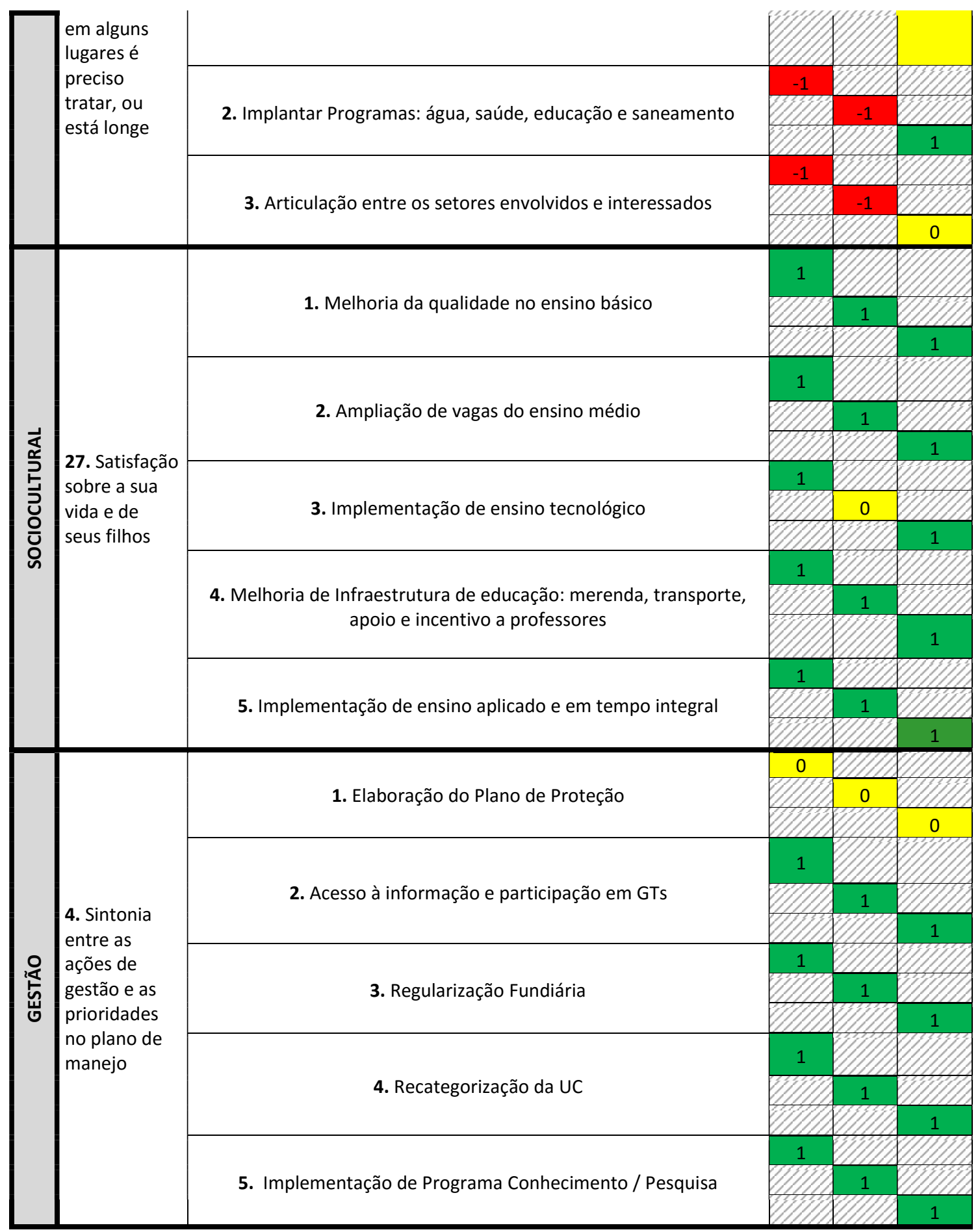


Quadro A.7. Resultados do monitoramento do desempenho de ações estabelecidas para os indicadores priorizados no ano de 2010 pelo conselho gestor do PE do Rio Negro (Setor Norte) a partir do planejamento estratégico resultante da aplicação do método SISUC.

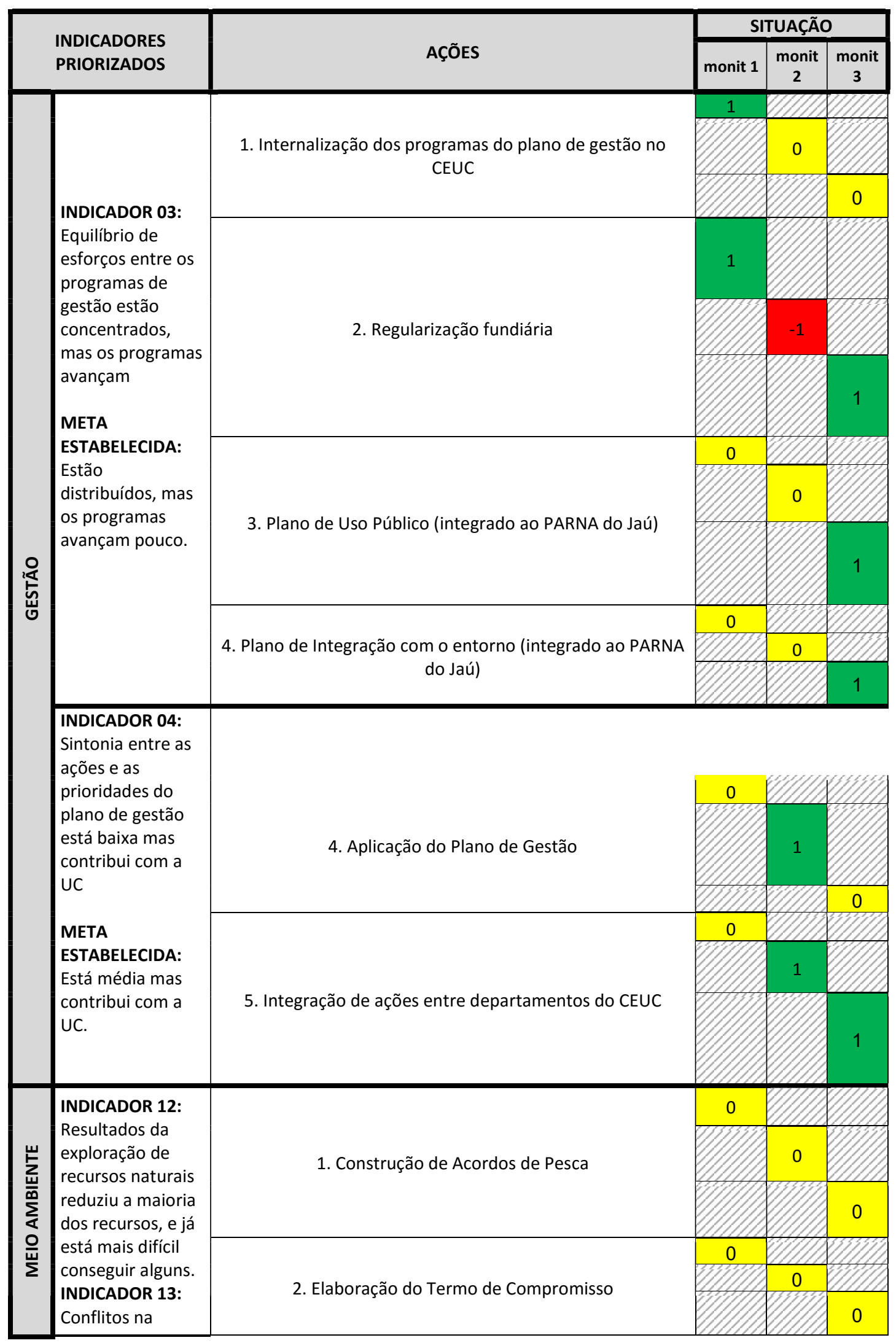




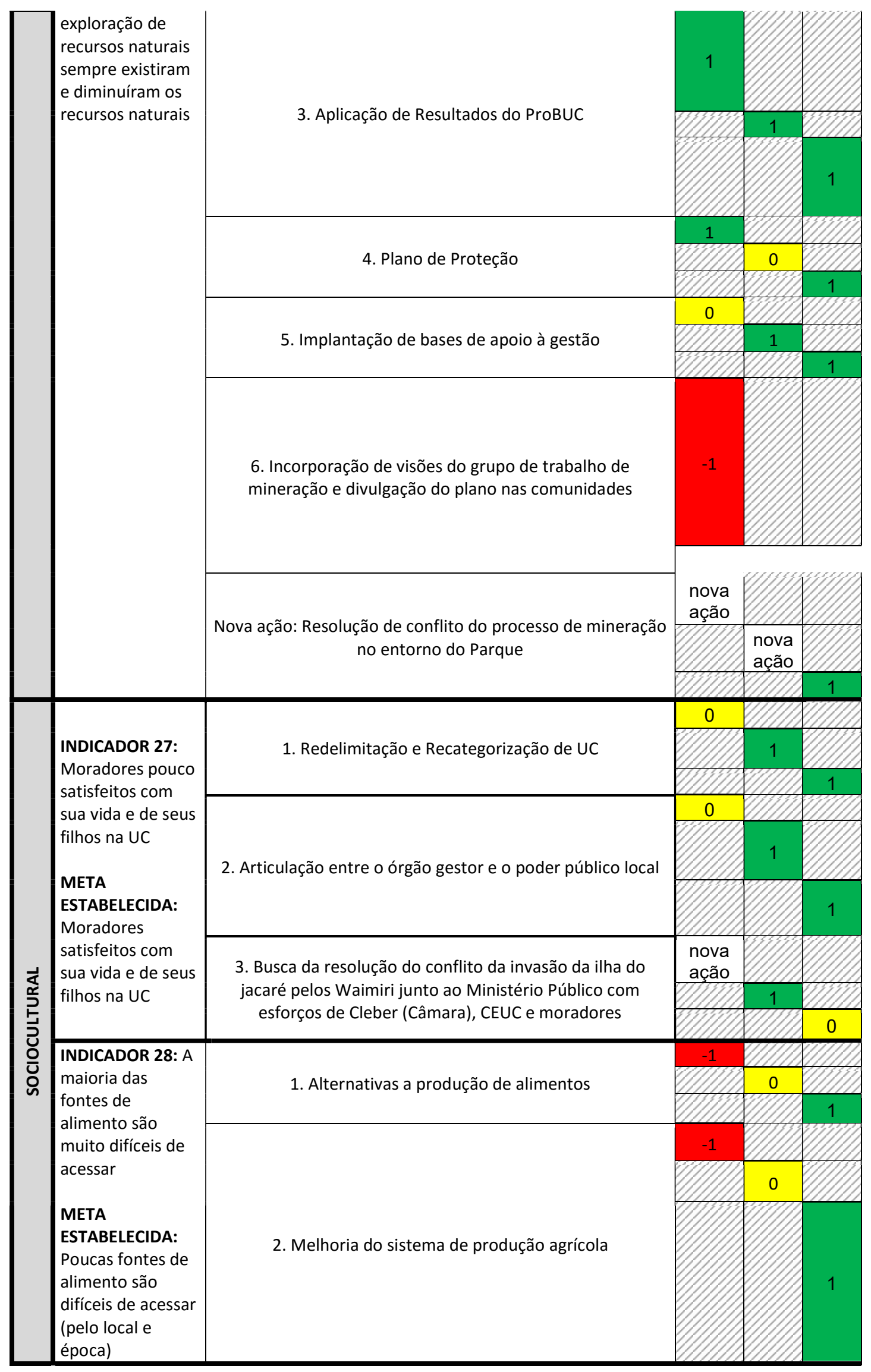


Quadro A.8. Resultados do monitoramento do desempenho de ações estabelecidas para os indicadores priorizados no ano de 2010 pelo conselho gestor da RDS do Rio Negro a partir do planejamento estratégico resultante da aplicação do método SISUC.

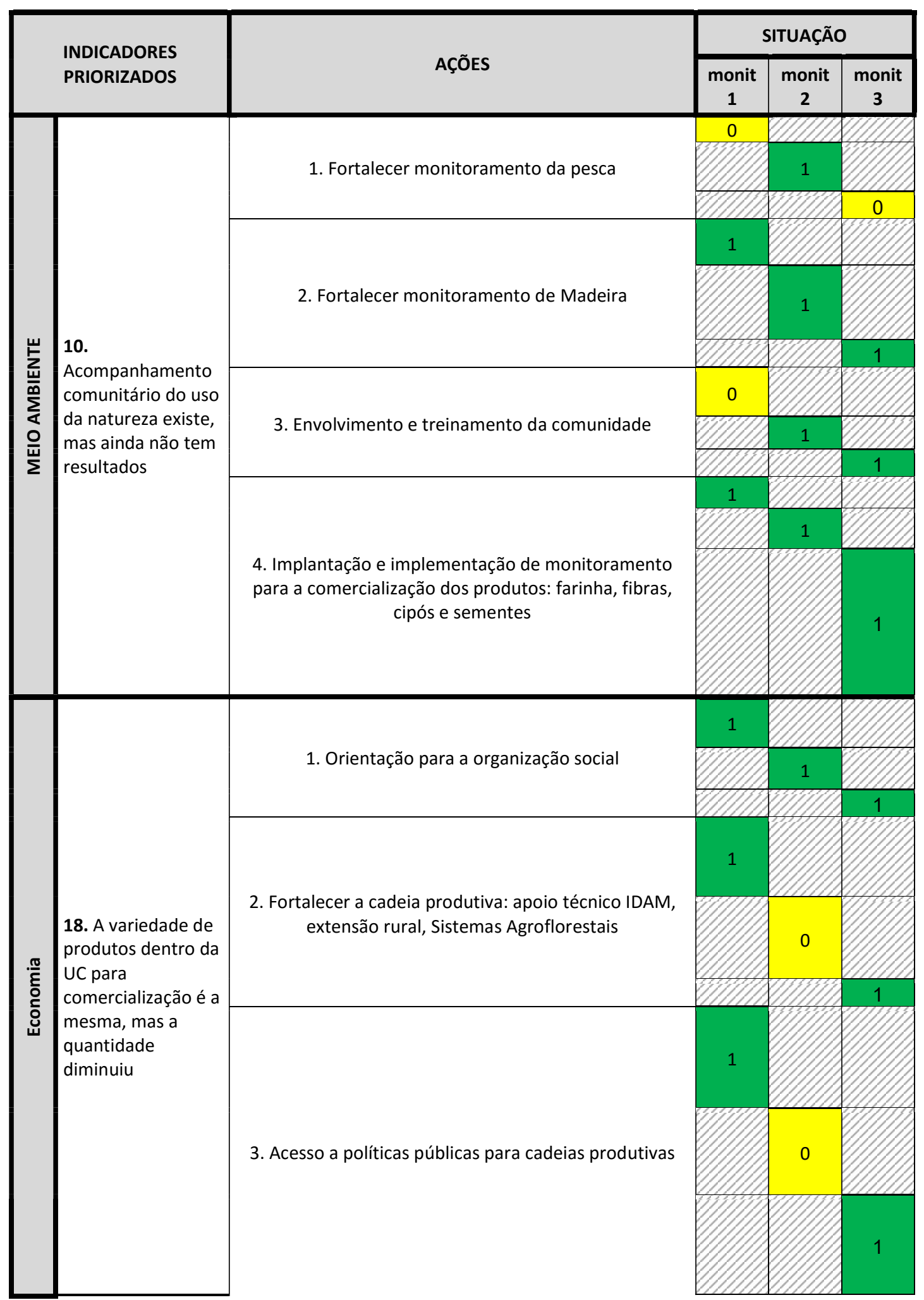




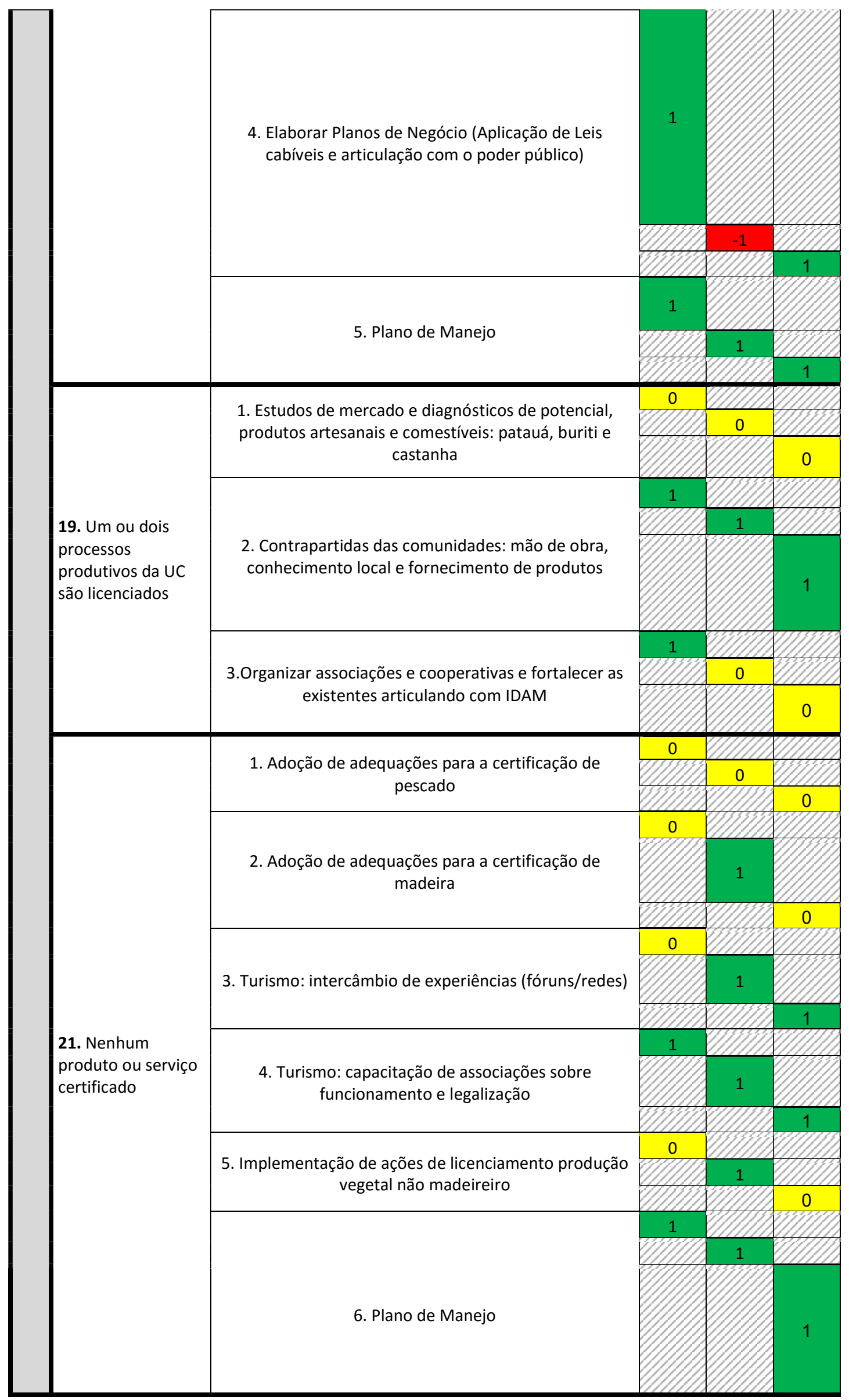




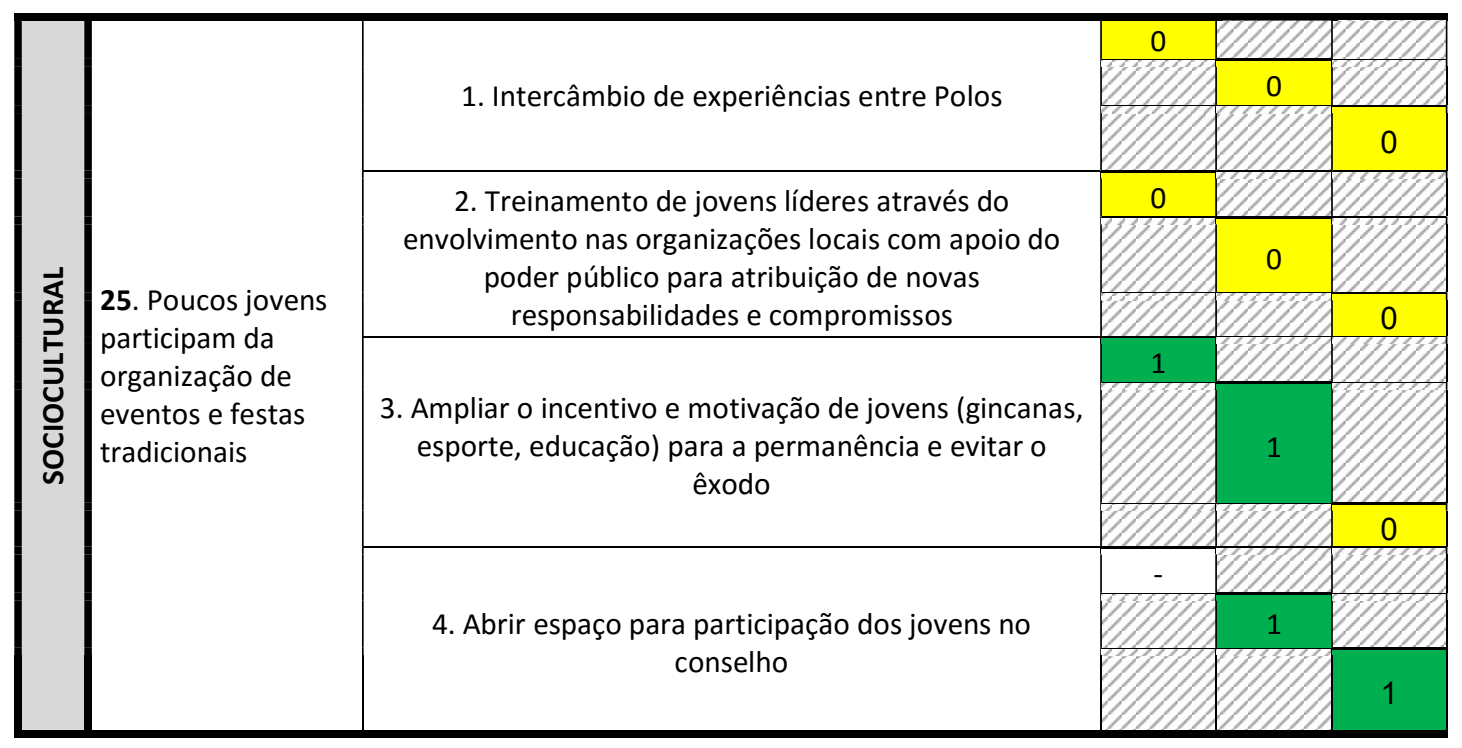

Quadro A.9. Resultados do monitoramento do desempenho de ações estabelecidas para os indicadores priorizados no ano de 2010 pelo conselho gestor do Parna de Anavilhanas a partir do planejamento estratégico resultante da aplicação do método SISUC.

\begin{tabular}{|c|c|c|c|c|c|}
\hline \multirow{2}{*}{\multicolumn{2}{|c|}{$\begin{array}{l}\text { INDICADORES } \\
\text { PRIORIZADOS }\end{array}$}} & \multirow{2}{*}{ AÇÕES } & \multicolumn{3}{|c|}{ SITUAÇÃO } \\
\hline & & & $\begin{array}{c}\text { monit } \\
1\end{array}$ & $\begin{array}{c}\text { monit } \\
2\end{array}$ & $\begin{array}{c}\text { monit } \\
3\end{array}$ \\
\hline \multirow{5}{*}{ 원 } & \multirow{3}{*}{$\begin{array}{l}\text { 7. Informações } \\
\text { sobre o Parque } \\
\text { chega em } \\
\text { alguns lugares, } \\
\text { mas não é } \\
\text { utilizada }\end{array}$} & $\begin{array}{l}\text { 1. Adoção de novo formato de divulgação dos } \\
\text { encaminhamentos do conselho: ata das reuniões com } \\
\text { tópicos-síntese por assunto. }\end{array}$ & & 0 & 0 \\
\hline & & $\begin{array}{l}\text { 2. Realização de reuniões por comunidade, pólos e setores } \\
\text { (via caravana de educação ambiental, com apoio de } \\
\text { lideranças e professores locais) e de Oficinas de } \\
\text { sensibilização no entorno do Parque }\end{array}$ & 0 & 1 & \\
\hline & & $\begin{array}{l}\text { 3. Divulgação de Boletins Informativos: via rádio (Cultura e } \\
\text { Difusora) na esfera do Mosaico, via vídeo (DVD) para } \\
\text { conselheiros, e via web (Internet) para sociedade }\end{array}$ & 0 & 0 & \\
\hline & \multirow{2}{*}{$\begin{array}{l}\text { 30. Decisões } \\
\text { do conselho } \\
\text { não demoram } \\
\text { mas são } \\
\text { executadas } \\
\text { apenas em } \\
\text { parte }\end{array}$} & $\begin{array}{l}\text { 1. Sinalização pelo ICMBio (via oficio) às instituições } \\
\text { solicitando anuência sobre condições e respaldo a } \\
\text { participação de seus representantes no conselho }\end{array}$ & 0 & 0 & \\
\hline & & $\begin{array}{l}\text { 2. Utilização da ferramenta SISUC como forma de estabelecer } \\
\text { rotinas nas reuniões do Conselho para: manutenção de } \\
\text { assuntos e debates prioritários, avaliação da atuação dos } \\
\text { conselheiros e de avanços nas ações propostas }\end{array}$ & 20202 & & \\
\hline 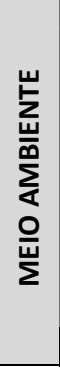 & $\begin{array}{l}12 \text { e } 13 . \\
\text { Conflitos no } \\
\text { uso de } \\
\text { recursos } \\
\text { naturais } \\
\text { acontecem e já } \\
\text { geraram } \\
\text { impacto sobre } \\
\text { a }\end{array}$ & $\begin{array}{c}\text { 1. Implementação e consolidação do GT Pesca de } \\
\text { Subsistência; e Aprovação do Termo de Compromisso para } \\
\text { Pesca }\end{array}$ & & 0 & \\
\hline
\end{tabular}




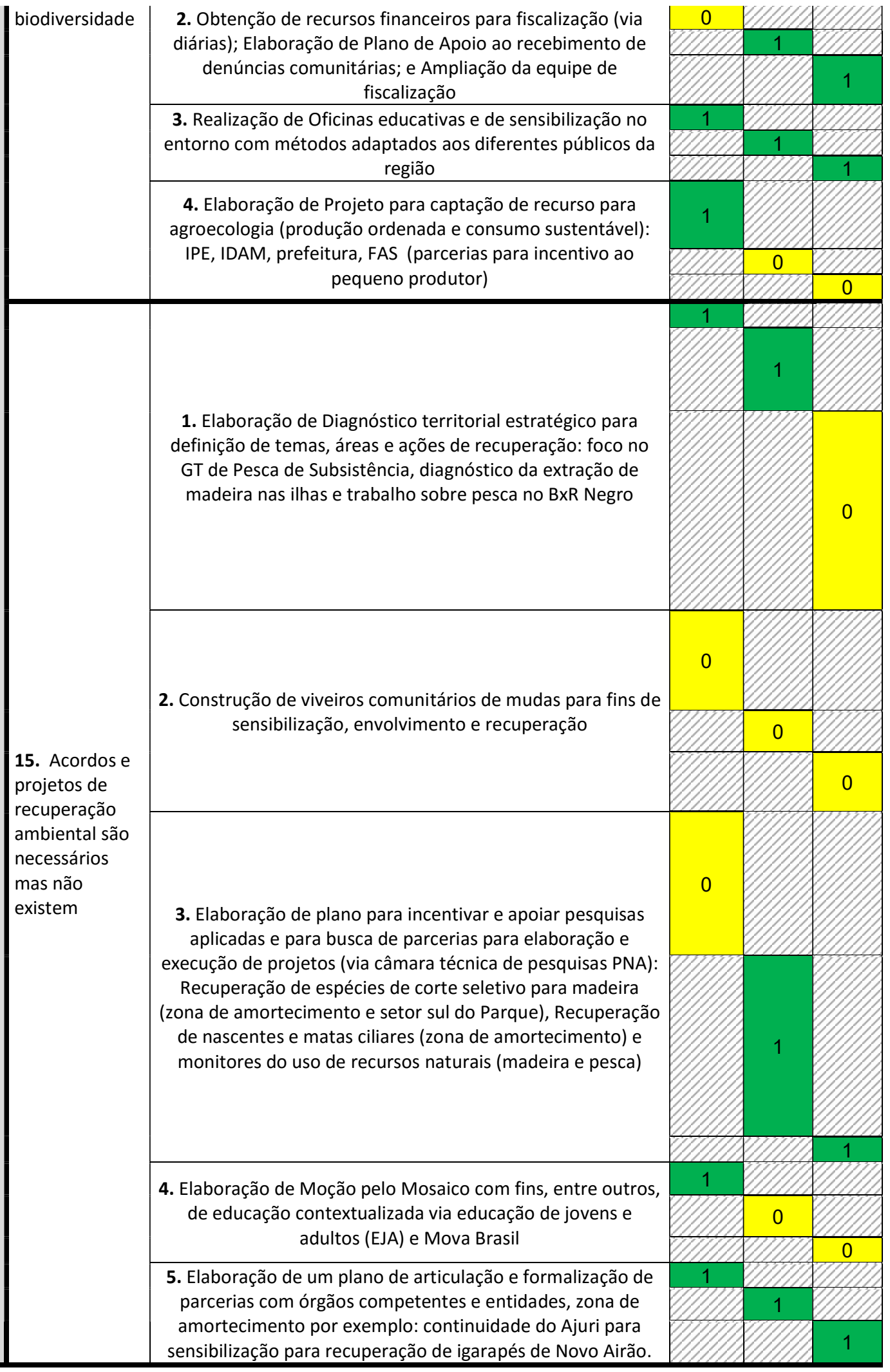


Quadro A.10. Resultados do monitoramento do desempenho de ações estabelecidas para os indicadores priorizados no ano de 2010 pelo conselho gestor do Parna do Jaú a partir do planejamento estratégico resultante da aplicação do método SISUC.

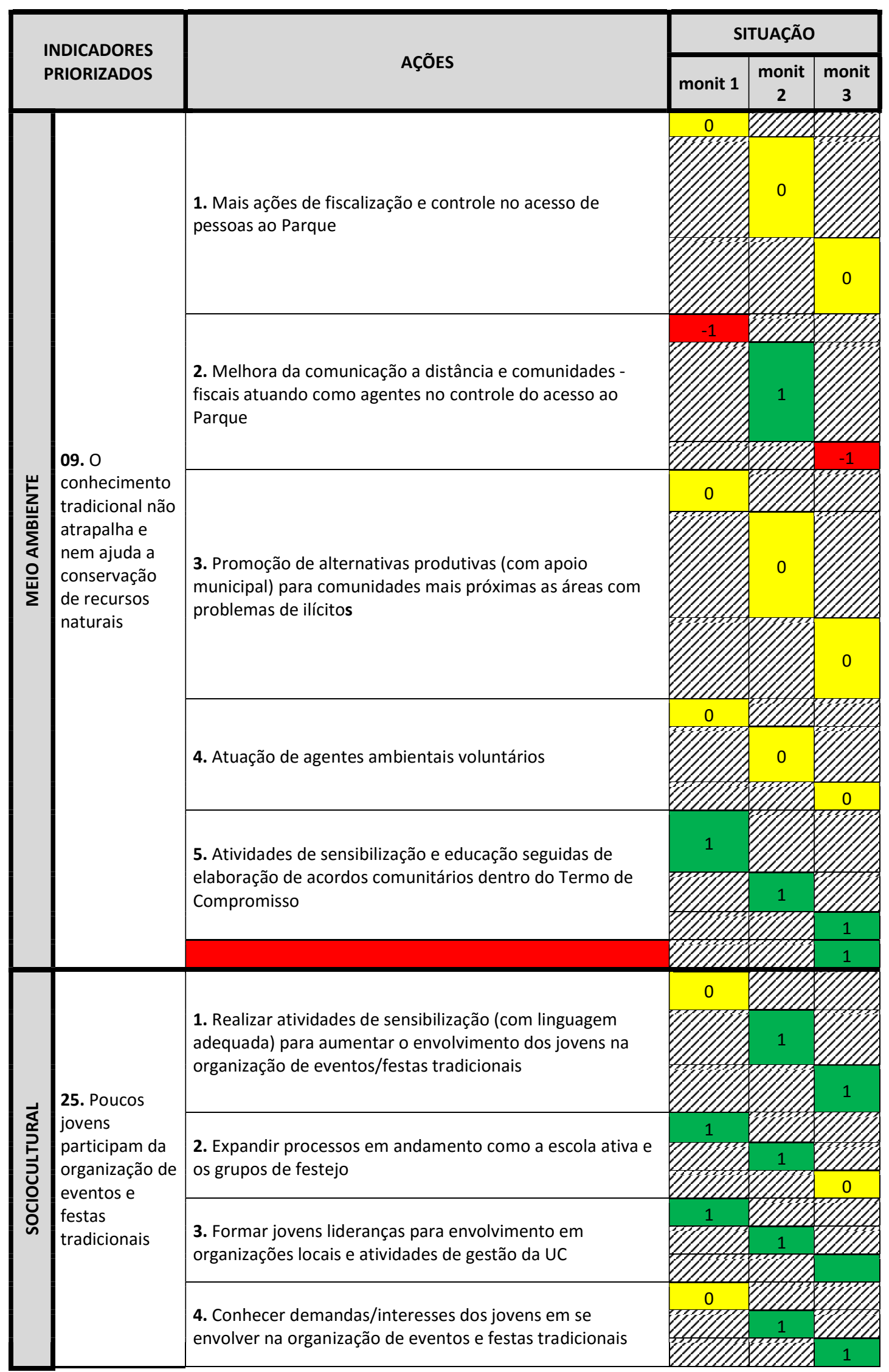




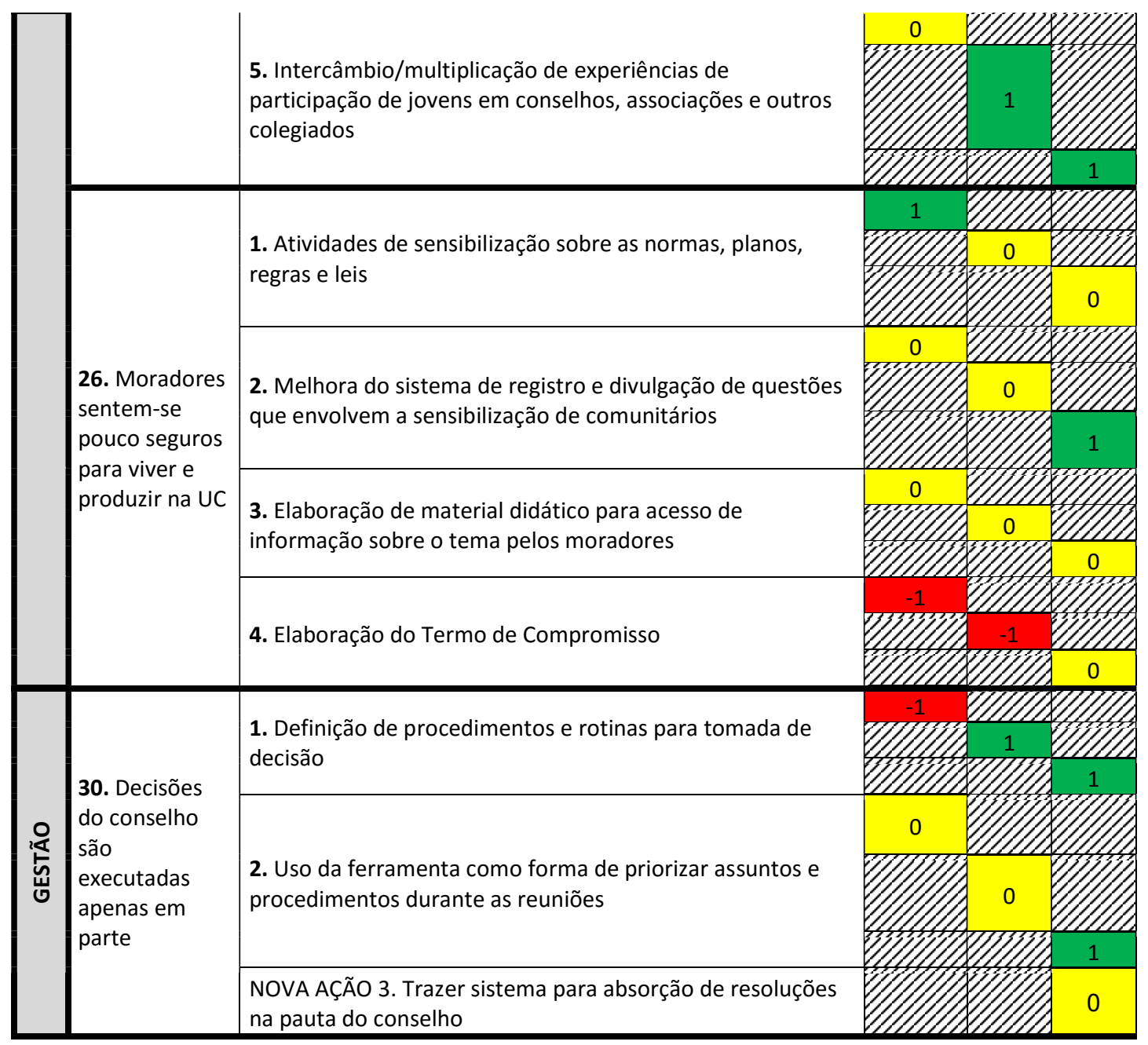

Quadro A.11. Resultados do monitoramento do desempenho de ações estabelecidas para os indicadores priorizados no ano de 2010 pelo conselho gestor da Resex Unini a partir do planejamento estratégico resultante da aplicação do método SISUC.

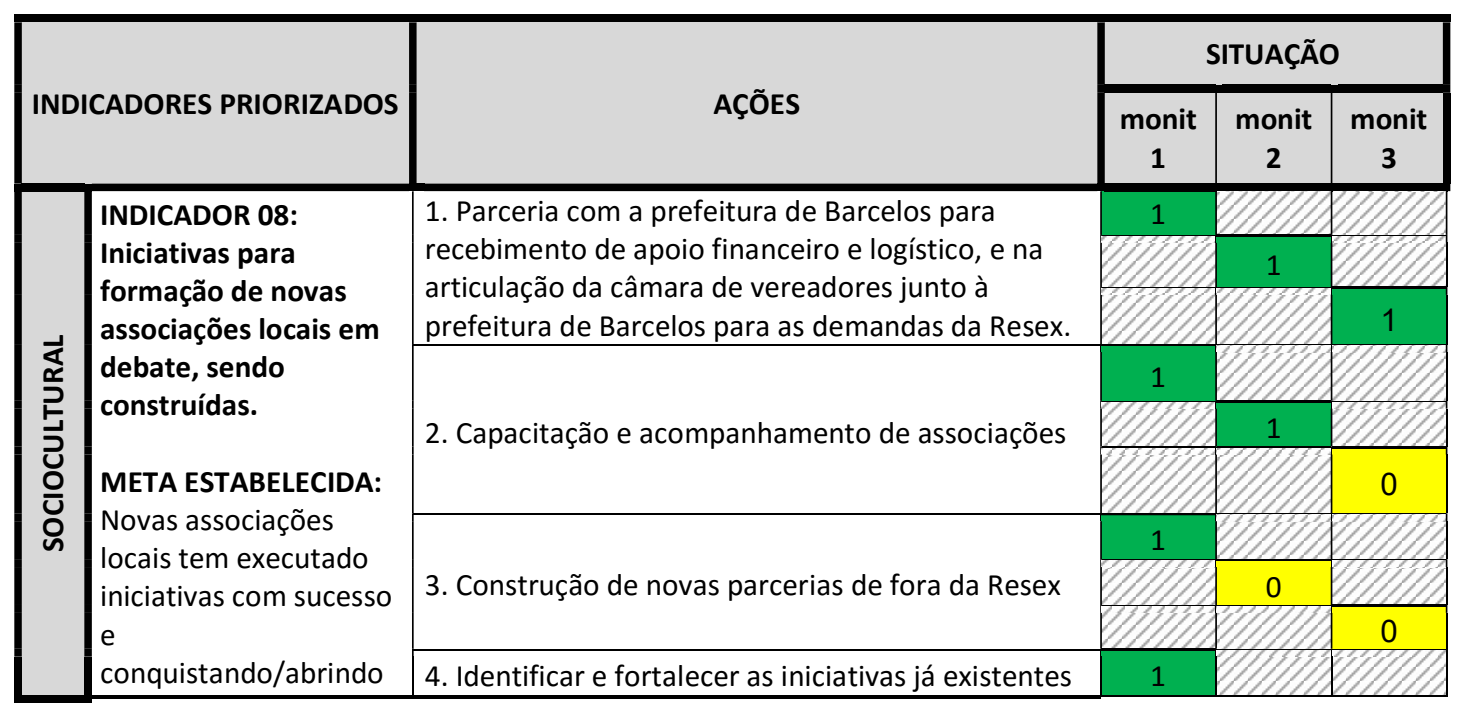




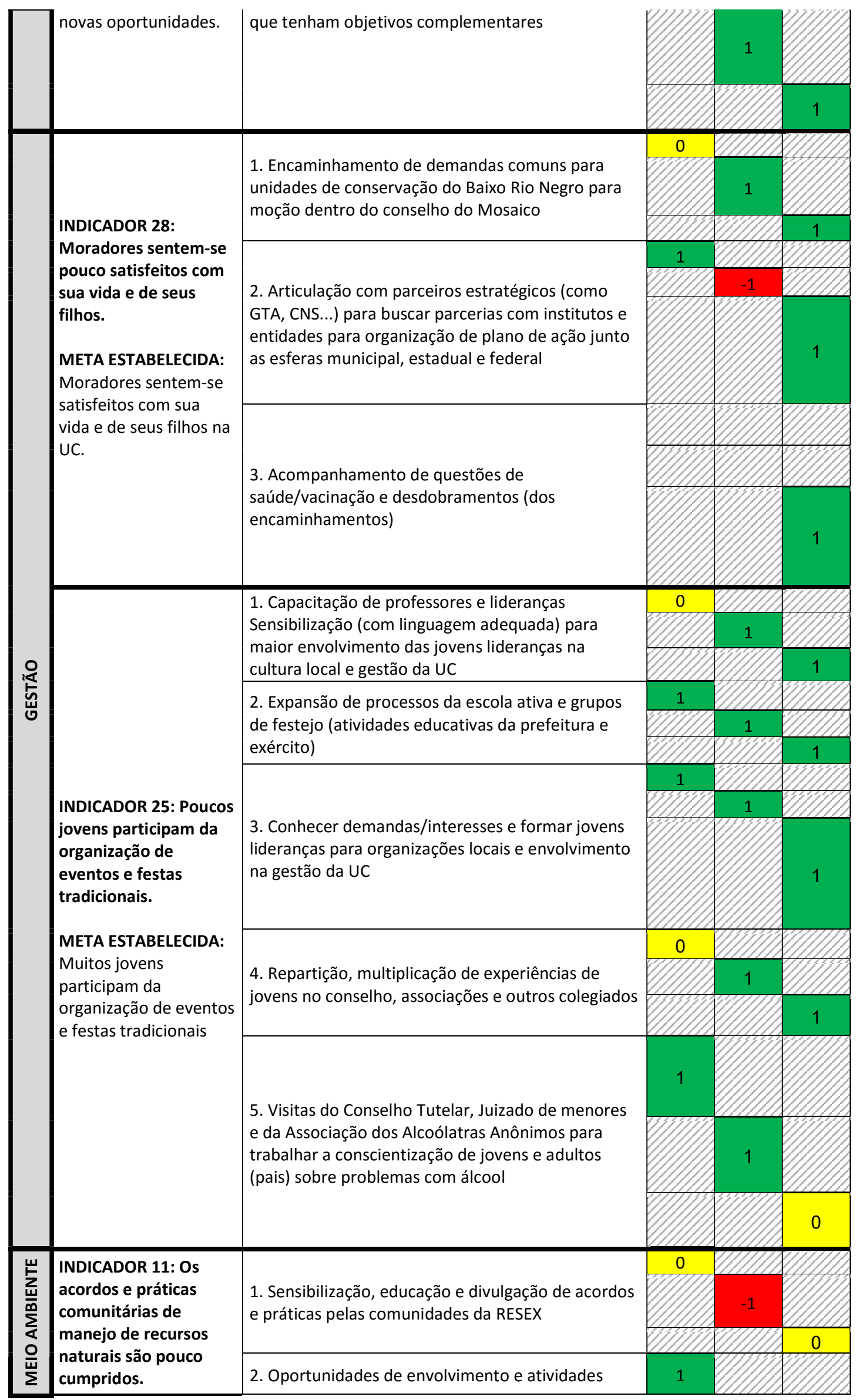




\begin{tabular}{|l|l|l|l|} 
META ESTABELECIDA: & específicas para público jovem e jovens lideranças \\
$\begin{array}{l}\text { Acordos e práticas } \\
\text { comunitárias de } \\
\text { manejo da natureza } \\
\text { são cumpridos e já são } \\
\text { usadas nos debates de } \\
\text { gestão da UC }\end{array}$ & $\begin{array}{l}\text { 3. Multiplicação de aprendizados locais: como o } \\
\text { Projeto da Castanha e jovens lideranças no } \\
\text { conselho }\end{array}$ & $\begin{array}{l}\text { 4. Aplicação dos resultados do monitoramento } \\
\text { participativo de uso recursos naturais na melhora } \\
\text { dos acordos e práticas }\end{array}$ \\
\cline { 2 - 5 } & \begin{tabular}{l} 
5. Intercâmbio de experiências com outras Ucs \\
\cline { 2 - 4 }
\end{tabular} & 6. Novas oportunidades e ocupação
\end{tabular}




\section{APÊNDICE 4. AgruPamento de AÇões ESTABELECIDAS A PARTIR do PLANEJAMENTO ESTRATÉGICO RESULTANTE DA APLICAÇÃo DO MÉTODO SISUC NO CONJUNTO DE UCS PESQUISADAS DO MBRN}

Os 25 indicadores priorizados no total das seis UCs pesquisadas, sendo 16 diferentes entre si, tiveram um total de 101 ações socioambientais estabelecidas para execução até 2014 com vistas a melhoria da situação dos mesmos. A lista de ações do SISUC que permitiram a obtenção de cada um desses resultados encontra-se na Tabela A da sessão Material e Métodos. A lista de ações socioambientais a serem executadas para que os indicadores priorizados melhorassem sua situação até 2014, acompanhada dos resultados do monitoramento e avaliação do desempenho de cada uma delas segue em Anexos.

As 101 ações estabelecidas foram divididas em 21 temas de ação diferentes entre si, conforme segue no Quadro A.5. Dados referentes ao desempenho das ações estabelecidas foram gerados nas ações 6 e 7 de aplicação do SISUC.

Quadro A.5. Lista dos temas de ação referentes ao conjunto de 101 ações socioambientais estabelecidas para melhorar a situação de 16 indicadores avaliados em condição indesejada no ano de 2010 no total do conjunto de UCs pesquisadas do MBRN.

\begin{tabular}{|l|c|}
\hline Tema de Ação & $\begin{array}{c}\text { Número de ações } \\
\text { relacionadas }\end{array}$ \\
\hline 1. Articulação e parcerias para as UCs & 10 \\
\hline 2. Treinamento e capacitação local nas UCs & 7 \\
\hline 3. Manejo de recursos naturais das UCs & 7 \\
\hline 4. Acordos e compromissos socioambientais nas UCs & 6 \\
\hline 5. Alternativas à produção e para recuper. de rec. nat. nas UCs & 6 \\
\hline 6. Marco regulatório de gestão de UCs & 6 \\
\hline 7. Acesso a bens e serviços públicos nas UCs & 6 \\
\hline 8. Sensibilização e educação socioambiental nas UCs & 6 \\
\hline 9. Atividades e oportunidades para o público jovem das UCs & 5 \\
\hline 10. Intercâmbios e espaços para sua promoção local e regional & 4 \\
\hline 11. Práticas no conselho gestor de UCs & 4 \\
\hline 12. Organização social local & 4 \\
\hline 13. Proteção ambiental (infraestrutura) de UCs & 4 \\
\hline 14. Instrumentos e práticas de gestão de UCs & 3 \\
\hline 15. Gestão e controle de demandas sociais locais & 3 \\
\hline 16. Divulgação e comunicação dentro da UC & 3 \\
\hline 17. Pesquisa e conhecimento da UC & 3 \\
\hline 18. Fiscalização e controle ambiental da UC e seu entorno & 3 \\
\hline 19. Diligência e atuação comunitária dentro da UC & 2 \\
\hline 20. Negócios e mercado a partir de produtos da UC & 2 \\
\hline 21. Políticas públicas (extra SNUC, 2000 e SEUC, 2007) & 101 \\
\hline Total de ações & \\
\hline
\end{tabular}


Anexos 


\section{ANEXo I. DOCUMENTO ENCAMINHADO AO CONSELHO GESTOR DO MBRN PARA SER UTILIZADO COMO SUBSÍDIO AOS DEBATES SOBRE O PLANO DE AÇ̃̃o REGIONAL}

Prezados,

O conjunto de Ações que segue abaixo foi especialmente preparado com fins de subsidiar os debates para definição do Plano de Ação para o Mosaico de Áreas Protegidas do Baixo Rio Negro. Ele é produto de um exercício de identificação de ações comuns e daquelas diretamente relacionadas entre si, a partir do planejamento de ações estratégicas executado pelos conselhos gestores das seis UCs em que o Sistema de Indicadores Socioambientais (SISUC) foi aplicado no período de 2010 a 2011, sendo elas: Parest do Rio Negro - setor norte, Parest do Rio Negro - setor sul, Parna do Jaú e Parna de Anavilhanas (de Proteção Integral) e RDS do Rio Negro e Resex Unini, de Uso Sustentável.

O planejamento de ações de cada UC é fruto do debate e discussão participativa pelos conselhos gestores de cada uma dessas UCs a partir dos resultados e análise da situação dos indicadores socioambientais de cada uma delas, considerado o intervalo dos últimos três anos até a primeira oficina de aplicação do SISUC. Em seguida foi realizada uma avaliação diagnóstica e validação de cada ação proposta e elaborada uma agenda de monitoramento das mesmas, a ser desenvolvido continuamente em cada reunião desses conselhos a partir de um treinamento de seus conselheiros realizado especificamente para esta finalidade.

0 material que segue abaixo é fruto de pesquisa particular e individual feitas por mim e que neste momento passam a ser gentilmente cedidas ao Conselho Gestor do Mosaico de Áreas Protegidas do Baixo Rio Negro para fins de utilização conforme apresentado no primeiro parágrafo deste documento e que devem ser utilizadas levando-se em consideração as seguintes premissas: 
1. A lista é dividida em macro-ações, que por sua vez são compostas por ações que aqui podem ganhar desdobramento como atividades, uma vez que ao se falar em Mosaico fala-se não somente em um território de gestão muito mais amplo (que o de uma única UC) mas também de um tempo maior. Levando-se isso em consideração, a lista de ações varia de acordo com o grupo de manejo e com a presença do fator de pressão sobre o indicador identificado para o conjunto de UCs que teve essa ação comum. Anavilhanas, por exemplo, deve ter as questões que dizem respeito as comunidades envolvidas sempre considerando o que tange ao entorno da UC.

2. Este conteúdo não é fechado/restrito/engessado. Existem informações mais detalhadas que não estão explícitas neste documento, que é uma síntese. Portanto, cada item deve ser considerado um tópico, que pode ter desdobramentos diferentes, de maneiras diferentes, em diferentes momentos e que podem se reagrupados em ítens que não necessariamente da maneira que seguem abaixo. Ações/atividades agrupados em Sensibilização podem fazer parte ou também (redigida ou não da mesma forma) estarem incluidas no item Capacitação. Para eventuais dúvidas sobre o que é possível, mediante sugestões concretas, estou a disposição para esclarecimentos.

Peço que o que ganhar espaço no Plano de Ação para o Mosaico, lá esteja sinalizado (originário da lista de ações do SISUC). Pode ser simplesmente com um asterisco que remeta a uma legenda no final do documento. Se for algo que já está no Plano (preliminar) do Mosaico, mas o SISUC corrobora, a mesma coisa - neste caso usar duas legendas diferentes. Com isso teremos um controle e memória sobre os critérios e bases de debate e decisões, o grau de sobreposição entre diferentes instrumentos de apoio a gestão e, porque creio que isso abrirá novas oportunidades para captação de recursos para o Mosaico.

Questões que são óbvias por já estarem acontecendo ou haver planos concretos para isso e que tiverem origem no SISUC, ainda assim devem ser consideradas e seguirem explícitas no Plano de Ação para o Mosaico.

AÇão 1. ElaboraÇão de um Plano de Articulação Estratégica (via redes como CNS, GTA etc) para formalização de parcerias com entidades com vistas a 
organização de um plano de ação junto ao poder público (municipal, estadual e federal) de atuação local. Vale ressaltar neste caso que, junto a prefeituras, para o recebimento de apoio (financeiro e logístico) e na articulação de suas câmaras de vereadores para as demandas das UCs e implementação de ICMS Ecológico.

Ação: início de curto prazo (até 1 ano), implementação de médio prazo (até 2 anos) e consolidação de longo prazo (3 anos)

AÇÃo 2. PromoçÃo DE INTERCÂMBIO DE EXPERIÊNCIAS para multiplicação de vivências e aprendizados locais/regionais, com destaque para os seguintes temas:

- Projeto da Castanha, Jovens lideranças nos conselhos gestores e Resultados do monitoramento do uso de recursos naturais (entre as UCs do Mosaico)

- Associação de moradores, Acordos e práticas comunitárias de manejo de recursos naturais e Turismo (com UCs de outras regiões)

\section{AÇão 3. Execução de Atividades de Sensibilização Contextualizada}

para maior divulgação e disseminação entre as comunidades, de questões dependentes do acesso à informação e apropriação, para geração de resultados em diversos âmbitos da gestão participativa, com destaque para os seguintes temas:

- Acordos, normas, termos, planos, regras e leis

- Drogas (pelo Conselho Tutelar, Juizado de Menores e AAA's)

- Resultados e avanços dos diferentes GTs e Reuniões de Conselhos

- Elaboração de atas (em tópicos simples) para distribuição ao final das reuniões dos conselhos

- Boletins informativos sobre as reuniões de conselhos: via rádio (Cultura e Difusora) e vídeo (entrega de DVD para conselheiros a cada reunião) 


\section{AÇÃo 4. Desenvolvimento de ATIVIDAdes Específicas PARA Jovens (com}

linguagem adequada) para reduzir o êxodo de jovens das UCs, manter as manifestações culturais locais e regionais, e prepará-los como agentes socioambientais mais envolvidos e ativos, entre as quais:

- Oficinas para conhecer os interesses e demandas deste público

- Envolvê-los nas organiz/associações locais, conselhos e outros colegiados

- Formação de uma futura geração de conselheiros das UCs do Mosaico

- Atribuir responsabilidades e compromissos junto as colegiados existentes

AÇão 5. Capacitação de Comunitários E Lideranças (com linguagem adequada) em atividades ligadas ao desenvolvimento socioambiental local sob bases sustentáveis, entre os quais:

- Monitoramento participativo do uso e recursos naturais

- Associativismo/Cooperativismo e SAF (pelo IDAM)

- Funcionamento e legalização do turismo

- Apropriação, registro e disseminação de conteúdos (para conselheiros)

\section{AÇão 6. Implementação de Programa de Gestão de Conhecimento com} vistas à redução de custos e otimização de resultados para alvos complementares (das UCs) que convergem para objetivos comuns ao Mosaico, como por exemplo:

- Subsidiar a elaboração de um Plano de Proteção integrado

- Desenvolver projetos agroflorestais e agroecológicos voltados a produção ordenada e consumo sustentável

- Aplicar as prioridades dos planos de gestão

- Construir de acordos de pesca

- Aplicar de resultados do monitoramento do uso de recursos naturais

- Elaborar estratégias para conservação de aves e mamíferos alvos de caça 
- Diagnósticar o território para definiçnao de áreas, temas e ações de recuperação, rehabilitação ou restauração

- Incentivar e apoiar pesquisas aplicadas e buscar parcerias para elaboração e execução de projetos

- Elaborar estudos de mercado e plano de negócios para produtos artesanais e comestiveis comuns as UCs como patauá, buriti e castanha

Ação 7. Mobilização pela Melhora do Ensino Público com vistas a valorização da vida no campo, ampliação de oportunidades socioeconômicas, melhora da qualidade de vida e maior envolvimento dos jovens na gestão participativa das UCs, entre as quais:

- Ampliação de vagas no ensino médio

- Melhoria de infraestrutura: merenda e transporte

- Ensino contextualizado (em todos os níveis)

- Ensino infantil em tempo integral

- Melhores condições, apoio e incentivo a fixação de professores

- Implementação de ensino tecnológico

AÇÃo 8. Fortalecimento dos instrumentos/Processos de Gestão com vistas a consolidação das UCs do Mosaico e geração de um modelo de Gestão Integrada, a partir das seguintes ações:

- Elaboração de Termos de Compromisso

- Integração do Plano de Uso Público ao Plano de Integração de Entornos

- Regularização Fundiária/Redelimitação/Recategorizaçao de UCs

- Implantação de sistemas de monitoramento do uso de recursos naturais para diagnosticar a situação das espécies utilizadas, com foco em madeira e pesca

- Integração de ações entre órgãos gestores

- Maior fiscalização e controle no acesso de pessoas as UCs 
- Melhora na comunicação a distância para que comunidades agentes de controle

- Instituições devem dar condições e repaldo a representantes nos conselhos

- Uso do SISUC para alimentação e continua revisão/debate da pauta prioritária e para avaliação dos avanços na gestão participativa e socioambiental

\author{
Carlos Eduardo Marinelli \\ Pesquisador da Universidade de Brasília e \\ Docente-Colaborador do Instituto Nacional de Pesquisas da Amazônia
}




\section{ANEXo II. DESCRIÇÃo DO PROCESSO DE ELABORAÇÃo DO MÉTODO SISUC ${ }^{12}$}

Modelos Conceituais: instrumento de apoio ao debate, aprendizado e geração de conhecimento coletivo

Lidar com o desafio de propor um novo sistema de informação que gere subsídios à gestão de UCs demanda que instituições e atores amazônicos, não só tenham interesse na utilização do novo método, como estejam envolvidos nos debates para construção do mesmo.

Na Amazônia já existem experiências sobre metodologias, como o ProBUC 13 (Marinelli et al., 2007), e de ferramentas, como os Indicadores de Implementação de UCs (Marinelli et al., 2008), que foram elaborados de maneira participativa e são voltados para uso e aplicação de resultados por atores de diferentes setores da sociedade interessados e envolvidos na gestão de UCs.

Partindo dessas experiências e do movimento de sinergia resultante dos debates na Amazônia, realizados em 2009, adotou-se uma estratégia baseada na integração de ações de ciência, tecnologia e sociedade (CT\&S) (Hoffmann, 2011) para geração de bases que fomentassem a elaboração de um novo sistema de informação para subsidiar a gestão de UCs. A continuidade dos exercícios coletivos de reflexão sobre a dinâmica socioambiental dessas áreas protegidas passou a ser somada a aplicação de métodos de Raciocínio Qualitativo'14 (RQ) e modelagem ao longo de cinco fóruns participativos, realizados em 2010.

A linha do RQ baseia-se na teoria qualitativa de processos (Forbus, 1984), que tem como pressuposto que processos são as causas primárias de mudanças em um sistema e mostram relações de causalidade explicitas. Modelos, por sua vez, são representações formais, abstratas e manipuláveis de sistemas que, entre outros, podem servir para aumentar a compreensão sobre sua estrutura e funcionamento, caso este em que são chamados modelos conceituais.

\footnotetext{
12 Extraído de item do artigo 2 (Marinelli et al, 2011), do encarte 2 (Do conceito à intervenção) da publicação de referência da ferramenta de aplicação do SISUC (Marinelli, 2011).

13 Programa de Monitoramento da Biodiversidade e do Uso de Recursos Naturais em Unidades de Conservação Estaduais do Amazonas - ProBUC (cf. Marinelli et al., 2007).

14 Raciocínio Qualitativo é uma área da Inteligência Artificial dedicada à representação de propriedades contínuas de sistemas e para exercícios de raciocínio automatizado diante de conhecimentos incompletos ou expressos apenas qualitativamente (Weld \& de Kleer, 1990).
} 
Modelos conceituais podem ser úteis em diversas situações: (a) oferecem um quadro referencial conceitual para trabalhos que reúnem pessoas com formação ou conhecimento diversificado; (b) sacrificam detalhes, em prol de representações mais genéricas, simplificando os conceitos a serem compartilhados; e (c) podem ajudar na proposição e teste de hipóteses.

De acordo com Jørgensen e Bendoricchio (2001), modelos conceituais possibilitam também a adoção de expressões verbais, desenhos, matrizes e diagramas de influência para representar conhecimentos incompletos, vagos ou incertos, para a descrição de sistemas. Desse modo, contribuem para organizar idéias ou para comunicar conceitos e propostas em construção (Haefner, 2005), sendo por isso, particularmente interessantes para resolução de conflitos e construção de consenso, como foi o caso dos debates acima citados.

Adotando a abordagem de RQ, idéias sobre um sistema constituído por um conjunto de variáveis foram organizadas em um modelo conceitual que representasse parte das dimensões e componentes das relações causais envolvidas na dinâmica socioambiental de UCs da Amazônia. 0 modelo passou a ser aplicado durante os fóruns que se sucederam para está finalidade, com dois objetivos (operacionais): (a) servir como referência para aprendizagem e difusão sobre as relações causais representadas; e (b) permitir a avaliação e a absorção das visões regionais e experiências dos diferentes setores da sociedade.

Para que pudesse ser apresentado e fosse apropriado pelos participantes dos fóruns, o modelo construído foi bastante simplificado, resultando em um diagrama de influências, o qual foi sendo aprimorado a cada rodada de debates (figura abaixo).

Partindo da incompletude que envolve qualquer tipo de modelo diante do que é, de fato, realidade, o sistema representado neste diagrama é formado por variáveis que, organizadas em suas respectivas dimensões, ou subsistemas (econômico, sociocultural, ambiental e de gestão), desencadeiam processos e geram influências. Variáveis simples, como etnoconhecimento e igualdade social, por exemplo, são influenciadas e geram influências sobre outras variáveis, na mesma dimensão ou em outra; variáveis orientadoras, como extrativismo tradicional e exploração sustentável, por sua vez, desencadeiam processos geradores de uma sequência de influências. 


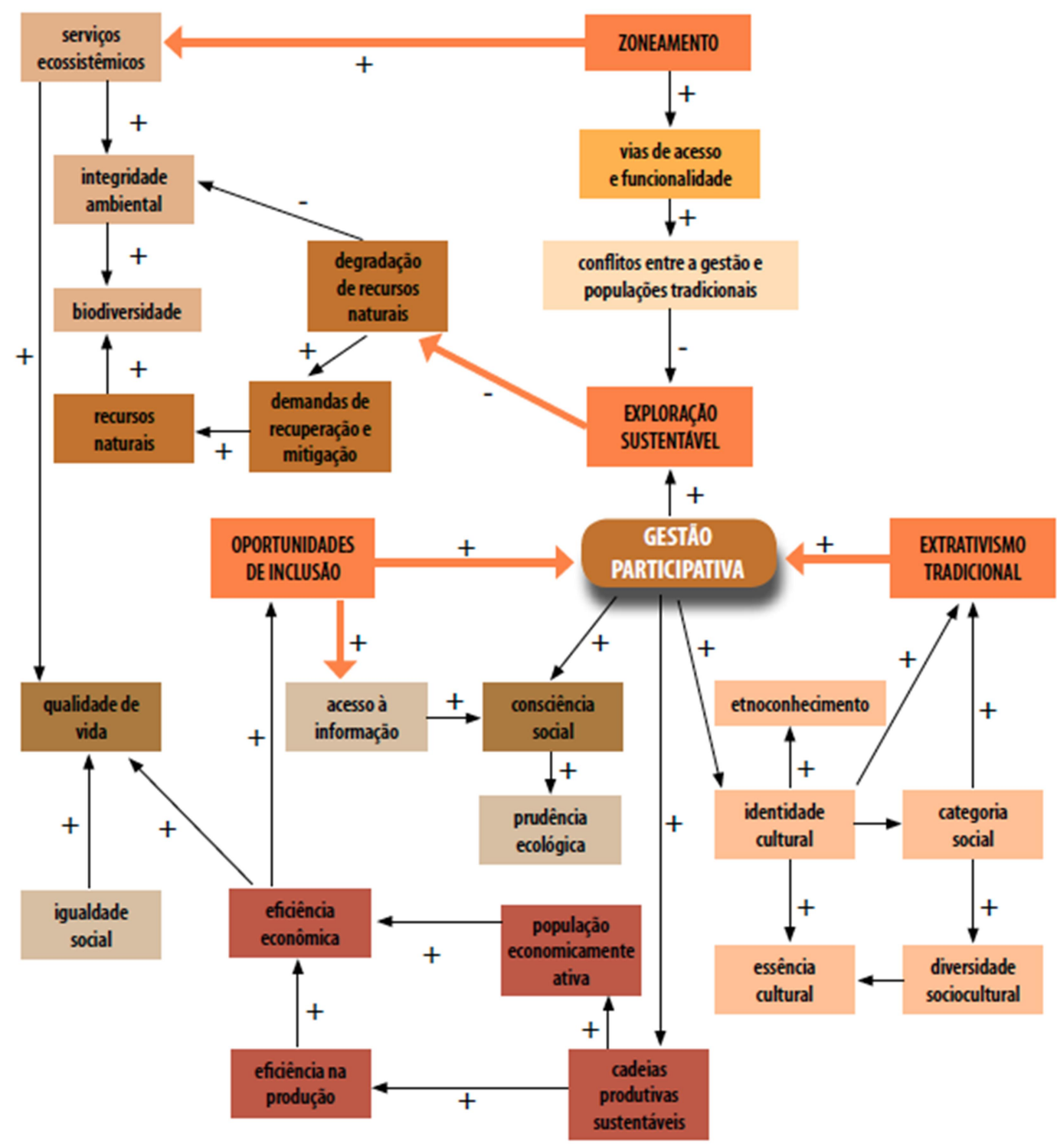

\begin{tabular}{|l|l|l|l|l|l|}
\hline Convençăo (dimensoes): & sodial & gestå & cultural & ambiental & económica \\
\hline
\end{tabular}

Figura 1. Diagrama de influências aprimorado após o seminário para o debate de conceitospráticos sobre a dinâmica de UCs na Amazônia, realizado em Brasília, em março de 2009. Convenções: dimensão social =azul; gestão=cinza, sociocultural=amarelo; ambiental=verde e; socioeconômica=rosa.

As relações entre as variáveis podem ser interpretadas da seguinte forma, por exemplo, para dimensão social: oportunidades de inclusão desencadeiam um processo que influencia (positivamente) o acesso a informação; esta variável, por sua vez, gera uma influência (positiva) sobre consciência social; esta gera uma influencia (positiva) sobre prudência ecológica; e assim por diante.

Durante oficinas regionais realizadas em Manaus e Belém, que reuniram 45 pessoas de 24 instituições, esse diagrama de influências foi debatido em maior 
profundidade e, adotada uma abordagem prática, mediante algumas premissas de modelagem, ele foi manipulado por pesquisadores, técnicos e gestores dos nove estados da Amazônia Legal, quanto a sua composição, estrutura, relações causais e terminologia.

Além de cumprir com seus objetivos operacionais, a adoção da modelagem conceitual durante esse processo permitiu: (a) aprimorar o conhecimento práticoconceitual coletivo, e melhorar a representação formal e entendimento sobre parte das relações causais envolvidas na dinâmica de UCs da Amazônia; (b) identificar variáveis, agentes e processos relevantes nessas relações (integridade ambiental, práticas tradicionais, oportunidades de inclusão, manejo participativo, cadeias produtivas e eficiência econômica); e (c), apoiar a organização de uma lista de potenciais alvos de informação que, posteriormente, viriam a ser priorizados e traduzidos em um conjunto de indicadores.

De Modelos a Alvos de Monitoramento, de Alvos a Indicadores Socioambientais

A apropriação do debate para construção de um sistema alternativo de informação sobre UCs da Amazônia adotando abordagem socioambiental remete a o que Bossel (2001) descreveu como: "sistemas dinâmicos complexos, formados por um conjunto de dimensões e variáveis que se correlacionam entre si e que podem ser compreendidas pela interpretação dos vetores resultantes de suas interações, ou seja, pela sustentabilidade desses sistemas" (figura abaixo).

Diante do que fora exposto até aqui, e dos argumentos de Bossel (2001), apresentados acima, é possível assumir que os vetores resultantes das interações envolvidas na dinâmica de UCs da Amazônia são passíveis de tradução em um conjunto de indicadores de processos socioambientais desses sistemas.

Indicadores são "pedaços de informação idealizada" que servem para responder questões específicas a partir do "empacotamento" de grandes quantidades de dados, desde que não percam seu significado diante da finalidade da análise pretendida (Bakkes et al., 1994). Existem indicadores de diferentes tipos, os quais podem ser adotados para avaliação de condições em relação a objetivos e metas, para indicação de estado ou de processos, e para geração de avisos antecipados. 


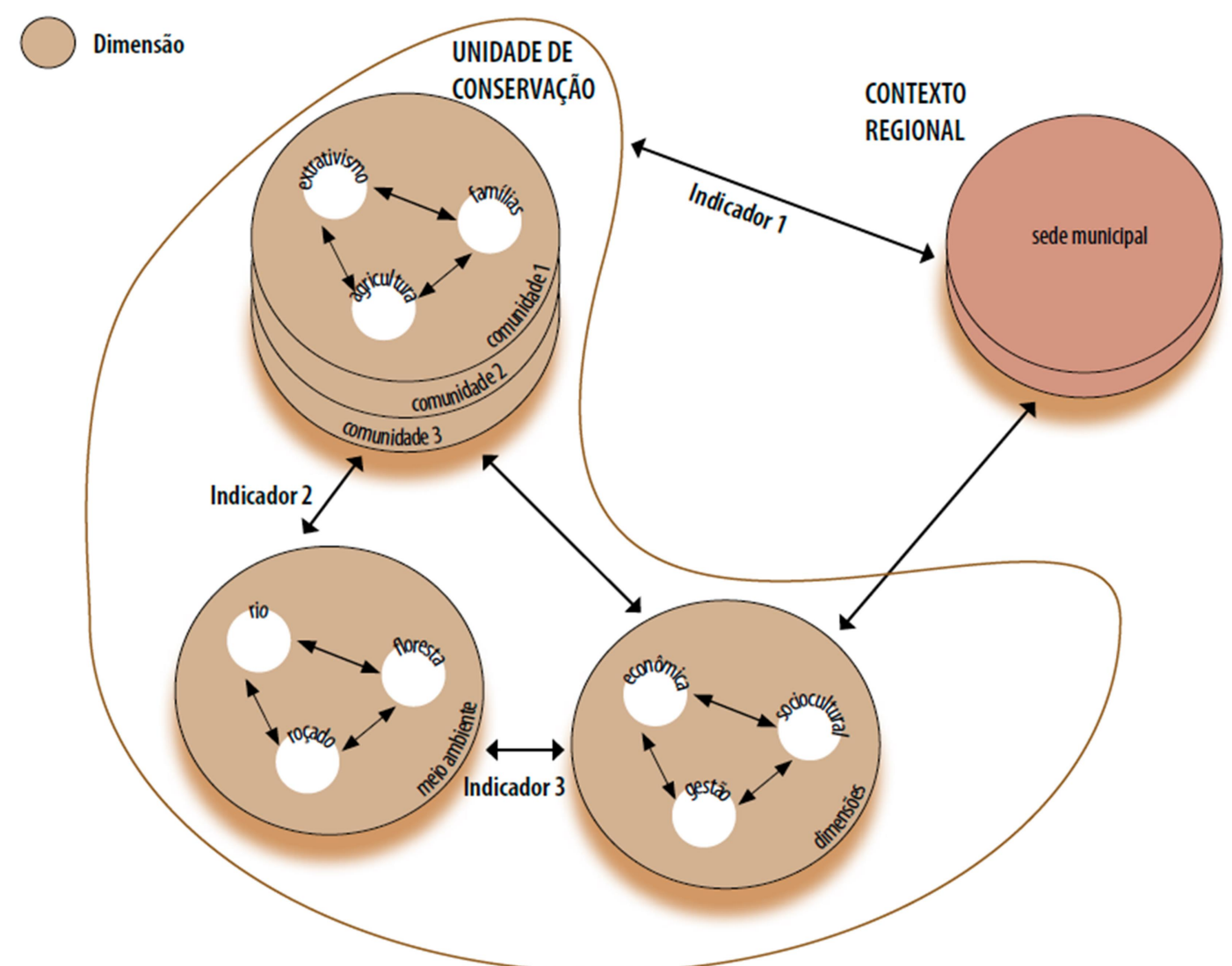

Figura 2. Diagrama de influências (adaptado de Bossel, 2001) para representar parte das relações causais (entre variáveis, entre dimensões, e de ambas entre si) envolvidas na dinâmica socioambiental de UCs na Amazônia.

A partir das considerações de Winsemius (ECE, 2001) sobre a utilização de indicadores, e considerando a questão sobre a dinâmica de UCs da Amazônia, pode-se afirmar que, indicadores podem servir para avaliar as condições de processos socioambientais locais, desde que conhecidos os objetivos de manejo, situação quanto à presença de populações residentes, instrumentos e fase particular de gestão, caso a caso. Indicadores podem ser usados para proposição de ações - visando à melhora na condição dos mesmos - e, automaticamente, ter um processo que caracterize avanços em sua condição atual, utilizado como referência para estabelecer metas para sua melhora em um prazo pré-determinado. Posteriormente, esses indicadores podem ser reavaliados e servir para verificação do desempenho na execução das ações planejadas, provendo alertas e possibilitando ajustes das metas (e ações) em bases adaptativas, evitando que ameaças tornem-se fatores de pressão ao seu cumprimento.

A utilização de modelos conceituais e os debates acerca da dinâmica de UCs da Amazônia possibilitaram identificar mais de 100 alvos socioambientais de informação sobre essas áreas protegidas. Deste total, 25 deles foram priorizados por um conjunto de 
treze organizações não-governamentais atuantes em UCs dos diferentes estados da Amazônia Legal e, posteriormente, levados para um workshop que reuniu 37 especialistas de 18 instituições e diferentes setores da sociedade de vários estados brasileiros, para tradução em um conjunto de indicadores.

Para construção dos indicadores foram adotados como pressupostos: não propor indicadores e variáveis já obtidos por outros sistemas/ferramentas; evitar problemas conceituais e/ou na operacionalização do indicador; desconsiderar informações marginais, ou apenas indiretamente relacionadas ao seu alvo; e desconsiderar dados essencialmente de origem científica, aqueles muito refinados, ou que remetessem a qualquer tipo de índice. Como premissa, esses indicadores deveriam: ser relevantes e realistas; não se sobrepor a outros já existentes; refletir o que acontece em campo; serem sucintos e compreensíveis; aplicáveis e confiáveis; automáticos e baratos; e generalizáveis.

Foram propostos 43 indicadores qualitativos, mensuráveis por meio de 79 variáveis, que então passaram por um longo e minucioso processo de validação, composto por três fases principais: qualificação (a priori), aplicação-piloto (em UCs da Amazônia) e análises (a posteriori).

Ao final desse processo, a primeira versão do conjunto de indicadores que compõem o protocolo de aplicação do Sistema de Indicadores Socioambientais de Unidades de Conservação (SISUC) é formada por 29 indicadores ${ }^{15}$ socioambientais para avaliação e monitoramento de processos econômicos, socioculturais, ambientais e de gestão dessas áreas protegidas.

\section{Referências Bibliográficas}

Bakkes JA, Van den Born GJ, Helder JC, Swart RJ, Hope CW \& JDE Parker (1994). An overview of environmental indicators: state of the art and perspectives. RIVM, National Institute of Public Health and Environmental Protection, Bilthoven, The Netherlands.

Bossel H (2001). Assessing viability and sustainability: a systems-based approach for deriving comprehensive indicator sets. Conservation Ecology 5 (2):12.

\footnotetext{
${ }^{15}$ Como descrito nos quadros apresentados no Apêndice 2, atualmente o protocolo de indicadores do método SISUC é composto por 27 indicadores.
} 
ECONOMIC Comission for Europe (ECE) (2001). Methodology for indicators in the Kiev Report. Paper do Committee on Environmental Policy - Ad Hoc Working Group on Environmental Monitoring. Preparatório para a segunda sessão da Economic Comission for Europe (ECE), realizada entre 28 de fevereiro a $1^{\circ}$ de março de 2002.

Forbus KD (1984). Qualitative process theory. Artificial Intelligence 24: 85-168.

Haefner JW (2005). Modeling Biological Systems: Principles and Applications. New York, N.Y.: Springer.

Hoffmann WAM (2011). Ciência, Tecnologia e Sociedade: desafios da construção do conhecimento. São Carlos: EDUFSCar. 313p.

Jørgensen SE \& G Bendoricchio (2001). Fundamentals of ecological modelling. Elsevier Science, 3rd edition, Oxford.

Marinelli C E, Carlos HSA, Batista R, Rohë F, Waldez FS, Kasecker T, Endo W \& Godoy R.F. (2007). O programa de monitoramento da biodiversidade e do uso de Recursos Naturais em Unidades de Conservação Estaduais do Amazonas. Áreas Protegidas da Amazônia, 1 (1): 61-64. Brasília: MMA.

Marinelli CE, Carvalho R, Pinheiro PS \& MC Bianchini (2008). Indicadores de Efetividade da Implementação de Unidades de Conservação Estaduais do Amazonas. Série Técnica Meio Ambiente e Desenvolvimento Sustentável. $N^{\circ} 8$ (2 ${ }^{\underline{a}}$ ed.). Secretaria de Estado do Meio Ambiente e Desenvolvimento Sustentável do Amazonas. Manaus. 63p.

Weld D \& J de Kleer (1990). Readings in Qualitative Reasoning about Physical Systems. San Mateo, CA: Morgan Kaufmann. 


\section{ANEXo III. DESCRIÇÃO DO PROCESSO DE ELABORAÇÃo DO MÉTODO SISUC EXTRAÍDO DO ITEM 3, DO ENCARTE 2 (Do CONCEITO À INTERVENÇÃO) DA PUBLICAÇÃO DE REFERÊNCIA DA FERRAMENTA DE APLICAÇÃo Do SISUC (MARINELLI, 2011)}

\section{A Intervenção da Sociedade Amazônica: reflexões em torno de um interesse comum}

A elaboração do SISUC constou de um conjunto de atividades, envolvendo pesquisa de literatura, fóruns participativos, construção de modelos, indicadores, protocolos e etapas de validação da metodologia, onde os avanços obtidos em cada atividade serviam como elemento provocativo e subsídio para atividades subsequentes.

\section{Fóruns Participativos}

Em um período de três anos, seis fóruns participativos diferentes foram instituídos para apoiar o debate continuado e construção do SISUC, reunindo mais de 500 participantes e 80 instituições, entre organizações da sociedade civil, movimento social, instituições de ensino superior e de pesquisa, e órgaõs públicos de gestão dos nove estados da Amazônia brasileira e do DF (quadro abaixo).

\begin{tabular}{|c|c|c|}
\hline Fórum/Local & Público-alvo: participantes & Produtos \\
\hline $\begin{array}{l}\text { Reuniões: DF e nos } \\
\text { nove estados da } \\
\text { Amazônia (2009) }\end{array}$ & $\begin{array}{c}\text { Gestores, técnicos, pesquisadores } \\
\text { e coordenadores: } 148 \text { pessoas de } \\
72 \text { instituições }\end{array}$ & $\begin{array}{l}\text { Apresentação da iniciativa e consulta } \\
\text { sobre visões, demandas e } \\
\text { expectativas (setoriais e regionais) }\end{array}$ \\
\hline $\begin{array}{l}\text { Seminário Nacional: } \\
\text { Brasília (2009) }\end{array}$ & $\begin{array}{c}\text { Especialistas em } \\
\text { desenvolvimento sustentável e } \\
\text { UCs da Amazônia: } 44 \text { pessoas de } \\
22 \text { instituições }\end{array}$ & $\begin{array}{l}\text { Qualificação da abordagem, } \\
\text { apresentação de modelos, e debates } \\
\text { prático-conceituais }\end{array}$ \\
\hline $\begin{array}{l}\text { Oficinas Regionais: } \\
\text { Amazônia Oriental e } \\
\text { Ocidental (2010) }\end{array}$ & $\begin{array}{l}\text { Lideranças sociais, gestores, } \\
\text { técnicos e especialistas dos } \\
\text { diferentes setores da sociedade: } \\
45 \text { pessoas de } 24 \text { instituições }\end{array}$ & $\begin{array}{l}\text { Aprimoramento de modelos, debate } \\
\text { de demandas regionais, identificação } \\
\text { de processos-chave e de fontes de } \\
\text { informação }\end{array}$ \\
\hline $\begin{array}{c}\text { Reuniões Regionais: } \\
\text { Amazônia Oriental e } \\
\text { Ocidental (2010) }\end{array}$ & $\begin{array}{l}\text { Secretários executivos e } \\
\text { coordenadores institucionais: } 20 \\
\text { pessoas de } 14 \text { instituições }\end{array}$ & $\begin{array}{l}\text { Priorização de alvos de processos- } \\
\text { chave e discussão do funcionamento } \\
\text { do sistema }\end{array}$ \\
\hline $\begin{array}{c}\text { Workshop Nacional: } \\
\text { Brasília (2010) }\end{array}$ & $\begin{array}{l}\text { Especialistas em monitoramento, } \\
\text { indicadores e UCs da Amazônia: } \\
37 \text { pessoas de } 18 \text { instituições }\end{array}$ & $\begin{array}{l}\text { Construção de um conjunto de } \\
\text { indicadores para avaliação e } \\
\text { monitoramento de alvos }\end{array}$ \\
\hline $\begin{array}{l}\text { Aplicação piloto da } \\
\text { metodologia: UCs do } \\
\text { Baixo Rio Negro, AM } \\
\quad(2010-11)\end{array}$ & $\begin{array}{c}\text { Conselheiros e lideranças: } 120 \\
\text { pessoas de seis UCs (federais e } \\
\text { estaduais) de Uso Sustentável e } \\
\text { de Proteção Integral }\end{array}$ & $\begin{array}{l}\text { Teste e avaliação da metodologia, e } \\
\text { apropriação e aplicação local de } \\
\text { resultados }\end{array}$ \\
\hline
\end{tabular}




\begin{tabular}{ccc}
\hline $\begin{array}{c}\text { Seis fóruns: } \\
\text { nacionais, } \\
\text { regionais e locais }\end{array}$ & $\begin{array}{c}\text { Mais de 500 pessoas e 80 } \\
\text { instituições dos nove estados } \\
\text { da Amazônia e DF envolvidas }\end{array}$ & $\begin{array}{c}\text { Metodologia coletivamente } \\
\text { construída e protocolo de } \\
\text { aplicação validado }\end{array}$ \\
\hline
\end{tabular}

Os fóruns participativos para elaboração do SISUC propiciaram a valorização de experiências regionais, e possibilitaram intercâmbio de visões e a integração de conhecimentos pulverizados pelas instituições e territórios da Amazônia brasileira ( $V$. LISTA DE INSTITUIÇõES PARTICIPANTES NA TABELA ABAIXO). Esse movimento de sinergia, representativo e legítimo, em torno do tema UCs da Amazônia, promoveu a identificação e assimilação de demandas comuns diante de realidades regionais e perspectivas setoriais distintas, instituindo um marco inédito de reflexões sobre essas áreas protegidas sob abordagem socioambiental.

\begin{tabular}{lc}
\hline Instituição* - UF/regional envolvida & SIGLA \\
\hline Agência de Desenvolvimento Turístico de Tocantins & ADT \\
Associação de Catadores de Palmas - TO & ASCAMPA \\
Associação de Defesa Etno-Ambiental Kanindé - RO & KANINDÉ \\
Associação Maranhense para a Conservação da Natureza & AMAVIDA \\
Associação Pró-Ilha de Algodoal-Maiandeua - PA & SUATÁ \\
Centro de Estudos da Cultura e do Meio Ambiente da Amazônia - RO & RIO TERRA \\
Centro dos Trabalhadores da Amazônia - AC & CTA \\
Companhia Paraense de Turismo & PARATUR \\
Conselho Nacional das Populações Extrativistas & CNS \\
Conservação Internacional - Brasil - PA e DF & CI \\
Cooperação Técnica Alemã - AM, AC e DF & GIZ \\
Embaixada Francesa & - \\
Empresa Brasileira de Pesquisa Agropecuária - DF e Jaguariuna/SP & EMBRAPA \\
Fundação de Apoio a Vida nos Trópicos - MT & ECOTROPICA \\
Fundação Estadual do Meio Ambiente, Ciência e Tecnologia de Roraima & FEMACT \\
Fundação Universidade do Tocantins & FUT \\
Fundação Vitória Amazônica - AM & FVA \\
Fundo Brasileiro para Biodiversidade - RJ & FUNBIO \\
GFA Consulting Group - DF & GFA \\
Grupo de Trabalho Amazônico - AM & GTA \\
Instituto Brasileiro de Geografia e Estatística - RJ & IBGE \\
Instituto Brasileiro do Meio Ambiente e dos Recursos Naturais Renováveis & IBAMA \\
Instituto Centro de Vida - MT & ICV \\
Instituto Chico Mendes de Conservação da Biodiversidade & ICMBio \\
Instituto de Conservação e Desenvolvimento Sustentável do Amazonas & IDESAM \\
Instituto de Defesa e Promoção dos Direitos Humanos e Meio Ambiente do & \\
Tocantins & - \\
Instituto de Estudos Sócio-Ambientais - AP & IESA \\
Instituto de Pesquisa e Formação em Educação Indígena - AP & IEPE \\
\hline
\end{tabular}


Instituto de Pesquisas Científicas e Tecnológicas do Estado do Amapá

IEPA

Instituto de Pesquisas Ecológicas - AM

IPE

Instituto do Homem e Meio Ambiente da Amazônia - PA

IMAZON

Instituto Estadual de Florestas do Amapá

IEF

Instituto Floresta Tropical - PA

IFT

Instituto Internacional de Educação do Brasil - DF

IEB

Instituto Madeira Vivo - RO

IMV

Instituto Nacional de Pesquisas da Amazônia - AM

INPA

Instituto Natureza do Tocantins

NATURATINS

Instituto Piagaçu - AM

IPI

Instituto Socioambiental

ISA

Ministério do Meio Ambiente

MMA

Movimento Hiphop da Floresta - RO

MHF

Movimento Interestadual das Quebradeiras de Coco Babaçu - MA

MIQCB

Museu da Amazônia - AM

MUSA

MPEG

Museu Paraense Emílio Goeldi

UNEP

Programa das Nações Unidas para o Meio Ambiente

SEMA-RO

Secretaria de Estado de Meio Ambiente de Rondônia

SEMA-MA

Secretaria de Estado de Meio Ambiente do Maranhão

SEMA-PA

Secretaria de Estado de Meio Ambiente do Pará

SEDAM

Secretaria de Estado do Desenvolvimento Ambiental do Amapá

SEMA-MT

Secretaria de Estado do Meio Ambiente de Mato Grosso

SEMA-AC

Secretaria de Estado do Meio Ambiente e Desenvolvimento Sustentável do

SDS-AM

Secretaria de Recursos Hídricos e Meio Ambiente do Tocantins

SRHM-MA

Secretaria Estadual de Florestas do Acre

SEF

Serviço Florestal Brasileiro

SFB

SOS Amazônia - AC

The Nature Conservancy - Brasil

TNC

União Internacional para a Conservação da Natureza $\quad$ UICN

Universidade de Brasília

UnB

Universidade de São Paulo

USP

Universidade Estadual de Mato Grosso

UNEMAT

Universidade Estadual do Maranhão

UEMA

Universidade Federal de Minas Gerais

UFMG

Universidade Federal de Roraima

UFRR

Universidade Federal do Amazonas

UFAM

Universidade Federal do Maranhão

UFMA

Universidade Federal do Mato Grosso

UFMT

Universidade Federal do Pará

UFPA

Universidade Federal do Rio de Janeiro

UFRJ

Universidade Federal do Tocantins

UFT

Universidade Tecnológica Federal do Paraná

UTFPR

World Wild Life Found - Brasil

WWF 
* Considerando as instituições com participação não-presencial que receberam os relatórios com os resultados dos fóruns participativos, o número de instituições envolvidas na iniciativa chega aproximadamente a 150 .

\section{Validação da Metodologia}

O processo de validação da metodologia de aplicação do SISUC constituiu-se de seis etapas: qualificação de indicadores construídos no workshop, construção de protocolo de aplicação da metodologia, aplicação-piloto do protocolo, avaliação da metodologia, análise de resultados e definição de protocolo.

Além do trabalho de bancada, e dos fóruns participativos (já citados) para o debate e elaboração da metodologia, deve ser destacada a aplicação-piloto do SISUC em UCs de Uso Sustentável e de Proteção Integral do Mosaico de Áreas Protegidas do Baixo Rio Negro, no Estado do Amazonas, sendo elas: Resex do Rio Unini, Parna do Jaú, Parna de Anavilhanas, RDS do Rio Negro, Parest do Rio Negro (Setor Norte) e Parest do Rio Negro (Setor Sul).

Seis especialistas, com experiência de atuação nos diferentes setores da sociedade, constituíram um Grupo de Trabalho de Acompanhamento e Avaliação da Elaboração do SISUC, que a cada etapa desse processo, reunia-se para debater os resultados obtidos e analisar avanços. Finalmente, a validação do método também aconteceu a partir de debates e considerações durante cerca de trinta apresentações sobre o SISUC realizadas durante a elaboração da metodologia, junto a instituições públicas, da sociedade civil e movimento social, parceiras e colaboradoras desta iniciativa, e durante a proferência de palestras e cursos em eventos técnicos e científicos regionais e nacionais junto a comunidade acadêmica. 